\title{
Durability Model of SOFC Anode Structure under Thermo- Mechanical and Fuel Gas Contaminants Effects
}

\author{
Gulfam Iqbal \\ West Virginia University
}

Follow this and additional works at: https://researchrepository.wvu.edu/etd

\section{Recommended Citation}

Iqbal, Gulfam, "Durability Model of SOFC Anode Structure under Thermo-Mechanical and Fuel Gas Contaminants Effects" (2012). Graduate Theses, Dissertations, and Problem Reports. 4870.

https://researchrepository.wvu.edu/etd/4870

This Dissertation is protected by copyright and/or related rights. It has been brought to you by the The Research Repository @ WVU with permission from the rights-holder(s). You are free to use this Dissertation in any way that is permitted by the copyright and related rights legislation that applies to your use. For other uses you must obtain permission from the rights-holder(s) directly, unless additional rights are indicated by a Creative Commons license in the record and/ or on the work itself. This Dissertation has been accepted for inclusion in WVU Graduate Theses, Dissertations, and Problem Reports collection by an authorized administrator of The Research Repository @ WVU.

For more information, please contact researchrepository@mail.wvu.edu. 


\title{
Durability Model of SOFC Anode Structure under Thermo-Mechanical and Fuel Gas Contaminants Effects
}

\section{GULFAM IQBAL}

\author{
Dissertation submitted to the \\ Benjamin M. Statler College of Engineering and Mineral Resources \\ at West Virginia University \\ in partial fulfillment of the requirements \\ for the degree of \\ Doctor of Philosophy \\ in \\ Mechanical Engineering
}

Bruce Kang, Ph.D., Chair

Ismail Celik, Ph.D.

Nianqiang Wu, Ph.D.

Randall Gemmen, Ph.D.

Mary Ann Clarke, Ph.D.

Ayyakkannu Manivannan, Ph.D.

Department of Mechanical and Aerospace Engineering

Morgantown, West Virginia

2012

Keywords: Solid Oxide Fuel Cell, Anode Structure Durability Model, ThermoMechanical Degradation, Fuel Gas Contaminants 


\title{
ABSTRACT \\ Durability Model of SOFC Anode Structure under Thermo- Mechanical and Fuel Gas Contaminants Effects
}

\author{
Gulfam Iqbal
}

Solid Oxide Fuel Cells (SOFCs) operate under harsh environments, which cause the deterioration of anode material properties and reduce their service life. In addition to electrochemical performance, structural integrity of the SOFC anode is essential for successful long-term operation. Anode-supported SOFCs rely on the anode to provide mechanical strength to the positive-electrolyte-negative (PEN) structure. The stress field in the anode may arise from a variety of phenomena including thermal expansion mismatch between layers in the PEN structure, thermal/redox cycles and external mechanical loads. Moreover, some fuel contaminants such as phosphine $\left(\mathrm{PH}_{3}\right)$ interact with the anode materials which lead to the formation of secondary phases and grain growth. These mechanisms result in the formation of microcracks, and degrade anode structural and electrochemical properties. Assessments of the evolution of anode mechanical properties during long-term operation are therefore essential to predict SOFC working life.

The principal objective of this research is to develop a structural durability model for the SOFC anode that takes into account thermo-mechanical and fuel contaminants effects on the anode material properties. The model is implemented in finite element analysis through a user defined subroutine to predict anode long-term structural integrity. The model is exploited to predict the stress-strain relations of Ni-YSZ at temperatures and porosities which are difficult to generate experimentally. Accelerated exposure tests under high contaminant concentrations dictate that the electrochemical degradation is the principal mode of cell failure while the cell structure is still intact. However, the model predicts that under lower contaminant concentrations, the anode structural degradation may be significant as compared to the electrochemical degradation in long-term operation.

The proposed model is enhanced for the planar-SOFC configurations exposed to $\mathrm{PH}_{3}$. The model predicts that under pure thermo-mechanical effect, the critical location for structure failure is near the corner of highest thermal gradient. However when fuel contaminant structural effect is superimposed on the thermo-mechanical effect, the critical location may shift depending on the flow configuration. Under similar operating conditions, i.e. same current density, co-flow configuration yields a higher anode structural life than counter-flow or cross-flow configurations. The knowledge obtained from this research will be useful to establish control parameters to achieve desired service life of the SOFC stack under various operating conditions. 


\section{ACKNOWLEDGEMENTS}

I would like to express my gratitude to my research advisor, Dr. Bruce S. Kang, for his supervision, encouragement, and support throughout my graduate studies at the West Virginia University. His mentorship was absolutely vital in the completion of this dissertation. He encouraged me to develop not only as a researcher but also as an instructor. It's a great experience to complete my doctoral studies under his guidance.

Special thanks to Dr. Ismail Celik for providing me with valuable technical suggestions and comments throughout my research. I would also like to thank all the members of my committee: Dr. Ismail Celik, Dr. Nianqiang Wu, Dr. Randall Gemmen, Dr. Mary Ann Clarke and Dr. Ayyakkannu Manivannan, for the time and efforts they devoted to review my dissertation. They have been readily accessible for advising and support despite their busy schedule. It's an honor to have them in my committee.

I am also thankful to Dr. Raju Pakalapati and Dr. Francisco Elizalde-Blancas from Dr. Celik's research group for providing me the temperature fields and species concentrations of solid oxide fuel cell through DREAM-SOFC. Thanks are also due to all of my fiends for their help and encouragement specially Huang Guo whose experimental set help me to validate the model.

Finally I would like to express my gratitude to my wife, Sumera Gulfam, and daughter, Sarinah Iqbal for their love, patience and support through these tough times. 


\section{TABLE OF CONTENTS}

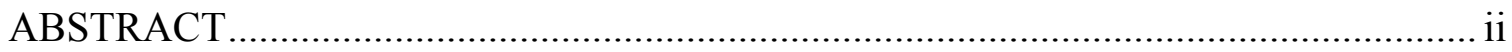

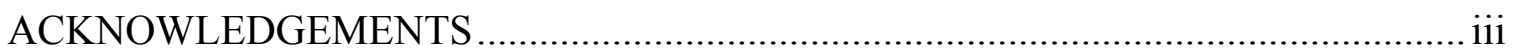

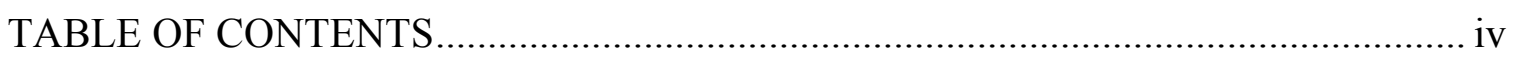

LIST OF FIGURES ………………………………........................................... vii

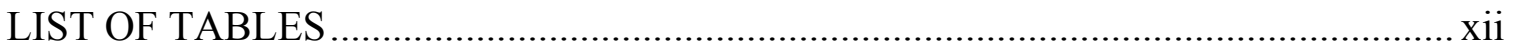

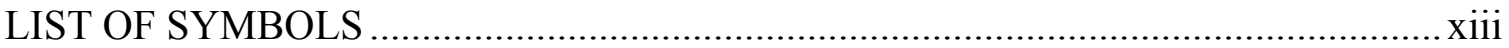

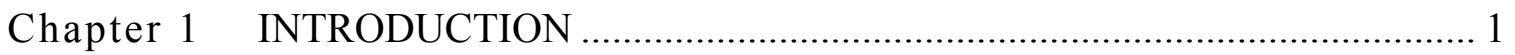

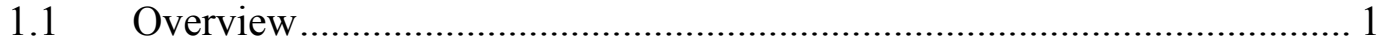

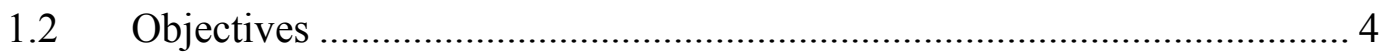

$1.3 \quad$ Thesis Outline and Scope................................................................. 5

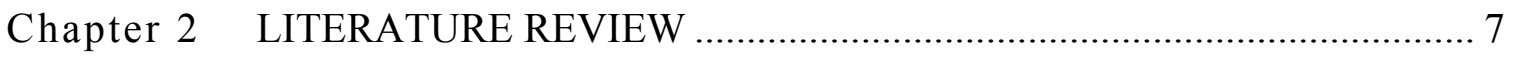

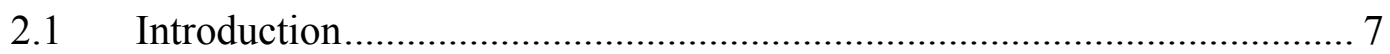

2.1.1 Fuel Cell Structure and Working Principle.............................................. 7

2.1.2 Types of Fuel Cell........................................................................ 9

2.1.3 Solid Oxide Fuel Cell....................................................................... 11

2.1.4 Cell and Stack Designs .................................................................... 12

2.2 Thermodynamics of Fuel cells................................................................ 16

2.3 Structural Degradation Mechanisms of SOFC Anode ............................... 20

2.3.1 Thermo-Mechanical Effects on Anode Microstructure ……………...... 21

2.3.2 Redox Cycle Effects on Anode Mechanical Properties ……………….. 27

2.3.3 Fuel Gas Contaminants Effects on Anode Microstructure ................... 31

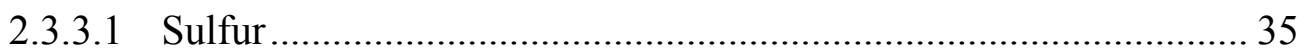

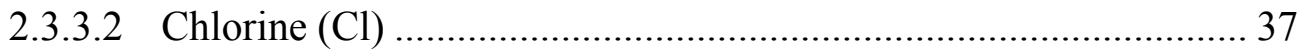

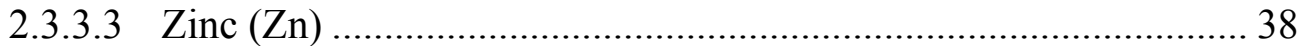

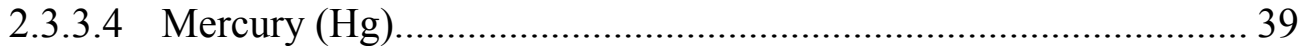

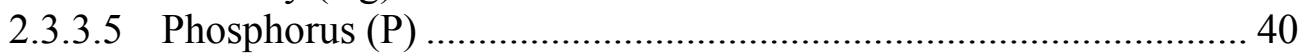

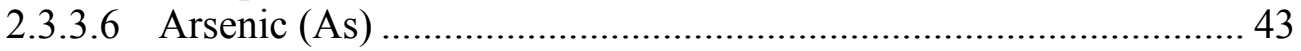

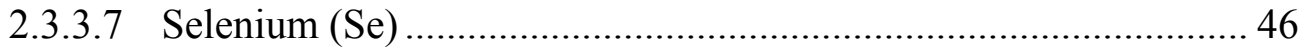

Chapter 3 DEGRADATION MECHANICS …………............................................ 48

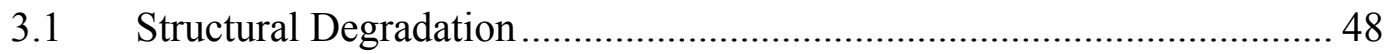

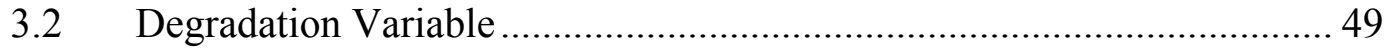

3.3 Thermodynamics of Degradation ......................................................... 51

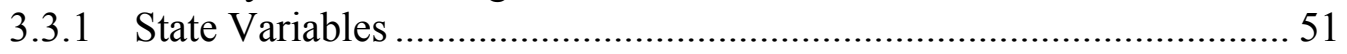




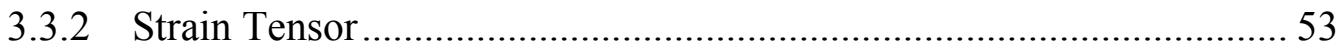

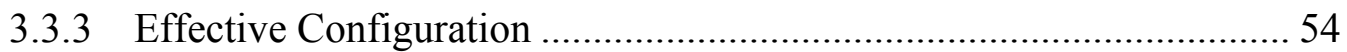

3.3.3.1 Strain equivalence principle ........................................................ 56

3.3.3.2 Stress equivalence principle …………………........................... 58

3.3.3.3 Strain-Energy density hypothesis................................................. 59

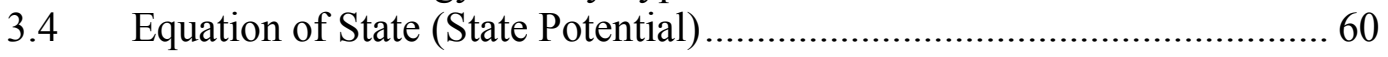

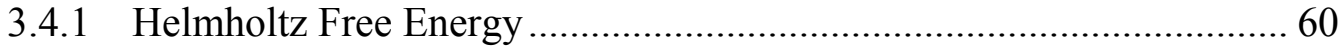

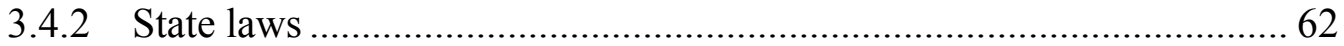

3.4.3 Yield function and Kuhn-Tucker conditions ........................................ 63

Chapter 4 ANODE MATERIAL DEGRADATION MODEL...................................66

4.1 Anode Structural Degradation Mechanisms ...............................................66 66

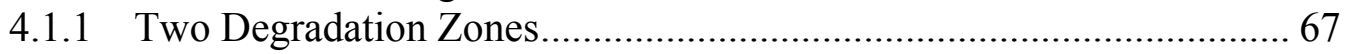

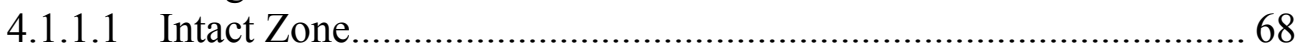

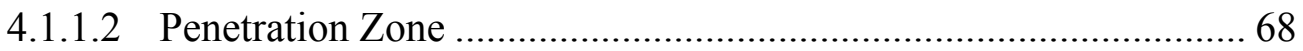

4.1.2 Degradation Variables (Multi-Mechanism) ……………………........... 69

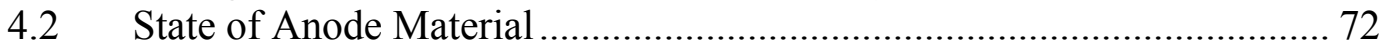

4.2.1 Helmholtz Free Energy ………………………….............................. 73

4.2.2 Dissipation Potential ......................................................................... 76

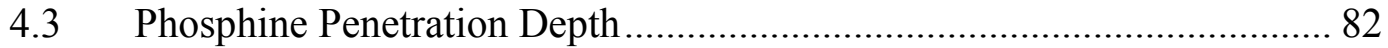

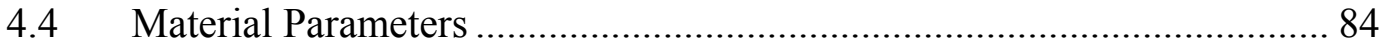

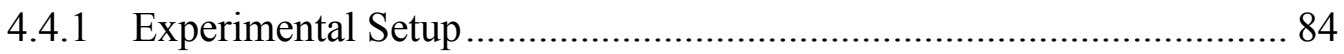

4.4.1.1 Validation of Experimental Test Methodology................................ 86

4.4.2 Complementary Analytical Solution...................................................... 88

4.4.2.1 Boundary Condition Correction Factor.......................................... 91

4.4.3 Contaminant Structural Degradation Parameter $\left(\mathrm{a}_{1}\right)$........................... 92

4.4.4 Temperature Dependent Material Properties ....................................... 92

4.4.5 Porosity Dependent Material Properties ………………………………... 94

4.4.6 Temperature and Porosity Dependent Young's Modulus...................... 97

4.4.7 Degradation Threshold $\left(\mathrm{K}_{\mathrm{o}}\right)$ \& Hardening/Softening Variable (h)....... 98

Chapter 5 MODEL IMPLEMENTATION AND VALIDATION ………………....... 100

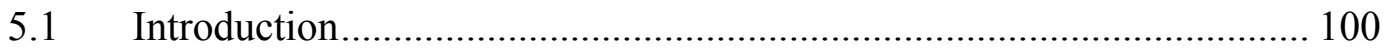

5.2 Model Verification and Validation ......................................................... 104

5.2.1 Validation of Constitutive Relations................................................. 104

5.2.2 Predicted Stress-Strain Relations for Ni-YSZ ................................. 109

5.2.3 Verification of Contaminant Penetration Depth .................................. 114

5.3 Button Cell Simulation Results.......................................................... 116

5.3.1 Anode Structural Degradation ......................................................... 118

5.3.1.1 Thermo-mechanical degradation............................................... 118

5.3.1.2 Structural degradation due to contaminant interaction ................. 121

5.3.1.3 Cumulative structural degradation ............................................. 123

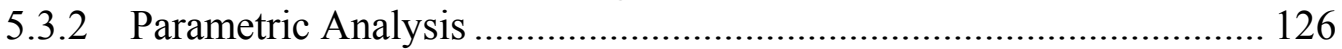

5.3.2.1 Contaminant factor $\left(\mathrm{a}_{1}\right)$ and contaminant concentration (ppm) .. 126 
5.3.2.2 Anode porosity and contaminant concentration....................... 127

5.3.3 Electrochemical vs. structural degradation .................................... 129

5.4 Planar-SOFC Simulation Results........................................................ 131

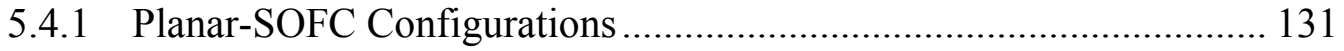

5.4.2 Temperature and Contaminant Distribution ................................... 132

5.4.3 Physical Boundary Conditions................................................... 135

5.4.4 Anode Structural Degradation ................................................... 136

5.4.4.1 Thermo-mechanical degradation........................................... 137

5.4.4.2 Structural degradation due to contaminant interaction ................ 141

5.4.4.3 Cumulative structural degradation ........................................ 142

5.4.5 Comparison of anode structural degradation for planar-SOFCs........ 146

Chapter 6 CONCLUSION AND FUTURE WORK ......................................... 148

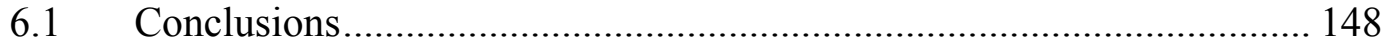

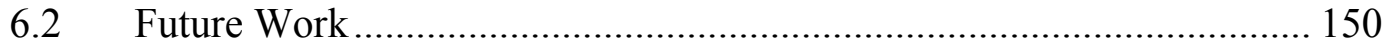

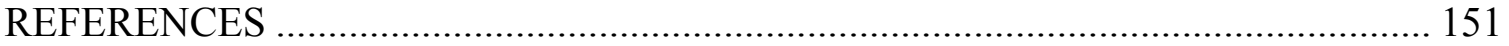




\section{LIST OF FIGURES}

Figure 2-1 Schematic of a single fuel cell.................................................................8

Figure 2-2 (a) Cross-flow planar-SOFC design; (b) Exploded view [12] .................13

Figure 2-3 Tubular SOFC: (a) Accumentric design [13]; (b) Schematic crosssection of Siemens Westinghouse tubular cell, redrawn from [14] ...........14

Figure 2-4 Relative gas flow directions in SOFC: (a) co-flow (b) counter-flow (c)

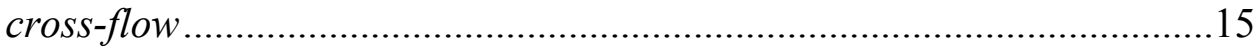

Figure 2-5 Fuel cell polarization and power density curves .....................................18

Figure 2-6 Schematic diagram of a three-layer SOFC anode side with a localized damage band [21] ............................................................................22

Figure 2-7 Upper limit of tetragonal phase in $\mathrm{ZrO}_{2}-\mathrm{Y}_{2} \mathrm{O}_{3}$ system as function of aging time(h) at $1000^{\circ} \mathrm{C}[24]$

Figure 2-8 Curvature recorded before and after $50 \mathrm{~h}$ stress relaxation test at 800 ${ }^{\circ} \mathrm{C}$ at an initial elastic stress of $45 \mathrm{MPa}$ for a Ni-YSZ test specimen [26]

Figure 2-9 Predictions of damage and failure progressions (D_SDV1) from an initial G18/yttria-stabilized zirconia interface crack [28] .......................25

Figure 2-10 Creep Strain in Ni/YSZ over time [30] ...............................................25

Figure 2-11 NiO/YSZ bulk anode sample sintered at (a) $1200^{\circ} \mathrm{C}$ and (b) $1400^{\circ} \mathrm{C} \mathrm{\ldots ....28}$

Figure 2-12 (a) Ball-on-ring setup with a sample (b) dimension of the setup, $F$ if the load [38]

Figure 2-13 Mechanical degradation in terms of relative loss of elastic modulus of $\mathrm{NiO}$-YSZ composites due to redox cycles [39] ........................................30

Figure 2-14 Sulfur poisoning effects at different temperature [57] .............................35

Figure 2-15 Sulfur poisoning and recovery processes [57] .......................................36

Figure 2-16 SOFC power density operating at $800^{\circ} \mathrm{C}$ and $0.7 \mathrm{~V}$ over time with $\mathrm{HCl}$ concentrations of $0 \mathrm{ppm}, 20 \mathrm{ppm}$, and $160 \mathrm{ppm}$ [59].

Figure 2-17 Performance of SOFC with $10 \mathrm{ppm} \mathrm{Zn}$ Vapor $\left(\sim 0.7 \mathrm{~V}\right.$ and $\left.0.2 \mathrm{~A} / \mathrm{cm}^{2}\right) \ldots . .38$

Figure 2-18 (a) Power density variation with time under $7 \mathrm{ppm} \mathrm{Hg}$ vapor at $750^{\circ} \mathrm{C}$

(b) I-V curve of the cell after $150 \mathrm{~h}$.

Figure 2-19 Electrochemical degradation of anode-supported cell in coal gas with phosphorus [60]..... 


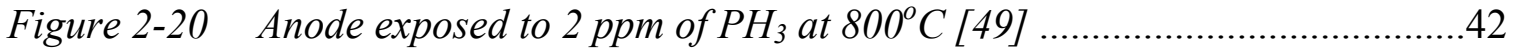

Figure 2-21 Penetration depths after $990 \mathrm{~h}$ with $\mathrm{PH}_{3}$ in coal syngas [60] ...................42

Figure 2-22 Ni agglomeration and microcrack formation after $1000 \mathrm{~h}$ test with 5 ppm of $\mathrm{PH}_{3}$, after O. A. Marina et al. [60]....

Figure 2-23 SOFC power density operating at (a) $750{ }^{\circ} \mathrm{C}$, (b) $800{ }^{\circ} \mathrm{C}, 0.25$, and

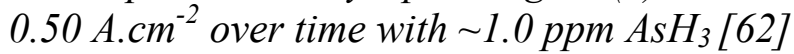

Figure 2-24 Performance of SOFC with $10 \mathrm{ppm} \mathrm{As(g)}$ vapor at $750^{\circ} \mathrm{C}$ after $60 \mathrm{~h}$ [41]

Figure 2-25 Delamination of Ni mesh from anode at 10 ppm As contaminant [41] .....45

Figure 2-26 Effect of $\mathrm{H}_{2} \mathrm{~S}$ and $\mathrm{H}_{2} \mathrm{Se}$ on anode-supported $\mathrm{SOFC}$ at $800^{\circ} \mathrm{C}[65] \ldots \ldots \ldots . . .46$

Figure 3-1 Net resisting area and effective section of a degraded material [67] .......49

Figure 3-2 Evolution of Damage in a material ......................................................50

Figure 3-3 Generalized stress-strain relation of a elastic, plastic, and degradation strain.

Figure 3-4 A cylindrical bar subjected to uniaxial tension both voids and cracks

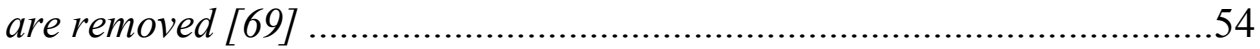

Figure 3-5 Concept of effective stress and principle of strain equivalence [77] .........57

Figure 3-6 Concept of effective strain and principle of stress equivalence [77].........58

Figure 3-7 Material deformation and corresponding Kuhn-Tucker condition ...........65

Figure 4-1 Penetration depths after $990 \mathrm{~h}$ with 5ppm $\mathrm{PH}_{3}$ in coal syngas, after $\mathrm{O}$. A. Marina et al. [60]

Figure 4-2 Two degradation zones (a) intact and penetration zones (b) stiffness

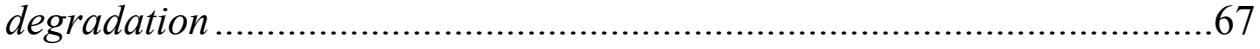

Figure 4-3 Increase in penetration depth with time ................................................68

Figure 4-4 Change in multiplicative cumulative degradation variable with individual degradation variable

Figure 4-5 Change in additive cumulative degradation variable with individual degradation variable .......................................................................70

Figure 4-6 Creep Strain in Ni/YSZ over time [30] ................................................72

Figure 4-7 Degradation trend in the penetration zone .............................................80

Figure 4-8 Time required to consume nickel with anode material under different $\mathrm{PH}_{3}$ concentrations [60] .............................................................82

Figure 4-9 Time required $\mathrm{PH}_{3}$ to start penetration in the Anode ..............................83 
Figure 4-10 NexTech Probostat ${ }^{T M}$ integrated with Sagnac interferometry and IR thermometer.

Figure 4-11 (a) Fringes on a spot location of the Ni wire mesh, (b) button cell surface rotation before and after loading.

Figure 4-12 Fringe patterns on Ni mesh at $r=3 \mathrm{~mm}$ from the center with different applied pressures: (a) 0 psi, (b) 7 psi, (c) 13 psi....

Figure 4-13 Button cell modeled as a three-layered thin membrane

Figure 4-14 Temperature dependent Young's modulus of anode, cathode and electrolyte.

Figure 4-15 Temperature dependent coefficient of thermal expansion of anode, cathode and electrolyte....

Figure 4-16 Young's $(E)$ and shear $(G)$ moduli of unreduced and reduced Nibased anode as a function of porosity [9] .96

Figure 4-17 Determining the initial degradation threshold .......................................98

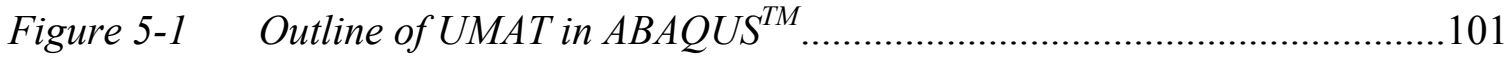

Figure 5-2 Flow chart of the subroutine implementation ........................................103

Figure 5-3 Stress-Strain relation of an elastic brittle material ................................105

Figure 5-4 Damage-Strain relation of an elastic brittle material ............................ 105

Figure 5-5 Predicted results of Young's modulus with strain ...................................106

Figure 5-6 Stress-Strain relation under uniaxial tension ......................................107

Figure 5-7 Predicted results of Young's modulus under uniaxial tension ..................107

Figure 5-8 Predicted stress-strain curve of Ni-YSZ at $800^{\circ} \mathrm{C}$..................................109

Figure 5-9 Predicted stress-strain curve of Ni-YSZ at $300^{\circ} \mathrm{K}, 700^{\circ} \mathrm{K}$, and $1073^{\circ} \mathrm{K} \ldots 110$

Figure 5-10 Predicted stress-strain curve of Ni-YSZ at $300^{\circ} \mathrm{K}$ for different porosities.

Figure 5-11 Predicted stress-strain curve of Ni-YSZ at $1073^{\circ} \mathrm{K}$ for different porosities

Figure 5-12 Ni-YSZ predicted initial damage surface biaxial stress space......

Figure 5-13 Comparison of penetration depth under different concentration of $\mathrm{PH}_{3}$

Figure 5-14 Temperature field $(\mathrm{K})$ from DREAM-SOFC incorporated in $A B A Q U S^{T M}$

Figure 5-15 FE model of a button cell and physical boundary conditions 
Figure 5-16 Principal stresses in PEN structure (a) anode (b) electrolyte (c) cathode

Figure 5-17 Evolution of thermo-mechanical degradation in anode material without incorporating fuel contaminant effects (a) $9500 \mathrm{~h}$ (b) $15000 \mathrm{~h}$ (c) $20000 \mathrm{~h} \mathrm{(d)} 25000 \mathrm{~h} \mathrm{(e)} 35000 \mathrm{~h} \mathrm{(f)} 40000 \mathrm{~h}$

Figure 5-18 Thermo-mechanical degradation in anode material (a) $3900 \mathrm{~h}$ (b) $7400 \mathrm{~h}$ (c) $15900 \mathrm{~h}$ (d) $21400 \mathrm{~h}$

Figure 5-19 Evolution of thermo-mechanical degradation through anode thickness .121

Figure 5-20 Structure contaminant degradation in anode under 5ppm $\mathrm{PH}_{3}$ (a) $510 \mathrm{~h}(\mathrm{~b}) 10400 \mathrm{~h}(\mathrm{c}) 17900 \mathrm{~h}$ (d) $21400 \mathrm{~h}$

Figure 5-21 Evolution of structural contaminant degradation through the anode thickness under $5 \mathrm{ppm}$ of $\mathrm{PH}_{3}$

Figure 5-22 Cumulative degradation in anode material (a) 1900h (b) $7400 \mathrm{~h}$ (c) $15900 h(d) 21400 h$

Figure 5-23 Evolution of anode structural degradation at the critical location ..........124

Figure 5-24 Effective stresses in the anode ..........................................................124

Figure 5-25 Evolution of effective stresses at the exposed surface and interface .......125

Figure 5-26 (a) Effective stresses through the anode thickness without

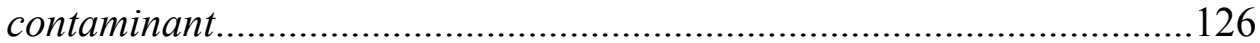

Figure 5-27 Predicted anode structural life in terms of contaminant concentration for different contaminant factor.

Figure 5-28 Predicted anode structural life in terms of contaminant concentration for different porosity

Figure 5-29 Comparison of predicted anode structural life and time required to reach to interface.

Figure 5-30 (a) Schematic view of a co-flow planar-SOFC (b) PEN structure (c) top view of the anode exposed surface.

Figure 5-31 Temperature $\left({ }^{\top} K\right.$ ) profile on (a) co-flow planar (b) counter-flow and (c) cross-flow SOFC anode under same current density

Figure 5-32 (a) Temperature field (b) $\mathrm{PH}_{3}$ contaminant profile on a co-flow planar SOFC anode imported in ABAQUS ${ }^{T M}$....

Figure 5-33 FEA model of the PEN structure and applied physical boundary conditions.....

Figure 5-34 Principal stresses through the co-flow PEN structure (a) anode at the anodelelectrolyte interface (b) electrolyte (c) cathode 
Figure 5-35 Principal stresses at the anodelelectrolyte interface (a) co-flow (b) counter-flow (c) cross-flow

Figure 5-36 Evolution of thermo-mechanical degradation in anode at the anodelelectrolyte interface without incorporating fuel contaminant effects for co-flow(a) $5410 \mathrm{~h}$ (b) $10410 \mathrm{~h}$ (c) $20000 \mathrm{~h}$ (d) $30000 \mathrm{~h}$ (e) $40000 \mathrm{~h}$

Figure 5-37 Thermo-mechanical degradation in anode at (i) interface and (e) exposed surface (a) 510h (b) $7410 \mathrm{~h} \mathrm{(c)} 12410 \mathrm{~h}$ (d) $18410 \mathrm{~h}$

Figure 5-38 Evolution of the thermo-mechanical degradation at the critical location through the anode thickness

Figure 5-39 Anode structural degradation due to contaminant along the fuel flow and across anode thickness under 5ppm of $\mathrm{PH}_{3}$ exposure (a) $510 \mathrm{~h}$ (b) $7410 \mathrm{~h}$ (c) $12410 \mathrm{~h}$ (d) $18410 \mathrm{~h}$

Figure 5-40 Evolution of the contaminant structural degradation at the critical location through the anode thickness

Figure 5-41 Cumulative structural degradation in anode at (i) interface and (e) exposed surface (a) $510 \mathrm{~h}$ (b) 12410h (c) 16410h (d) $18410 \mathrm{~h}$

Figure 5-42 Variation of the structure degradation along the fuel flow on the surface.

Figure 5-43 Evolution of the anode structural degradation at the critical location ...144

Figure 5-44 Predicted anode structural life in terms of contaminant concentration ..145

Figure 5-45 Anode structure failure locations comparison (a) co-flow:19920h (b) counter-flow:16310h (c) cross-flow: $18450 \mathrm{~h}$ 146 


\section{LIST OF TABLES}

Table 2-1 Key characteristics of the main fuel cell types [1, 4]

Table 2-2 Percentage length change $\Delta l / l_{0}$ of NiO/YSZ sintered at different temperature after successive redox cycles at $950^{\circ} \mathrm{C}[36]$.........................28

Table 2-3 Coal-derived Syngas compositions (mole percent) [45, 46] ......................32

Table 2-4 Trace impurities and their concentration (ppmv) in coal syngas [41] ......33

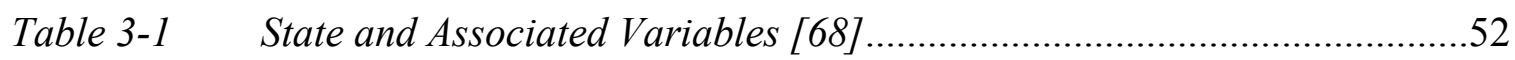

Table 4-1 Comparison among experimental, FE simulating and analytical

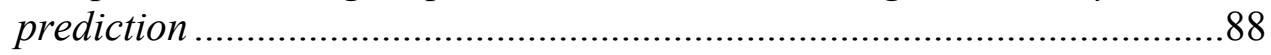

Table 4-2 Numerical and Analytical results of out of plane deformation of a button cell under uniform pressure.............................................................90

Table 4-3 Porosity dependent constant of NiO-YSZ and Ni-YSZ for exponential models [9] …….............................................................................97

Table 4-4 Material Properties obtained from SECA database ..................................98

Table 5-1 Material parameters for an elastic brittle material [82] ..........................104

Table 5-2 Predicted material parameters for Ni-YSZ at different temperatures and porosities ....................................................................................112 


\section{LIST OF SYMBOLS}

a Material constant describing the effect of porosity on Young's modulus

$\mathrm{A}_{\mathrm{o}} \quad$ Original area

A Effective area

$\mathrm{a}_{1} \quad$ Contaminant structural degradation parameter

b Material constant describing the effect of porosity on material strength

$\mathrm{C}_{\mathrm{o}} \quad$ Boundary condition correction factor related to the button cell deformation

$C_{i j k l} \quad$ Original/reference stiffness matrix

D Cumulative degradation variable

$\mathrm{D}_{\mathrm{c}} \quad$ Contaminant structure degradation variable

$\mathrm{D}_{\mathrm{m}} \quad$ Thermo-mechanical degradation variable

E Young's modulus

$\bar{E} \quad$ Effective Young's modulus

$\mathrm{E}_{\mathrm{i}} \quad$ Reference Young's modulus

$\mathrm{E}_{\mathrm{o}} \quad$ Young's modulus at zero porosity

$\Delta \mathrm{E}_{\mathrm{N}} \quad$ Nernst potential

F Faraday's constant (coulomb/mole)

$\mathrm{F}_{\mathrm{d}} \quad$ Damage yield function

$\mathrm{F}_{\mathrm{p}} \quad$ Plastic yield function

$\Delta \mathrm{G} \quad$ Change in Gibbs free energy

$h \quad$ Material parameter associasted with the damage hardening/softening

I Electric current

K Damage hardening variable associated with the thermodynamic conjugate force

$K_{o} \quad$ Material constant which represents the initial damage threshold

$K_{i j k l} \quad$ Degraded stiffness matrix

$n \quad$ Molar consumption rate of the fuel 


$\begin{array}{ll}\mathrm{p} & \text { Porosity } \\ \mathrm{p}(\mathrm{t}) & \text { Penetration zone } \\ \mathrm{P} & \text { Pressure } \\ \mathrm{R} & \text { Universal gas constant } \\ \mathrm{r}_{\mathrm{o}} & \text { Cell radius } \\ \mathrm{S} & \text { Entropy } \\ \mathrm{S}_{\mathrm{o}} & \text { Material strength at zero porosity } \\ \mathrm{T} & \text { Absolute temperature } \\ \mathrm{t}_{\mathrm{a}} & \text { Anode thickness } \\ \mathrm{t}_{\mathrm{e}} & \text { Electrolyte thickness } \\ \mathrm{t}_{\mathrm{c}} & \text { Cathode thickness } \\ \mathrm{W} & \text { Out of plane displacement } \\ \mathrm{x}(\mathrm{t}) & \text { Intact zone } \\ \mathrm{z} & \text { Moles of electrons }\end{array}$

\section{Greek}

$\begin{array}{ll}\alpha & \text { Isotropic hardening } \\ \delta_{i j} & \text { Kronecker delta } \\ \varepsilon & \text { Total strain } \\ - & \text { Effective strain } \\ \varepsilon & \text { Elastic strain } \\ \varepsilon^{\mathrm{e}} & \text { Plastic strain } \\ \varepsilon^{\mathrm{p}} & \text { Strain tensor } \\ \varepsilon_{i j} & \text { Activation overpotential } \\ \eta_{\mathrm{a}} & \text { Ohmic overpotential } \\ \eta_{\Omega} & \text { Concentration overpotential } \\ \eta_{\mathrm{c}} & \text { Internal variable characterized the degradation hardening/softening } \\ \kappa & \text { Lagrange parameter (consistency parameter) } \\ \lambda & \text { Possion ratio } \\ v & \end{array}$




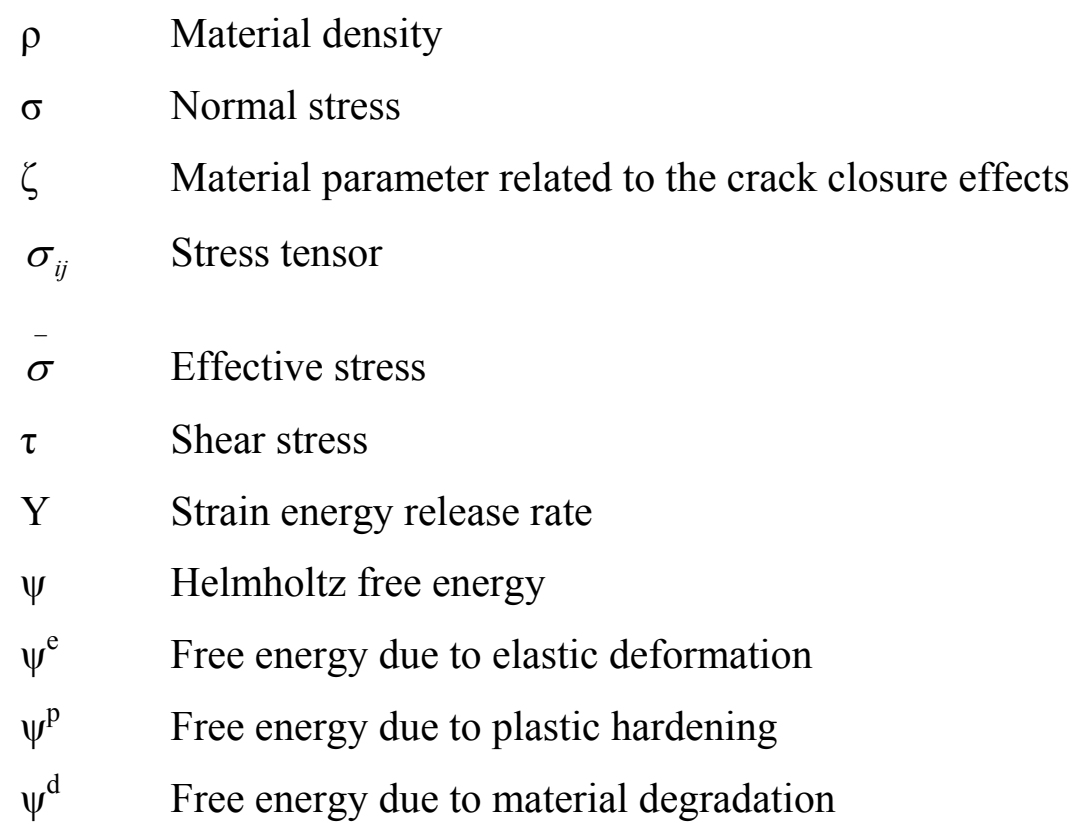

\section{Subscripts}
a Anode
c Cathode
e Electrolyte

\section{Superscripts}

$\begin{array}{ll}\mathrm{d} & \text { Degradation } \\ \mathrm{e} & \text { Elastic } \\ \mathrm{p} & \text { Plastic }\end{array}$




\section{Chapter 1 INTRODUCTION}

\subsection{Overview}

Fuel cells have emerged as an alternative technology to conventional power generation; promising high efficiency and low environmental impacts. Although the fuel cell was invented by Sir William Grove in 1839, the National Aeronautics and Space Administration (NASA) space program was the first to utilize alkali fuel cells onboard the Apollo spacecraft in the 1960s to produce electricity and drinking water. A fuel cell is an electrochemical device which directly converts fuel chemical energy into electrical energy and heat by means of electrochemical reactions. This technology presents many advantages over conventional power generation systems including high efficiency, fuel flexibility, quiet operation, and low levels of $\mathrm{NO}_{\mathrm{x}}$ and $\mathrm{SO}_{\mathrm{x}}$ emissions. They are proven to be technically feasible for automobiles, portable electronic devices, residential and commercial stationary power sources. However, further research is required to make them reliable and economically practical as compared to conventional power sources. Fuel cell operation is similar to a battery but in the case of fuel cells, fuel and oxidant are continuously supplied to the anode and cathode sides, respectively, and the power is generated as long as there is a fuel and oxidant supply along with some other system requirements. Unlike heat engines, it does not directly combust the fuel in air but electrochemically oxidizes the fuel. Thus fuel cell efficiency is not limited by the Carnot cycle and it can achieve comparatively higher efficiency.

Presently, there is a great active research in progress throughout the world on solving engineering problems that currently have prevented the fuel cell technology from becoming commercially feasible as compared to conventional power generation. These include higher manufacturing cost, lack of the infrastructure to store and deliver fuels, 
and other issues related to fuel cell reliability. During the past decade, fuel cell technology research and development (R\&D) activities have been intensified in industries and research institutes through the world. Consequently, fuel cells are now moving towards commercialization. Previously fuel cell technology was limited to niche application such as spacecraft due to high manufacturing and operating costs. The recent R\&D activities in fuel cell technology have reduced the cost to about $\$ 1500 / \mathrm{kW}$. However, the analysts have estimated that the fuel cell cost must reach around $\$ 400 / \mathrm{kW}$ to make the technology competitive.

The United States government established the Solid State Energy Conversion Alliance (SECA) in 1999 to combine the efforts of government, industry, and the scientific community to promote the development of Solid Oxide Fuel Cells (SOFCs) for a variety of energy applications. One of the specific goals of the SECA alliance is to expedite the commercial readiness of SOFCs in the range of $3 \mathrm{~kW}$ to $10 \mathrm{~kW}$ for stationary, transportation, and military applications.

The integration of coal gasification with SOFCs is potentially an efficient technology for generating electric power from coal which is expected to be the single largest fuel source in the foreseeable future. Naturally occurring coal contains many contaminants and some of these contaminants end up in the fuel gas stream in the form of vapor or fine particulate matters. As a high temperature fuel cell, SOFC has many advantages over other types of fuel cells such as high kinetic activity, no need of precious catalysts, fuel flexibility and the possibility of internal fuel reforming. Many fuel gas contaminants such as $\mathrm{Hg}, \mathrm{Si}, \mathrm{Zn}$ and $\mathrm{NH}_{3}$, do not significantly affect the SOFC anode electrochemical performance. However, some fuel gas contaminants (e.g. P, S and As) can interact with SOFC anode material and degrade its electrochemical performance and/or structure properties during long-term operation. Hence, SOFCs operating on coal-derived syngas can play an important role in the commercialization of this technology after these contaminants are reduced to an acceptable level. It is important to establish the tolerance 
of SOFCs for coal-derived syngas contaminants to facilitate proper design of the fuel feed system that would not catastrophically degrade the SOFCs electrochemical performance or structural integrity.

Many types of materials have been studied in the literature for the SOFCs anode. Nickel-Yttria Stabilized Zirconia (Ni-YSZ) however, is the current choice for SOFCs anode material. Ni-YSZ is preferred because of its chemical and structure stability, good thermal and electrical conductivity, catalytic performance, low cost and compatibility with the other materials of SOFC. Anode-supported SOFCs rely on the anode to provide mechanical strength to the positive-electrolyte-negative (PEN) structure. Thin layers of the PEN structure are inherently susceptible to mechanical failure when subjected to moderate stresses. The stress field in the cell can arise from a variety of phenomena including thermal stresses due to thermal expansion mismatch of the layered cell structure, residual stresses and stresses induced by external mechanical loads. These stresses can result in formation of micro-defects and degrade anode structural properties.

Currently, most research efforts are focused on the fuel cell electrochemical performance degradation mechanisms but the structural degradation phenomena due to thermo-mechanical effects and coal syngas contaminants are not given much attention. There is a need to identify the mechanisms that degrade anode structural properties and to determine the effects of those mechanisms on SOFCs structure during long-term operation. Accelerated exposure tests under high contaminant concentrations dictate that the electrochemical degradation is the principal mode of cell failure while the cell structure is still intact. However, under lower contaminant concentration the anode structural degradation may be significant as compared to electrochemical degradation that needs to be addressed. Experimental techniques are time consuming, expensive and might not examine a variety of designs and working conditions. To this end, electrochemical and structural models are highly advantageous to expedite the development and understanding of SOFCs degradation mechanisms. 
In this research a phenomenological structural durability model is developed for the SOFC anode material and implemented in finite element analysis with the help of a user defined material subroutine. The model accounts for thermo-mechanical and fuel gas contaminants effects on the anode material to predict long-term structural integrity of the SOFC anode. The knowledge obtained from this research will be useful to establish control parameters to achieve desired service life of the SOFC stacks.

\subsection{Objectives}

In addition to electrochemical performance, structural integrity of the SOFC anode is essential for successful long-term operation. Currently, most research efforts related to the fuel cells are focused on their electrochemical performance. Anode structural degradation phenomena under synergistic effects of thermo-mechanical and fuel contaminant, in contrast, are not given much consideration. There is a need to identify the mechanisms that degrade anode structural properties and to determine the effects of these mechanisms on SOFCs anode structure behavior during long-term operation.

The objectives of this research are the following:

- Develop a durability model that incorporate thermo-mechanical degradation and fuel gas contaminants effects on the SOFC anode structural properties.

- Implement the model in finite element analysis to predict long-term structural integrity of SOFC anode.

- Validate the methodology using a NexTech Probostat ${ }^{\mathrm{TM}}$ SOFC button cell test apparatus integrated with a Sagnac optical setup and infrared sensor for in-situ surface deformation and temperature measurements.

- To establish a correlation between the degradation model and experimental measurements, a two-layer analytical solution of a thin membrane under uniform pressure is modified to obtain surface deformation of a three-layer thin membrane 
which can be considered as a button cell with anode, electrolyte and cathode layers.

- The model is exploited to predict the stress-strain relations of Nickel-Yttria Stabilized Zirconia (Ni-YSZ) at temperatures and porosities which are difficult to generate experimentally. These curves are utilized to obtain degradation threshold variable and hardening/softening variable at different temperatures and porosities.

- Enhance the proposed model for the planar configurations of SOFC i.e. co-flow, counter-flow and cross-flow.

- Conduct the parametric studies to estimate the anode material reliability under different conditions.

- The ultimate goal of this research is to establish the acceptable limit of contaminants that would not degrade anode structure to an unacceptable level for a specified period of time.

\subsection{Thesis Outline and Scope}

This dissertation consists of six chapters. Chapter-1 contains the research objectives and motivations with the background of fuel cell development. Literature review related to the fuel cell technology is presented in Chapter-2. Different types of fuel cells and their characteristics are discussed followed by a synopsis of the mechanisms that degrade SOFC anode electrochemical and structural properties including thermo-mechanical, fuel gas contaminants, and redox cycles effects. In Chapter-3, the basic concepts of damage mechanics are discussed including state variable, effective configuration, Helmholtz free energy, etc. The proposed model development is presented in Chapter-4. Formulations for both thermo-mechanical degradation and fuel gas contaminant effect on the anode structure are described in detail. Experimental setup for the model validation is also presented. Model validations including an elastic brittle degradation model and fuel contaminant penetration model are explained in Chapter-5. The proposed constitutive 
relations are used to predict Ni-YSZ stress-strain relations at different temperatures and porosities, and some of the material parameters are obtained. The simulation results of the button cell and planar sells are also presented in this chapter. Conclusion and future work are discussed in Chapter-6.

Fuel contaminants which significantly reduce the anode electrochemical performance in short periods of time, such as sulfur (S) and selenium (Se), are not the subject of this study. Anode material is assumed to be isotropic elastic brittle material in the operating temperature range and that the material degradation does not induce anisotropy. Thermo-mechanical degradation of the electrolyte and cathode are not considered in this study. Consequently, their mechanical properties are assumed to be constant. The effect of the interconnect channel is not considered on the PEN structure deformation. 


\section{Chapter 2 LITERATURE REVIEW}

\section{$2.1 \quad$ Introduction}

Fuel cells have emerged as an alternative technology to conventional power generation; promising high efficiency and low environmental impacts. They have been

utilized successfully in many special purpose tasks such as space missions and there is a great active research in progress throughout the world to commercialize the technology. They are proven to be technically feasible for automobiles, portable electronic devices, residential and commercial stationary power sources. However, further research is required to make them reliable and economically practical as compared to conventional power generation technologies.

This chapter presents a concise introduction to fuel cell technology followed by a literature review on the thermo-mechanical degradation mechanisms and fuel gas contaminants effects on both cell electrochemical performance and anode structural properties.

\subsubsection{Fuel Cell Structure and Working Principle}

A fuel cell is a device which directly converts fuel chemical energy into electrical energy and heat by means of electrochemical reactions. Their operation is similar to a battery, however in the case a of fuel cell, the fuel and oxidant are continuously supplied to the anode and cathode sides respectively, and power is generated as long as there is a fuel and oxidant supply along with some other system requirements. Unlike heat engines, a fuel cell does not directly combust the fuel in the air but oxidizes it electrochemically. 
Thus fuel cell efficiency is not limited by the Carnot cycle and it can achieve comparatively higher efficiency. A fuel cell system is divided into following three modules [1]:

(i) Unit Cell

(ii) Fuel Cell Stacking

(iii) Balance of Plant

A unit cell is the electrochemically active composite layer of a fuel cell which consists of three fundamental components: anode, electrolyte, and cathode. It is also called positive electrode-electrolyte-negative electrode (PEN) assembly. Fuel gas and oxidant are continuously supplied to the anode and cathode sides respectively. At the anode, fuel is oxidized and electrons are produced which flow through the external circuit. A schematic representation of the unit cell is shown in Figure 2-1.

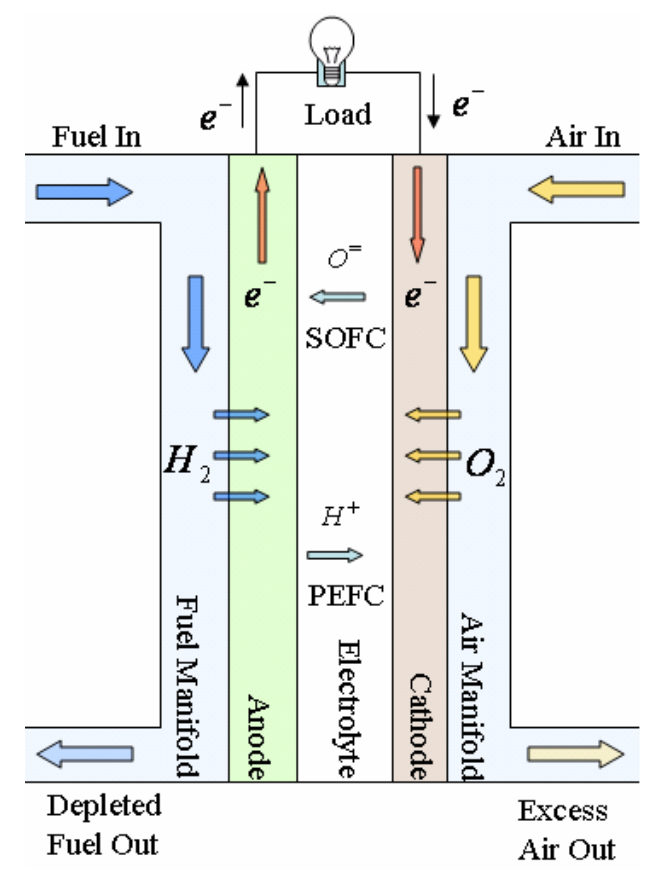

Figure 2-1 Schematic of a single fuel cell 
In addition to providing electrochemical reactions sites, the electrodes and electrolyte also have some other critical roles to fulfill. The electrolyte conducts ionic charges between the electrodes and thus completes the cell electric circuit internally. It also prevents the fuel and oxidant species from direct combustion. Electrodes also conduct electrons to and from reaction sites, act as current collectors, and in some cases provide structural support to the unit cells. Since the maximum power density that can be achieved using a Nickel-Yttria Stabilized Zirconia (Ni-YSZ) anode fueled with hydrogen at $800{ }^{\circ} \mathrm{C}$, is less than $1 \mathrm{~W} / \mathrm{cm}^{2}$ [2], the unit cells must be combined into cell stacks to generate a power output level required for a desired application. The stacking involves electrically connecting multiple cells in series by means of interconnects.

Fuel cell systems require several other sub-systems and components called balance of plant (BoP), which are essential for the system operation. The BoP sub-system depends on the fuel cell type, fuel and oxidant choice, and application. The BoP generally covers fuel preparation, air supply, thermal management, water management, and electric power conditioning equipment [1]. Noticeably, BoP represents a significant portion of weight, volume, and cost of the most fuel cell systems.

\subsubsection{Types of Fuel Cell}

Several types of fuel cells are in different stages of development [1, 3]. They are generally categorized by the type of electrolyte used such as solid oxide fuel cell (SOFC), molten carbonate fuel cell (MCFC), polymer electrolyte fuel cell (PEFC), phosphoric acid fuel cell (PAFC), and alkaline fuel cell (AFC) etc. The choice of electrolyte determines the cell operating temperature and thus the level of fuel processing required before it can be fed to the fuel cell. Key characteristics of several types of fuel cells are given in Table 2-1. Fuel cells are also classified based on their operating temperature: SOFC and MCFC are categorized as high temperature $\left(600{ }^{\circ} \mathrm{C}-1000{ }^{\circ} \mathrm{C}\right)$ fuel cells, while PEFC, PAFC, and AFC are categorized as low temperature $\left(30^{\circ} \mathrm{C}-200{ }^{\circ} \mathrm{C}\right)$ fuel 
cells. Much attention has been given to commercialize SOFC and PEFC in recent years for the stationary and automotive applications respectively.

Table 2-1 Key characteristics of the main fuel cell types [1,4]

\begin{tabular}{|c|c|c|c|c|c|}
\hline & PEFC & $\mathrm{AFC}$ & PAFC & MCFC & SOFC \\
\hline Electrolyte & $\begin{array}{c}\text { Polymeric Ion } \\
\text { Exchange } \\
\text { Membranes } \\
\text { (e.g. Nafion) }\end{array}$ & $\begin{array}{c}\text { Potassium } \\
\text { Hydroxide in } \\
\text { asbestos } \\
\text { matrix }\end{array}$ & $\begin{array}{c}\text { Liquid } \\
\text { Phosphoric } \\
\text { Acid in } \mathrm{SiC}\end{array}$ & $\begin{array}{c}\text { Molten } \\
\text { Carbonate in } \\
\text { LiAlO2 }\end{array}$ & $\begin{array}{c}\text { Perovskites } \\
\text { (Ceramics) } \\
\text { (YSZ) }\end{array}$ \\
\hline $\begin{array}{l}\text { Charge } \\
\text { Carrier }\end{array}$ & $H^{+}$ & $O H^{-}$ & $H^{+}$ & $\mathrm{CO}_{3}^{2-}$ & $O^{2-}$ \\
\hline Electrode & Carbon & $\begin{array}{c}\text { Transition } \\
\text { Metals }\end{array}$ & Carbon & $\begin{array}{c}\text { Nickel and } \\
\text { Nickel Oxide }\end{array}$ & $\begin{array}{c}\text { Perovskite } \\
\text { Cermet } \\
\text { (Ni-YSZ,LSM) }\end{array}$ \\
\hline Catalyst & Platinum & Platinum & Platinum & $\begin{array}{l}\text { Electrode } \\
\text { Material }\end{array}$ & $\begin{array}{c}\text { Electrode } \\
\text { Material (Ni) }\end{array}$ \\
\hline $\begin{array}{l}\text { Operating } \\
\text { Temperature }\end{array}$ & $40^{\circ} \mathrm{C}-80^{\circ} \mathrm{C}$ & $65^{\circ} \mathrm{C}-220^{\circ} \mathrm{C}$ & $205^{\circ} \mathrm{C}$ & $650^{\circ} \mathrm{C}-800^{\circ} \mathrm{C}$ & $600^{\circ} \mathrm{C}-1000^{\circ} \mathrm{C}$ \\
\hline Applications & Automobile & $\begin{array}{c}\text { Space } \\
\text { Program }\end{array}$ & $\begin{array}{l}\text { Stationary } \\
\text { Application }\end{array}$ & $\begin{array}{c}\text { Large } \\
\text { Stationary and } \\
\text { Marine }\end{array}$ & $\begin{array}{c}\text { Stationary, } \\
\text { vehicles APU }\end{array}$ \\
\hline
\end{tabular}

Due to high vapor pressure at high temperature, aqueous electrolyte cells operate below $200{ }^{\circ} \mathrm{C}$. Low-temperature fuel cells require pure hydrogen as the electrode catalysts are easily poisoned by $\mathrm{CO}$ and other contaminants that may be present in the fuel stream. Low-temperature fuel cells offer lower electrical efficiency as compared to high temperature fuel cells but they are more suitable for portable electrical devices and 
automotive applications which require frequent fast start up and shut down. Hightemperature fuel cells electrolyte offer high ionic conductivity at operating temperature. They can internally reform $\mathrm{CH}_{4}$ and $\mathrm{CO}$ or even directly oxidize them electrochemically. High-temperature fuel cells are developed for power generation where high start up and shut down time is not a concern.

\subsubsection{Solid Oxide Fuel Cell}

A Solid Oxide Fuel Cell (SOFC) is a high temperature fuel cell that operates above $700{ }^{\circ} \mathrm{C}$. The cell contains a solid non-porous electrolyte, usually yttria-stabilized zirconia $\left(\mathrm{Y}_{2} \mathrm{O}_{3}\right.$ stabilized $\left.\mathrm{ZrO}_{2}\right)$ which conducts oxide $\left(\mathrm{O}^{-}\right)$ions from cathode to anodes. In general, the anode is made of Ni-8YSZ cermet and the cathode is made of Sr-doped $\mathrm{LaMnO}_{3}$ (LSM). Many types of materials have been studied in the literature for the SOFCs anode such as $\mathrm{La}_{\mathrm{x}} \mathrm{Sr}_{1-\mathrm{x}} \mathrm{VO}_{3-\delta}$ (LSV) [5], $\mathrm{CoS}_{1.035}, \mathrm{WS}_{2}$, and $\mathrm{Li}_{2} \mathrm{~S} / \mathrm{CoS}_{1.035}$ [6], $\mathrm{Ni} /$ scandia-stabilized zirconia (Ni-ScSZ) [7], $\mathrm{Cu}-\mathrm{CeO}_{2}-\mathrm{YSZ}$ [8] etc. Nickel-Yttria Stabilized Zirconia (Ni-YSZ), however, is the current choice for SOFCs anode material [9-11]. Ni-YSZ is preferred because of its chemical and structure stability, good thermal and electrical conductivity, catalytic performance, cost and compatibility with the other materials of SOFC [11].

Fuel gas is supplied to the anode side which diffuses through the porous anode to the electrochemical active layer. Similarly, the oxidant species (usually air) is supplied to the porous cathode. At the triple phase boundary (YSZ, Ni, and fuel), fuel gas (e.g. hydrogen or syngas) is oxidized by the oxide ions (produced at the cathode) and electrons are released which flow through the external circuit to the cathode side as depicted in Figure 2-1. For a hydrogen fuel cell, the half cell reaction at the anode can be represented by Eq. (2. 1).

$$
\mathrm{H}_{2}+\mathrm{O}^{2-} \rightarrow \mathrm{H}_{2} \mathrm{O}+2 e^{-}
$$


Similarly, the oxidant species (usually air) is supplied to the porous cathode side. Air is reduced by the electrons from the external circuit and oxide ions are produced which migrate through the electrolyte to the anode side, hence completing the cell internal electrical circuit as shown in Figure 2-1. The half cell reaction at the cathode side can be represented by the following equation:

$$
1 / 2 \mathrm{O}_{2}+2 e^{-} \rightarrow \mathrm{O}^{2-}
$$

The overall electrochemical reaction in a simple hydrogen fuel cell can be represented by Eq. (2.3).

$$
\mathrm{H}_{2}+1 / 2 \mathrm{O}_{2} \rightarrow \mathrm{H}_{2} \mathrm{O}
$$

Electrons generated at the anode travel through the external circuit to the cathode and the oxide ions produced at the cathode migrate through the electrolyte to the anode side, and hence the cell electrical circuit is completed.

\subsubsection{Cell and Stack Designs}

The maximum power density that can be achieved using Ni-YSZ anode fueled with hydrogen at $800^{\circ} \mathrm{C}$ is less than $1 \mathrm{~W} / \mathrm{cm}^{2}$ [2]. In order to obtain desired power output, the fuel cells are combined in series or parallel circuit: a series circuit generates higher voltage while with the parallel combination a larger current can be drawn. Interconnects, also known as bipolar plates or separator plates, are placed in between the anode of one cell and the cathode of the adjacent cell. Such combination of individual cells is called a fuel cell stack. Since SOFC entirely consists of solid-state components, a wide variety of stacking configurations are possible. The following types of cell stacking designs for SOFC have been considered in the literature. 


\section{Tubular cell}

2. Planar cell

\section{Segmented cell}

4. Monolithic cell

Tubular and planar cells arrangement drew more interest than other cell stacking options. Tubular cell stack design is unique to SOFC due to its solid state design: other types of fuel cells exclusively concentrate on planar stack configuration [1].

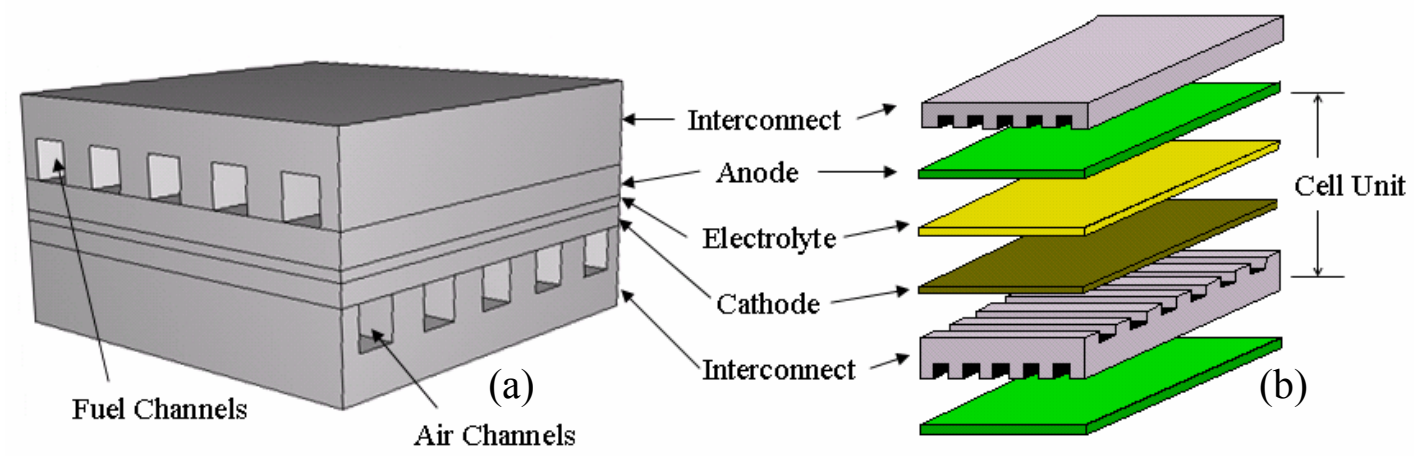

Figure 2-2 (a) Cross-flow planar-SOFC design; (b) Exploded view [12]

Siemens Westinghouse has been working intensely to develop tubular SOFC for more than 20 years [15]. They have developed the basic cell design, materials and manufacturing process, and have verified tubular SOFC performance through an extensive testing program. In 1997, Siemens Westinghouse delivered an atmospheric 100-kWe SOFC-CHP (combine heat and power) system to a Dutch/Danish utility consortium in Netherlands. Through 1999, it was the largest operating SOFC system, supplying around 105 to $110 \mathrm{kWe}$ net $\mathrm{AC}$ to the utility grid and producing about $65 \mathrm{~kW}$ to the hot water district heating system. 

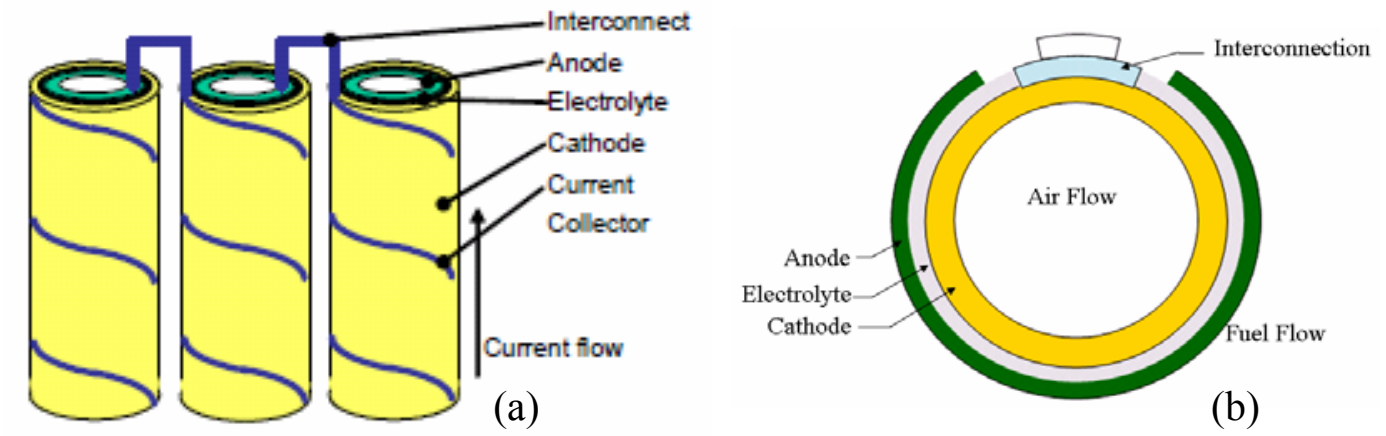

Figure 2-3 Tubular SOFC: (a) Accumentric design [13]; (b) Schematic cross-section of Siemens Westinghouse tubular cell, redrawn from [14]

Planar cell arrangement is the most common fuel cell stack configuration where individual unit cells are electrically connected by means of interconnects to generate desired power as shown in Figure 2-2. Recently planar stack designs have received much attention because they are simpler to fabricate and easier to be formed into various shapes than other configurations [16]. Interconnects serve two main purposes: (1) provide electrical connection between adjacent cells and (2) keep fuel and oxidant of the adjacent cells from mixing. Planar design offers shorter electric current path which causes less resistant losses as compared to tubular design. In most cases, interconnects also accommodate channels that distribute the fuel and oxidant over the fuel cells.

Planar stacks design can be further divided into the following categories according to the relative fuel and oxidant flow directions.

(a) Co-flow: fuel and oxidant flow in the same direction (Figure 2-4(a))

(b) Counter-flow: fuel and oxidant flow in opposite directions (Figure 2-4(b))

(c) Cross-flow: fuel and oxidant flow perpendicular to each other (Figure 2-4(c)) 

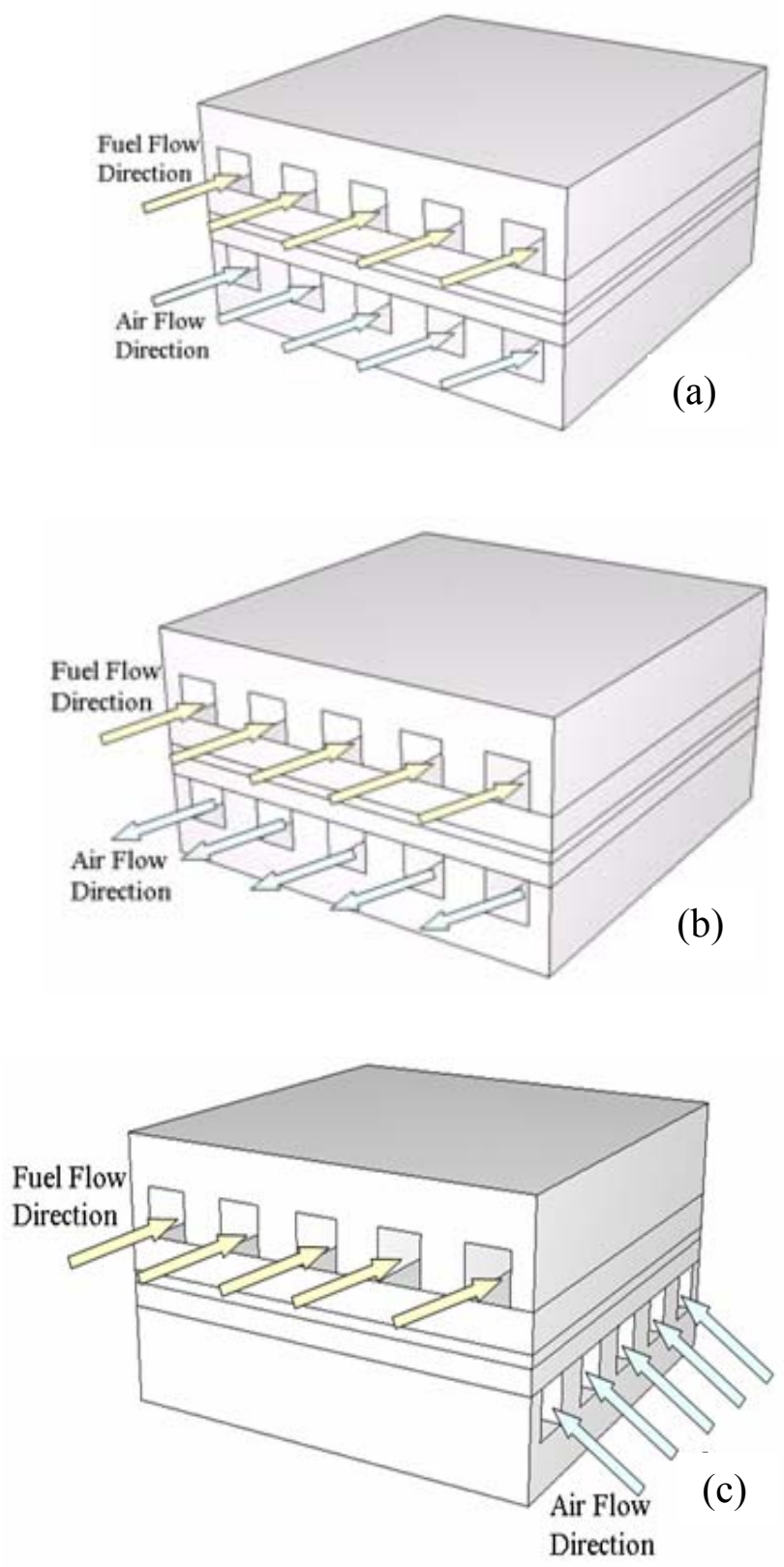

Figure 2-4 Relative gas flow directions in SOFC: (a) co-flow (b) counter-flow (c) cross-flow 


\subsection{Thermodynamics of Fuel cells}

In fuel cells, electricity is generated by means of electrochemical reactions. Unlike other energy conversion techniques, it is not apparent what form of energy is being transformed into electrical energy in fuel cells [17]. The chemical energy changes in the operation of fuel cells can be described in terms of Gibbs free energy change $\Delta \mathrm{G}$, which is defined as " the energy available to do external work, neglecting any work done by changes in pressure and/or volume" [4]. For chemical reactions, Gibbs free energy is determined by the energy released during the chemical process as defined by the following equation:

$$
\Delta \mathrm{G}=\text { Products Gibbs Energy - Reactants Gibbs Energy }
$$

Under ideal conditions all of the available energy released during a chemical reaction will be converted into useful electrical power. Then, Gibbs free energy can be used to quantify the open circuit voltage (OCV) by the following equation:

$$
\Delta E_{N} I=-\dot{n} \Delta G
$$

where $\Delta \mathrm{E}_{\mathrm{N}}$ is the $\mathrm{OCV}$ also known as Nernst cell voltage, $\mathrm{I}$ is the current, and $\dot{n}$ is the molar consumption rate of fuel. In a chemical reaction, the current produced and amount of fuel consumed is related through stoichiometry. If $\mathrm{z}$ moles of electrons are generated from one mole of fuel, the total current produced by the chemical reaction can be expressed as the following:

$$
I=z \dot{n} F
$$

where F (96487 coulomb/mole of electron) is the Faraday's constant. From Eq. (2. 5) and Eq. (2. 6), the OCV can be derived as following: 


$$
\Delta G=-z F \Delta E_{N}
$$

The change in Gibbs free energy $\Delta \mathrm{G}$ depends on the temperature and the activities of the reactant and product species. Under standard operating conditions and when all the species have unit activity, the change in Gibbs free energy can be expressed as the following:

$$
\Delta G_{o}=-z F \Delta E_{o}
$$

Now the Nernst potential can be written in terms of the cell ideal potential $\left(\Delta \mathrm{E}_{\mathrm{o}}\right)$ under unit activity, species partial pressure, and operating temperature as shown in Eq. (2.9):

$$
\Delta E_{N}=\Delta E_{o}-\frac{R T}{z F} \ln \Sigma\left(\frac{p_{i}}{p_{o}}\right)^{v_{i}}
$$

where $\mathrm{R}$ is the universal gas constant, $\mathrm{T}$ is the absolute temperature, $\mathrm{p}_{\mathrm{i}}$ is the partial pressure of species $\mathrm{i}, \mathrm{p}_{\mathrm{o}}$ is the standard pressure, and $\mathrm{v}_{\mathrm{i}}$ is a positive stoichiometric coefficient for product and negative coefficient reactant species $i$.

The Nernst potential describes the upper limit or maximum performance that can be achieved by fuel cells under given conditions. Fuel cell actual performance (potential) is less than from its ideal performance due to some irreversible losses. These potential losses are referred to as overpotential or polarization losses and are classified as activation losses, resistance losses and concentration losses. Each type of loss is dominated in a certain range of current drawn as shown in Figure 2-5. 


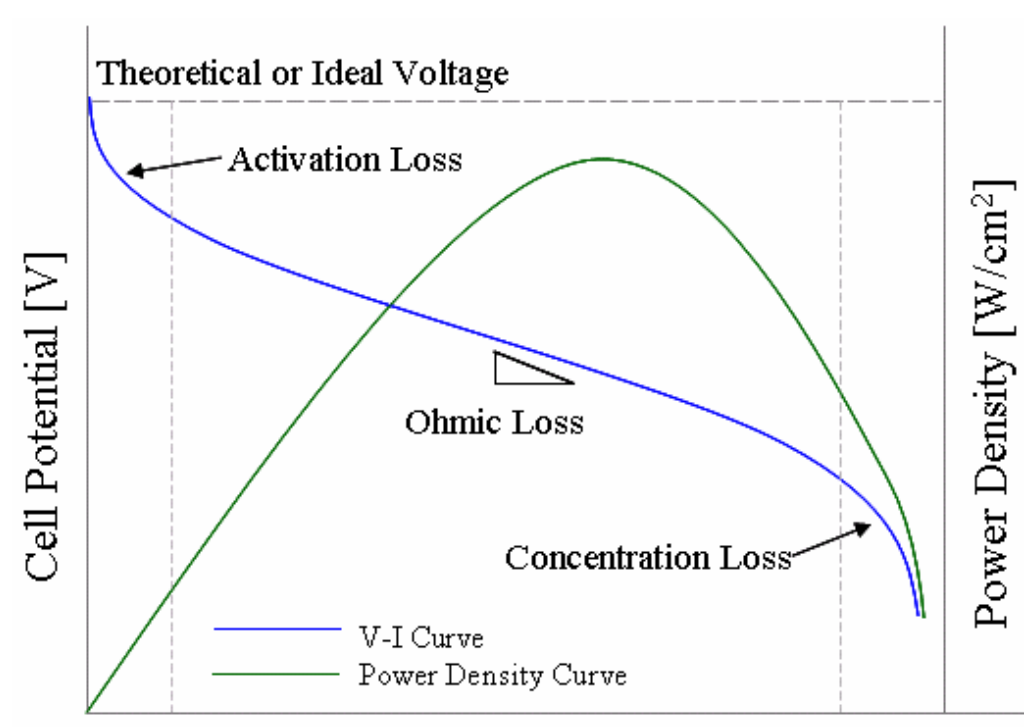

Current Density $\left[\mathrm{A} / \mathrm{cm}^{2}\right]$

Figure 2-5 Fuel cell polarization and power density curves

The polarization curve is the most important performance measure of a fuel cell that is the voltage output as a function of electrical current drawn. Cell actual working voltage (E), can be written in terms of Nernst voltage $\left(E_{N}\right)$, activation overpotential $\left(\eta_{a}\right)$ due to slow electrodes reactions, Ohmic overpotential $\left(\eta_{\Omega}\right)$ due to electrical and ionic resistance, and concentration overpotential $\left(\eta_{c}\right)$ due to mass diffusion limitations, as shown in Eq. (2. $10)$.

$$
E=E_{N}-\left(\eta_{a}+\eta_{\Omega}+\eta_{c}\right)
$$

Activation losses result from slow electrochemical reactions at the electrodes. These losses are dominated at low current density and there is a sharp drop in voltage for a slight increase in current drawn. These losses depend on electrochemical reactions, catalyst material, operating temperature, reactant activities and current density [1]. Ohmic losses arise from electrolyte and electrodes ionic resistance, electrodes electrical resistance and contact resistances. These losses are proportional to the applied current 
and depend on operating temperature, stack geometry and cell materials. Concentration losses are dominated at high current density as shown in Figure 2-5. These losses are caused by the mass transfer limitations to and from the electrodes electrochemical reaction sites, and strongly depend on current density and electrodes structure. 


\subsection{Structural Degradation Mechanisms of SOFC Anode}

Solid Oxide Fuel Cells (SOFCs) operate under harsh environments, which cause deterioration of the anode material properties and service life. In addition to electrochemical performance, structural integrity of the SOFC anode is indispensable for successful long-term operation. The SOFC anode is subjected to stresses at high temperature, thermal/redox cycles, thermal aging, and fuel gas contaminants effects during long-term operation. The SOFC anode is expected to maintain material integrity to prevent mechanical failures for an extended period of time (40000hrs).

Anode-supported SOFCs rely on the anode to provide mechanical strength to the PEN (positive electrode - electrolyte - negative electrode) structure. The stress field in the anode can arise from a variety of phenomena including thermal expansion mismatch between layers in the PEN structure, thermal/redox cycles and external mechanical loads. Moreover, some of the fuel contaminants such as $\mathrm{P}$ and As, interact with the anode materials which lead to the formation of secondary phases and grain growth. These mechanisms can result in the formation of microcracks and degrade anode structural properties and electrochemical performance. Assessments of the evolution of anode mechanical properties during long-term operation are, therefore, essential to predict SOFC working life.

In this research, the anode structural degradation mechanisms are divided into two broad categories: thermo-mechanical degradation and fuel gas contaminants effects on anode microstructure. The thermo-mechanical degradation encompasses thermal stress

and thermal aging effects whereas the contaminant degradation takes the effects of fuel gas contaminants into account on the anode structural properties. 


\subsubsection{Thermo-Mechanical Effects on Anode Microstructure}

Solid oxide fuel cells (SOFCs) typically operate above $700{ }^{\circ} \mathrm{C}$ which leads to severe thermal stresses caused by the coefficient of thermal expansion mismatch among its components. Anode-supported SOFCs rely on the anode cermet as mechanical support for the electrolyte and cathode [1]. The service life of a Ni-cermet anode is deteriorated by a variety of microstructural changes which mainly result from material transport, deactivation and thermo-mechanical mechanisms $[18,19]$.

A thin layer of anode material is inherently susceptible to mechanical failure when subjected to moderate stresses [20]. A variety of stresses exist in the anode material that can arise from coefficient of thermal expansion mismatch, residual stresses, spatial or temporal temperature, and external mechanical loading. These stresses can result in formation of microcrack or delamination of layers and degrade anode material properties. Interfacial and peeling stresses are two types of thermal stress that cause the mechanical failure of the SOFC. Lin Liu et al. [21] developed a generalized model for crack nucleation in multi-layered structure under thermal cycling and utilized it for life prediction. They introduced a non-dimensional damage parameter $(\omega)$, as shown in Eq. (2. 11) and Figure 2-6.

$$
\omega=\frac{D}{b}
$$

On the bases of thermo-mechanical mechanisms, the SOFCs may encounter catastrophic mechanical failure under operating conditions. The catastrophic failure often occurs because of material fracture or interfacial delamination between the layers. The failure may originate from a combination of thermo-mechanical, chemical and electrical driving forces. 


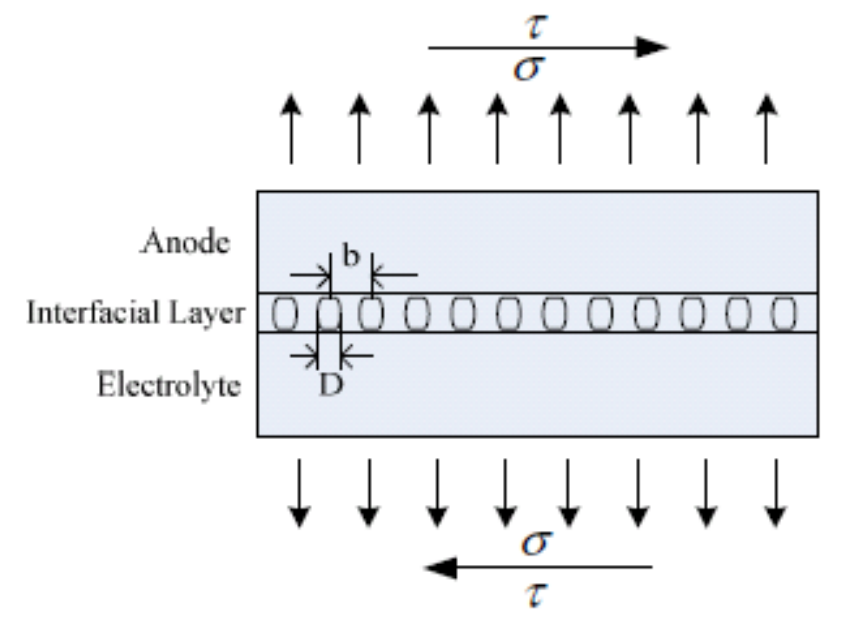

Figure 2-6 Schematic diagram of a three-layer SOFC anode side with a localized damage band [21]

Additional research is needed in order to quantify and predict the contribution of the thermal stresses to the failure of the cell [22]. The current knowledge on the mechanical phenomena in SOFC does not allow modeling for the purpose of life assessment.

Previous studies showed material aging effects of stabilized zirconia components when exposed to high temperature for an extended period of time and the most affected property by aging phenomenon is the strength reduction [23]. It is well known that the conductivity of YSZ degrades after long-term operation of SOFC. The deterioration in conductivity is related to the gradual formation of fine tetragonal phase in the cubic phase [24]. In some circumstances, the mechanical properties of multiphase brittle materials strongly depend on the level of residual micromechanical stresses that arise upon cooling/heating due to thermal and elastic mismatch between the constituent phases [25]. 


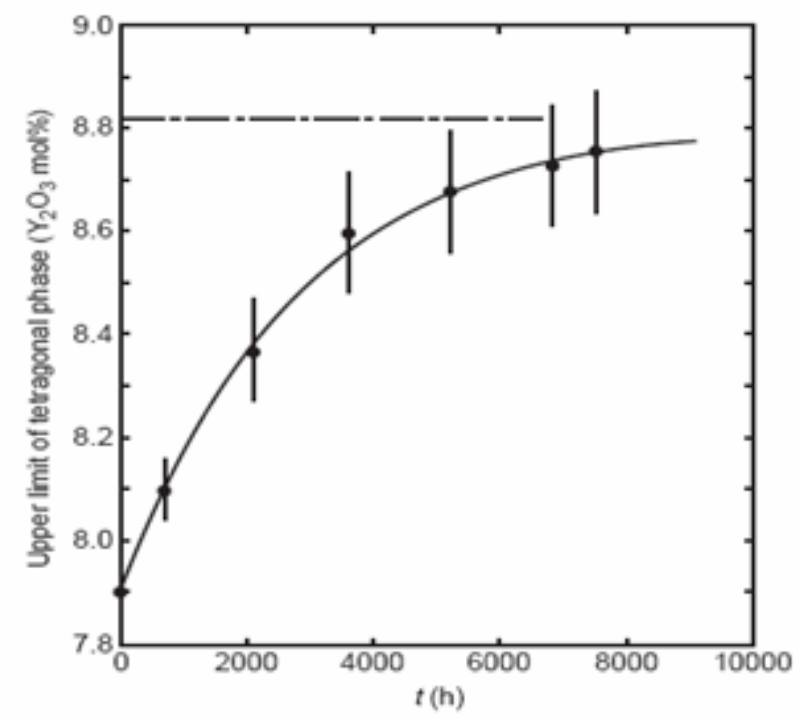

Figure 2-7 Upper limit of tetragonal phase in $\mathrm{ZrO}_{2}-\mathrm{Y}_{2} \mathrm{O}_{3}$ system as function of aging time (h) at $1000^{\circ} \mathrm{C}[24]$

The cubic-tetragonal phase boundary at $1000^{\circ} \mathrm{C}$ is around the $9 \mathrm{~mol} \% \mathrm{Y}_{2} \mathrm{O}_{3}$ in $\mathrm{ZrO}_{2}$ [24], as shown in Figure 2-7. Their results also suggest that the (tetragonal + cubic)/cubic phase boundary is located at the $\mathrm{Y}_{2} \mathrm{O}_{3}$ content of about $7.9 \mathrm{~mol} \%$ at $1400^{\circ} \mathrm{C}$; the cubictetragonal phase transformation boundary decreases $\left(\mathrm{mol} \% \mathrm{Y}_{2} \mathrm{O}_{3}\right.$ in $\left.\mathrm{ZrO}_{2}\right)$ with the increase in temperature. Therefore the phase boundary must be higher at $\mathrm{Y}_{2} \mathrm{O}_{3}$ content $(>9 \%)$ at the SOFCs operating temperature which is around $800^{\circ} \mathrm{C}$. Moreover, increasing mol\% of $\mathrm{Y}_{2} \mathrm{O}_{3}$ in $\mathrm{ZrO}_{2}$, decreases its conductivity and leads to higher ohmic loses. It is possible that the gradual formation of fine tetragonal phase in the cubic phase also degrades anode structural properties due to the elastic and thermal coefficient mismatch between the constituent phases of YSZ.

Prediction of remaining creep life of SOFCs materials is also an important and complicated issue. Creep deformation is one of the mechanisms responsible for changes in residual stresses in Ni-YSZ/YSZ bilayers at high temperature [26]. Creep behavior 
ultimately controls the design and lifetime of the components operating for prolonged periods of time at high temperatures under stress [27].

Lara-Curzio et al, [26] investigated thermal cycle and thermal aging effects on $\mathrm{Ni}$ YSZ/YSZ bilayers with the results showing modification of residual stresses and reduction of material strength. They also concluded that Ni-YSZ showed propensity for creep deformation at $800^{\circ} \mathrm{C}$ as shown in Figure 2-8.

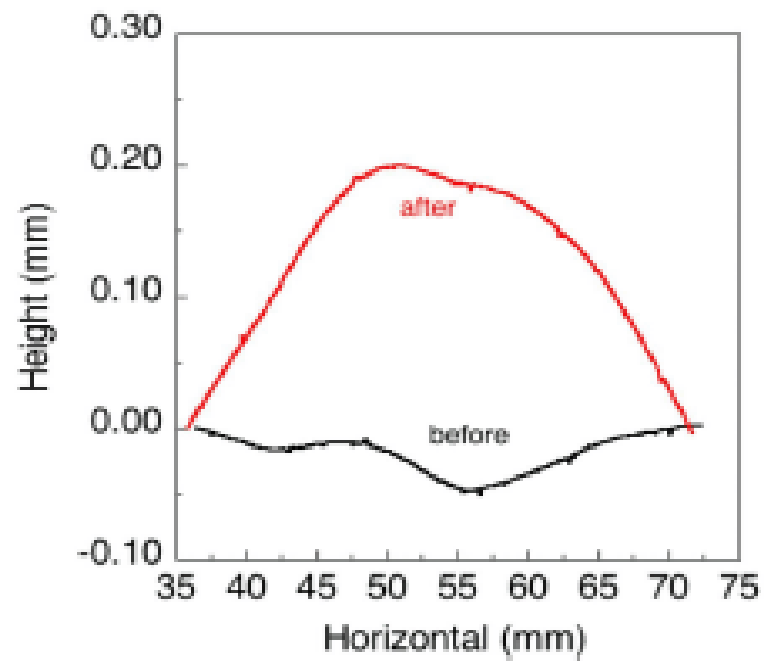

Figure 2-8 Curvature recorded before and after $50 \mathrm{~h}$ stress relaxation test at $800^{\circ} \mathrm{C}$ at an initial elastic stress of $45 \mathrm{MPa}$ for a Ni-YSZ test specimen [26]

Nguyen et al, [28] conducted failure analyses and developed a CDM model for glass seal (G-18) and ceramic materials used in SOFCs. The CDM model accounts for material degradation caused by various mechanisms i.e. void growth, void nucleation, and coalescence, in a phenomenological way through a scalar degradation variable $\mathrm{D}$, that governs the reduction of the homogenized elastic modulus [29] as shown in Eq. (2. 12).

$$
E(T, D)=E_{o}(T) \cdot(1-D)
$$




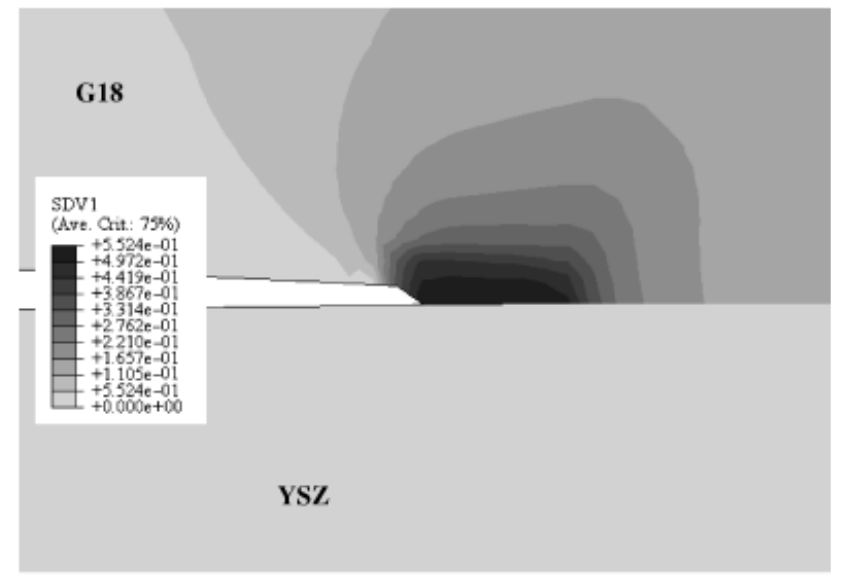

Figure 2-9 Predictions of damage and failure progressions (D_SDV1) from an initial G18/yttria-stabilized zirconia interface crack [28]

W. Liu and J. Qu [30] developed a micromechanical based constitutive model to describe the creep behavior of Ni/YSZ. They found that the creep deformation in the $\mathrm{Ni} / \mathrm{YSZ}$ is primarily in the Ni phase as indicated by nickel volume fraction in Eq. (2. 13). They derived a closed form solution that gives the strain rate of the entire Ni/YSZ mixture as a function of the overall effective stress as shown in Figure 2-10:

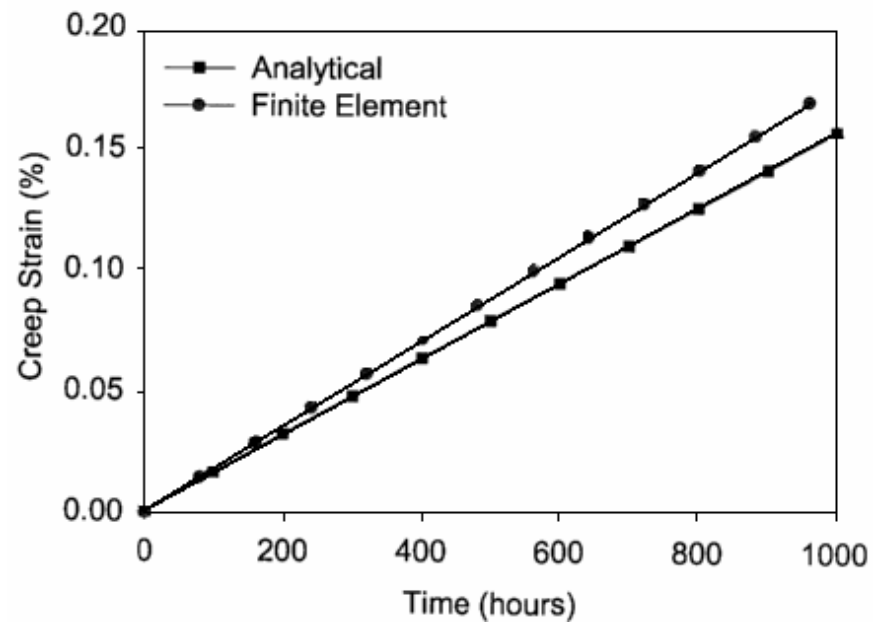

Figure 2-10 Creep Strain in Ni/YSZ over time [30] 


$$
\frac{d \bar{\varepsilon}}{d t}=\frac{c_{N}}{3 \eta} \sigma^{n_{c}}
$$

where $c_{N}$ is nickel phase volume fraction, $\eta$ is viscous coefficient, and $\sigma^{-}$is the stress. The chemical instability at the interfaces is one of the major problems for the stationary application, whereas for the transportation application, the thermo-mechanical instability is important because of repeated thermal cycles [31]. They are influenced by the interaction of material, stack, system parameters and operating conditions and generally amplify with increasing cell size $[32,33]$. The porous anode provides the structural support to the thin YSZ electrolyte layer. Thus the mechanical integrity of Ni-YSZ anode is critical for preventing failure of the PEN structure. One of the major sources for internal stresses build-up is creep deformation which may lead to the cracking of the electrolyte or delamination of the cathode/anode [30]. It is therefore important to understand the degradation mechanisms for these issues in detail. 


\subsubsection{Redox Cycle Effects on Anode Mechanical Properties}

The SOFCs are anticipated to go through several redox cycles when used in longterm operation: 5-20 cycles per year during the lifetime of the cell [34]. The 5 years expected commercial lifetime of SOFC corresponds to a total of 25 to 100 cycles.

As long as the fuel is continuously supplied to the anode (Ni/YSZ) and the anode is maintained in a reduced environment, Ni remains in metallic form in the anode [35]. However, if the fuel supply is interrupted, oxygen may continue to reach anode through electrolyte or through seal leakage and oxidize the metallic $\mathrm{Ni}$ into $\mathrm{NiO}$. Oxidation of the anode may also occur when the fuel utilization is too great causing the oxygen activity to rise above that for equilibrium between $\mathrm{Ni}$ and $\mathrm{NiO}$. The oxidation of $\mathrm{Ni}$ to $\mathrm{NiO}$ is accompanied by an increase of solid volume as the anode expands in dimension [35]. Although it is possible to maintain the reduced environment at all times, it is often impractical and uneconomical.

The restoration of fuel supply converts the $\mathrm{NiO}$ back into $\mathrm{Ni}$, but in general the original state of the anode is not fully recovered. Thus the changes in anode dimension can build up over many redox cycles and this generates internal stresses in the anode and other cell components that can cause material degradation, loss of performance, or even complete loss of structure integrity [35]. 

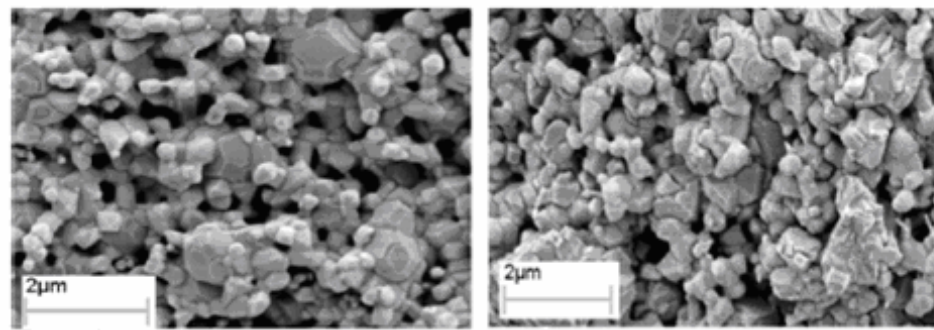

(a)
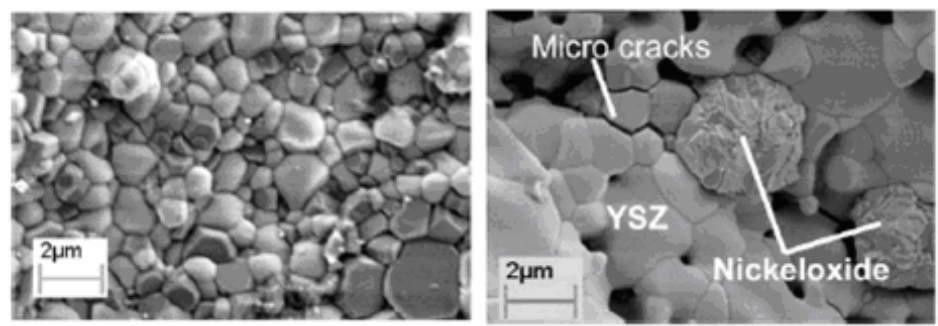

(b)

Figure 2-11 $\mathrm{NiO} / \mathrm{YSZ}$ bulk anode sample sintered at (a) $1200^{\circ} \mathrm{C}$ and (b) $1400^{\circ} \mathrm{C}$

Left: before redox cycle, Right: after passing through 4 redox cycles [36]

The microstructural changes after four redox cycles on samples sintered at $1200{ }^{\circ} \mathrm{C}$ and $1400{ }^{\circ} \mathrm{C}$ are shown in Figure 2-11. For the sample sintered at $1400{ }^{\circ} \mathrm{C}$, cracks are evident caused by higher sintering temperature having less porosity to accommodate the volume change during oxidation.

Table 2-2 Percentage length change $\Delta l / l_{o}$ of $N i O / Y S Z$ sintered at different temperature after successive redox cycles at $950^{\circ} \mathrm{C}$ [36]

\begin{tabular}{|l|c|c|c|c|c|}
\hline Sintering Temperature & $\mathbf{1 1 0 0}^{\mathbf{}} \mathbf{C}$ & $\mathbf{1 1 5 0}^{\mathbf{}} \mathbf{C}$ & $\mathbf{1 2 0 0}^{\mathbf{}} \mathbf{C}$ & $\mathbf{1 3 0 0}^{\mathbf{}} \mathbf{C}$ & $\mathbf{1 4 0 0}^{\mathbf{C}} \mathbf{C}$ \\
\hline After 1/2 redox cycle & 0.1 & 0.2 & 0.1 & 0.4 & 0.6 \\
\hline After 2/3 redox cycle & 0.2 & 0.2 & 0.1 & 0.6 & 0.5 \\
\hline After 3/4 redox cycle & 0.3 & 0.4 & 0.2 & 0.6 & 0.6 \\
\hline Total & $\mathbf{0 . 6}$ & $\mathbf{0 . 8}$ & $\mathbf{0 . 4}$ & $\mathbf{1 . 6}$ & $\mathbf{1 . 7}$ \\
\hline
\end{tabular}

D. Fouquet et al., [36] have studied dimensional changes due to redox cycles by dilatometry and have related to the $\mathrm{NiO} / \mathrm{YSZ}$ sintering temperature and particle sizes as shown in Table 2-2. Stathis et al. [37] performed oxidation experiments on Ni/YSZ samples with different geometries (bars and discs), at different temperatures $\left(550{ }^{\circ} \mathrm{C}-\right.$ 
$950{ }^{\circ} \mathrm{C}$ ). They found that the macroscopic strain increases with the oxidation temperature; from $0.27 \%$ at $650{ }^{\circ} \mathrm{C}$ to $0.54 \%$ at $800{ }^{\circ} \mathrm{C}$. Thus the higher the oxidation temperature, the larger the bulk volume changes, such that the oxidation at $950{ }^{\circ} \mathrm{C}$ caused spontaneous mechanical failure [37].

Faes et al, [38] compare the redox cyclic effects on the curvature and strength of half-cells composed of a Ni-YSZ support: a Ni-YSZ anode and an 8\%YSZ electrolyte. They measured the strength by the ball-on-ring method as shown in Figure 2-12 and the thermal stresses were estimated from the curvature of the half-cell.
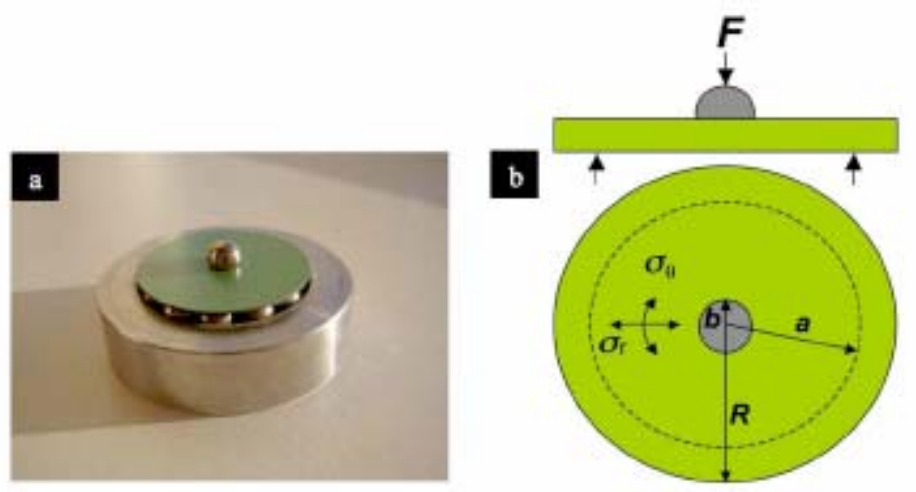

Figure 2-12 (a) Ball-on-ring setup with a sample (b) dimension of the setup, $F$ is the load [38]

They concluded that the redox cycles increase the cell curvature compared to standard reduction and the redox cycles at higher temperature lead to higher cell curvature.

Pihlatie et al. [39] studied the redox cyclic effects on the stiffness of anode material and found that the Young's modulus of the samples decrease almost linearly with the cumulative redox strain (CRS) as shown in Figure 2-13. 


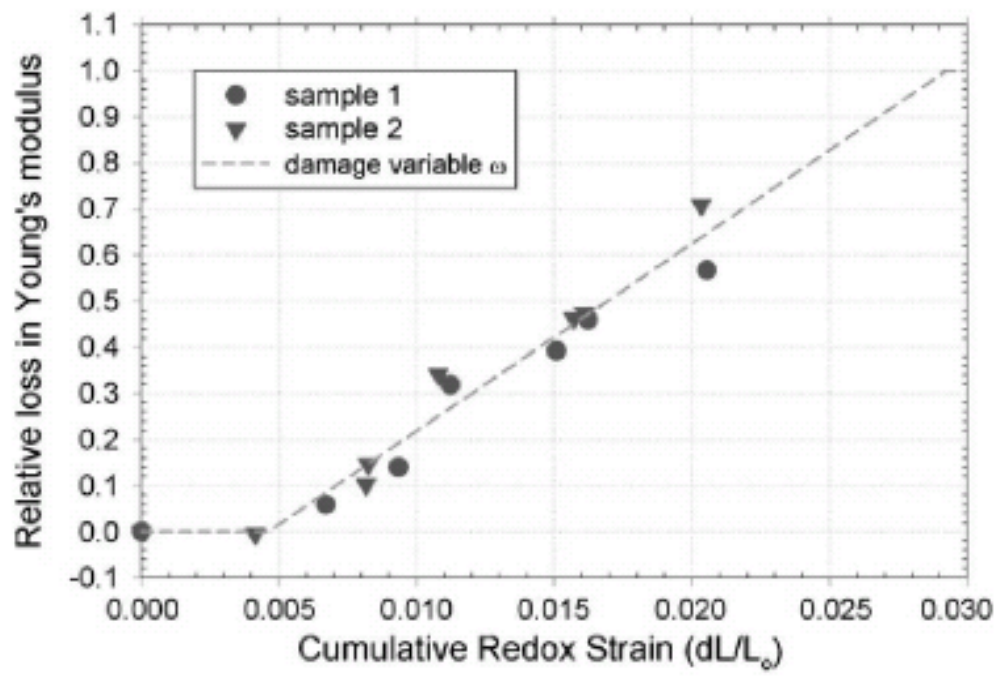

Figure 2-13 Mechanical degradation in terms of relative loss of elastic modulus of $\mathrm{NiO}$ YSZ composites due to redox cycles [39]

They used an isotropic continuum damage model for the elastic degradation of the samples as shown in the following equation:

$$
E=E_{o}(1-\omega)
$$

where $E_{o}$ is the initial stiffness, $E$ is the degraded stiffness and $\omega$ is the damage variable having values from 0 to 1 . Fitting a damage parameter $\omega(\mathrm{CRS})$ to redox cycling degradation data yields the following value of the variable [39].

$$
\omega(C R S)=\left\{\begin{array}{l}
0, \quad C R S<0.0046 \\
40.655 \cdot C R S-0.1879, \quad 0.0046 \leq C R S<0.0292 \\
1, \quad C R S \geq 0.0292
\end{array}\right.
$$




\subsubsection{Fuel Gas Contaminants Effects on Anode Microstructure}

As a high temperature fuel cell, SOFC has many advantages over other types of fuel cells such as high kinetic activity, no need of precious catalysts, fuel flexibility and possibility of internal fuel reforming [40]. Most of the fuel gas contaminants, found in coal syngas such as $\mathrm{Hg}, \mathrm{Si}, \mathrm{Zn}$ and $\mathrm{NH}_{3}$, do not significantly affect the SOFC anode performance [41-43]. SOFC is, therefore, potentially an efficient technology for direct utilization of coal-derived syngas to generate electric power. The integration of coal gasification with SOFCs will reduce the operating cost and environmental effects in comparison with conventional power generation systems.

Gasification is a process in which coal or other carbonaceous materials are mixed with a controlled amount of oxygen and steam in a reactor at high temperature and pressure. This method produces synthesis gas (syngas), primarily consisting of $\mathrm{H}_{2}, \mathrm{CO}$, $\mathrm{CO}_{2}$, and $\mathrm{H}_{2} \mathrm{O}$, and trace amounts of nearly all of the elements depending on the rank and geological source of the coal, and the type of gasification system [44]. The composition of coal-derived syngas from three major types of coal gasification systems, moving-bed, fluid-bed and entrained flow, is shown in Table 2-3. 
Table 2-3 Coal-derived Syngas compositions (mole percent) [45, 46]

\begin{tabular}{|c|c|c|c|c|c|c|}
\hline \multirow{2}{*}{$\begin{array}{c}\text { Gasifier } \\
\text { Type }\end{array}$} & \multirow{2}{*}{$\begin{array}{c}\begin{array}{c}\text { Moving- } \\
\text { Bed }\end{array} \\
\text { Lurgi }\end{array}$} & $\begin{array}{c}\text { Fluidized- } \\
\text { Bed }\end{array}$ & \multicolumn{4}{|c|}{$\begin{array}{c}\text { Entrained- } \\
\text { Bed }\end{array}$} \\
\hline & & Winkler & Destec & $\begin{array}{c}\text { Koppers- } \\
\text { Totzek }\end{array}$ & Texaco & Shell \\
\hline \multirow{2}{*}{ Coal } & Illinois & Texas & Appalachian & Illinois & Illinois & Illinois \\
\hline & No. 6 & Lignite & Bit. & No. 6 & No. 6 & No. 6 \\
\hline $\mathrm{Ar}$ & trace & 0.7 & 0.8 & 0.9 & 0.9 & 1.1 \\
\hline $\mathrm{CH}_{4}$ & 3.3 & 4.6 & 0.6 & - & 0.1 & - \\
\hline $\mathrm{C}_{2} \mathrm{H}_{4}$ & 0.1 & - & - & - & - & - \\
\hline $\mathrm{C}_{2} \mathrm{H}_{6}$ & 0.2 & - & - & - & - & - \\
\hline $\mathrm{CO}$ & 5.8 & 33.1 & 45.2 & 43.8 & 39.6 & 63.1 \\
\hline $\mathrm{CO}_{2}$ & 11.8 & 15.5 & 8.0 & 4.6 & 10.8 & 1.5 \\
\hline $\cos$ & trace & - & - & 0.1 & - & 0.1 \\
\hline $\mathrm{H}_{2}$ & 16.1 & 28.3 & 33.9 & 21.1 & 30.3 & 26.7 \\
\hline $\mathrm{H}_{2} \mathrm{O}$ & 61.8 & 16.8 & 9.8 & 27.5 & 16.5 & 2.0 \\
\hline $\mathrm{H}_{2} \mathrm{~S}$ & 0.5 & 0.2 & 0.9 & 1.1 & 1.0 & 1.3 \\
\hline $\mathrm{N}_{2}$ & 0.1 & 0.6 & 0.6 & 0.9 & 0.7 & 4.1 \\
\hline $\mathrm{NH}_{3}+\mathrm{HCN}$ & 0.3 & 0.1 & 0.2 & - & - & - \\
\hline
\end{tabular}

The levels of contaminants found in the coal-derived syngas depend on the type of coal, coal gasifier, and gas stream cleanup process. The concentrations of many trace contaminants in coal-based gas stream are not known accurately. Krishnan et al., [41] gives a detail of the typical level of contaminants found in coal-based syngas. Trace impurities and their concentrations in coal-derived syngas produced by a gasification facility at the Eastman Chemical Company at Kingsport, Tennessee and an estimate from 
University of North Dakota Energy and Environmental Research Center are shown in Table 2-4.

Table 2-4 Trace impurities and their concentration (ppmv) in coal syngas [41]

\section{Contaminant Species}

As $\left(\mathrm{AsH}_{3}\right)$

Thiophene

Chlorine

$\mathrm{CH}_{3} \mathrm{~F}$

$\mathrm{CH}_{3} \mathrm{Cl}$

$\mathrm{HCl}$

$\mathrm{Fe}(\mathrm{CO})_{5}$

$\mathrm{N} 3(\mathrm{CO})_{5}$

$\mathrm{CH}_{3} \mathrm{SCN}$

$\mathrm{PH}_{3}$

Antimony

Cadmium

Chromium

Mercury

Potassium

Sodium

Selenium

Vanadium

Lead

Zinc
Kingsport facility

0.15 to 0.58

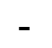

-

2.6

2.01

$<1$

0.05 to 5.6

0.001 to 0.025

2.1

1.9

0.025

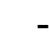

$<0.025$

$<0.025$

$-$

-

$<0.15$

$<0.025$

-

9.0
0.07

\section{UND-EERC Estimate}

0.2

1.6

120

0.01

6.0

0.002

512

320

0.17

0.26 
The Solid State Energy Conversion Alliance (SECA) program of the U.S. Department of Energy (DoE) is committed to develop solid oxide fuel cell systems that could generate power at a cost of $\$ 400 / \mathrm{kW}$. Utilizing coal-based syngas in SOFC will reduce the operating cost in comparison with other fuels. Although studies $[47,48]$ have shown the feasibility of utilizing coal syngas as a fuel for a SOFC system, the electrochemical performance and materials durability of SOFC are affected when exposed to certain contaminants in the syngas $[41,42,49]$. Coal syngas cleanup techniques such as absorption, diffusion through a membrane, chemical conversion and filter have been used to bring down the contaminants concentration to very low level. However these processes are carried out at ambient temperature and hence a significant portion of syngas thermal energy is lost.

At present, nickel-yttria stabilized zirconia (Ni-YSZ) is the most widely used anode material for YSZ electrolyte based SOFCs $[39,51,52]$. It is a cermet in which nickel metal particles and YSZ particles are mixed and sintered to form a porous anode. Ni particles act as a catalyst for fuel (hydrogen, $\mathrm{CO}$, etc) oxidation and electron conductor. YSZ provides structural support and ionic conductivity to permit the oxide ions to diffuse farther into the anode. When exposed to syngas contaminants, Ni-YSZ performance may degrade due to the following phenomena:

- adsorption of the contaminants on the anode surface block the gas diffusion channels

- impurity atoms on the surface deactivate the triple phase boundaries

- secondary phase formation due to some contaminants reduce the YSZ ability to transport the oxide ions and electrical conductivity of $\mathrm{Ni}$

- structural integrity of the anode and seal material deteriorate due to grain growth and microcrack formation 
In the following sections, a brief literature review on the effect of coal syngas contaminants on the SOFC anode electrochemical performance and structural integrity is presented.

\subsubsection{Sulfur}

The Ni-based anode is readily poisoned by the trace amount of sulfur contaminants in the fuel such as hydrogen sulfide $\left(\mathrm{H}_{2} \mathrm{~S}\right)$ [53-56]. The sulfur poisoning mechanisms for the Ni-based anode, however, are still not fully understood [56].The level of sulfur poisoning strongly depends on the operating temperature, contaminant concentration, and applied current density [54].

Experimental studies show that sulfur adsorbs more easily on the anode surface at lower temperature as shown in Figure 2-14. Matsuzaki et al. [54] found that for a Nibased anode, the electrode activity starts degrading significantly from $0.5 \mathrm{ppm}$ of $\mathrm{H}_{2} \mathrm{~S}$ at $900{ }^{\circ} \mathrm{C}$ to $0.05 \mathrm{ppm}$ at $750{ }^{\circ} \mathrm{C}$. Based on these observations, Cheng et al. [56] suggested that the sulfur poisoning is caused by the adsorption of sulfur on the electrode surface.

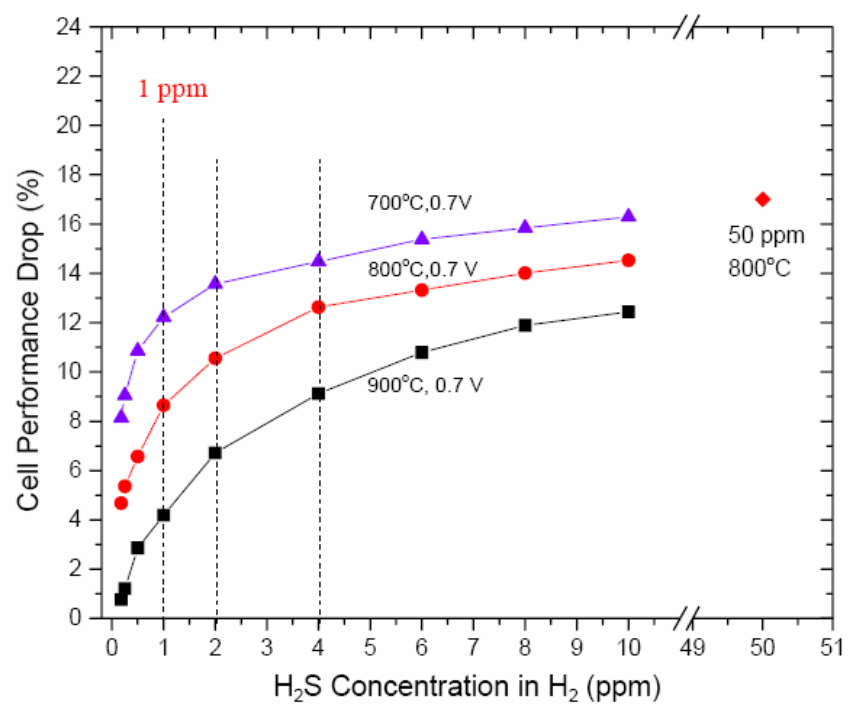

Figure 2-14 Sulfur poisoning effects at different temperature [57] 
Experimental studies showed that the poisoning effects of sulfur on Ni-YSZ anode occur in two stages: rapid cell performance degradation in the first few hours followed by slower, gradual degradation that may last up to several hundred hours as shown in Figure $2-15$.

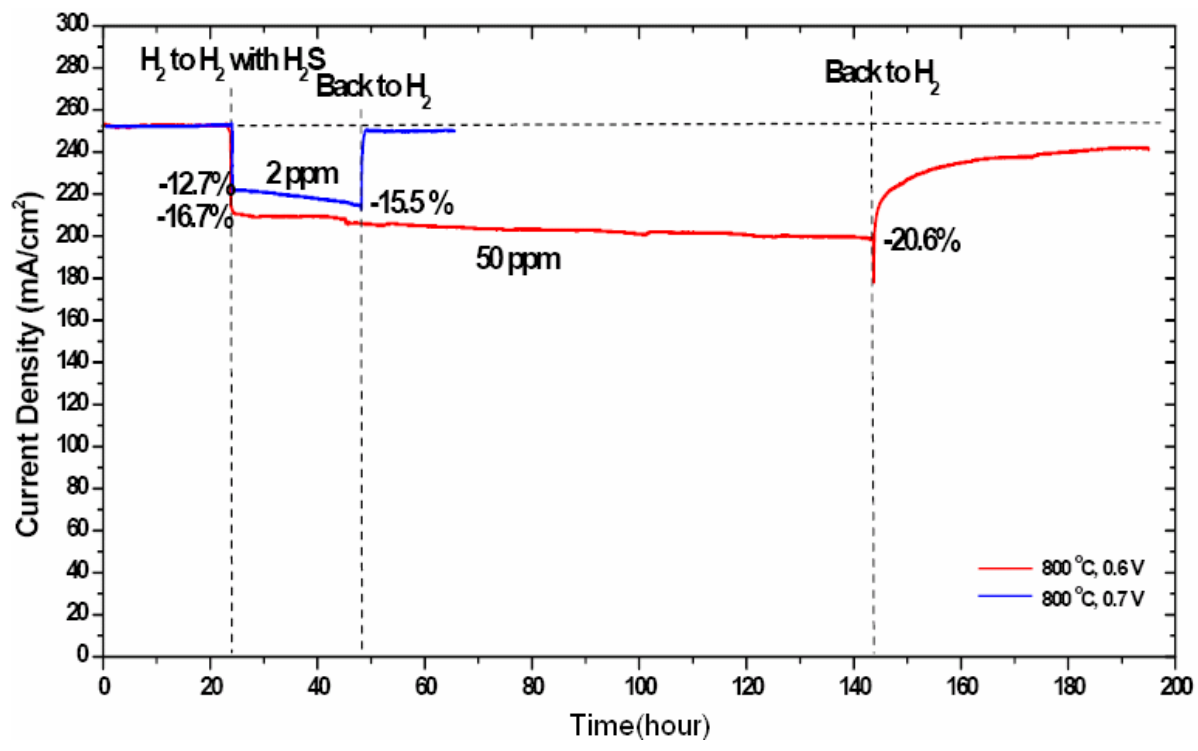

Figure 2-15 Sulfur poisoning and recovery processes [57]

Upon introducing $\mathrm{H}_{2} \mathrm{~S}$ into the fuel stream, fast adsorption of sulfur occurs in minutes which block the triple phase reaction sites and lead to the rapid electrochemical degradation. The degradation due the initial fast adsorption is recoverable. In the second stage, the performance degrades slowly over the time, possibly due to the formation of multilayer nickel sulfides on $\mathrm{Ni}$ surface, diffusion of sulfur into $\mathrm{Ni}$ grains and/or interaction of sulfur with the electrolyte [57].

Sasaki et al. [58] investigated the Ni-S-O phase diagram at $800{ }^{\circ} \mathrm{C}$ and concluded that the formation of bulk nickel sulfide may not be feasible by several ppm of $\mathrm{H}_{2} \mathrm{~S}$ because bulk sulfide (e.g. $\mathrm{Ni}_{3} \mathrm{~S}_{2}$ ) is unstable at that temperature until the $\mathrm{H}_{2} \mathrm{~S}$ is above 200 ppm. 


\subsubsection{Chlorine (Cl)}

Chlorine is typically present in coal syngas in the forms of hydrogen chloride ( $\mathrm{HCl})$ and methyl chloride $\left(\mathrm{CH}_{3} \mathrm{Cl}\right)$. Krishnan et al. [41] investigated the effects of $\mathrm{HCl}$ and $\mathrm{CH}_{3} \mathrm{Cl}$ vapors on SOFC performance. They observed no significant performance degradation during $100 \mathrm{~h}$ testing with $40 \mathrm{ppm}$ of $\mathrm{HCl}$ vapor at both $750{ }^{\circ} \mathrm{C}$ and $800{ }^{\circ} \mathrm{C}$. Similar results were observed with $40 \mathrm{ppm}$ of $\mathrm{CH}_{3} \mathrm{Cl}$ at $800{ }^{\circ} \mathrm{C}$. However, as the temperature increased to $850{ }^{\circ} \mathrm{C}$, the cell performance was decreased significantly.

Trembly et al. [59] also studied the effects of $\mathrm{HCl}$ at $800{ }^{\circ} \mathrm{C}$ and $900{ }^{\circ} \mathrm{C}$ with 0,20 , and $160 \mathrm{ppm}$. The test results show that $\mathrm{HCl}$ causes significant degradation to SOFC performance at higher concentration (e.g. $160 \mathrm{ppm}$ ). The cell performance loss was attributed mostly to the increase in charge transfer resistance at $800{ }^{\circ} \mathrm{C}$ and to the increase in the ohmic and charge transfer resistance at $900{ }^{\circ} \mathrm{C}$. However $\mathrm{HCl}$ concentration after hot/warm gas cleanup is expected to be much lower $(>1 \mathrm{ppm})$ that will not cause any significant performance losses in SOFCs.

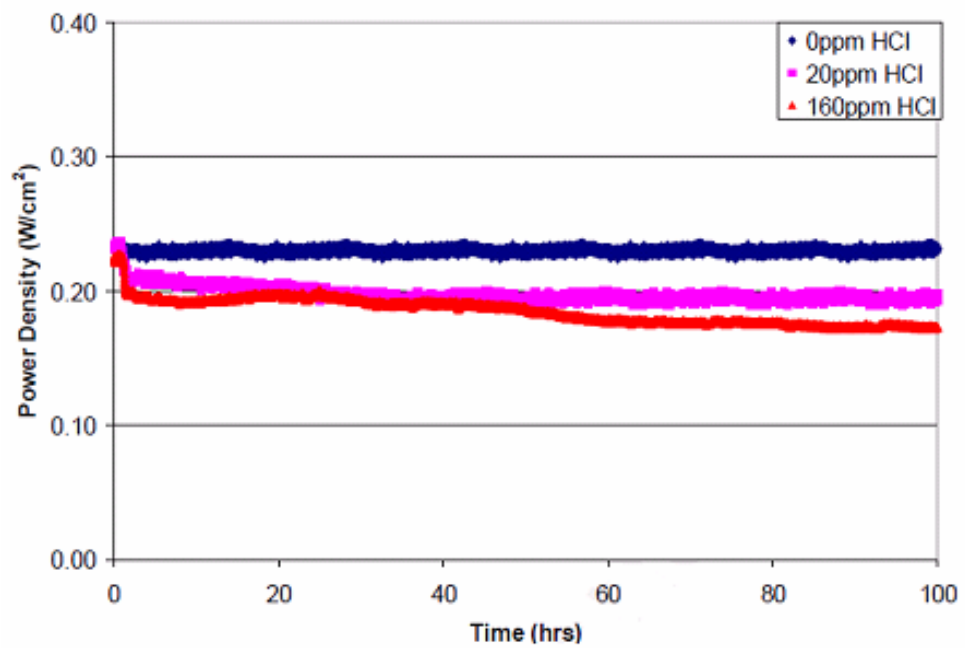

Figure 2-16 SOFC power density operating at $800^{\circ} \mathrm{C}$ and $0.7 \mathrm{~V}$ over time with $\mathrm{HCl}$ concentrations of 0 ppm, 20 ppm, and 160 ppm [59]. 
Post-trial analyses performed using XRD, SEM, and EDS show no sign of secondary chloride phases and no effects on the anode materials. The poisoning effect of $\mathrm{HCl}$ on the SOFC anode was shown to be reversible with $\mathrm{HCl}$ concentration as high as $160 \mathrm{ppm}$ : upon the removal of $\mathrm{HCl}$ from the syngas, the cell performance was recovered back to the original state of the cell before injecting $\mathrm{HCl}$.

\subsubsection{Zinc (Zn)}

At elevated temperature, Zinc $(\mathrm{Zn})$ is highly soluble in Ni metal. Hence the cell degradation due to $\mathrm{Zn}$ strongly depends on the cell operating temperature. Thermodynamics calculation predicts that $\mathrm{Zn}$ is expected to form a condensed metal oxide at warm gas conditions [41]. Hence the zinc concentration should not be higher in the gas stream that reaches the anode to avoid electrochemical degradation [42].
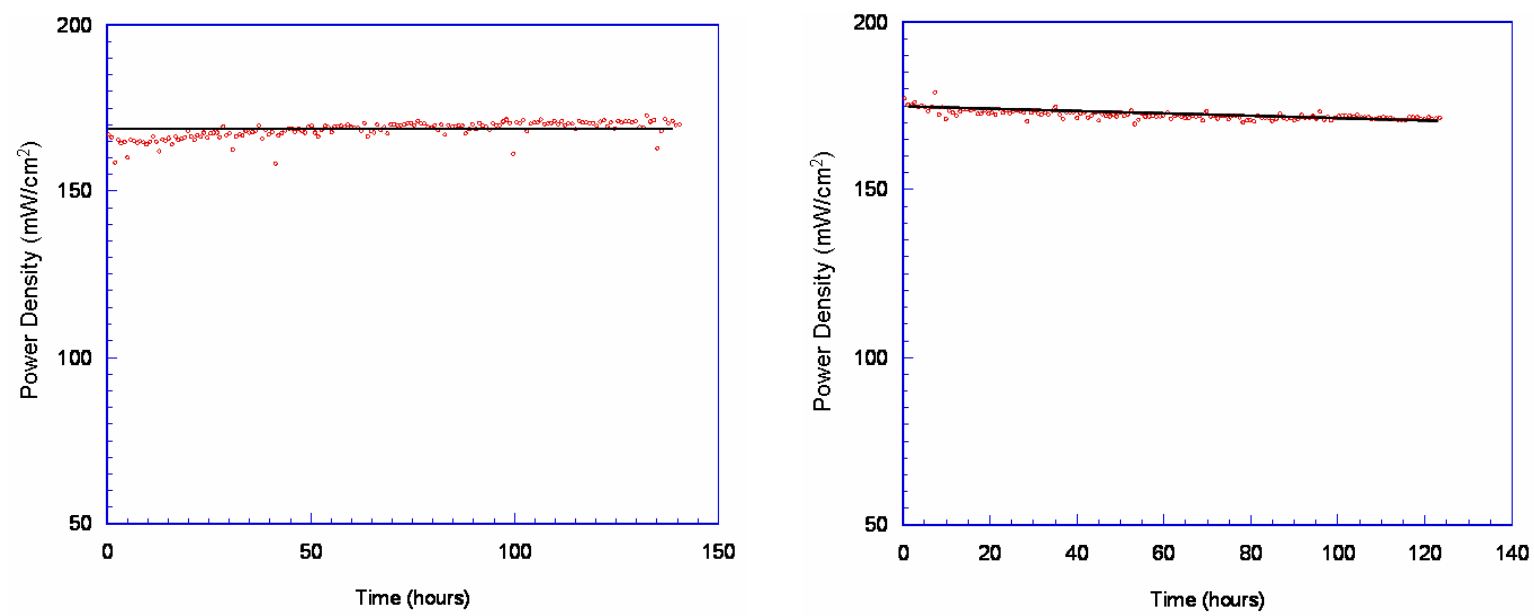

Figure 2-17 Performance of SOFC with $\left.10 \mathrm{ppm} \mathrm{Zn} \mathrm{Vapor} \mathrm{(} \mathrm{0.7} \mathrm{V} \mathrm{and} 0.2 \mathrm{~A} / \mathrm{cm}^{2}\right)$

(a) $750{ }^{\circ} \mathrm{C}$ (b) $800{ }^{\circ} \mathrm{C}[41]$

Figure 2-17 shows the power density changes with time when the cell was exposed to $10 \mathrm{ppm}$ of $\mathrm{Zn}$ vapors at $750^{\circ} \mathrm{C}$ and $800{ }^{\circ} \mathrm{C}$. At lower temperature, no significant degradation 
was observed in the power density during $140 \mathrm{~h}$ test. However at $800^{\circ} \mathrm{C}$, slow decline (ca. $0.02 \%$ per h) in power density was observed.

\subsubsection{Mercury (Hg)}

Mercury $(\mathrm{Hg})$ is present in the vapor phase in the coal syngas due to its high vapor pressure. The operating temperature and pressure of the gas cleanup system is not anticipated to influence the equilibrium form of mercury [43]. It is expected that $\mathrm{Hg}$ present in the syngas will escape through the gas cleanup system to influence the SOFC anode. However, the experimental study [41] shows that when a button cell was exposed to $7 \mathrm{ppm}$ of $\mathrm{Hg}$ vapor, the cell performance showed no significant degradation at $750{ }^{\circ} \mathrm{C}$ and $800{ }^{\circ} \mathrm{C}$ for $150 \mathrm{~h}$ tests as shown in Figure 2-18.
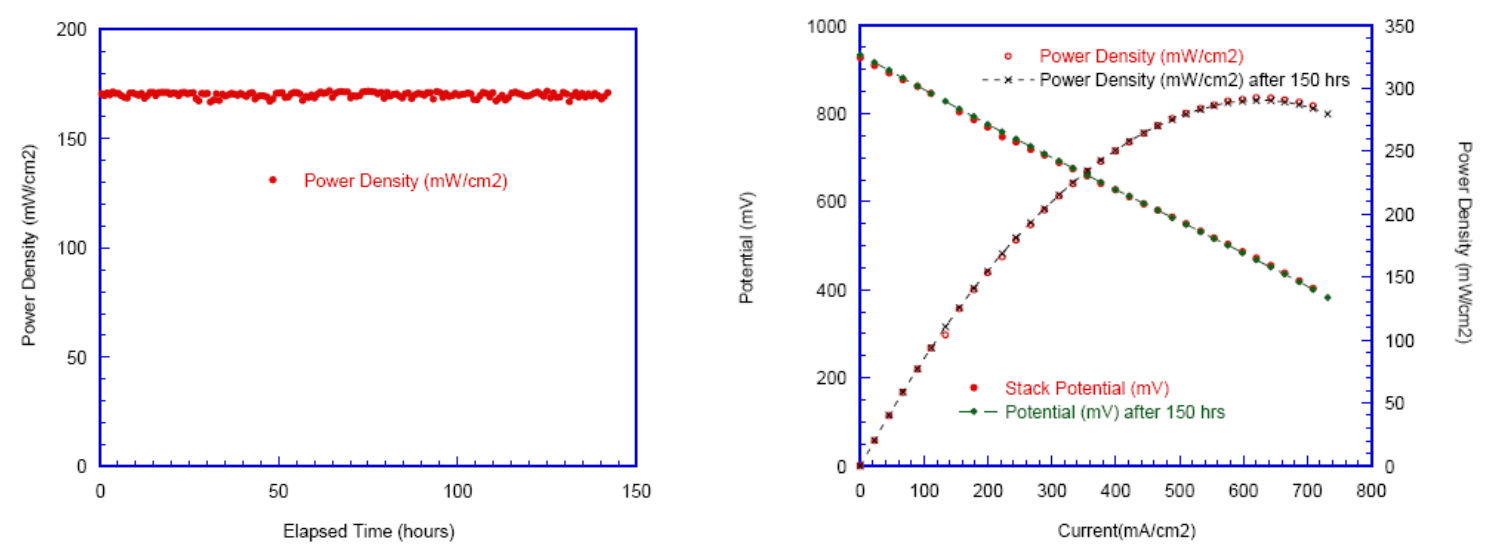

Figure 2-18 (a) Power density variation with time under $7 \mathrm{ppm} \mathrm{Hg}$ vapor at $750^{\circ} \mathrm{C}$ (b) I$V$ curve of the cell after $150 \mathrm{~h}$

The test results at $800{ }^{\circ} \mathrm{C}$ showed a small decline in performance at high current levels. It was thought that $\mathrm{HgO}$ could possibly be condensed and deposited on the anode 
surface and may hinder the fuel gas diffusion to the reaction sites [42]. Further research is required to quantify the extent of degradation.

\subsubsection{Phosphorus (P)}

Phosphorus (P) is one of the few contaminants that interact strongly with nickel contained in the SOFC anode and degrade its electrochemical performance and structural properties during long term operation $[42,49,50,60]$. Equilibrium calculations indicated that the temperature and pressure of the gas clean-up system have little influence on the

phase equilibrium behavior of phosphorous [43]. Although the nature of the phosphorous compounds in the coal-derived syngas is not known accurately, the equilibrium calculations indicated that phosphorous may present in the form of $\left(\mathrm{P}_{2} \mathrm{O}_{3}\right)_{2}$ (g) as a dominant vapor phase and trace amount of $\mathrm{PH}_{3}(\mathrm{~g})$, depending on the temperature and pressure.

Thermodynamics calculations showed that $\mathrm{PH}_{3}$ (g) has the potential to react with the nickel in the SOFC anode: the Gibb's free energy of the reaction, Eq. (2. 16), was negative.

$$
2 \mathrm{PH}_{3}(g)+5 \mathrm{Ni}(s) \rightarrow \mathrm{Ni}_{5} \mathrm{P}_{2}(s)+3 \mathrm{H}_{2}(\mathrm{~g})
$$

Eq. (2.16) shows the phosphorous interaction that may take place with the anode Ni under SOFC operating conditions [43]. Krishnan et al. [41] suggested that phosphorous may exist as $\mathrm{PH}_{3}(\mathrm{~g})$ in the coal-derived syngas when the gas is cooled down to low temperature at high pressures. However, under SOFC operating conditions, $\mathrm{PH}_{3}(\mathrm{~g})$ is hydrolyzed to form primarily $\mathrm{HPO}_{2}$ vapor.

Marina et al. [50] investigated the interaction of phosphorus in syngas with the nickel-based anode. The tests were performed at $700{ }^{\circ} \mathrm{C}$ and $800{ }^{\circ} \mathrm{C}$ from 0.5 to $10 \mathrm{ppm}$ 
phosphine $\left(\mathrm{PH}_{3}\right)$ in both anode- and electrolyte-supported configurations. They related the cell performance degradation to the two primary modes. The most noticeable was the formation of a series of bulk nickel phosphide phases $\left(\mathrm{Ni}_{3} \mathrm{P}, \mathrm{Ni}_{5} \mathrm{P}_{2}, \mathrm{Ni}_{12} \mathrm{P}_{5}\right.$ and $\left.\mathrm{Ni}_{2} \mathrm{P}\right)$ where $\mathrm{P}$ was completely captured by the anode and formed a clear boundary between secondary phase and unconverted anode portion [50]. The second mode of degradation was attributed to the surface diffusion of $\mathrm{P}$ to the active anode/electrolyte interface. Moreover, the secondary phase formation induces grain growth and causes micro-crack within the anode support. Marina et al. [50,60] suggested that the cell electrochemical degradation may be very low if an electrical pathway to the anode-electrode active interface is maintained.

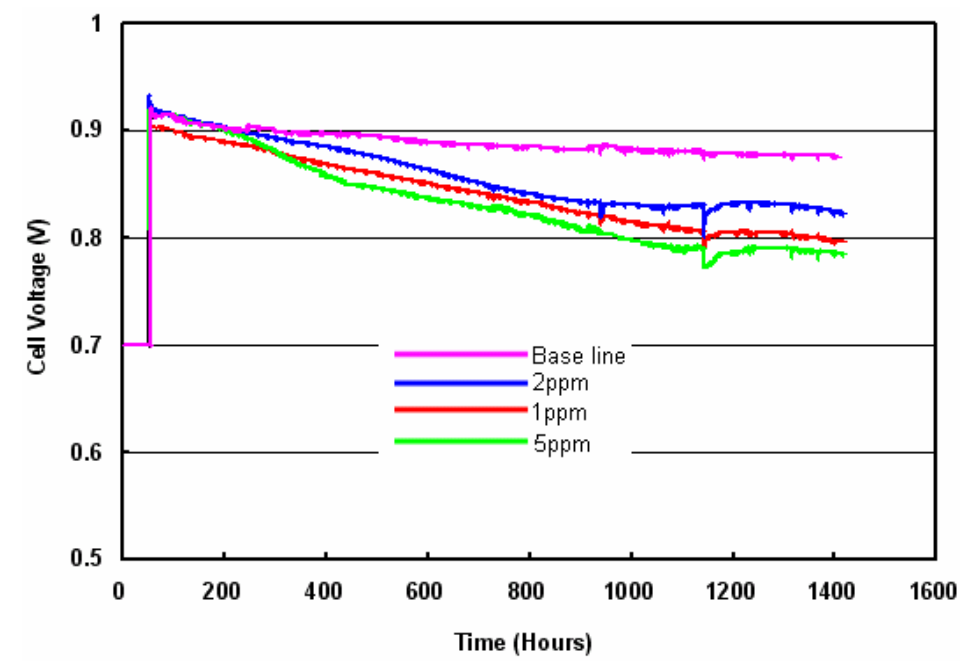

Figure 2-19 Electrochemical degradation of anode-supported cell in coal gas with phosphorus [60]

$\mathrm{PH}_{3}(2 \mathrm{ppm})$ at $800{ }^{\circ} \mathrm{C}$ for $380 \mathrm{~h}$ coarsened $\mathrm{Ni}$ and converted it into $\mathrm{Ni}_{3} \mathrm{P}$ within the top $60 \mu \mathrm{m}$ as shown in Figure 2-20. The extension of material degradation is presently unknown. 


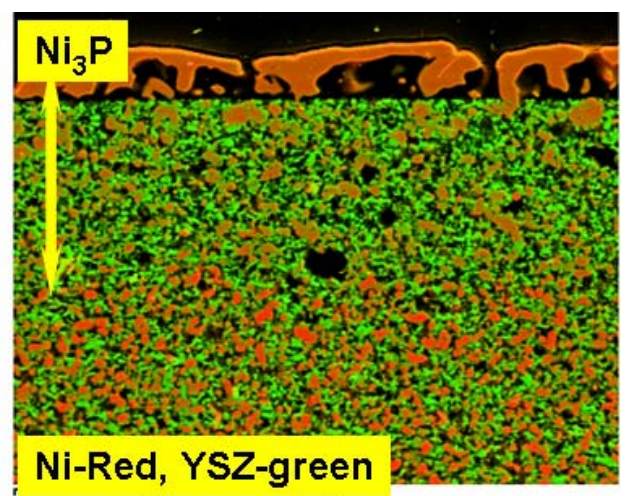

Figure 2-20 Anode exposed to 2 ppm of $\mathrm{PH}_{3}$ at $800^{\circ} \mathrm{C}$ [49]

In a recent study, Olga Marina et al. [60] found that the penetration depth of the secondary phase is proportional to the concentration of the $\mathrm{PH}_{3}$ in the fuel gas as shown in Figure 2-21.

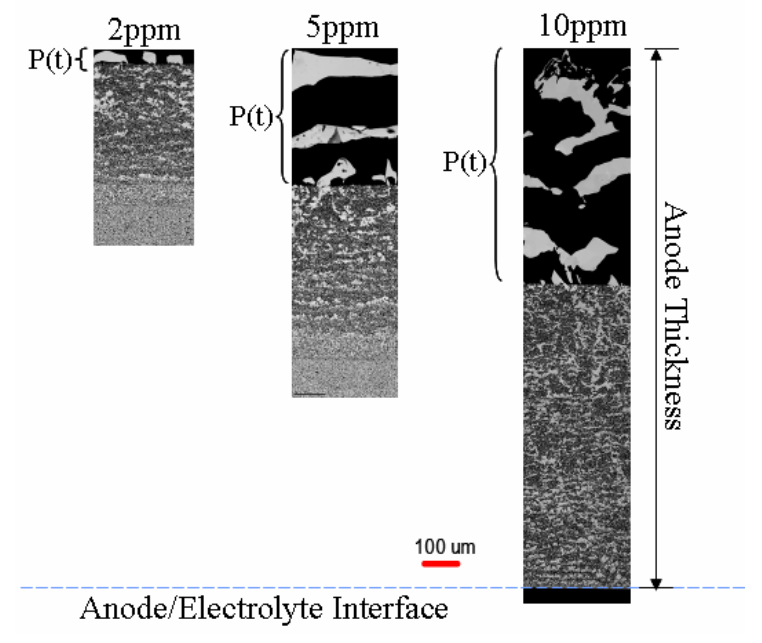

Figure 2-21 Penetration depths after $990 \mathrm{~h}$ with $\mathrm{PH}_{3}$ in coal syngas [60]

Olga Marina et al. [60] observed that due to the $\mathrm{PH}_{3}$ contaminants, the nickel particles in the anode material agglomerate and cause microcrack formation at the anode surface as shown in Figure 2-22. 


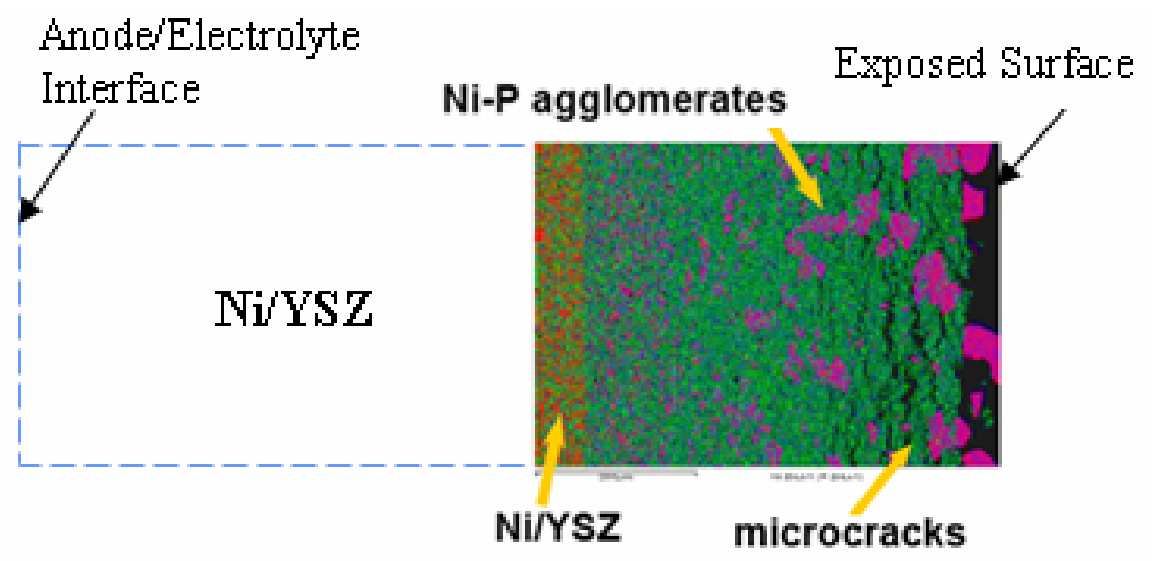

Figure 2-22 Ni agglomeration and microcrack formation after $1000 \mathrm{~h}$ test with $5 \mathrm{ppm}$ of $\mathrm{PH}_{3}$, after O. A. Marina et al. [60]

Furthermore the addition of phosphorus $(\mathrm{P})$ depresses the melting point of Ni such that agglomeration of $\mathrm{Ni}$ may occur [41], and causes reduction of electrochemical sites, which degrades the electrical conductivity. This phenomenon also leads to the redistribution of temperature and stress fields. Such changes in anode microstructure suggest the possibility of degradation of its mechanical properties during long-term operation.

\subsubsection{Arsenic (As)}

Thermodynamics calculation shows that both cleanup system temperature and pressure have an effect on the partition of arsenic between gas and condensed phase as well as equilibrium composition formed [43].

Arsenic is found in coal with concentration ranging 0.5 to $2090 \mathrm{ppm}$ by weight [61]. In the reducing environment, almost all arsenic is converted to $\mathrm{AsH}_{3}$ [62]. However, several species of As vapor, e.g. $\mathrm{As}_{4}(\mathrm{~g}), \mathrm{AsH}_{3}(\mathrm{~g}), \mathrm{AsSe}_{(\mathrm{g})}$, and $\mathrm{As}_{3} \mathrm{Sb}_{(\mathrm{g})}$, are shown to form in coal syngas after passing through a warm gas cleanup system. $\mathrm{AsH}_{3}(\mathrm{~g})$ has shown the potential to interact with $\mathrm{Ni}$ contained in the SOFC anode material [62]. Eq. (2. 17) 
represents the possible interaction of As that may take place with Ni under SOFC operating conditions.

$$
\mathrm{AsH}_{3}(\mathrm{~g})+\mathrm{Ni}(s) \rightarrow \mathrm{NiAs}(s)+1.5 \mathrm{H}_{2}(g)
$$

Thermodynamic calculations [63] have shown that $\mathrm{AsH}_{3}(0.15-0.60$ ppm) may interact with Ni contained in the SOFC anode and formed secondary phase nickelarsenide as shown in Eq. (2. 17). Trembly et al. [62] observed that 1ppm of $\mathrm{AsH}_{3}$ (g) at $750{ }^{\circ} \mathrm{C}$ and $800{ }^{\circ} \mathrm{C}$, did not cause any significant degradation in the cell performance during short term tests as shown in Figure 2-23. However, long term tests indicated that even $0.1 \mathrm{ppm}$ of $\mathrm{AsH}_{3}$ may interact with anode material and decrease its performance.
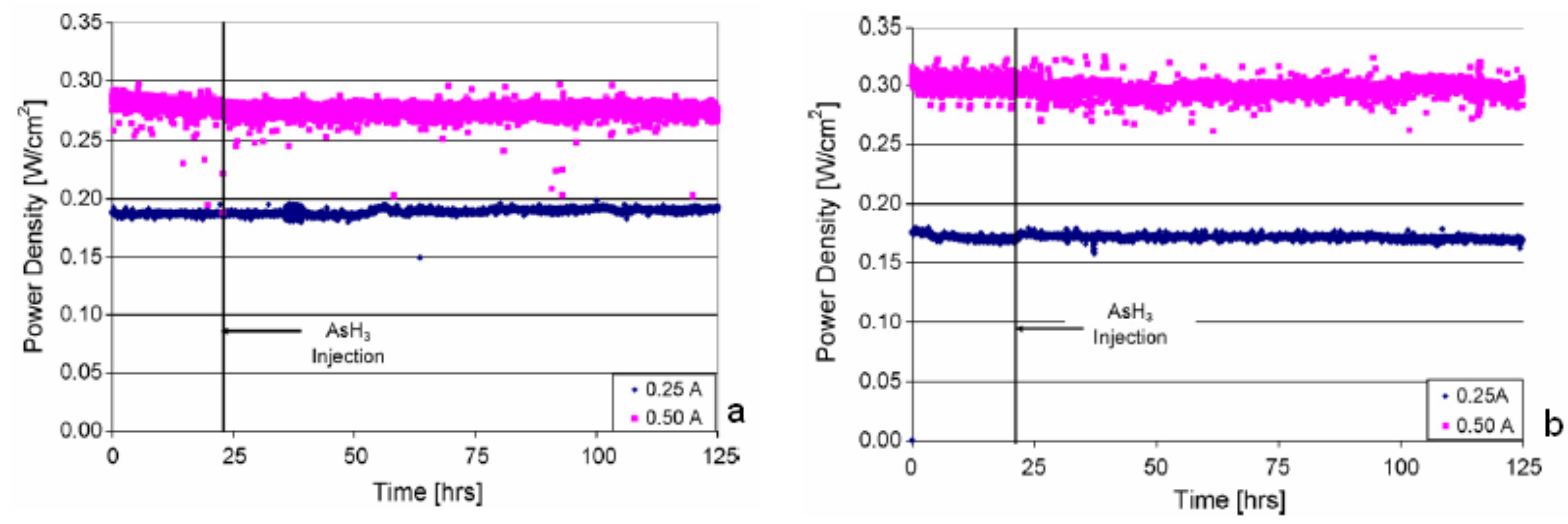

Figure 2-23 SOFC power density operating at (a) $750^{\circ} \mathrm{C}$, (b) $800^{\circ} \mathrm{C}, 0.25$, and 0.50

$$
\text { A.cm-2 over time with } \sim 1.0 \mathrm{ppm} \mathrm{AsH}_{3} \text { [62] }
$$

Krishnan et al, [41] showed that when a button cell was exposed to $10 \mathrm{ppm}$ of arsenic vapor at $750^{\circ} \mathrm{C}$, the cell exhibited erratic power density level with time (Figure 2-24), and the current collector became loose and was found broken after 100 hours exposure test as shown in Figure 2-25. Such failure mechanism is not observed in cells that are not exposed to As contaminant. 
As shown in Figure 2-24a, a significant degradation occurred within initial $10 \mathrm{~h}$ of injecting As followed by a slow but steady performance loss. It was also found that the area specific resistance (ASR) increased from 1.40 to $1.75 \Omega . \mathrm{cm}^{2}$ after $60 \mathrm{~h}$ of operation. The current collector became loose and was found broken after $100 \mathrm{~h}$ exposure test as shown in Figure 2-25.
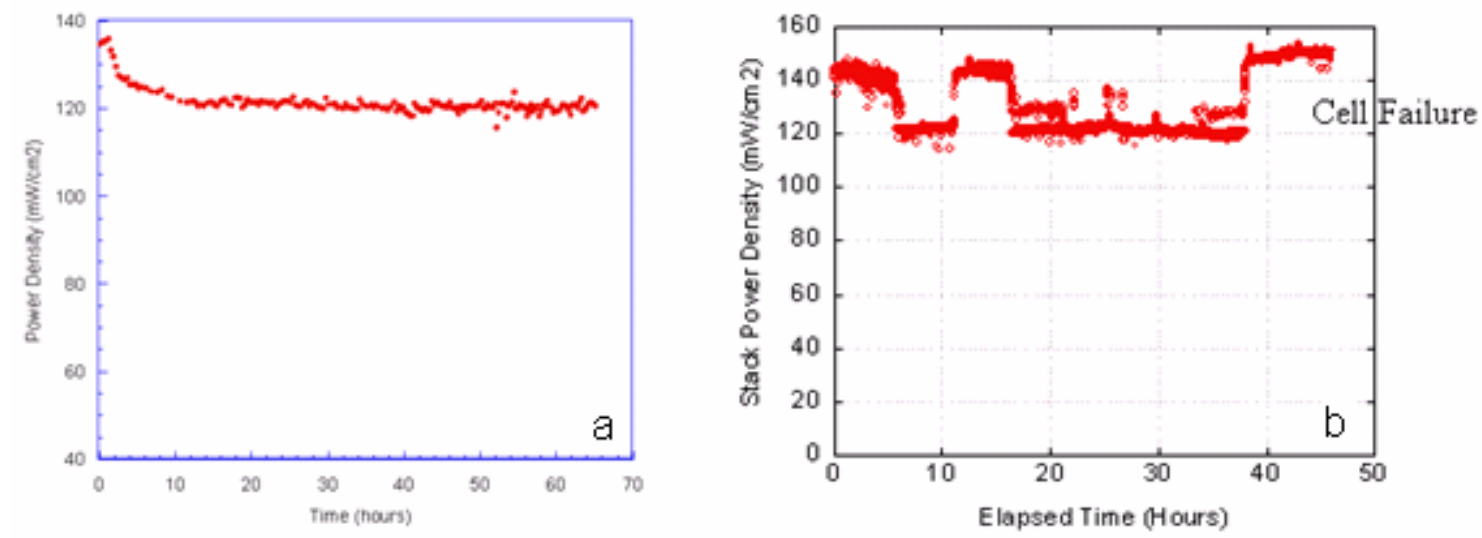

Figure 2-24 Performance of SOFC with $10 \mathrm{ppm} A \mathrm{~s}(\mathrm{~g})$ vapor at $750^{\circ} \mathrm{C}$ after $60 \mathrm{~h}$ [41]

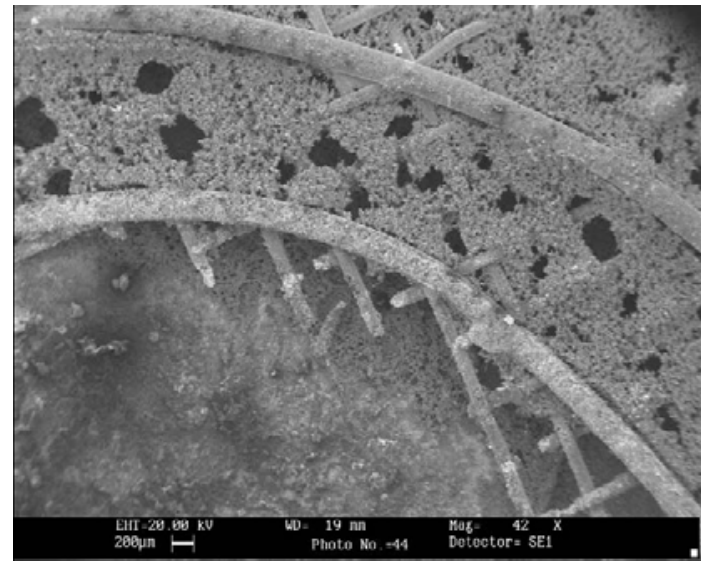

Figure 2-25 Delamination of Ni mesh from anode at 10 ppm As contaminant [41]

Krishnan et al. [41] also performed the cell post mortem analysis by scanning electron microscope to understand the failure mechanisms. They found that As 
preferentially reacted with Ni contained in the anode. The formation of secondary phase (nickel arsenide) embrittled nickel metal screen and the porous nickel layer. Moreover, incorporation of arsenic in the Ni particles produced an increase of the particle size [64]. These changes may delaminate the current collector (nickel wire mesh) from the anode surface leading to inconsistent cell power densities.

\subsubsection{Selenium (Se)}

Selenium (Se) affects the SOFC electrochemical performance similar to sulfur $[65,66]$, but the degradation is less reversible as shown in Figure 2-26.

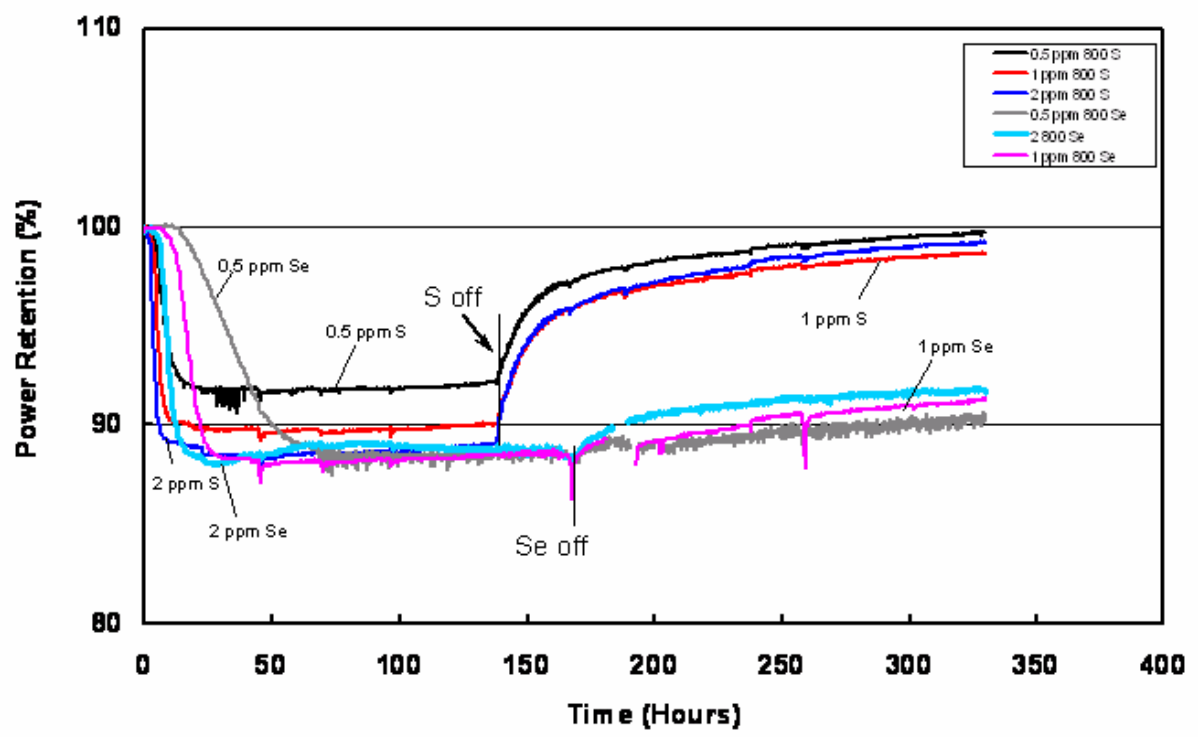

Figure 2-26 Effect of $\mathrm{H}_{2} \mathrm{~S}$ and $\mathrm{H}_{2} \mathrm{Se}$ on anode-supported SOFC at $800^{\circ} \mathrm{C}$ [65]

The temperature and pressure of a gas cleanup system affect the partition of Se [62]. At the lower temperature $\left(200{ }^{\circ} \mathrm{C}-300{ }^{\circ} \mathrm{C}\right)$, Se was found in the form of condensed phases of $\mathrm{CdSe}(\mathrm{s})$ and $\mathrm{PbSe}(\mathrm{s})$. At the higher temperature $\left(400{ }^{\circ} \mathrm{C}-500{ }^{\circ} \mathrm{C}\right)$, Se was found to be partitioned between gas vapor and condensed phases. 
The reversible portion of the electrochemical indicates the surface adsorption of Se into anode surface similar to sulfur. While the unrecoverable portion of the degradation implies either the formation of a secondary phase or partial mechanical degradation of the current collector [62], although recent experimental studies [65] found no secondary phase formation due to Se contaminant in the fuel. 


\section{Chapter 3 DEGRADATION MECHANICS}

\subsection{Structural Degradation}

Structural degradation is a progressive physical process which deteriorates a material load carrying capability. Material degradation may occur due to several mechanisms depending on the environment and loading conditions. From a general standpoint, degradation of a material microstructure is due to non-reversible phenomena such as formation of microcracks, microvoids, and debonding between the constitutive phases particles in a multiphase material. Experimental studies have shown that the accumulation of microdefects leads to the formation of macroscopic localized defect, which is a precursor of failure.

Fracture mechanics is concerned with the analysis of existing macroscopic cracks. Under some conditions, especially for the brittle materials, it might be too late to prevent a failure once a macroscopic crack is formed. Therefore, the question arises regarding the precursory state that is the evolution of internal degradation before macroscopic cracks become visible. Continuum mechanics is considered as a general scheme to specify the progressive degradation of materials and structure. It relates the effects microstructure defects such as microvoids, microcracks, and other discontinuities to the quantities that can be observed and measured at the macroscopic scale such as material stiffness, electrical resistance, and density. Material degradation of SOFCs ceramics components often remains undetectable until the material fails catastrophically. CDM facilitates to predict the state of material degradation and to estimate the remaining strength and useful life of the material. Our model will establish the combined effect of thermo-mechanical 
and syngas contaminants effects on the anode structural properties and strength, we call it continuum durability model.

\subsection{Degradation Variable}

Material Degradation can be represented in various ways. Generally a geometrical description of material degradation is specified at the macroscopic level. Consider a representative volume element in a degraded body. Consider an elemental cross plane, cutting through an element and identified by its normal $\vec{n}$, as shown in the Figure 3-1.

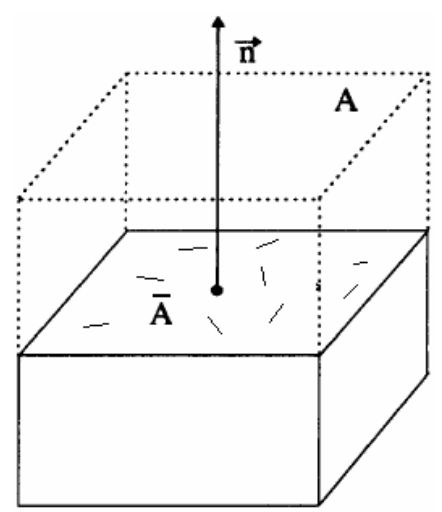

Figure 3-1 Net resisting area and effective section of a degraded material [67]

The degradation is quantified by the surface density of the microdefects and their mutual interaction. Thus a degradation variable is mathematically defined as the following:

$$
\begin{aligned}
& D=1-\frac{\bar{A}}{A} \\
& 0 \leq D \leq 1
\end{aligned}
$$


where $\mathrm{A}$ is the original area in the undamaged (or reference) state and $\overline{\mathrm{A}}$ is the net resisting (effective) area as shown in Figure 3-1. For a virgin material, the effective area is the same as the original area and therefore the damage is specified to be zero. As the material degrades under the load and environmental effects, the effective area decreases due to the formation of microvoid and microcracks. Eventually the micro defects coalescence to form macrocracks which lead to the material failure as shown in Figure $3-2$.

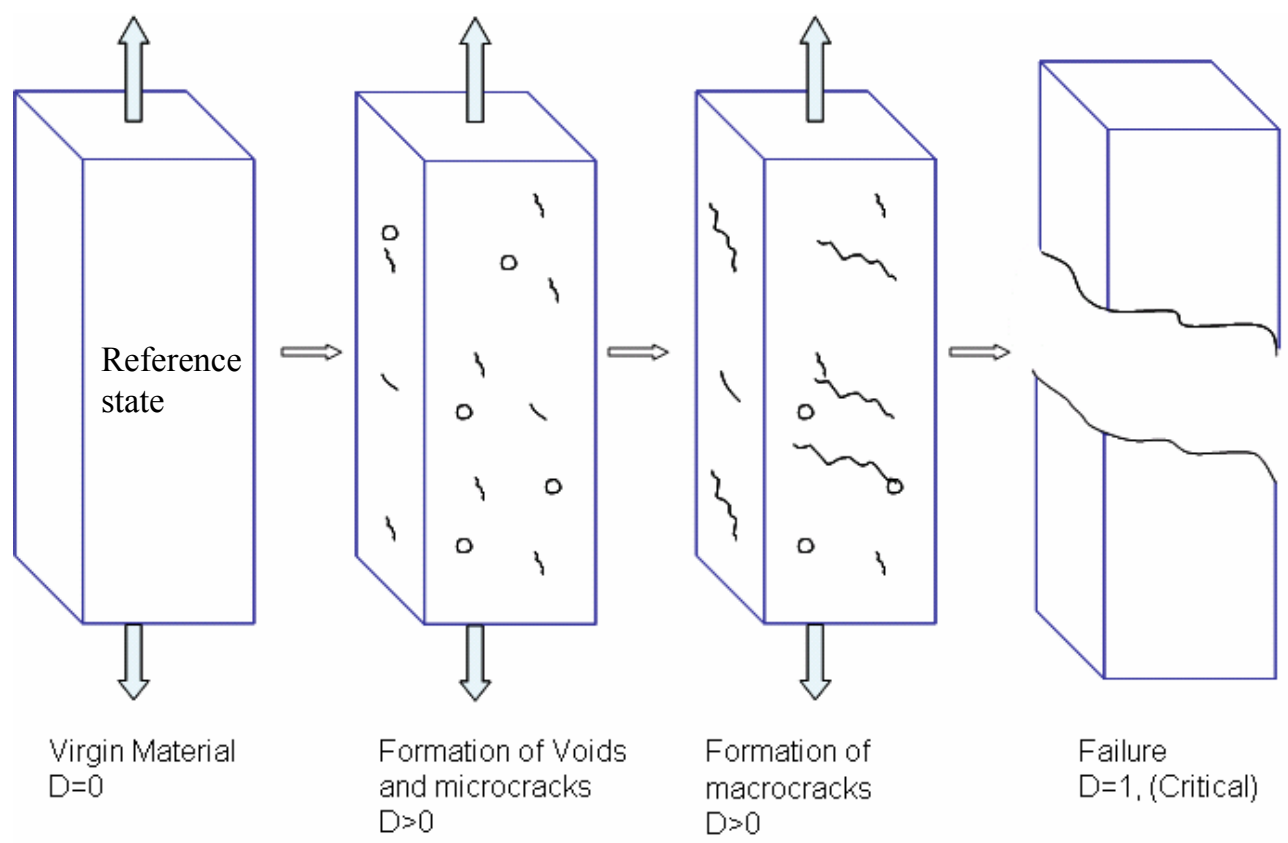

Figure 3-2 Evolution of Damage in a material

In the case of isotropic degradation, a single degradation variable is defined that relates the original and degraded configuration. For an anisotropic degradation model, the degradation variable depends on the choice of the normal $\vec{n}$ to the representative element and a tensorial formulation is employed for the degradation variable. Anisotropic degradation formulations address degradation using either a second order tensor or fourth order tensor, even eighth order tensors as have been proposed in the literature. If, however, material degradation can be considered the same regardless of the orientation of 
the cross section on which it is measured, then degradation is isotropic and is quantified by one single scalar variable, $\mathrm{D}$ : a dimensionless number between zero and one as shown in Eq. (3. 1).

\subsection{Thermodynamics of Degradation}

The constitutive equations for a given material behavior e.g. plasticity or degradation, can be derived in the framework of the thermodynamics of irreversible phenomena through a certain number of variables called state variables [68]. In this framework, a material model is developed such that the thermodynamic state of material at a given point in space and time is completely determined by a given set of state variables at that point.

\subsubsection{State Variables}

The complete characterization of a thermodynamic system (a continuum in this case) describes the state of the system. This description is specified by several thermodynamic and kinematic quantities called state variables. A change of the state variables with time characterizes a thermodynamics process.

The state variables are divided into two sets: observable state variables and internal state variables. The observable variables are those that can be measured directly and which appear regardless of the material phenomenon such as elasticity, plasticity, or degradation [69]. Temperature and total strain is an example of observable state variables. Plastic strain, degradation strain, and degradation variable are an example of internal variables. 
Table 3-1 State and Associated Variables [68]

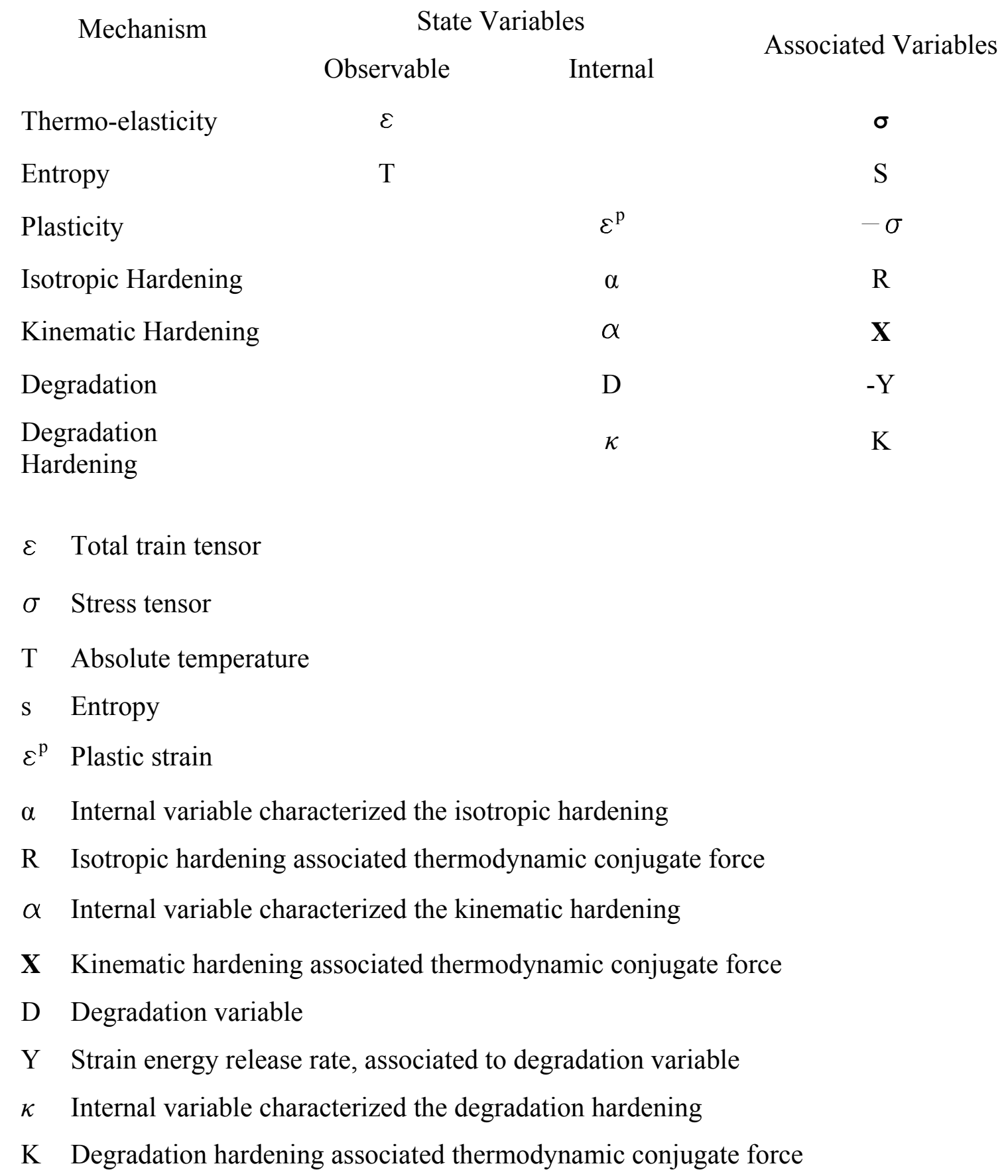

We choose the state variables in accordance with the physical mechanisms of deformation and degradation of the material i.e. elasticity, plasticity, or degradation. For 
example, in a pure elasticity phenomenon, material state can be completely defined by a set of observable state variables at a point i.e. stress and strain. However to define the inelastic phenomenon, we require an additional set of internal state variables because the material has a history dependency.

\subsubsection{Strain Tensor}

Assuming small strain, the total strain tensor can be decomposed into elastic and inelastic strain tensor components by simple superposition. Although the degradation process is thermodynamically an irreversible deformation, the deformation due to degradation strain can be partially or completely recovered upon unloading. Both reversible and irreversible parts cause degradation in the material stiffness. Hence, in small strain theory, the total strain can be additively decomposed as shown in Eq. (3. 2):

$$
\varepsilon=\varepsilon^{e}+\varepsilon^{d}+\varepsilon^{p}
$$

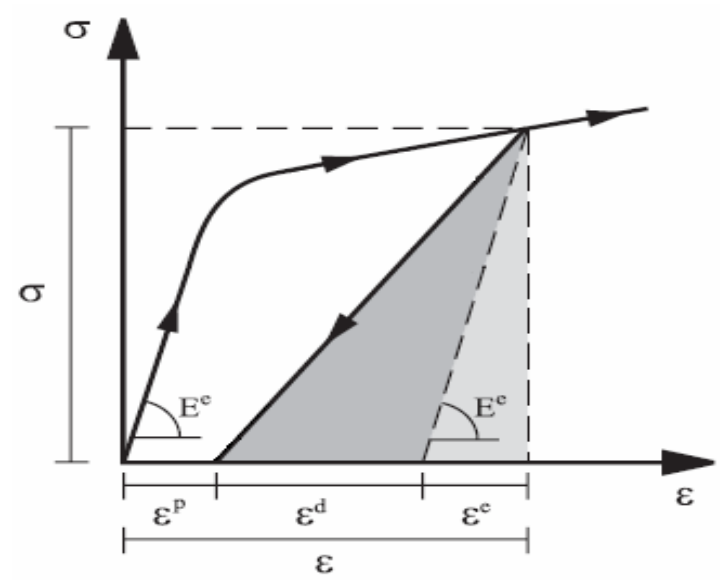

Figure 3-3 Generalized stress-strain relation of a elastic, plastic, and degradation strain 
where $\varepsilon^{\mathrm{e}}$, $\varepsilon^{\mathrm{p}}$, and $\varepsilon^{\mathrm{d}}$, are the elastic, plastic, and degradation strain respectively. For brittle materials, plastic deformation is negligible as compared to the elastic strain.

$$
\begin{aligned}
& \frac{\varepsilon^{p}}{\varepsilon^{e}}<1 \\
& \varepsilon^{e}>\varepsilon^{p}
\end{aligned}
$$

When microcracks are initiated without a large amount of plastic deformation, the damage is called brittle [68], as shown in Eq. (3. 3).

\subsubsection{Effective Configuration}

In order to employ the principles of CDM, an imaginary undamaged configuration is considered known as an effective configuration as shown in Figure 3-4. In the effective configuration all types of material defects, including micro-voids and micro-cracks, are removed from the material and the stresses are replaced by effective stresses.

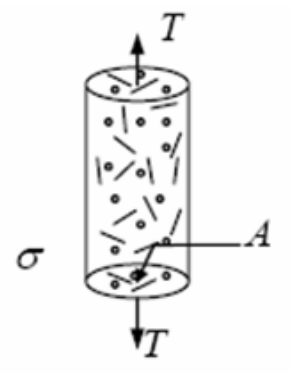

Actual Configuration

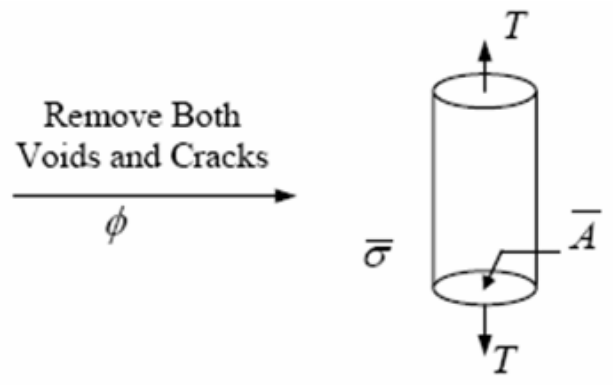

Effective Configuration

Figure 3-4 A cylindrical bar subjected to uniaxial tension both voids and cracks are removed [69] 
The actual and effective configurations are subjected to the same applied load. Based on the effective configuration, Figure 3-4, the applied load equations can be written as following.

$$
\sigma A=\bar{\sigma} \bar{A}=T
$$

where $\bar{\sigma}$ is the effective stress, $\bar{A}$ is the effective area and $\mathrm{T}$ is the applied load. The effective stress can be expressed in terms of actual stress and the effective and apparent areas as following.

$$
\bar{\sigma}=\frac{A}{\bar{A}} \sigma
$$

The introduction of a degradation variable leads to the concept of effective stress. It is defined as the force divided by the effective resisting area of the representative volume element [70]. In the uniaxial case with isotropic degradation, the effective stress is defined by combining Eq. (3. 1) and Eq. (3. 5) as shown in Eq. (3. 6).

$$
\bar{\sigma}=\frac{\sigma}{1-D}
$$

In the multi-axial case of isotropic degradation, the operator 1/(1-D) can be applied to all the stress components acting on the same effective area, and the effective stress tensor $\left(\sigma_{\mathrm{ij}}\right)$ is simply defined as following [68].

$$
\bar{\sigma}_{i j}=\frac{\sigma_{i j}}{1-D}
$$

The stress-strain relation for actual and effective configurations can be written from Figure 3-4, as following: 


$$
\begin{aligned}
& \sigma=E \varepsilon \\
& \bar{\sigma}=\bar{E} \bar{\varepsilon}
\end{aligned}
$$

In order to completely define the relation between the actual and effective configuration, various hypotheses are proposed. A convenient way to avoid a micromechanical analysis for each type of defect and each type of mechanism of degradation is to postulate an equivalence principal [71-76]. Following are the most commonly adopted hypotheses.

(1) Strain equivalence principle

(2) Stress equivalence principle

(3) Strain-energy density hypothesis

\subsubsection{Strain equivalence principle}

The transformation of stress from the degradation state to the effective state in this work is derived through the use of the concept of equivalent strain principle. This concept assumes that the strain in the degraded state and in the effective state is equivalent $(\bar{\varepsilon}=\varepsilon)$ [67]. The principal of strain equivalence states that [68]:

"Any strain constitutive equation for a degraded material may be derived in the same way as for the virgin material except that the usual stress is replaced by the effective stress". 


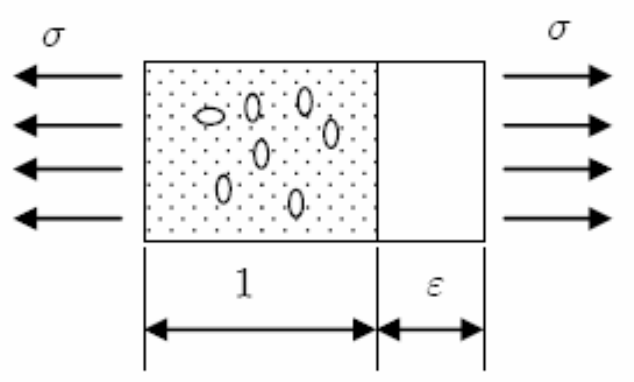

Physical space

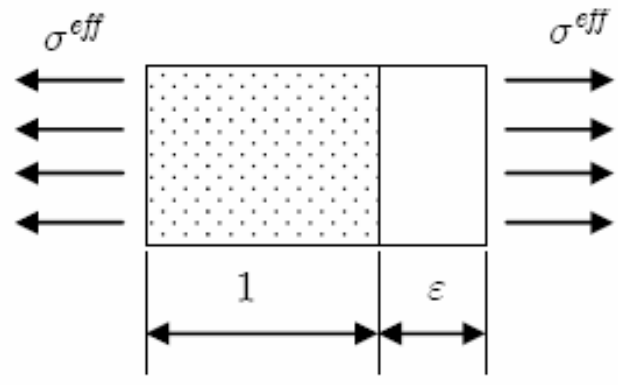

Effective space

Figure 3-5 Concept of effective stress and principle of strain equivalence [77]

Employing this concept to the elastic strain tensor, one can obtained a relationship between the degraded modulus of elasticity, $\mathrm{E}$ and the isotropic degradation variable $\mathrm{D}$. Comparing Eq. (3.8) and Eq. (3.9):

$$
\frac{\bar{\sigma}}{\bar{E}}=\frac{\sigma}{E}
$$

Substituting Eq. (3.6) in Eq. (3. 10), we obtain the following relation based on the strain equivalence principle.

$$
\frac{E}{\bar{E}}=(1-D)
$$

where $\mathrm{E}$ is the elastic modulus of degraded and $\bar{E}$ is the elastic modulus of comparable un-degraded material. The loss of stiffness can be measured by some conventional nondestructive testing such as direct tension tests, change in hardness and change in electrical resistance, and correlates the degradation at the microscopic scale to the structural scale. 
Thus the deformation behavior of the material is only affected by degradation in the form of effective stress; the constitutive equations of the degraded material are the same as those of the virgin material with no degradation where the stress is simply replaced by the effective stress as shown in Figure 3-5.

\subsubsection{Stress equivalence principle}

Similarly in the stress equivalence principle approach, the stress associated with a degraded state under the applied strain is equivalent to the stress associated with its undegraded state under the effective strain, Figure 3-6.

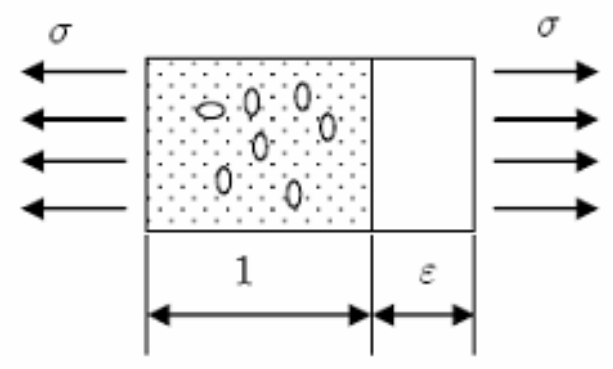

Physical space

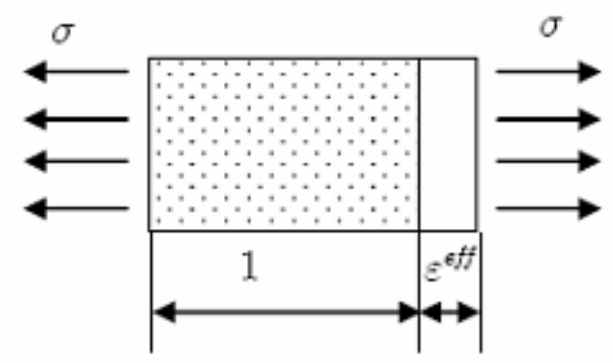

Effective space

Figure 3-6 Concept of effective strain and principle of stress equivalence [77]

Naturally, in the strain-based formulation the elastic energy density is written as a function of strain tensor, while in the stress-based formulation the complementary form is used as a function of stress tensor. 


\subsubsection{Strain-Energy density hypothesis}

An elastic strain energy formulation is also exercised in the literature in order to define the equivalence between the reference and degraded configuration [68-78]. This approach assumes that the elastic strain energy is the same in both initial and effective configurations. From Figure 3-4, the strain energy density for the initial and effective configuration can be written as following.

$$
\begin{gathered}
\int_{0}^{\varepsilon} \sigma \mathrm{d} \varepsilon=\int_{0}^{\bar{\varepsilon}} \bar{\sigma} \mathrm{d} \bar{\varepsilon} \\
\sigma \varepsilon=\bar{\sigma} \bar{\varepsilon}
\end{gathered}
$$

Substituting Eq. (3. 8) and Eq. (3. 9) into Eq. (3. 13)

$$
\begin{gathered}
\sigma \frac{\sigma}{E}=\bar{\sigma} \frac{\bar{\sigma}}{\bar{E}} \\
E=\bar{E}\left(\frac{\sigma}{\bar{\sigma}}\right)^{2}
\end{gathered}
$$

From Eq. (3. 6) and Eq. (3. 15)

$$
E=\bar{E}(1-D)^{2}
$$

In this research, we adopted the strain energy equivalence principle as explained in section 3.3.3.1. 


\subsection{Equation of State (State Potential)}

To characterize a macroscopic system in classical thermodynamics, a state potential is introduced. Several forms of state potential are available in the literature such as the internal energy, Helmholtz free energy, enthalpy and Gibbs free energy.

\subsubsection{Helmholtz Free Energy}

The Helmholtz free energy $(\psi)$, which is a scalar function of the state variables, has been utilized by many researchers $[67,74]$ to characterize a macroscopic system. This thermodynamics potential describes the current state of energy in the material, and it is a function of the observable state variables and the internal state variables under consideration as shown in Eq. (3. 17).

$$
\psi=\psi\left(\varepsilon_{i j}, \varepsilon_{i j}^{p}, \alpha, \kappa, D\right)
$$

If the degradation and plasticity are assumed to be uncoupled, the Helmholtz free energy per unit mass $(\psi)$ can be expressed as following.

$$
\psi=\psi^{e}\left(\varepsilon_{i j}-\varepsilon_{i j}^{p}, D\right)+\psi^{p}(\alpha)+\psi^{d}(\kappa)
$$

where

$\psi^{e} \quad$ free energy due to elastic deformation

$\psi^{p} \quad$ free energy due to plastic hardening

$\psi^{d}$ free energy due to degradation hardening

$\varepsilon_{i j} \quad$ total strain tensor

$D$ degradation variable

$\alpha \quad$ internal state variable corresponding to plastic hardening 
$\kappa \quad$ internal state variable corresponding to degradation hardening/softening

For brittle material, the free energy associated with the plastic hardening $\psi^{p}(\alpha)$ is negligible. The proposed definition of Helmholtz free energy $(\psi)$ allows the derivation of the constitutive equations and the internal dissipation.

The second principle of thermodynamics, written as the Clausius-Duhem inequality is satisfied when the degradation rate is positive i.e. the $2^{\text {nd }}$ principle of thermodynamics requires the mechanical dissipation work to be positive. Clausius - Duhem inequality can be expressed as following.

$$
\gamma=\sigma_{i j} \dot{\varepsilon}_{i j}-\rho \dot{\psi} \geq 0
$$

where $\gamma$ is the power dissipation, $\rho$ is the mass density, and the dot represents the time derivative of the variables. Helmholtz free energy is a function of state variables. We can express the time derivative of the free energy with respect to the internal state variable as following.

$$
\dot{\psi}=\frac{\partial \psi}{\partial \varepsilon_{i j}^{e}} \dot{\varepsilon}_{i j}^{e}+\frac{\partial \psi}{\partial D} \dot{D}+\frac{\partial \psi}{\partial \alpha} \dot{\alpha}+\frac{\partial \psi}{\partial \kappa} \dot{\kappa}
$$

Substituting the time derivative equation of the Helmholtz free energy, Eq. (3. 20), and the strain additive relation, Eq. (3. 2), into the Clausius-Duhem inequality, Eq. (3. 19), we obtain thermodynamic constrains as following:

$$
\left(\sigma_{i j}-\rho \frac{\partial \psi}{\partial \varepsilon_{i j}^{e}}\right) \dot{\varepsilon}_{i j}^{e}+\sigma_{i j} \dot{\varepsilon}_{i j}^{p}-\rho \frac{\partial \psi}{\partial D} \dot{D}-\rho \frac{\partial \psi}{\partial \alpha} \dot{\alpha}-\rho \frac{\partial \psi}{\partial \kappa} \dot{\kappa} \geq 0
$$




\subsubsection{State laws}

From Eq. (3. 21), the following thermodynamic state laws are obtained for the conjugate thermodynamic forces corresponding to the internal variables.

$$
\begin{gathered}
\sigma_{i j}=\rho \frac{\partial \psi}{\partial \varepsilon_{i j}^{e}} \\
K=\rho \frac{\partial \psi}{\partial \kappa} \\
R=\rho \frac{\partial \psi}{\partial \alpha} \\
\mathrm{Y}=-\rho \frac{\partial \psi}{\partial D}
\end{gathered}
$$

Substituting Eq. (3. 22) to Eq. (3. 25) into Eq. (3.21) yields the following inequality form.

$$
\gamma=-\rho \frac{\partial \psi}{\partial \varepsilon_{i j}^{e}} \dot{\varepsilon}_{i j}^{e}+\mathrm{Y} \dot{D}-K \dot{\kappa}-R \dot{\alpha}+\sigma_{i j} \dot{\varepsilon}_{i j} \geq 0
$$

The inequality, Eq. (3. 26), can be separated into dissipation due to plasticity and dissipation due material degradation if the two mechanisms are assumed to be uncoupled $[69,74]$.

$$
\gamma^{p}=-\rho \frac{\partial \psi}{\partial \varepsilon_{i j}^{e}} \dot{\varepsilon}_{i j}^{e}-R \dot{\alpha}+\sigma_{i j} \dot{\varepsilon}_{i j} \geq 0
$$




$$
\gamma^{d}=\mathrm{Y} \dot{D}-K \dot{\kappa} \geq 0
$$

\subsubsection{Yield function and Kuhn-Tucker conditions}

In order to determine the possibility of plastic deformation and/or material degradation, the yield surface function $\left(\mathrm{F}_{\mathrm{p}}\right)$ and damage surface function $\left(\mathrm{F}_{\mathrm{d}}\right)$ are defined. These functions are given in terms of state variables and their conjugate forces.

$$
\begin{aligned}
& F_{p}\left(\sigma_{i j}, R\right)=0 \\
& F_{d}(Y, K)=0
\end{aligned}
$$

The material response is elastic if the following conditions are satisfied.

$$
F_{p}<0 \text { and } F_{d}<0
$$

Plastic deformation or material degradation is only possible under the following necessary conditions.

$$
F_{p}=0 \quad \text { or } \quad F_{d}=0
$$

The evolution laws can be derived from the postulate of maximum dissipation using Eqs.(3. 29)-(3. 32) by finding stresses and forces for the given thermodynamics fluxes, such that the dissipation equation is maximized. This postulate leads to the following evolution laws [68-79].

$$
\varepsilon_{i j}^{\cdot p}=\dot{\lambda}_{p} \frac{\partial F_{p}}{\partial \sigma_{i j}}
$$




$$
\begin{gathered}
\dot{\alpha}=-\dot{\lambda}_{p} \frac{\partial F_{p}}{\partial R} \\
\dot{D}=\dot{\lambda}_{d} \frac{\partial F_{d}}{\partial \mathrm{Y}} \\
\dot{\kappa}=-\dot{\lambda}_{d} \frac{\partial F_{d}}{\partial K}
\end{gathered}
$$

where $\lambda_{\mathrm{p}}$ and $\lambda_{\mathrm{d}}$ are Lagrange multipliers also known as consistency parameters. Lagrange multipliers are assumed to follow the Kuhn-Tucker conditions as shown in Eq. (3. 37) and depicted Figure 3-7.

$$
\begin{array}{ll}
\dot{\lambda}_{d} \geq 0 & \dot{\lambda}_{p} \geq 0 \\
F_{d}=0, & F_{p}=0 \\
\dot{\lambda}_{d} F_{d}=0, & \dot{\lambda}_{p} F_{p}=0
\end{array}
$$




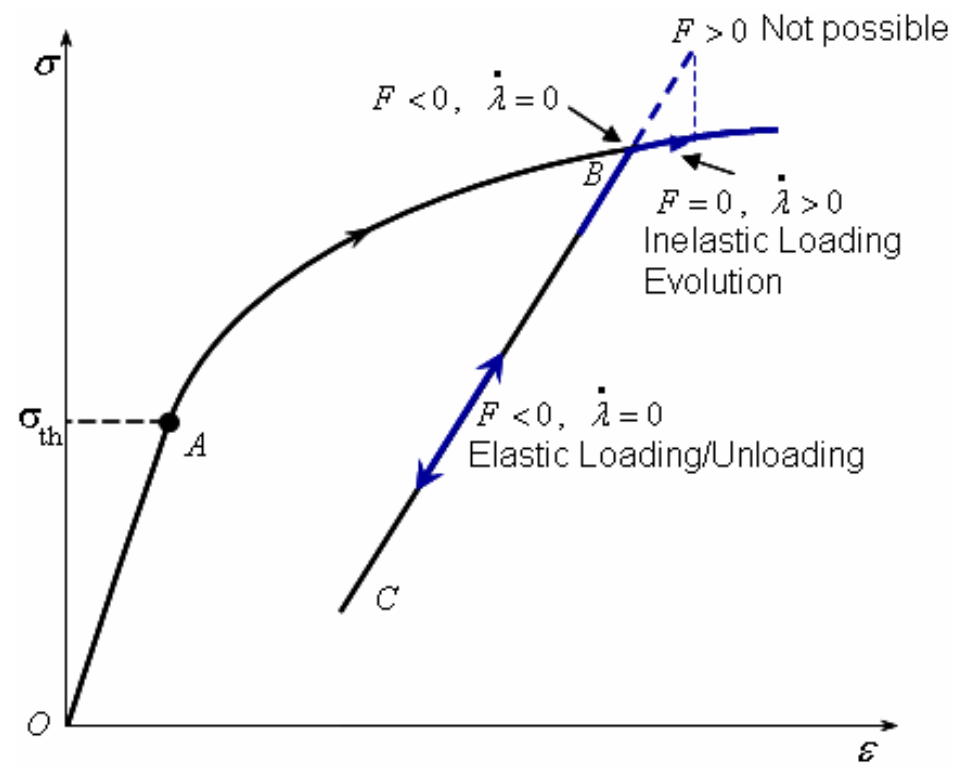

Figure 3-7 Material deformation and corresponding Kuhn-Tucker condition 


\section{Chapter 4 ANODE MATERIAL DEGRADATION MODEL}

Many types of materials have been studied in the literature for the SOFCs anode including $\mathrm{La}_{\mathrm{x}} \mathrm{Sr}_{1-\mathrm{x}} \mathrm{VO}_{3-\delta}$ (LSV) [5], $\mathrm{CoS}_{1.035}, \mathrm{WS}_{2}$, and $\mathrm{Li}_{2} \mathrm{~S} / \mathrm{CoS}_{1.035}$ [6], Ni/scandiastabilized zirconia (Ni-ScSZ) [7], $\mathrm{Cu}-\mathrm{CeO}_{2}-\mathrm{YSZ}$ [8] etc. Nickel-Yttria Stabilized Zirconia (Ni-YSZ), however, is the current choice for SOFCs anode material $[9,39,51,52]$. It is preferred because of its chemical and structure stability, good thermal and electrical conductivity, catalytic performance, cost and compatibility with the other materials of SOFC [11]. Since Ni-YSZ is a heterogeneous porous material that consists of nickel (Ni) and yttria-stabilized zirconia (YSZ), its mechanical properties are widely scattered and hard to define. However for the convenience of analysis and design, anode material is often considered homogenous at the macroscopic level $[9,16]$.

\subsection{Anode Structural Degradation Mechanisms}

Anode structural degradation may occur due to several mechanisms depending on loading and environmental conditions. The service life of a Ni-cermet anode is deteriorated by a variety of microstructural changes which mainly result from material transport, deactivation and thermo-mechanical mechanisms $[18,19]$. Some of the fuel gas contaminants (e.g. P, As) penetrate from the anode exposed surface and interact with anode (Ni-YSZ) material $[41,50,60]$. These contaminants form secondary phases with $\mathrm{Ni}$ and YSZ, which cause grain growth and microcrack formation within the anode material. Recent studies [50,60] at the Pacific Northwest National Laboratory (PNNL), on the interaction of phosphine $\left(\mathrm{PH}_{3}\right)$ with SOFC anode, showed a correlation of the penetration 
depth with the contaminant concentration and duration of exposure as shown in Figure 2-21 and Figure 4-1.

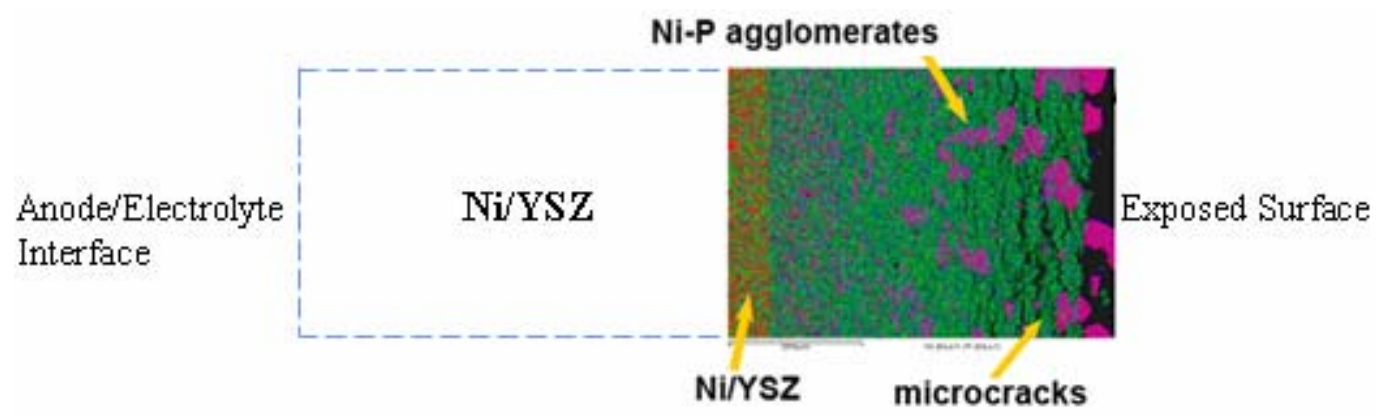

Figure 4-1 Penetration depths after $990 \mathrm{~h}$ with 5ppm $\mathrm{PH}_{3}$ in coal syngas, after O. A. Marina et al. [60]

\subsubsection{Two Degradation Zones}

From the experimental studies $[50,60]$, we propose that the structural degradation of the anode can be considered into two different zones across the anode thickness: (i) the intact zone, $x(t)$, and (ii) the penetration zone, $p(t)$, as shown in Figure 4-2. The major structural degradation in the intact zone is due to thermo-mechanical effects whereas the penetration zone is further degraded by the fuel gas contaminants interaction with the anode material.

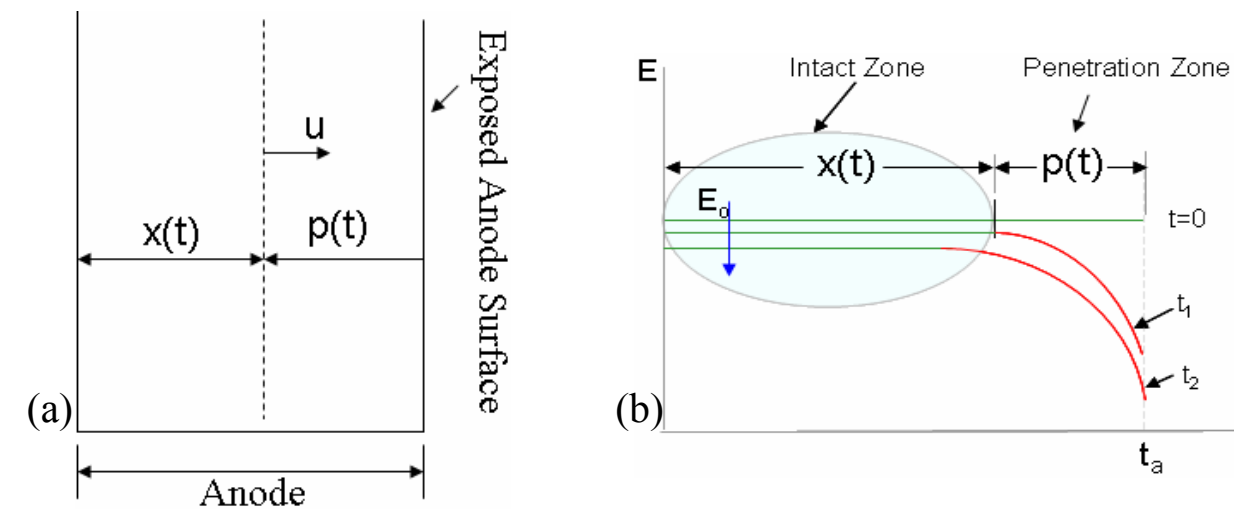

Figure 4-2 Two degradation zones (a) intact and penetration zones (b) stiffness degradation 


\subsubsection{Intact Zone}

As shown in Figure 4-2 (a), $x(t)$ is the intact zone where the effect of coal syngas contaminations is assumed to be negligible. The major material degradation in the intact zone is due to the thermo-mechanical effects. In this zone, the degradation mechanisms are stress/strain and thermal aging effects. The Young's modulus degradation in this zone can be expressed as following.

$$
E_{i}(t)=E_{o}-f(\sigma, D, t, . .)
$$

where $E_{o}$ is the initial Young's modulus and $E_{i}(t)$ is the degraded Young's modulus in the chemically sound zone (intact zone).

\subsubsection{Penetration Zone}

We propose the existence of a penetration zone, $\mathrm{p}(\mathrm{t})$, where the coal syngas contaminants can cause anode material degradation coupled with the thermo-mechanical degradation as shown in Figure 4-2. The depth of this zone would increase with time and it should be proportional to the level of the contaminants in the coal syngas. The penetration zone would increase and intact zone decrease with time within the anode thickness as shown in Figure 4-3.

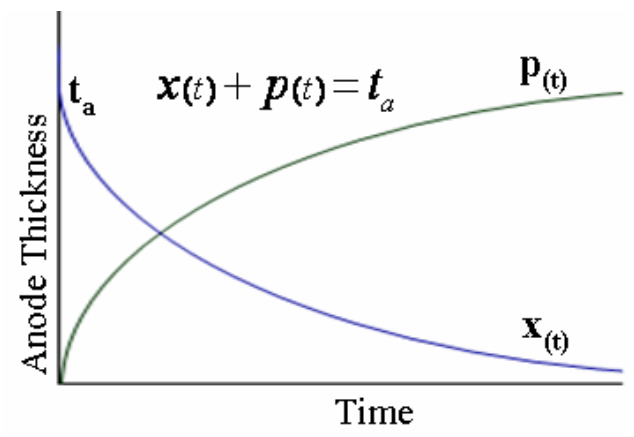

Figure 4-3 Increase in penetration depth with time 
The penetration zone is further degraded due to the syngas contaminants as shown in Figure 4-2(b). The level of degradations depends on the syngas contaminants concentration. It can be expressed as following:

$$
E_{p}(t)=E_{i}(t)-f(\text { syngas contaminan ts })
$$

where $E_{i}$ is the thermo-mechanical degraded Young's modulus and $E_{p}$ is the degraded Young's modulus due to fuel contaminants effects.

\subsubsection{Degradation Variables (Multi-Mechanism)}

Several mechanisms are involved in the process of anode material degradation. Each mechanism requires a different degradation variable to be specified [71-74]. In the proposed degradation model, we have specified two degradation variables i.e. $D_{m}$ : thermo-mechanical degradation variable, and $D_{c}$ : structural contaminant degradation variable. The cumulative effect of the two degradation mechanisms to which the material is exposed at the same time can be assumed either a simple addition or multiplicative [7173] of the two mechanisms as shown in Eq. (4. 3) and Eq. (4. 4) respectively.

$$
\begin{aligned}
& D=D_{m}+D_{c} \\
& D=1-\left(1-D_{m}\right) \cdot\left(1-D_{c}\right)
\end{aligned}
$$

For Eq. (4. 4), $D$ still satisfies the following necessary condition that is typical for a degradation variable. It is also depicted in Figure 4-4.

$$
0 \leq D \leq 1, \quad \dot{\mathrm{D}} \geq 0
$$



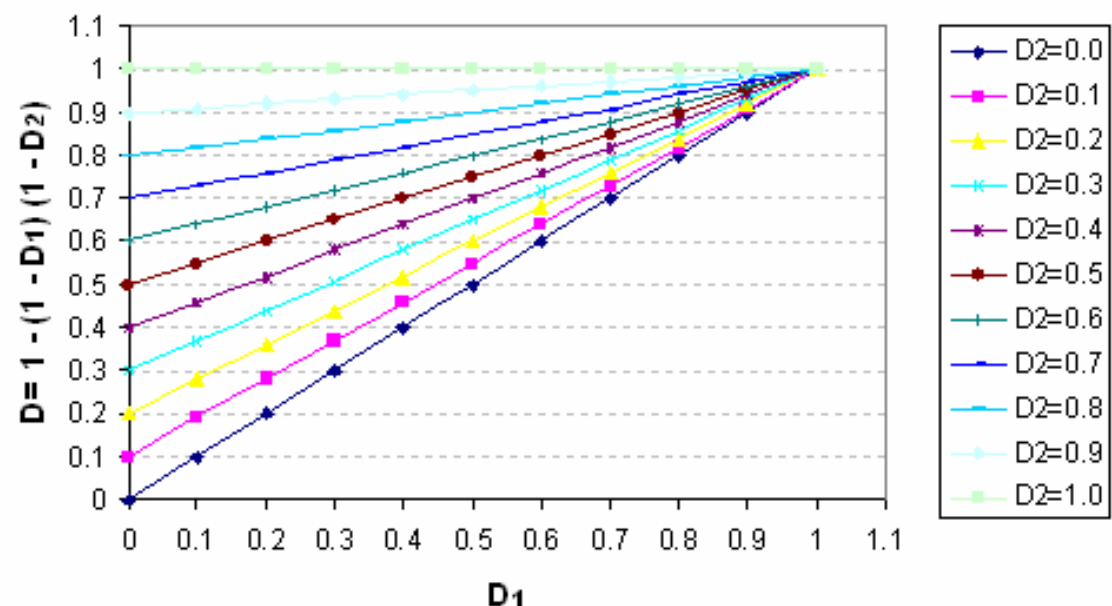

Figure 4-4 Change in multiplicative cumulative degradation variable with individual degradation variable

Eq. (4. 3) and Eq. (4. 4) represents different interpretation of the cumulative degradation variable [71]. In some situations, a simple additive relation may violate the necessary condition i.e. $0 \leq D \leq 1$ as depicted in Figure 4-5.

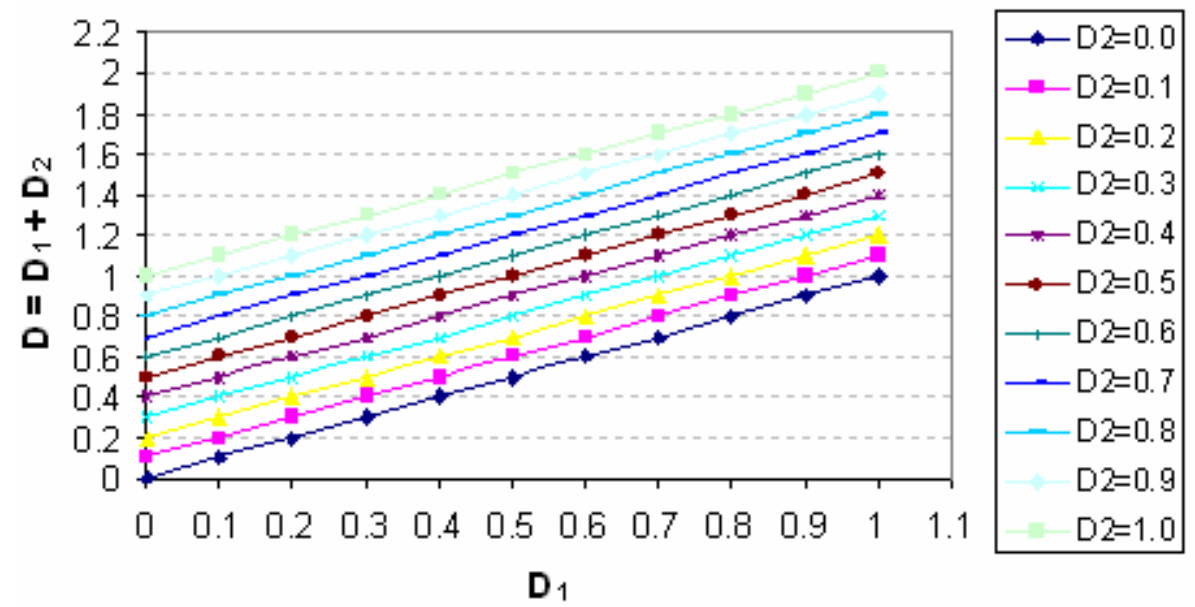

Figure 4-5 Change in additive cumulative degradation variable with individual degradation variable 
Consider a representative volume element (RVE) of a material that is damaged by two different mechanisms. Let $\mathrm{A}_{\mathrm{o}}$ be the original area of cross section of a plane with the RVE as shown in Figure 3-1. Let $A_{m}$ and $A_{c}$ be the areas of intersection of microcracks associated with the thermo-mechanical and fuel contaminant effects respectively. The density of microcracks associated with the thermo-mechanical effects can be described as $\mathrm{A}_{\mathrm{m}} / \mathrm{A}_{\mathrm{o}}$ considering the original area $\mathrm{A}_{\mathrm{o}}$. Similarly, the density of microcracks associated with the fuel contaminant can be described based on the remaining area. Now the total area of intersection of microcracks with the cutting plane can be described as following.

$$
\begin{aligned}
& A_{t}=A_{m}+A_{c} \frac{\left(A_{o}-A_{m}\right)}{A_{o}} \\
& A_{t}=A_{m}+A_{c}-\frac{A_{m} A_{c}}{A_{o}}
\end{aligned}
$$

The last term in Eq. (4. 7) indicates that the microcracks resulted from the two mechanisms should not be projected twice [74]. The cumulative damage can be obtained as the effective surface density of microcracks.

$$
\begin{aligned}
& D=\frac{A_{t}}{A_{o}}=\frac{A_{m}}{A_{o}}+\frac{A_{c}}{A_{o}}-\frac{A_{m} A_{c}}{A_{o}^{2}} \\
& D=D_{m}+D_{c}-D_{m} D_{c}
\end{aligned}
$$

Eq. (4. 9) can be rearranged in the form of Eq. (4. 4). For the model formulation in this research, we have adopted this multiplicative relation. In the intact zone, the degradation variable $\left(\mathrm{D}_{\mathrm{c}}\right)$ is zero and the total degradation variable reduces to the thermomechanical degradation variable $\left(\mathrm{D}_{\mathrm{m}}\right)$.

W. Liu and J. Qu [30] developed a micromechanical based constitutive model to describe the creep behavior of Ni/YSZ. They found that the creep deformation in the 
$\mathrm{Ni} / \mathrm{YSZ}$ is primarily in the Ni phase as indicated by nickel volume fraction in Eq. (4. 10). They derived a closed form solution that gives the strain rate of the entire Ni/YSZ mixture as a function of the overall effective stress as shown in Figure 4-6.

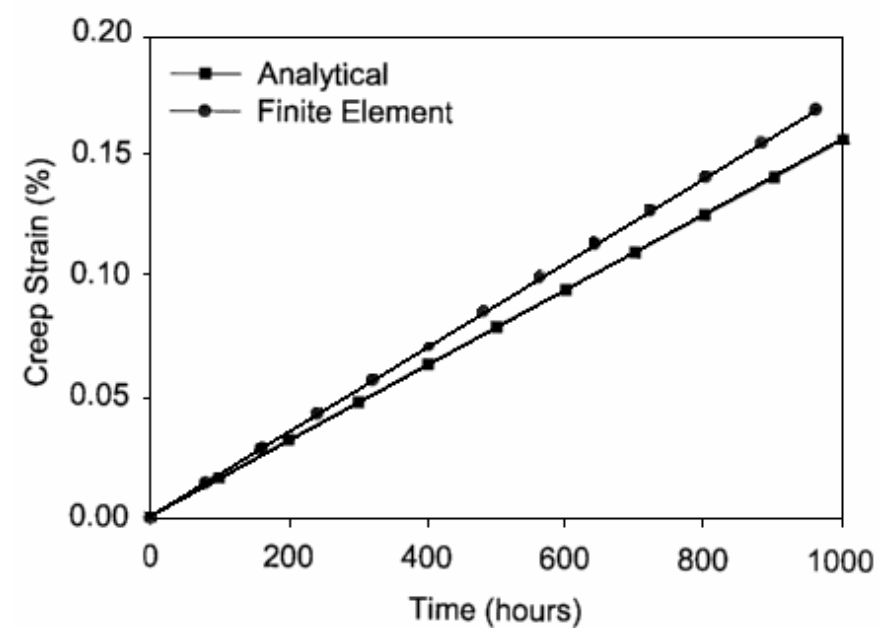

Figure 4-6 Creep Strain in Ni/YSZ over time [30]

$$
\frac{d \bar{\varepsilon}}{d t}=\frac{c_{N}}{3 \eta} \sigma^{-n_{c}}
$$

where $\mathrm{c}_{\mathrm{N}}$ is nickel phase volume fraction, $\eta$ is viscous coefficient of Ni phase, and $\bar{\sigma}$ is the level of effective stress. It can be estimated from Figure 4-6 that the strain rate of $\mathrm{Ni} / \mathrm{YSZ}$ is about $3.325 \mathrm{c}_{\mathrm{N}} \times 10^{-6}$ per hr per MPa.

\subsection{State of Anode Material}

The analysis and design of a structure requires prior knowledge of its material mechanical properties. When continuum mechanics formulation is considered, an elastic 
damage model is generally the standard approach to describe the behavior of brittle materials degradation [80, 82]. In this approach, the effects of the progressive microcracks and strain softening or hardening on the mechanical properties of the materials are represented by a set of internal state variables. These state variables govern the material behavior such as stiffness reduction at the macroscopic level.

\subsubsection{Helmholtz Free Energy}

The current state of energy in a material can be described by a thermodynamics potential such as Helmholtz free energy, which is a function of the observable state variables and the internal state variables under consideration. The proposed definition of Helmholtz free energy $(\psi)$ allows the derivation of the constitutive equations and the internal dissipation. Anode material (Ni-YSZ) remains brittle from room temperature to the SOFC operating temperature [81]. Elastic-brittle materials refer to materials which are degraded by the formation of microcracks and their final fracture take place by the coalescence of microdefects without significant inelastic deformation [82]. Therefore the free energy associated with the plastic hardening $\psi^{p}$ is negligible. Eq. (3. 18) can now be written as following.

$$
\psi=\psi^{e}\left(\varepsilon_{i j}-\varepsilon_{i j}^{p}, D_{m}, D_{c}\right)+\psi^{d}(\kappa)
$$

where $\psi^{e}$ is the free energy associated with the elastic deformation coupled with damage,

$\psi^{d}$ is the free energy associated with the degradation softening/hardening, $\varepsilon_{i j}$ is the strain tensor, $\mathrm{D}_{\mathrm{m}}$ and $\mathrm{D}_{\mathrm{c}}$ are degradation variables. The form of the first term $\psi^{e}$ in Eq. (4. 11) has been postulated in continuum mechanics and is based on the concept of the effective stress, so that it presents the same strain or same elastic energy as a degraded element subjected to the nominal stress. The expression for the elastic free energy is chosen as following. 


$$
\rho \psi^{e}=\frac{1}{2}(1-D) C_{i j k l} \varepsilon_{i j}^{e} \varepsilon_{k l}^{e}
$$

where $C_{i j k l}$ is the fourth order reference elasticity stiffness tensor, $\rho$ is the density and $\varepsilon_{i j}^{e}$ is the elastic strain tensor. To incorporate thermo-mechanical degradation and fuel gas contaminants effects on the anode structure, Eq. (4. 12) can be written as following:

$$
\rho \psi^{e}=\frac{1}{2}\left(1-D_{m}\right)\left(1-D_{c}\right) C_{i j k l} \varepsilon_{i j}^{e} \varepsilon_{k l}^{e}
$$

The relationships between internal state variables and thermodynamic conjugate forces are defined based on the material being investigated and different relationships can be selected. The energy term related to the degradation isotropic hardening conjugating force relationship can be expressed in the form of a power or exponential relationship. Thus the energy terms related to the isotropic hardening can be selected from one of the following $[77,80]$.

Power Law

$$
\rho \psi^{d}(\kappa)=\frac{h}{n+1} \kappa^{n+1}
$$

Exponential Law

$$
\rho \psi^{d}(\kappa)=h\left(\kappa+\frac{1}{n} e^{-n \kappa}\right)
$$

Here $\mathrm{h}$ and $\mathrm{n}$ are positive material parameters. For the current formulation, we have selected power law relation. Substituting Eq. (4. 13) and Eq. (4. 14) into Eq. (4. 11), we proposed the following relation for the Helmholtz free energy.

$$
\rho \psi=\frac{1}{2}\left(1-D_{m}\right)\left(1-D_{c}\right) C_{i j k l} \varepsilon_{i j}^{e} \varepsilon_{k l}^{e}+\frac{h}{n+1} \kappa^{n+1}
$$


The second principle of thermodynamics gives the elasticity law coupled with degradation. Substituting Eq. (4. 16) into Eq. (3. 22) yields.

$$
\sigma_{i j}=\rho \frac{\partial \psi}{\partial \varepsilon_{i j}^{e}}=\left(1-D_{m}\right)\left(1-D_{c}\right) C_{i j k l} \varepsilon_{k l}^{e}
$$

Utilizing the energy terms into the Helmholtz free energy, the state laws equation result in definitions for the degradation hardening - thermodynamic conjugate forces as power relations of the corresponding state variables. From Eq. (4. 16) and Eq. (3.23)

$$
K=\rho \frac{\partial \psi}{\partial \kappa}=h \kappa^{n}
$$

We will assume the following quadratic form $(\mathrm{n}=1)$ as a simplest expression in $\kappa$ as following.

$$
\rho \psi^{d}(\kappa)=\frac{1}{2} h \kappa^{2}
$$

From Eq. (4. 18)

$$
K=h \kappa
$$

The associated variable for D is defined from Eq. (4. 16) and Eq. (3. 25) as following.

$$
\overline{\mathrm{Y}}=\rho \frac{\partial \psi}{\partial D}=-\frac{1}{2} C_{i j k l} \varepsilon_{i j}^{e} \varepsilon_{k l}^{e}
$$

This equation allows $\mathrm{Y}$ to be called the strain energy release rate. The strain energy density release rate, by definition of an associated variable in the thermodynamics, is the principal variable which governs the phenomenon of degradation. This is the energy released by the loss of stiffness of the representative element in which the degradation 
occurred. It is equivalent to the energy release rate in the fracture mechanics. In order to work with a positive quantity for the convenience of further formulization, we define the following substitution.

$$
\mathrm{Y}=-\overline{\mathrm{Y}}=\frac{1}{2} C_{i j k l} \varepsilon_{i j}^{e} \varepsilon_{k l}^{e}
$$

From Eq. (3. 19), Clausius-Dehum inequality can be written as following

$$
\gamma=-\rho \frac{\partial \psi}{\partial \varepsilon_{i j}^{e}} \dot{\varepsilon}_{i j}^{e}-\rho \frac{\partial \psi}{\partial D} \dot{D}-\rho \frac{\partial \psi}{\partial \kappa} \dot{\kappa}+\sigma_{i j} \dot{\varepsilon}_{i j} \geq 0
$$

The evolution of the thermodynamic conjugate forces can be obtained through the evolution of the internal state variables, which are obtained by assuming the physical existence of the dissipation potential i.e. degradation surface $F_{d}$. The energy dissipation due to degradation is found by substituting the thermodynamics state laws into the Clausius-Duhem inequality and is thus given as the product of the thermodynamic conjugate forces with the respective fluxes variables.

$$
\begin{gathered}
\dot{D}=\dot{\lambda}_{d} \frac{\partial F_{d}}{\partial \mathrm{Y}} \\
\dot{\kappa}=-\dot{\lambda}_{d} \frac{\partial F_{d}}{\partial K}
\end{gathered}
$$

$\dot{\lambda}_{d}$ is a Lagrange multiplier also known as consistency parameter. It can be determined using consistency condition as described in section 3.4.3.

\subsubsection{Dissipation Potential}

In order to derive the degradation evolution equations, a proper expression of the dissipation potential must be established. One can assume the existence of a dissipation 
potential which should be a convex and homogenous function in the space of the thermodynamic conjugate forces [82]. Similar to Chow et al. [83] and Murakami et al. [82], we will assume a homogenous function for the degradation surface as expressed in Eq. (4. 26):

$$
F_{d}=\mathrm{Y}^{e}-\left(K_{o}+K\right)
$$

where

$$
\mathrm{Y}^{e}=\sqrt{\frac{1}{2} Y_{i j} L_{i j k l} Y_{k l}}
$$

$\mathrm{L}_{\mathrm{ijk} k \mathrm{l}}$ is the fourth order tensor, called a degradation characteristic tensor. According to Murakami et al. [82], this characteristic tensor can be expressed as follows.

$$
L_{i j k l}=\frac{1}{2}\left(\delta_{i k} \delta_{j l}+\delta_{i l} \delta_{j k}\right)
$$

$\mathrm{K}_{\mathrm{o}}$ is a material constant which represents the initial threshold of degradation evolution similar to the initial yield stress in the theory of plasticity. For isotropic degradation, the strain energy release rate is a scalar quantity and the equivalent strain energy principle is adopted for the isotropic degradation formulation. The energy dissipation due to degradation is found by substituting the thermodynamics state laws into the ClausiusDuhem inequality. Thus it is given as the product of the conjugate forces with the respective fluxes variables. Substituting Eq.(4. 26) into Eq.(4. 24) and Eq.(4. 25):

$$
\begin{gathered}
\dot{D}=\dot{\lambda}_{d} \frac{Y}{2 \mathrm{Y}^{e}} \\
\dot{\kappa}=\dot{\lambda}_{d}
\end{gathered}
$$

$\dot{\lambda}_{d}$ is determined using consistency condition $\dot{F}_{d}=0$ that is the state of stress must remain on the degradation surface during evolution. 


$$
\begin{aligned}
& \dot{F_{d}}(Y, K)=0 \\
& \frac{\partial F_{d}}{\partial Y} \dot{Y}+\frac{\partial F_{d}}{\partial K} \dot{K}=0
\end{aligned}
$$

Substituting Eq. (4. 26) and Eq. (4. 20) into Eq. (4. 32), we can obtain $\dot{\lambda}_{d}$ as following:

$$
\dot{\lambda}_{d}=\frac{1}{h} \frac{\partial F_{d}}{\partial Y} \dot{Y}
$$

From Eq. (4. 22) and Eq.(4. 33)

$$
\dot{\lambda}_{d}=\frac{1}{h} \frac{\partial F_{d}}{\partial Y} \frac{\partial Y}{\partial \varepsilon_{k l}} \dot{\varepsilon}_{k l}^{e}
$$

From Eq. (4. 17)

$$
\sigma_{i j}=\rho \frac{\partial \psi}{\partial \varepsilon_{i j}^{e}}=f(\varepsilon, D)
$$

Taking the time derivative of Eq. (4. 35)

$$
\dot{\sigma}_{i j}=\frac{\partial \sigma_{i j}}{\partial \varepsilon_{k l}} \cdot \dot{\varepsilon}_{k l}+\frac{\partial \sigma_{i j}}{\partial D} \dot{D}
$$

Substituting Eq. (4. 24) into Eq. (4. 36)

$$
\dot{\sigma}_{i j}=\frac{\partial \sigma_{i j}}{\partial \varepsilon_{k l}} \dot{\varepsilon}_{k l}+\frac{\partial \sigma_{i j}}{\partial D} \dot{\lambda}_{d} \frac{\partial F_{d}}{\partial Y}
$$

Substitute $\dot{\lambda}_{d}$ from Eq. (4. 34) 


$$
\begin{gathered}
\dot{\sigma}_{i j}=\frac{\partial \sigma_{i j}}{\partial \varepsilon_{k l}^{e}} \dot{\varepsilon}_{k l}^{e}+\frac{\partial \sigma_{i j}}{\partial D} \frac{1}{h} \frac{\partial F_{d}}{\partial Y} \frac{\partial Y}{\partial \varepsilon_{k l}^{e}} \varepsilon_{k l}^{e} \frac{\partial F_{d}}{\partial Y} \\
\dot{\sigma}_{i j}=\left(\frac{\partial \sigma_{i j}}{\partial \varepsilon_{k l}^{e}}+\frac{\partial \sigma_{i j}}{\partial D} \frac{1}{h} \frac{\partial F_{d}}{\partial Y} \frac{\partial Y}{\partial \varepsilon_{k l}^{e}} \frac{\partial F_{d}}{\partial Y}\right) \dot{\varepsilon}_{k l}^{e} \\
\dot{\sigma}_{i j}=\left(\frac{\partial \sigma_{i j}}{\partial \varepsilon_{k l}^{e}}+\frac{1}{h} \frac{\partial \sigma_{i j}}{\partial D} \frac{\partial F_{d}}{\partial Y} \frac{\partial Y}{\partial \varepsilon_{k l}^{e}} \frac{\partial F_{d}}{\partial Y}\right) \dot{\varepsilon}_{k l}^{e} \\
\dot{\sigma}_{i j}=\left(\frac{\partial \sigma_{i j}}{\partial \varepsilon_{k l}^{e}}+\frac{1}{h} \frac{\partial \sigma_{i j}}{\partial D} \frac{\partial F_{d}}{\partial Y} \frac{\partial Y}{\partial \varepsilon_{k l}^{e}} \frac{\partial F_{d}}{\partial Y}\right) \\
\left.\dot{\varepsilon}_{k l}^{e}\right) \\
K_{i j k l}=\frac{\partial \sigma_{i j}}{\partial \varepsilon_{k l}^{e}}+\frac{1}{h} \frac{\partial \sigma_{i j}}{\partial D} \frac{\partial F_{d}}{\partial Y} \frac{\partial Y}{\partial \varepsilon_{k l}^{e}} \frac{\partial F_{d}}{\partial Y}
\end{gathered}
$$

where $\mathrm{K}_{\mathrm{ijkl}}$ is the material tangential stiffness (Jacobian matrix). Substituting Eq. (4. 17) into Eq. (4. 42),

$$
K_{i j k l}=\left[\left(1-D_{m}\right)\left(1-D_{c}\right)\right] C_{i j k l}+\frac{1}{h} \frac{\partial \sigma_{i j}}{\partial D} \frac{\partial F_{d}}{\partial Y} \frac{\partial Y}{\partial \varepsilon_{k l}^{e}} \frac{\partial F_{d}}{\partial Y}
$$

where $\mathrm{Dc}$ is the degradation due to the syngas contaminants, which is determined in the next step. In the intact zone, the chemical degradation variable is set to be zero (i.e. $\mathrm{Dc}=0)$. 
Increase in the penetration zone is assumed to be proportional to the syngas contaminants concentration. The following law is assumed;

$$
p(t)=c t^{1 / n}
$$

where $t$ is the time of exposure and $c$ is a parameter which depends on the syngas contaminants concentration. It will be determined experimentally. The width of the penetration zone increases with time while the rate of propagation decreases. The position of the penetration can be assumed proportional to the square root of time [72].

$$
p(t)=c \sqrt{t}
$$

The shape of the degradation trend in the penetration zone could be linear, exponential or logarithmic as shown in Figure 4-7. The three degradation trends in Figure 4-7 have same area under the curves for comparison as shown in Eq. (4. 49). These curves essentially show similar degradation value in the penetration zone.

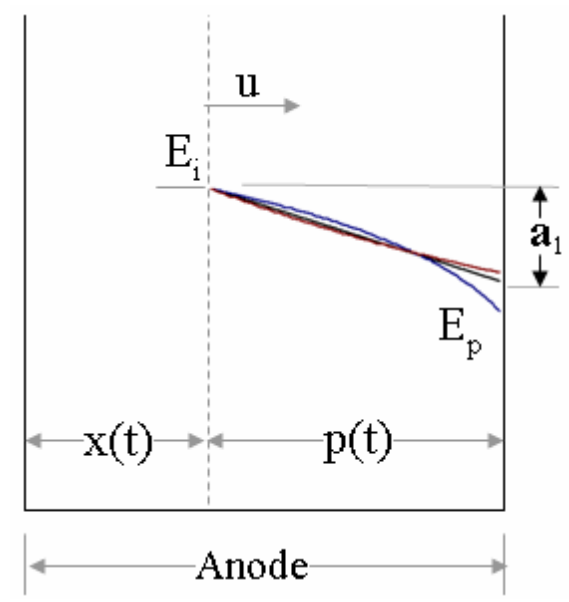

Figure 4-7 Degradation trend in the penetration zone 
Linear form

$$
E_{p}=E_{i}\left(1-\frac{a_{1}}{p_{o}} u\right)
$$

Logarithmic form

$$
E_{p}=E_{i} f\left(\log \left(p_{o}-u\right)\right)
$$

Exponential form

$$
E_{p}=E_{i} \exp \left(-a_{2} u\right)
$$

Normalized area under the curve

$$
\int_{0}^{1}\left(1-\frac{a_{1}}{p_{o}} u\right) d u=\int_{0}^{1} \exp \left(-a_{2} u\right) d u=\int_{0}^{1} f\left(\log \left(p_{o}-u\right)\right) d u
$$

where $E_{i}$ and $E_{p}$ are the anode stiffness at the penetration zone interface and at the anode exposed surface, and $\mathrm{a}_{1}$ is a parameter that quantifies the anode structural degradation due to contaminant interaction; we called it a contaminant structural degradation parameter. To estimate the slope of this curve, it is assumed that when the penetration reaches $p_{o}$ of the anode thickness, the Young's modulus further degrades by a factor of $a_{1}$ of the Young's modulus at the penetration zone interface as shown in Figure 4-7. Therefore the stiffness degradation due to fuel contaminant can be expressed in the form of Eq. (4. 50).

$$
E_{p}=E_{i}-\frac{a_{1} E_{i}}{p_{o}} u
$$

Therefore the degradation due to the syngas contaminants can be defined as following.

$$
D_{c}=1-\frac{E_{p}}{E_{i}}=\frac{a_{1}}{p_{o}} u
$$

where $u$ is the displacement from penetration zone interface to the point of interest as show in Figure 4-7. The parameter $a_{1}$ will be determined experimentally as explained in 
the following sections. Eq. (4. 51) is to be substituted into Eq. (4. 43) to incorporate the effect of syngas contaminants on the material degradation.

\subsection{Phosphine Penetration Depth}

Phosphorus is one of the few contaminants that interact strongly with nickel contained in the SOFC anode and it degrades the anode's electrochemical performance and structural properties during long term operation $[42,50,60]$. Moreover, $\mathrm{PH}_{3}$ forms secondary phases with the SOFC anode material which induce grain growth and microcracks within the anode support as shown in Figure 4-1. Marina et al. [60] suggested that the cell electrochemical degradation may be very low under the formation of secondary phases and microcracks if an electrical pathway to the anode-electrolyte active interface is maintained. A recent study at the Pacific Northwest National Laboratory (PNNL), on the interaction of phosphine $\left(\mathrm{PH}_{3}\right)$ with SOFC anode, showed a correlation of the penetration depth with the contaminant concentration and the duration of exposure [60], as shown in Figure 4-8

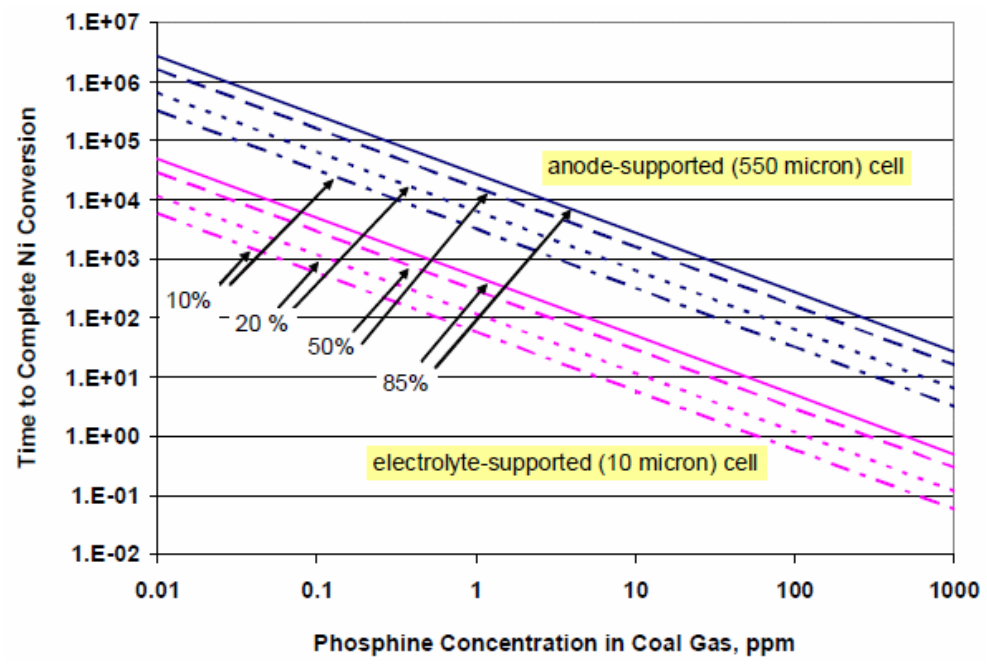

Figure 4-8 Time required to consume nickel with anode material under different $\mathrm{PH}_{3}$ concentrations [60] 
For the anode supported SOFCs, Figure 4-8 can be represented by the following equations.

$$
\begin{aligned}
& p(t)=517.39 \log (t)-y_{\text {int }} \\
& y_{\text {int }}=1711.5-507.90 \log (\text { ppm })
\end{aligned}
$$

where $\mathrm{p}(\mathrm{t})$ is the contaminant penetration depth, $\mathrm{t}$ is the time of exposure, ppm is the contaminant concentration, and $\mathrm{y}_{\text {int }}$ is a parameter which depends on the contaminant concentration. In a flow-by configuration, Marina et al. [50] examined a Ni-YSZ coupon under $0.5 \mathrm{ppm}$ of $\mathrm{PH}_{3}$ exposure. They observed extensive phosphorous capture within a short distance $(4 \mathrm{~mm})$ from the gas inlet after $500 \mathrm{~h}$. Although along the flow penetration is not given explicitly, the same equation will be used in the model for this purpose with a factor.

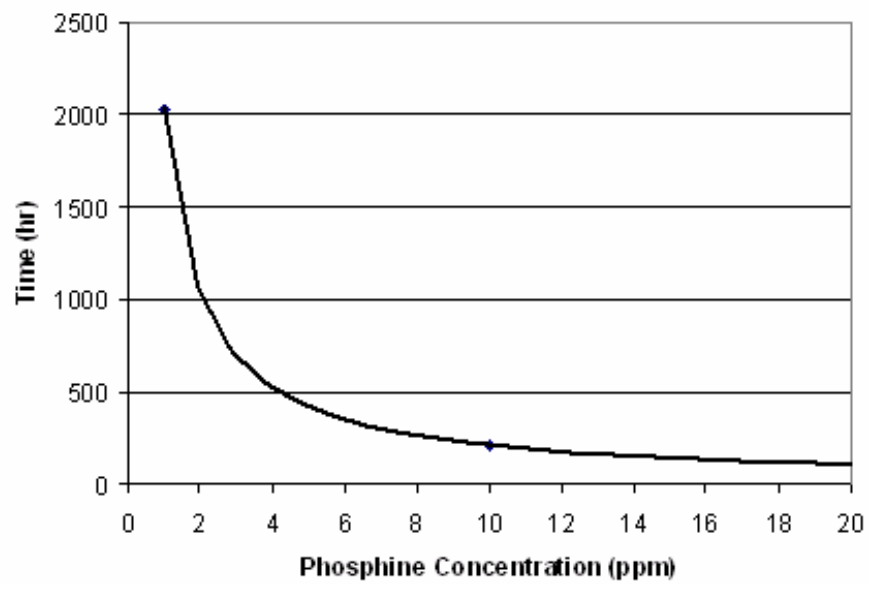

Figure 4-9 Time required $\mathrm{PH}_{3}$ to start penetration in the Anode 
It is evident from Eq. (4. 52) and Eq. (4. 53) that there is a time interval required for $\mathrm{PH}_{3}$ to start penetrating in the anode material depending on its concentration as shown in Figure 4-9. It can be represented approximately by the following equation.

$$
t_{p}=2032.3(p p m)^{-0.982}
$$

where $\mathrm{t}_{\mathrm{p}}$ is the time required to start penetration and ppm is the $\mathrm{PH}_{3}$ concentration. For the specific case of $\mathrm{PH}_{3}$, these equations are incorporated into the model to estimate the $\mathrm{PH}_{3}$ penetration depth.

\subsection{Material Parameters}

Material parameters for the proposed model are obtained from literature and experimental setup. An in-situ SOFC button cell test apparatus is used for the assessment of the SOFC anode material parameters under operating conditions. The experimental setup is based on the concept of a thin circular membrane (i.e. button cell) under uniformly distributed pressure.

\subsubsection{Experimental Setup}

In this research, a NexTech Probostat ${ }^{\mathrm{TM}} \mathrm{SOFC}$ button cell test apparatus is integrated with a Sagnac optical setup and an infrared thermometer sensor for in-situ anode surface deformation and temperature measurements as shown in Figure 4-10. The Sagnac interferometer, also referred to as a beam splitter interferometer, is an amplitude splitting device which was used by Sagnac to measure the angular velocity of a rotating system [86]. As shown in Figure 4-10, a collimated laser light is split into two beams which travel in identical but opposite directed paths. The two beams recombine to form interferometric fringes. The fringe density indicates the extension of the specimen 
rotation but it is relatively insensitive to rigid body motion of the test specimen. Notable advantage of this optical method is that the optical window does not have any effect on the fringe formation and thus it can be applied to in-situ, non-contact surface deformation measurement at elevated temperature.

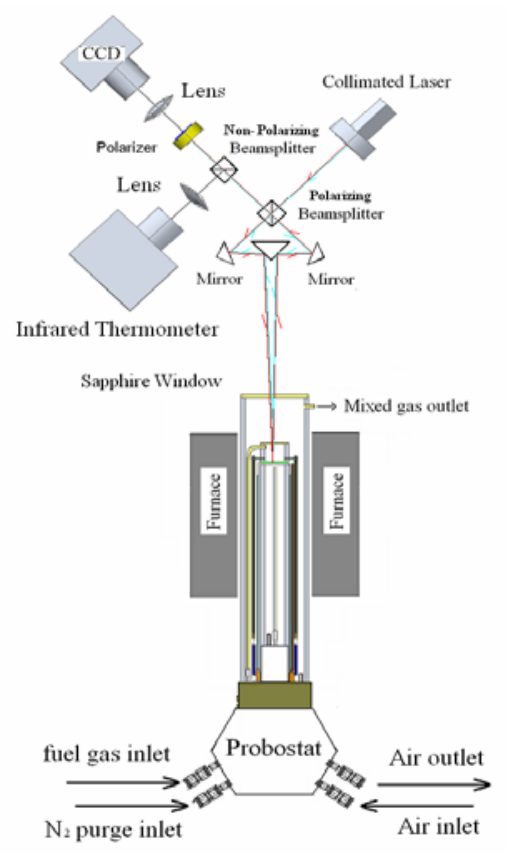

Figure 4-10 NexTech Probostat ${ }^{T M}$ integrated with Sagnac interferometry and IR thermometer*

For Sagnac interferometry, changes of the surface slope (S) and the corresponding out-of-plane displacements (W) can be represented by the following relation.

$$
W=\frac{N \cdot \lambda}{2}
$$

where $\lambda$ is the wavelength of the light source and $\mathrm{N}$ is the fringe order. The challenge in implementing Sagnac interferometry to measure surface deformation of button cell is the requirement of smooth surface morphology since the measurement sensitivity is half the wave length. After some trial and error, it is found that fringes can be obtained on a spot 
location on the nickel wire mesh that is the current collector for anode electrode, as shown in Figure 4-11(a). It should be emphasized that the fringe formation is insensitive to rigid-body out-of-plane translation and is only sensitive to out-of-plane rotation as schematically explained in Figure 4-11(b).
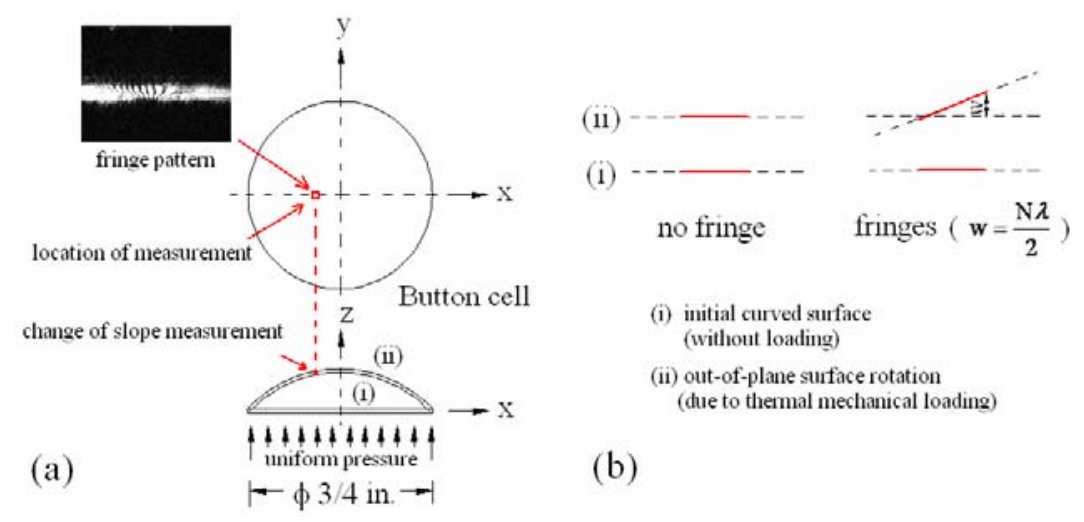

(b)

Figure 4-11 (a) Fringes on a spot location of the Ni wire mesh, (b) button cell surface rotation before and after loading.

\subsubsection{Validation of Experimental Test Methodology}

For the proof of concept, the Sagnac optical setup was assembled and preliminary work carried out at room temperature and $800{ }^{\circ} \mathrm{C}$. Anode-supported SOFCs manufactured by Materials and Systems Research Inc. (MSRI) were tested in this study. Each button cell was $3.00 \mathrm{~cm}$ in diameter with an anode composed of a $1 \mathrm{~mm} \mathrm{Ni-8YSZ} \mathrm{support}$ structural layer and a $25 \mu \mathrm{m}$ thick interlayer composed of a highly catalytic Ni-8YSZ mixture. The electrolyte was a $20 \mu \mathrm{m}$ thick layer, and cathode was composed of a $25 \mu \mathrm{m}$ thick $\mathrm{La}_{0.8} \mathrm{Sm}_{0.2} \mathrm{MnO}_{3}$ (LSM)-8YSZ interlayer and a $25 \mu \mathrm{m}$ thick current-collection layer made of LSM. The button cell was mounted between two mica rings using AREMCO 
516 high temperature cement. Mass flow controllers (MFC) were used to control the fuel and air stream flow rates, pressure and compositions. The optical setup consisted of a $20 \mathrm{~mW}$ diode laser ( $\lambda=658 \mathrm{~nm}$, laser spot size is $2 \mathrm{~mm}$ in diameter), a beam splitter, and several mirrors used as beam directing elements. A long distance microscope fitted with a CCD camera was used to record the fringes on a small surface spot of the Ni wire.

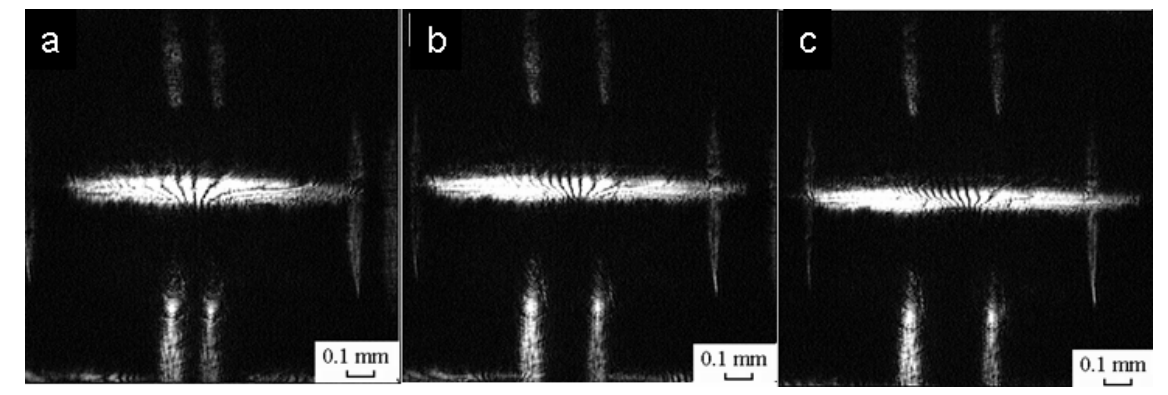

Figure 4-12 Fringe patterns on Ni mesh at $r=3 \mathrm{~mm}$ from the center with different applied pressures: (a) 0 psi, (b) 7 psi, (c) 13 psi

Figure 4-12 shows fringe patterns on Ni mesh located at $r=3 \mathrm{~mm}$ from the center of the button cell. As shown, the fringe patterns are stable under uniform pressure and the optical window placed in the optical path has no effect on the fringe formation. Figure 4-12 (a) shows the initial fringe pattern due to the initial curved surface of the Ni wire without applied pressure. As the applied pressure increases, the fringe density increases as shown in Figure 4-12 (b) and (c). The fringe density can be related to the anode surface deformation under different applied pressures as shown in Table 4-1. For validation, FE simulation and analytical solution as discussed in section 4.4.2 are performed. The comparison among experimental, FE simulation and analytical prediction is shown in Table 4-1. 
Table 4-1 Comparison among experimental, FE simulating and analytical prediction

\begin{tabular}{|c|c|c|c|c|c|}
\hline \multirow{2}{*}{\multicolumn{2}{|c|}{$\begin{array}{l}\text { Applied Pressure } \\
\text { (Psi) }\end{array}$}} & \multicolumn{2}{|c|}{ Experimental Results } & \multirow{2}{*}{$\begin{array}{c}\text { Simulation Result } \\
\Delta \mathrm{S} / \Delta \mathrm{P}\end{array}$} & \multirow{2}{*}{$\begin{array}{c}\text { Analytical } \\
\text { Result } \Delta \mathrm{S} / \Delta \mathrm{P}\end{array}$} \\
\hline & & Slope S & $\Delta \mathrm{S} / \Delta \mathrm{P}$ & & \\
\hline Room & 5 & $4.038 \times 10^{-3}$ & & & \\
\hline temperature & 10 & $4.227 \times 10^{-3}$ & $3.82 \times 10^{-5}$ & $3.70 \times 10^{-5}$ & $3.81 \times 10^{-5}$ \\
\hline \multirow[t]{2}{*}{ (RT) } & 15 & $4.420 \times 10^{-3}$ & & & \\
\hline & 5 & $5.484 \times 10^{-3}$ & & & \\
\hline \multirow[t]{2}{*}{$800^{\circ} \mathrm{C}$} & 10 & $5.185 \times 10^{-3}$ & $5.95 \times 10^{-5}$ & $6.32 \times 10^{-5}$ & $6.23 \times 10^{-5}$ \\
\hline & 15 & $4.889 \times 10^{-3}$ & & & \\
\hline
\end{tabular}

where $\Delta \mathrm{S} / \Delta \mathrm{P}$ is the change of slope per unit applied pressure. As shown in Table 4-1, good agreement is noted and difference is less than $5 \%$. These results are promising and support the proposed experimental test methodology.

\subsubsection{Complementary Analytical Solution}

The experimental setup is based on the concept of a thin circular membrane under uniformly distributed pressure. The button cell will be subjected to uniform pressure at various time intervals, and the corresponding out-of-plane displacements will be measured using an in-house developed optical method. To establish connection between the durability model and related experimental measurements, a two-layer analytical solution [84] is modified to obtain surface deformation of a three-layered thin membrane under uniform pressure which can be considered like a button cell with anode, electrolyte and cathode layers. 


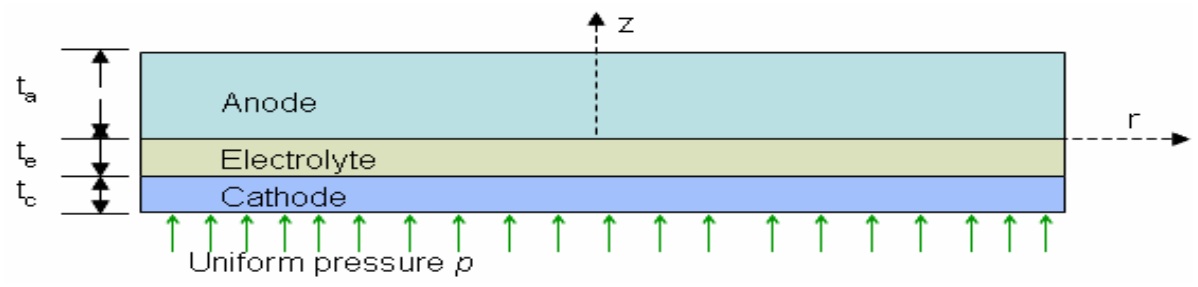

Figure 4-13 Button cell modeled as a three-layered thin membrane

$$
W=\frac{A}{A \cdot C-B^{2}} \cdot \frac{p \cdot r_{o}^{4}}{64}\left[1-2\left(\frac{r}{r_{o}}\right)^{2}+\left(\frac{r}{r_{o}}\right)^{4}\right]
$$

where $W$ is the out-of-plane deflection under uniform pressure $p, \mathrm{r}_{\mathrm{o}}$ is the radius of the cell and the coefficients are defined as follows.

$$
\begin{aligned}
A & =\int_{-h 1}^{h 2} \frac{E_{a}}{1-v^{2}} d z \\
& =\int_{0}^{t a} \frac{E_{a}}{1-v^{2}} d z+\int_{-t e}^{0} \frac{E_{e}}{1-v^{2}} d z+\int_{-(t e+t c)}^{-t e} \frac{E_{c}}{1-v^{2}} d z \\
B & =\int_{-h 1}^{h 2} \frac{E_{e}}{1-v^{2}} z d z \\
& =\int_{0}^{t a} \frac{E_{a}}{1-v^{2}} z \cdot d z+\int_{-t e}^{0} \frac{E_{e}}{1-v^{2}} z \cdot d z+\int_{-(t e+t c)}^{-t e} \frac{E_{c}}{1-v^{2}} z \cdot d z \\
C & =\int_{-h 1}^{h 2} \frac{E_{c}}{1-v^{2}} z^{2} \cdot d z \\
& =\int_{0}^{t a} \frac{E_{a}}{1-v^{2}} z^{2} \cdot d z+\int_{-t e}^{0} \frac{E_{e}}{1-v^{2}} z^{2} \cdot d z+\int_{-(t e+t c)}^{-t e} \frac{E_{c}}{1-v^{2}} z^{2} \cdot d z
\end{aligned}
$$

where $t_{a}, t_{e}, t_{c}$ are anode, electrolyte and cathode thicknesses, $E_{a}, E_{e}, E_{c}$ are their stiffness, and $v$ is Poisson ratio. 
Table 4-2 Numerical and Analytical results of out of plane deformation of a button cell under uniform pressure

\section{Button Cell Specification}

$\mathrm{E}_{\mathrm{a}}=1.05 \mathrm{e} 11 \mathrm{~N} / \mathrm{m}^{2} \quad \mathrm{E}_{\mathrm{e}}=2.125 \mathrm{e} 11 \mathrm{~N} / \mathrm{m}^{2} \quad \mathrm{E}_{\mathrm{c}}=1.1 \mathrm{e} 11 \mathrm{~N} / \mathrm{m}^{2}$

Cell Radius $=12.5 \mathrm{~mm}$ Applied Pressure $=50 \mathrm{kPa}$

$\begin{array}{ccccc}\text { Anode } & \text { Electrolyte } & \text { Cathode } & & \\ \mathrm{t}_{\mathrm{a}}=600 \mu \mathrm{m} & \mathrm{t}_{\mathrm{e}}=10 \mu \mathrm{m} & \mathrm{t}_{\mathrm{c}}=50 \mu \mathrm{m} & \mathrm{W}_{\text {Analytical }} & \mathrm{W}_{\text {FEA }} \\ v_{\mathrm{a}}=0.317 & v_{\mathrm{e}}=0.310 & v_{\mathrm{c}}=0.300 & & \\ \mathrm{E}_{\mathrm{a}}=1.05 \mathrm{e} 11 \mathrm{~N} / \mathrm{m}^{2} & \mathrm{E}_{\mathrm{e}}=2.125 \mathrm{e} 11 \mathrm{~N} / \mathrm{m}^{2} & \mathrm{E}_{\mathrm{c}}=1.1 \mathrm{e} 11 \mathrm{~N} / \mathrm{m}^{2} & 6.569 \mu \mathrm{m} & 6.520 \mu \mathrm{m} \\ \text { Cell Radius }=12.5 \mathrm{~mm} \quad \text { Applied Pressure }=50 \mathrm{kPa} & & \end{array}$

Out-of-Plane Displacement at

$$
\text { Center } r=0
$$

A combination of the A, B and C coefficients is defined as following.

$$
A_{o}=\frac{A}{A \cdot C-B^{2}}
$$

The change of slope with the applied pressure can be obtained by differentiating Eq. (4. 45 ) with respect to the radius $r$.

$$
\frac{\partial W}{\partial r} / p=\frac{A_{o}}{16}\left(r^{3}-r \cdot r_{o}^{2}\right)
$$

The three-layered thin membrane analytical solution is validated using finite element analysis code ABAQUS ${ }^{\mathrm{TM}}$ and MSC-Marc ${ }^{\mathrm{TM}}$, as shown in Table 4-2. Eq. (4. 59) also provides the location of the maximum change of slope per unit applied pressure. It is at $1 / \sqrt{3}$ of the normalized radius of the button cell from the center. For this research, test results are conducted on this location. 


\subsubsection{Boundary Condition Correction Factor}

In practical SOFC button cell testing, the button cell periphery is not clamped but relatively free to rotate similar to a simply supported circular plate. This requires a correction factor to be included in Eq. (4. 59). By comparing the analytical solution of a clamped and simply supported single layer circular plate under uniform pressure [85], it is deduced that the slope of the simply supported plate can be obtained from the slope of the clamped plate by multiplying it with the following correction factor $\mathrm{C}_{\mathrm{o}}$.

$$
C_{o}=\left[\left(r / r_{o}\right)^{2}-(3+v) /(1+v)\right]\left[1-\left(r / r_{o}\right)^{2}\right]^{-1}
$$

This correction factor is applicable only to the experimental setup where button cell is secured similar to the Probostat ${ }^{\mathrm{TM}}$. At the location of maximum slope change with applied pressure, assuming Poisson ratio of $v=0.3$, the correction factor from Eq. (4. 60) is calculated to be $C_{o}=3.31$. From FE analysis of the multi layered model (Figure 4-13) it is estimated that the correction factor is in the range of 3.39 to 3.55. For modeling purposes, a correction factor of 3.5 is assumed. Eq. (4. 59) can now be written in the following form.

$$
\frac{\partial W}{\partial r} / p=C_{o} \frac{A_{o}}{16}\left(r^{3}-r \cdot r_{o}^{2}\right)
$$

From the proposed experimental surface deformation measurement, anode material Young's modulus can then be determined from the three-layer model. Thus, a test methodology of long-time monitoring of SOFC anode structural integrity under simulated coal syngas can be carried out. If the change in Young's modulus of electrolyte and cathode is negligible as compare to change in anode Young's modulus, the change in anode effective Young's modulus can be estimated by using Eqs. (4. 56)-(4. 61), and by determining the change of slope of the button cell experimentally, and thus estimate the mechanical degradation of the anode material. 


\subsubsection{Contaminant Structural Degradation Parameter $\left(a_{1}\right)$}

Contaminant structural degradation parameter $\left(a_{1}\right)$ is a parameter that quantifies the anode structural degradation due to contaminant interaction with the anode as explained in section 4.1. The parameter is to be determined with the help of experimental set up that is especially designed for this purpose as shown in Figure 4-10. The cells are exposed to different concentration of $\mathrm{PH}_{3}$ and anode surface deformation is determined experimentally at different time intervals as described in section 4.4.1.1. Comparing the experimental results in the analytical Eq. (4. 56)-(4. 61), the parameter is determined.

\subsubsection{Temperature Dependent Material Properties}

Since SOFCs operate at high temperatures $\left(600{ }^{\circ} \mathrm{C}-800{ }^{\circ} \mathrm{C}\right)$, material properties at such high temperatures are required for better simulation results. Temperature dependent material properties for the PEN structure are primarily taken from the MENTAT-FC GUI [87-88] and ref [89] material database although MENTAT-FC software is not utilized in these simulations.

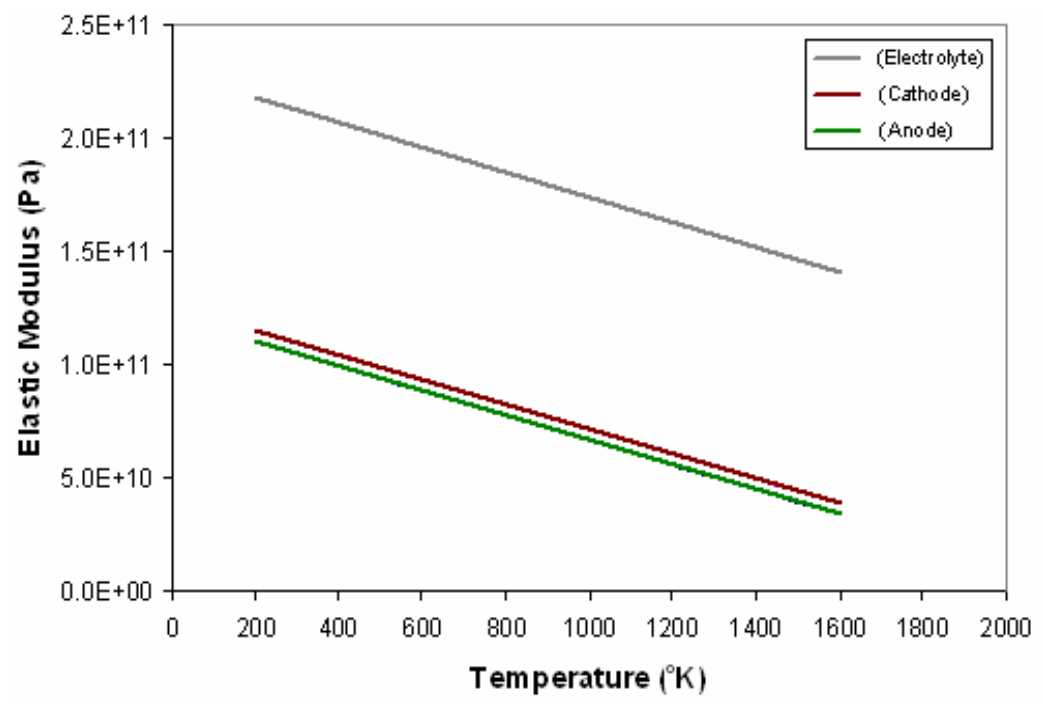

Figure 4-14 Temperature dependent Young's modulus of anode, cathode and electrolyte 
As shown in Figure 4-14, the stiffness of anode, electrolyte and cathode vary linearly with temperature and the relations can be represented mathematically by the following equations, respectively.

$$
\begin{aligned}
& E_{a}=1.213 \times 10^{11}-5.460 \times 10^{7} \cdot T \\
& E_{e}=2.289 \times 10^{11}-5.460 \times 10^{7} \cdot T \\
& E_{c}=1.263 \times 10^{11}-5.460 \times 10^{7} \cdot T
\end{aligned}
$$

Pihlatie et al. [39] used an impulse excitation technique (IET), to determine the elastic modulus and specific damping of $\mathrm{Ni} / \mathrm{NiO}-\mathrm{YSZ}$ composites in connection with the SOFCs applications. For NiO-YSZ, they observed an initial increase of the stiffness at $250^{\circ} \mathrm{C}$ and then a linear decrease with the temperature. In the reduced state (Ni-YSZ), the elastic modulus was found to linearly decrease with the temperature increase. The initial reduction temperature has no effect on the Young's modulus of the Ni-YSZ [39].

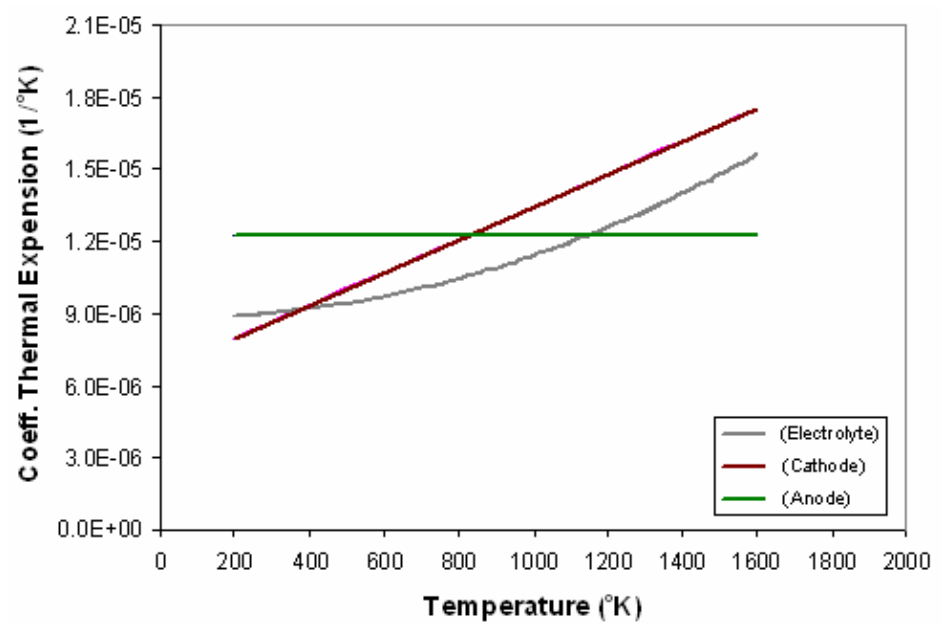

Figure 4-15 Temperature dependent coefficient of thermal expansion of anode, cathode and electrolyte 
Similar to Young's modulus, the coefficient of thermal expansion (CTE) of cathode and electrolyte also vary with temperature as shown in Figure 4-15. For anode material, the CTE does not change with temperature.

\subsubsection{Porosity Dependent Material Properties}

Porosity is a measure of the void space in a material. The porosity of a porous medium such as ceramics or rock describes the fraction of void space in the material compared to the total volume, as defined by the following equation:

$$
p=\frac{V_{v}}{V_{t}}
$$

where $\mathrm{p}$ is the material porosity, $\mathrm{V}_{\mathrm{v}}$ is the volume of void space and $\mathrm{V}_{\mathrm{t}}$ is the total volume of the material including void and solid parts. The porosity of a sample (e.g. anode material) can be estimated directly from the mass (m) of the sample in the air and the geometrical volume of the sample [38], as shown in the following equation:

$$
\begin{aligned}
& V_{v}=V_{t}-\frac{m}{\rho} \\
& p=1-\frac{m}{\rho V_{t}}
\end{aligned}
$$

where $\rho$ is the density of the anode material calculated from its composition. Numerous expressions for the relations between Young's modulus and porosity of a material have been proposed in literature [90]. However, it has long been accepted that the Young's modulus can be represented by the following empirical relation in terms of the material porosity and a material constant $[90,91]$ :

$$
E=E_{o} \exp (-a p)
$$


where $p$ is the material porosity, $\mathrm{E}_{\mathrm{o}}$ is the Young's modulus at zero porosity, and a is a material constant. Moreover, Rice [92, 93] showed that Eq. (4. 68) can also be applied to correlate the strength-porosity for a wide range of materials for which the strength and elastic modulus decrease proportionally with porosity according to the minimum solid area model. Hence the strength-porosity relation can be expressed as following:

$$
S=S_{o} \exp (-b p)
$$

where $p$ is the material porosity, $S_{o}$ is the material strength at zero porosity, and $b$ is a material constant. Eq. (4. 68) and Eq. (4. 69) are known as the Ryshkewitch-Duckworth equation and Spriggs' equation [91, 94] respectively, and generate a straight line when plotted on a semi logarithmic paper. Pihlatie et al. [39] found a linear relation between elastic modulus and porosity of the $\mathrm{Ni} / \mathrm{NiO}-\mathrm{YSZ}$. Wang [91] proposed a quadratic exponent correlation, Eq. (4. 70), between Young's modulus and porosity of a material and claimed that it is quite satisfactory over a wide range of porosity.

$$
E=E_{o} \exp \left[-\left(a p+b p^{2}\right)\right]
$$

Kupkova [90] derived a correlation, Eq. (4. 71), based on the connection between the sound velocity and elastic modulus by calculating the sound velocity as a function of porosity in a material:

$$
E=E_{o} \frac{1+a p+b p^{2}}{1+c p}
$$

where $\mathrm{a}, \mathrm{b}$, and c, are constants and independent of porosity, but dependent on the shape and size of the average pore as well as on the properties of the investigated material without pores. Radovic and Lara-Curzio [9] investigated the elastic modulus, biaxial strength and fracture toughness of unreduced (NiO-YSZ) and reduced (Ni-YSZ) anode material as function of porosity. They found that the mechanical properties of unreduced 
and reduced Ni-based anode materials depend strongly on the porosity as shown in Figure 4-16. They determined the anode sample elastic properties by impulse excitation (IE) using the commercially available Buzz-o-sonic1 software program.

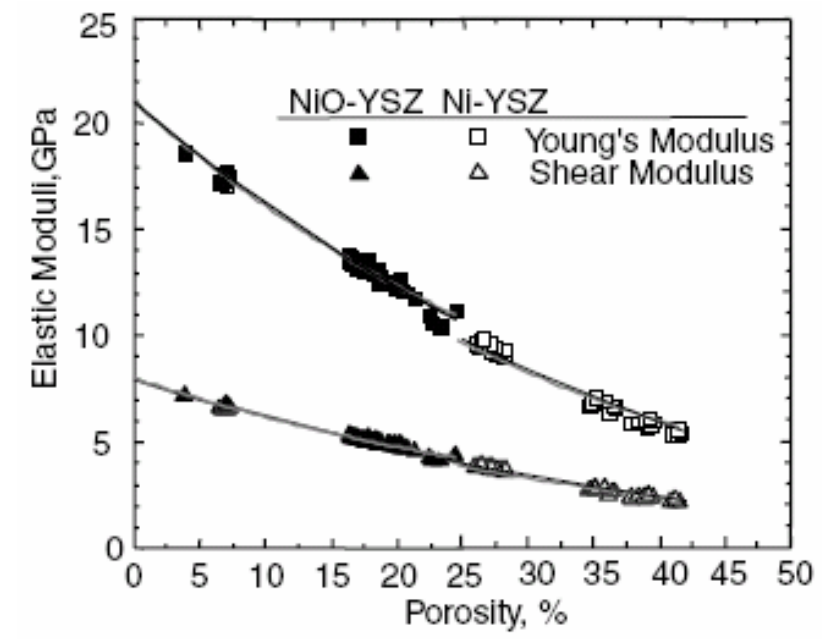

Figure 4-16 Young's $(E)$ and shear $(G)$ moduli of unreduced and reduced Ni-based anode as a function of porosity [9]

Young's modulus and shear modulus are determined by IE as a function of the porosity of unreduced and reduced anode materials as shown in Figure 4-16. They also indicate that the decrease in the elastic moduli during the reduction of NiO-YSZ anode is almost exclusively due to an increase in the Ni-YSZ anode porosity [95]. 
Table 4-3 Porosity dependent constant of NiO-YSZ and Ni-YSZ for exponential models [9]

Model

$\begin{array}{cccc} & & \text { NiO-YSZ } & \text { Ni-YSZ } \\ E=E_{o} \exp \left(-b_{E} p\right) & \mathrm{E}_{\mathrm{o}}, \mathrm{GPa} & 210.8 \pm 1.4 & 212.1 \pm 1.31 \\ G=G_{o} \exp \left(-b_{G} p\right) & \mathrm{b}_{\mathrm{E}} & 2.7 \pm 0.04 & 3.16 \pm 0.03 \\ & \mathrm{G}_{\mathrm{o}}, \mathrm{GPa} & 80.4 \pm 0.5 & 79.5 \pm 0.6 \\ & \mathrm{~b}_{\mathrm{G}} & 2.6 \pm 0.04 & 2.95 \pm 0.03\end{array}$

\subsubsection{Temperature and Porosity Dependent Young's Modulus}

Anode material stiffness and strength at different temperature and porosity can be described by combining the Eq. (4. 62) and Eq. (4. 68) as discussed above.

$$
E_{a}(T, p)=E_{o}(a-b T) \exp \left(-b_{E} p\right)
$$

Radovic and Lara-Curzio [9] determined the elastic modulus and biaxial strength of Ni-YSZ at zero porosity; the material constant $a=3.16 \pm 0.03$ and $b=5.12 \pm 0.67$. Eq. (4. 62), Eq. (4. 68) and Eq. (4. 69) can be combined in the normalized form to obtain stiffness and strength relations in terms of porosity and temperature in the form of Eq. (4. 73) and Eq. (4.74) respectively

$$
\begin{aligned}
& E_{a}(T, p)=E_{o}\left(1.1562-5.159 \times 10^{-4} T\right) \exp (-3.16 p) \\
& S(T, p)=S_{o}\left(1.1562-5.159 \times 10^{-4} T\right) \exp (-5.12 p)
\end{aligned}
$$


Table 4-4 Material Properties obtained from SECA database

\begin{tabular}{|c|c|c|c|c|}
\hline & $\begin{array}{l}\text { Density } \\
\left(\mathrm{Kg} / \mathrm{m}^{3}\right)\end{array}$ & $\begin{array}{l}\text { Conductivity } \\
\left(\mathrm{W} / \mathrm{m}-{ }^{\circ} \mathrm{K}\right)\end{array}$ & $\begin{array}{l}\text { Sp. Heat } \\
\left(\mathrm{J} / \mathrm{kg}_{-}{ }^{\mathrm{O}} \mathrm{K}\right)\end{array}$ & Poisson Ratio \\
\hline Anode & 4423.2 & 55.2 & 426.4 & 0.32 \\
\hline Electrolyte & 6050.0 & 2.0 & 400.0 & 0.31 \\
\hline Cathode & 2470.5 & 3.0 & 400.0 & 0.30 \\
\hline
\end{tabular}

\subsubsection{Degradation Threshold $\left(K_{o}\right) \&$ Hardening/Softening Variable (h)}

Material degradation evolution will only begin when the state of stress reaches a threshold value $\sigma_{\text {th }}$. The initial degradation threshold $\left(\mathrm{K}_{\mathrm{o}}\right)$ is a material parameter in the theory of degradation similar to the initial yield stress in the theory of elasticity as shown in Figure 4-17.

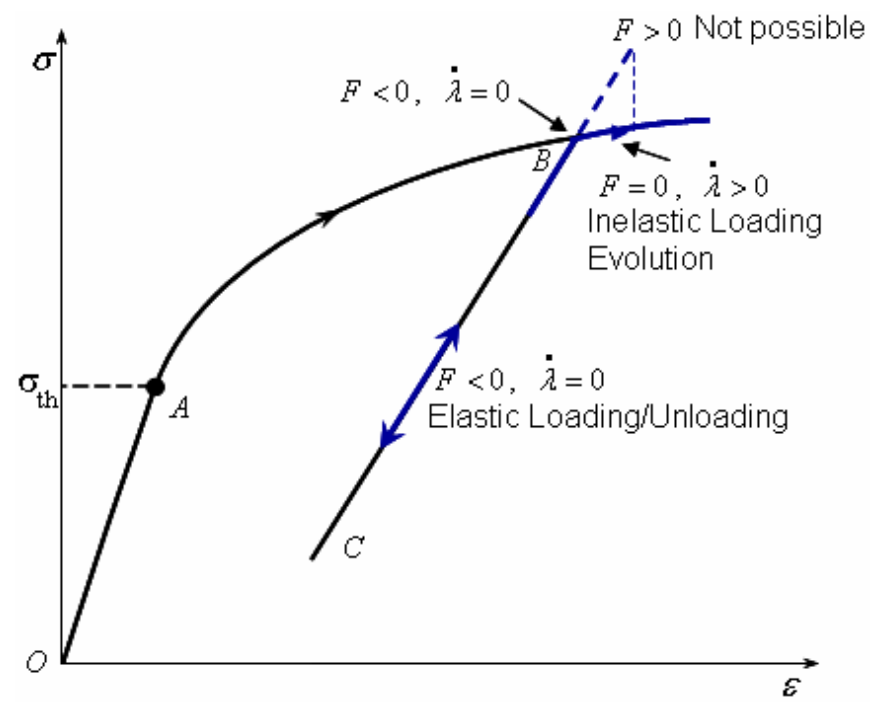

Figure 4-17 Determining the initial degradation threshold 
Degradation characteristics of the anode material may be degradation hardening or softening depending on the temperature. The proposed model formulation is used to predict the stress-strain relations of Ni-YSZ as a function of temperature and porosity, and the material parameters $\left(K_{o}\right.$ and $\left.h\right)$ are obtained with the help of a user-defined subroutine implemented in FEA as explained in section 5.2. 


\section{Chapter 5 MODEL IMPLEMENTATION AND VALIDATION}

\section{$5.1 \quad$ Introduction}

The proposed structure durability model is implemented in the finite element analysis software ABAQUS ${ }^{\mathrm{TM}}$ (Abaqus Inc., Providence, RI) to predict anode material behavior during long-term operation. User defined mechanical material behavior in ABAQUS $^{\mathrm{TM}}$ is provided by means of an interface whereby a constitutive model can be added to the library. It requires that a constitutive model be programmed in a userdefined subroutine UMAT (ABAQUS/Standard). While ABAQUS ${ }^{\mathrm{TM}}$ performs the standard finite element analysis, the subroutine governs the material behavior during different stages of loading. The feature is very general and powerful but its use is not a routine exercise and requires considerable effort and expertise [96]. A user subroutine is called at each material point for iterations of every increment. The subroutine is provided with the material state at the start of the increment i.e. stress, solution-dependent state variables, temperature, and any predefined field variables along with the increments in temperature, predefined state variables, strain, and time.

In addition to updating the stresses and the solution-dependent state variables to their values at the end of the increment, the subroutine must also provide the material Jacobian matrix $\partial \triangle \sigma / \partial \triangle \varepsilon$ for the mechanical constitutive model. This matrix will also depend on the integration scheme used if the constitutive model is in rate form and is integrated numerically in the subroutine [96]. An outline of the subroutine is shown in Figure 5-1. 


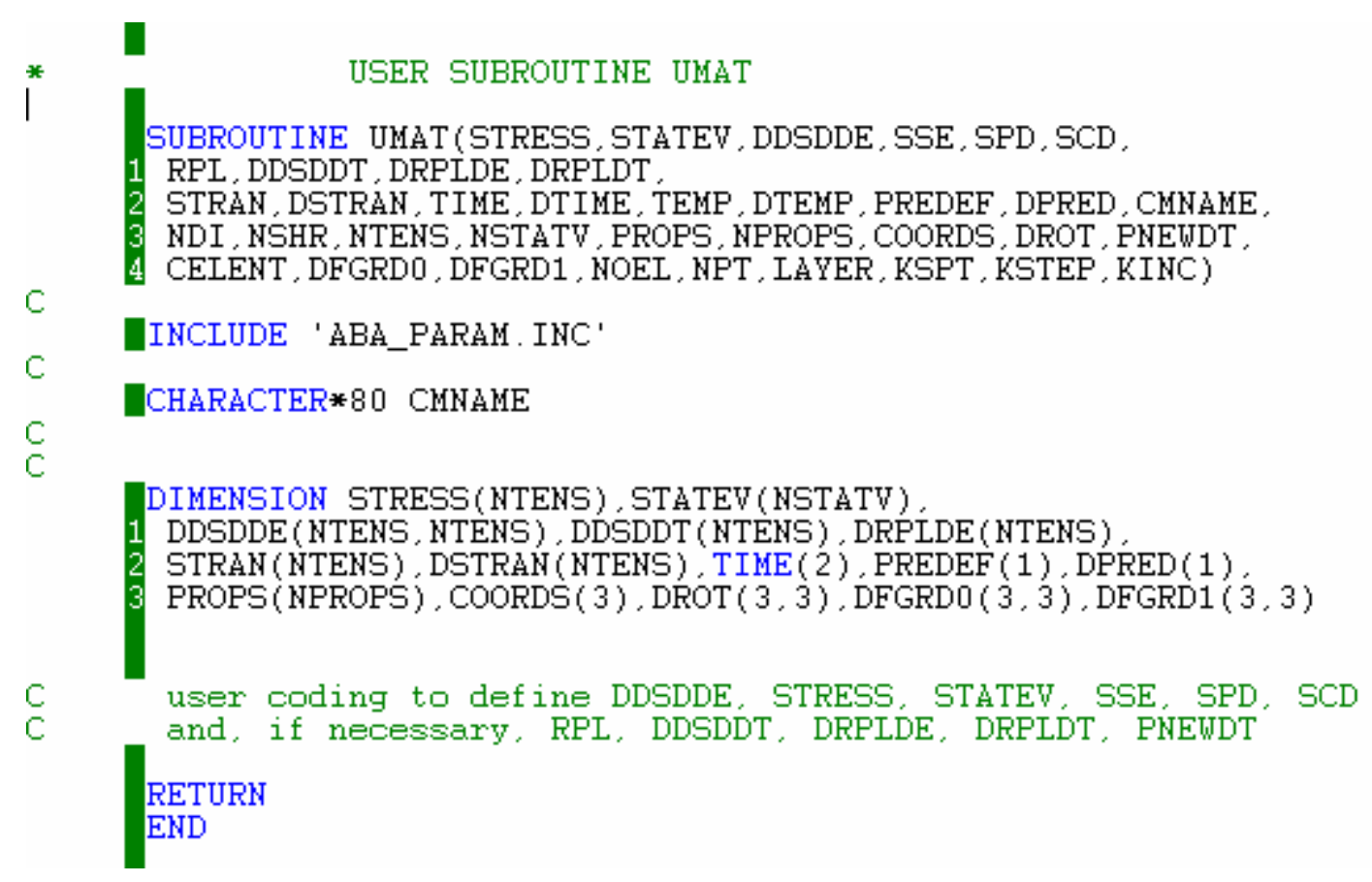

Figure 5-1 Outline of UMAT in ABAQUS ${ }^{T M}$

Further detail can be obtained from [96].

In order to implement the proposed durability model in $\mathrm{ABAQUS}{ }^{\mathrm{TM}}$, we have to provide the cell temperature field, temperature dependent material properties, degradation threshold and hardening/softening variable. We also need to define a degradation hardening parameter, its associated variable, degradation variables, Jacobian matrix and the state variables so that these can be recovered from the previous increment. If the degradation conditions are fulfilled, the subroutine would update the state variables, state of stress, and the Jacobian matrix for the next increment. 


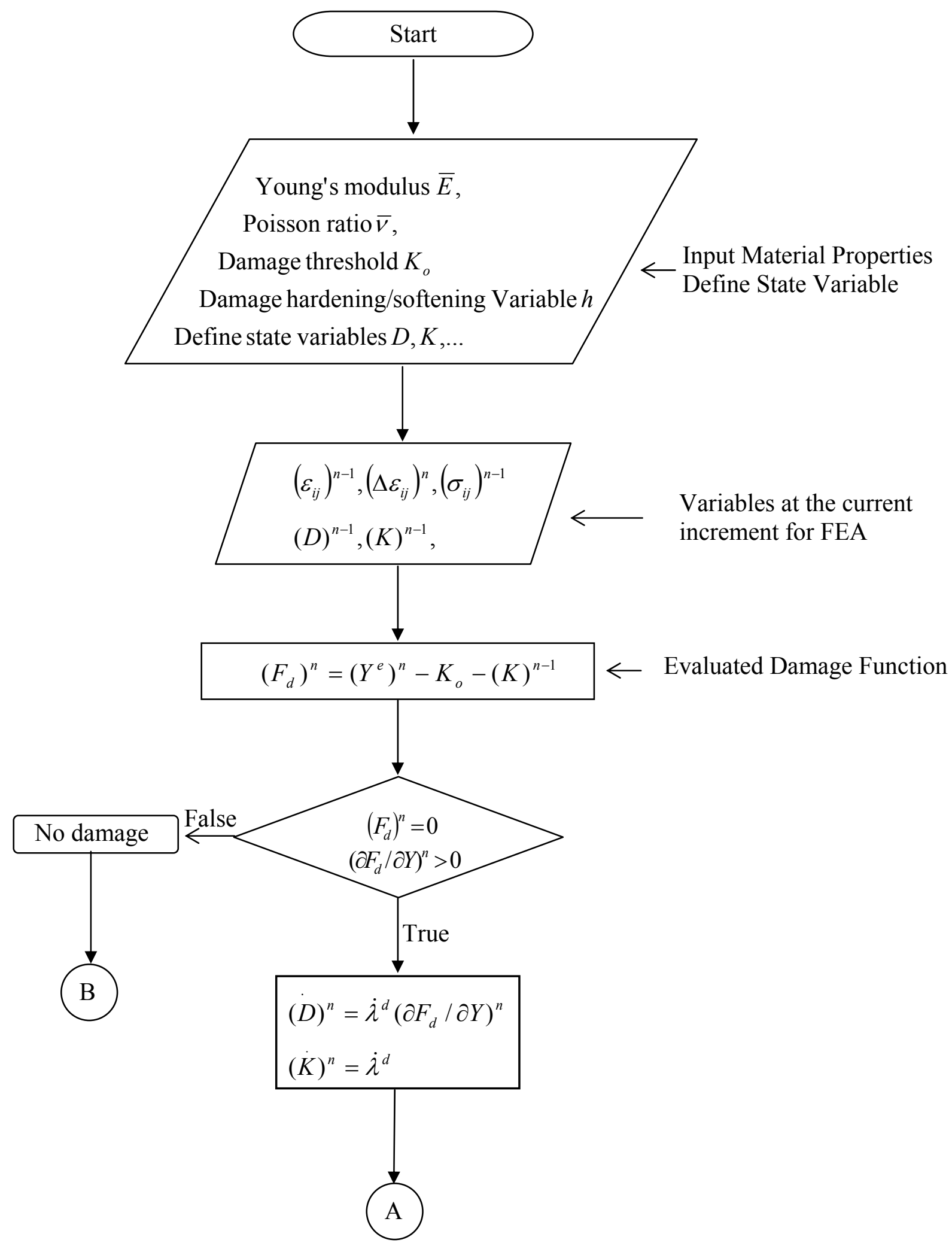




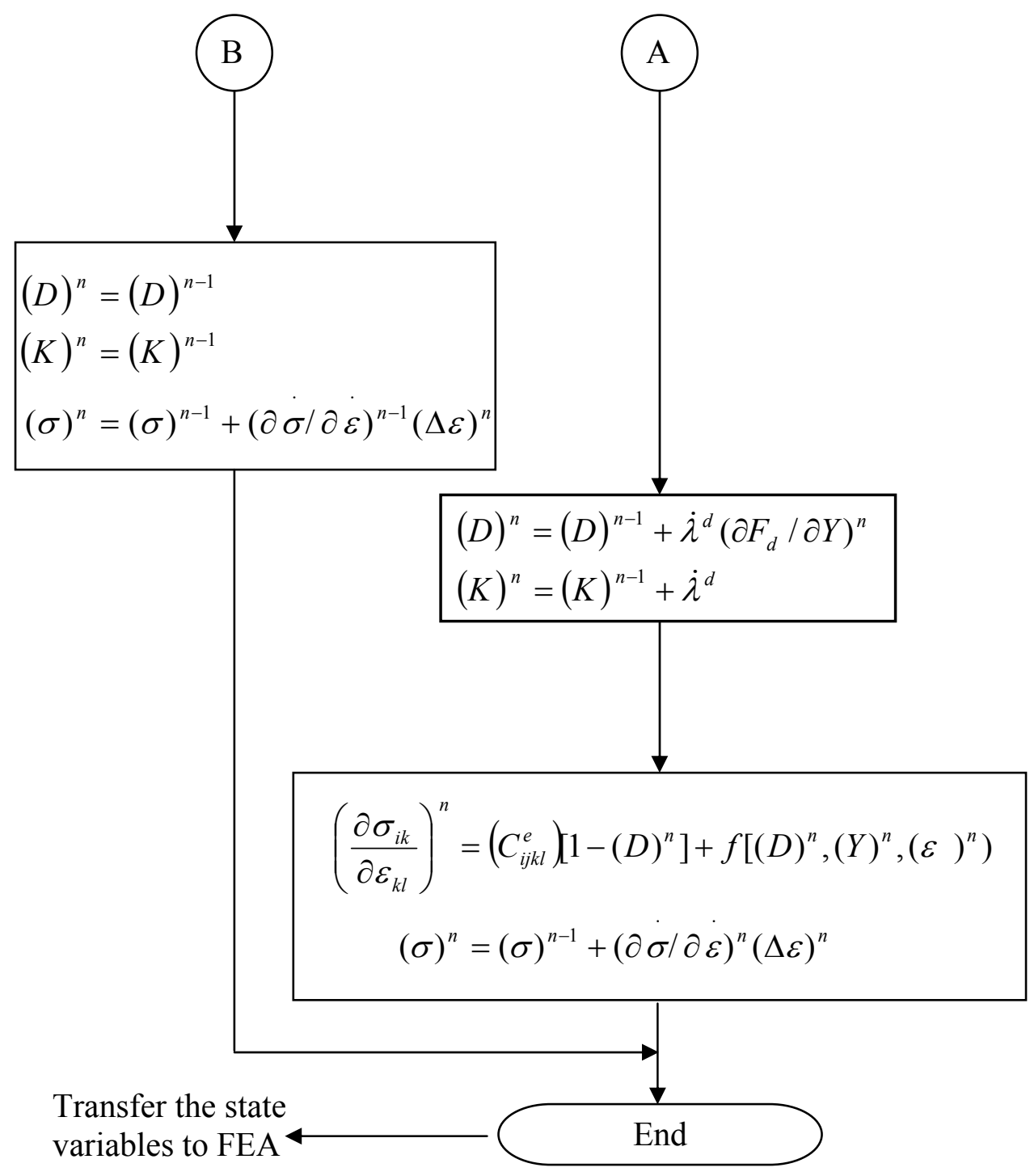

Figure 5-2 Flow chart of the subroutine implementation 


\subsection{Model Verification and Validation}

Validity of the proposed durability model is carried out by comparing the model results to the available experimental results and other models results for the same set of material parameters. The validation of the model is divided in the following sections.

\subsubsection{Validation of Constitutive Relations}

The constitutive relations of the proposed durability model are validated by comparing the model results with experimental results [97] and an independent model [82] for elastic brittle material. The material parameters used to validate the model are given in Table 5-1.

Table 5-1 Material parameters for an elastic brittle material [82]

$\begin{array}{cccc}\begin{array}{c}\text { Young's Modulus (E) } \\ (\mathrm{GPa})\end{array} & \text { Poisson Ratio (v) } & \begin{array}{c}\text { Damage Threshold (Ko) } \\ (\mathrm{MPa})\end{array} & \begin{array}{c}\text { Softening Hardening } \\ \text { variable (h) }\end{array} \\ 21.4 & 0.2 & 2.6 \times 10^{-3} & 0.04\end{array}$

In order to validate the elastic brittle model, a column specimen is analyzed using FEA under a uniaxial state of stress and the results are compared with those of the experimental [97] and model results [82] as shown in Figure 5-3 to Figure 5-7. 


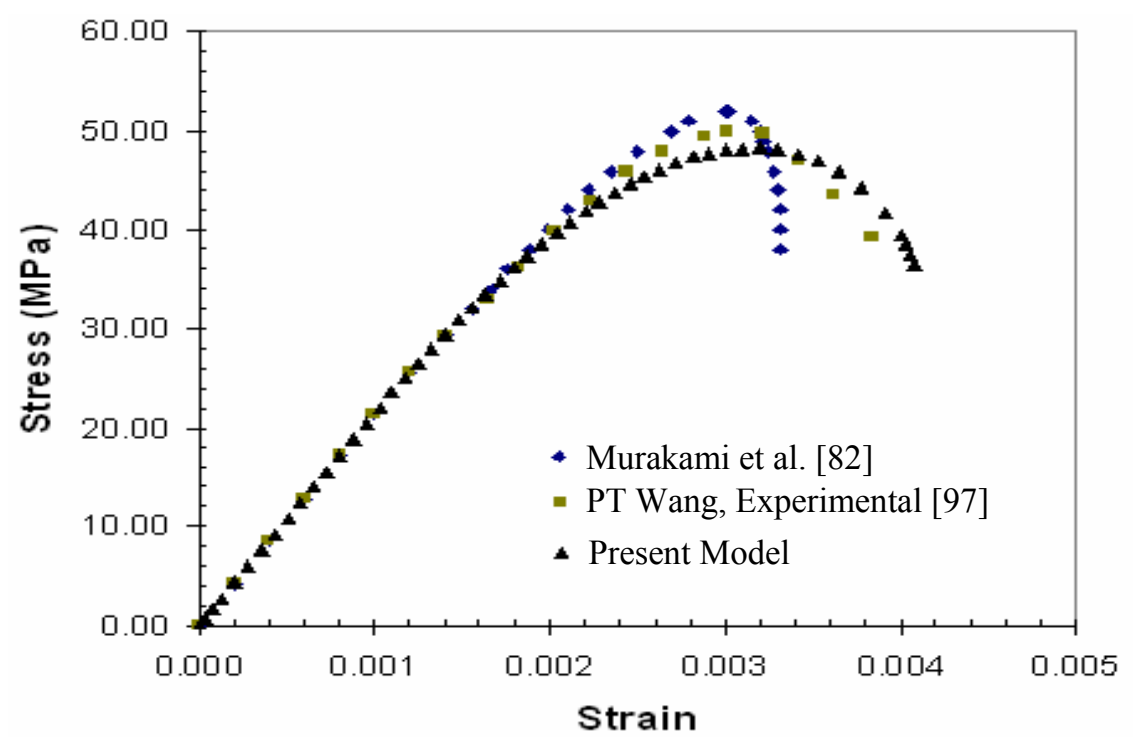

Figure 5-3 Stress-Strain relation of an elastic brittle material

Figure 5-3 represents the stress-strain relation of an elastic brittle material under compressive stress. As can be seen, the constitutive and evolution formulation simulate the experimental results with good accuracy for an elastic brittle material. The results are within $4 \%$ of error between the model and the experimental results.

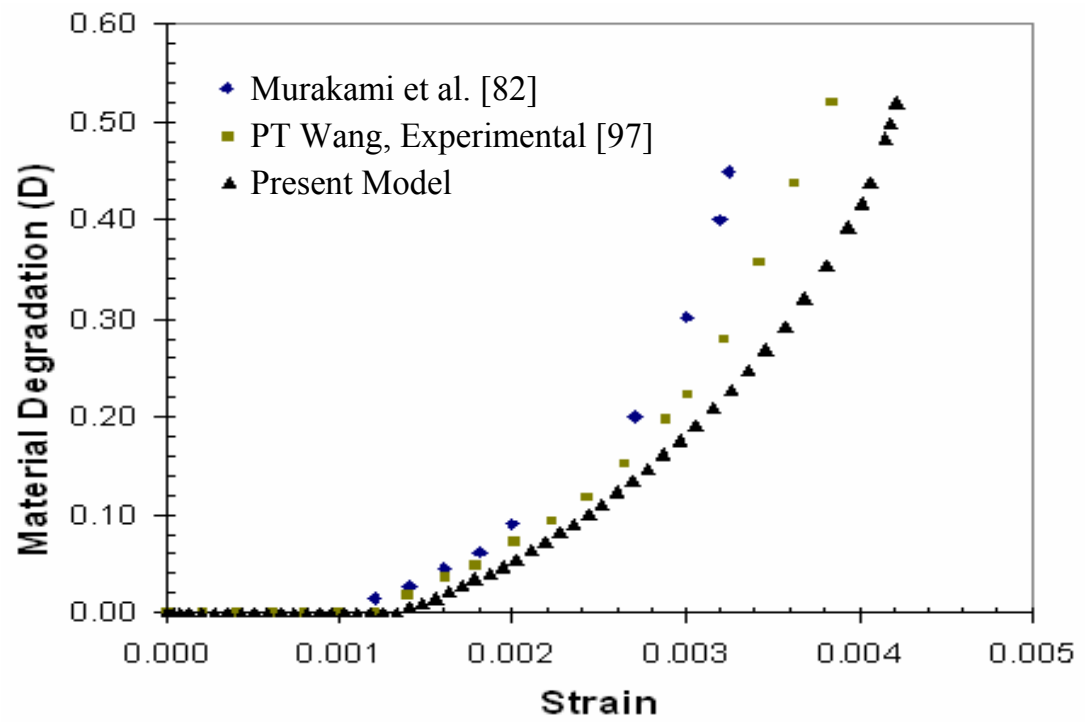

Figure 5-4 Damage-Strain relation of an elastic brittle material 


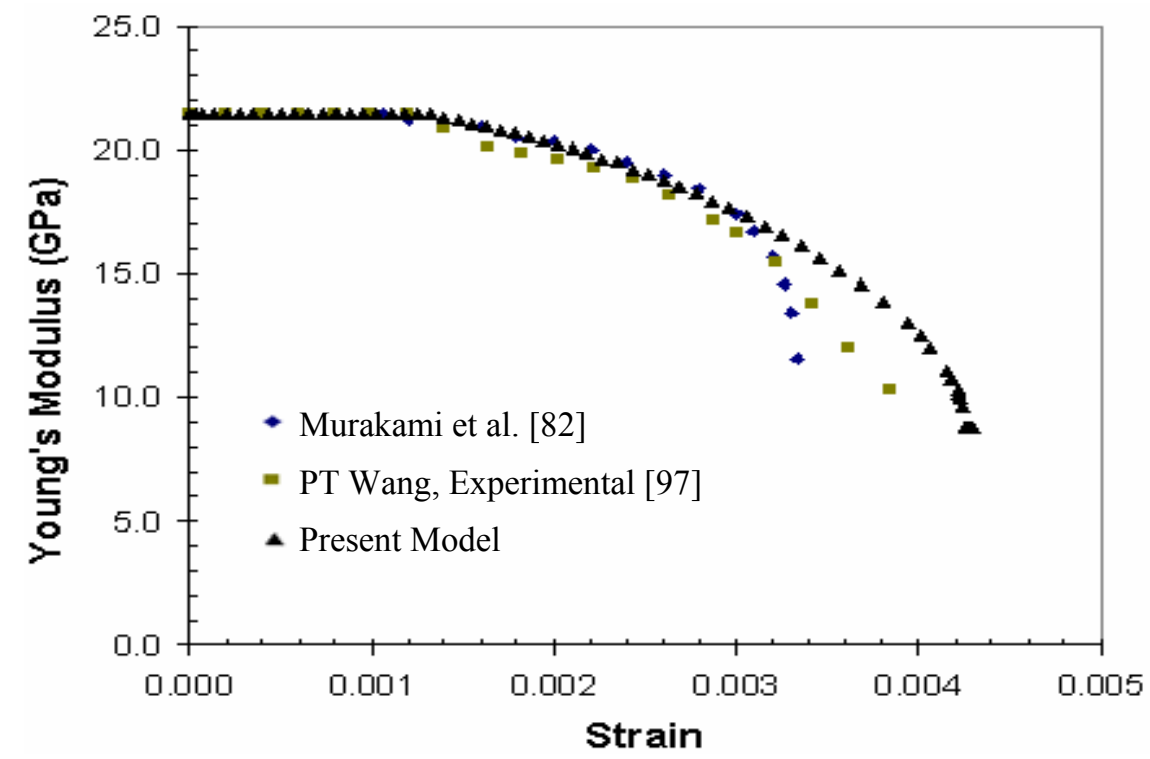

Figure 5-5 Predicted results of Young's modulus with strain

Figure 5-4 and Figure 5-5 represent the evolution of material degradation and the change in material stiffness with strain. A good agreement is observed between the model results and the experiment results at the lower strain value. The deviation at the higher strain could be due the large defomation or anisotropy developed in the material due to the material degradation called degradation induced anisotropy.

In order to differentiate material degradation due to compressive and tensile loading, a modified elastic strain tensor $[82,98]$ is employed as following.

$$
\bar{\varepsilon}_{i}^{e}=<\varepsilon_{i}^{e}>-\zeta<-\varepsilon_{i}^{e}>
$$

where $<>$ represents Macaulay brackets, $\varepsilon_{\mathrm{i}}$ is the principal strain, and $\zeta$ is a material constant that describes the crack closure effects; it is assumed to be 0.1 [82] for elastic brittle materials. 


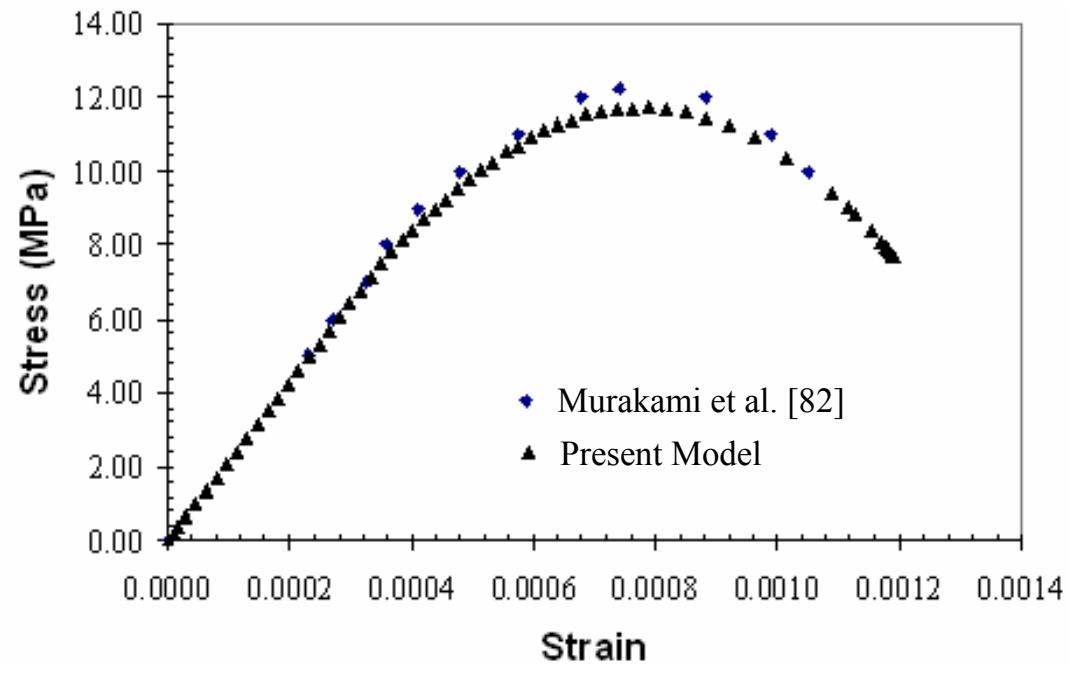

Figure 5-6 Stress-Strain relation under uniaxial tension

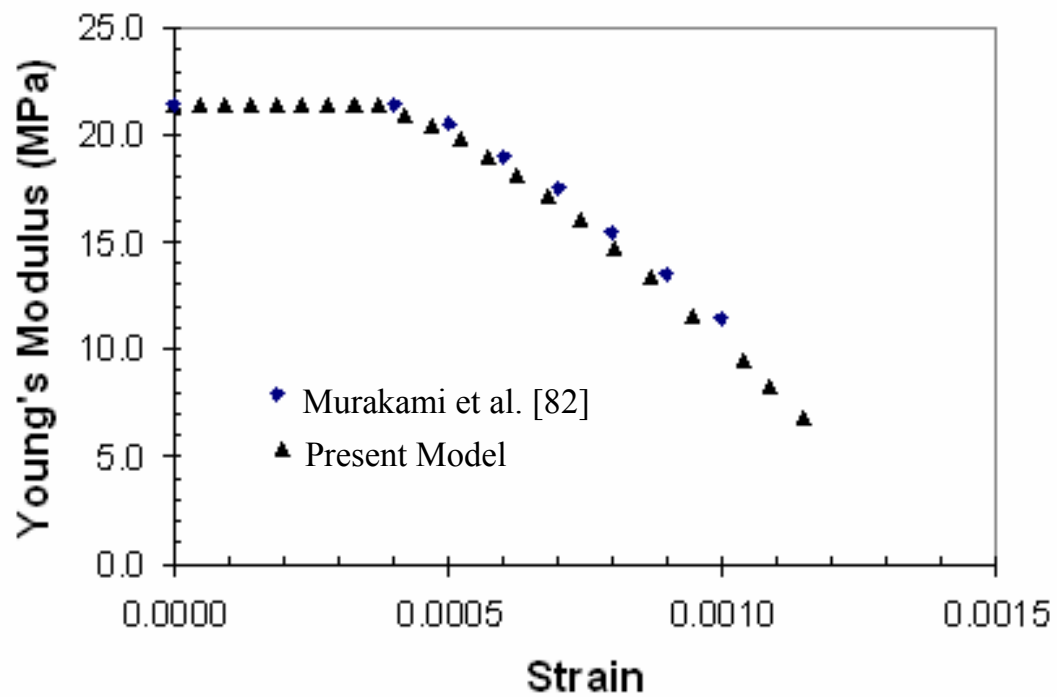

Figure 5-7 Predicted results of Young's modulus under uniaxial tension

There are theories available in the literature that have considered different formulation and different material parameters for tensile and compressive behavior of 
elastic brittle materials. In the proposed model we described the tensile and compressive behavior of the material using the same set of equations and material parameters by a modified strain tensor as shown in Eq. (5. 1). Figure 5-6 and Figure 5-7 show the stressstrain curve and change in material stiffness under uniaxial tensile stress using the same materials parameters as shown in Table 5-1. The degradation evolution equations are the same as those under compression. However, the strain energy release rate under uniaxial tension is different as compared to compression. Therefore, different material degradation is observed under these two conditions. 


\subsubsection{Predicted Stress-Strain Relations for Ni-YSZ}

From room to operating temperature, SOFC anode material (Ni-YSZ) behaves as an elastic brittle material [81]. Likewise, F. Mora et al. [99] found that the deformation behavior of an anode-supported bilayer consisting of Ni-YSZ substrate and YSZ layer is controlled by the deformation of the nickel phase in the temperature range of $1000{ }^{\circ} \mathrm{C}-$ $1200{ }^{\circ} \mathrm{C}$, however, anode-supported bilayer behaves as brittle material below $1100{ }^{\circ} \mathrm{C}$ [99].

After the model validation, the model formulation is used to predict the stress-strain relations of Ni-YSZ as a function of temperature and porosity. Additionally, some of the material parameters are obtained with the help of a user-defined subroutine implemented in FEA. At room temperature, the average strength of an anode-supported PEN is about $187 \mathrm{MPa}$ as measured by a ball-on-ring biaxial flexure test [89].

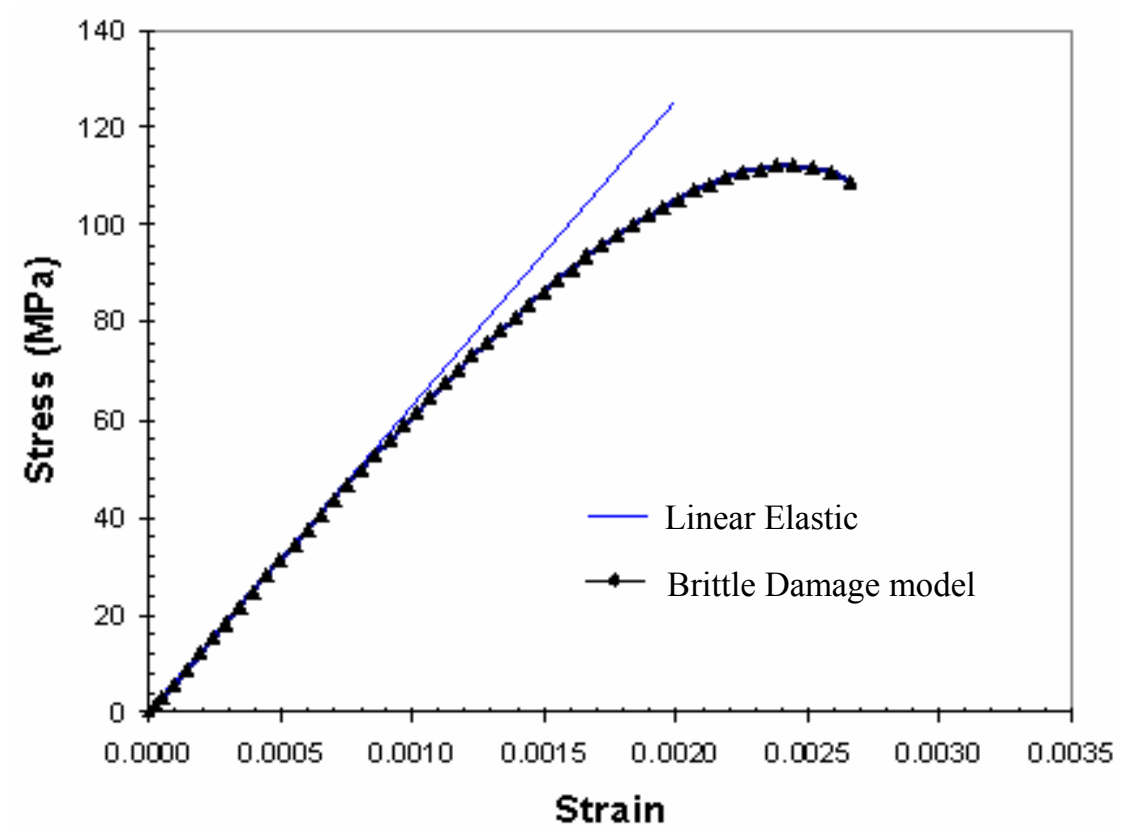

Figure 5-8 Predicted stress-strain curve of Ni-YSZ at $800^{\circ} \mathrm{C}$ 
Based on the decrease in the fracture stress of an oxidized anode at $800{ }^{\circ} \mathrm{C}, \mathrm{C} . \mathrm{K}$ Lin et al. [81] suggested that the strength of PEN would decreased from $187 \mathrm{MPa}$ at room temperature to $112 \mathrm{MPa}$ at $800{ }^{\circ} \mathrm{C}$. At $800{ }^{\circ} \mathrm{C}$ and $25 \%$ porosity, the average elastic modulus and strength of Ni-YSZ are respectively calculated from Eq. (4. 73) and Eq. (4. 74) to be $62.72 \mathrm{GPa}$ and $112.20 \mathrm{MPa}$ respectively. A predicted stress-strain relation obtained under these conditions is shown in Figure 5-8. The degradation threshold and degradation hardening/softening variables are calculated to be $0.0043 \mathrm{MPa}$ and 0.053 respectively with the help of a user defined subroutine.

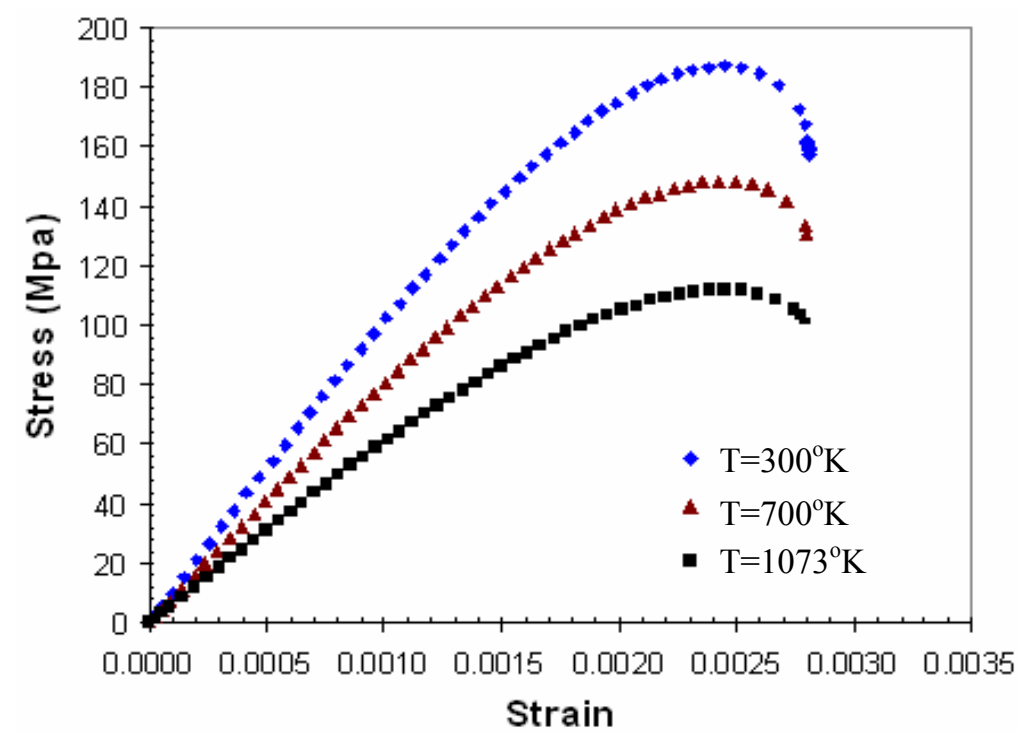

Figure 5-9 Predicted stress-strain curve of Ni-YSZ at $300^{\circ} \mathrm{K}, 700^{\circ} \mathrm{K}$, and $1073^{\circ} \mathrm{K}$

Eq. (4. 73) and Eq. (4. 74) are incorporated in the model with the help of a userdefined subroutine to predict stress-strain relations as a function of temperature and porosity. The material parameters are also obtained from finite element analysis with the help of a user defined subroutine. Figure 5-9 depicts the stress-strain relations of Ni-YSZ at various temperatures at a constant porosity of $25 \%$. It is found that at the same porosity, the material degradation depends on the level of strain regardless of the temperature but the material fails at lower stress level at high temperature. This 
paradoxical phenomenon can be explained with the help of strain energy release rate i.e. Eq.(4. 22): at higher temperature, lower load is required to produce a specified level of strain than at lower temperature.

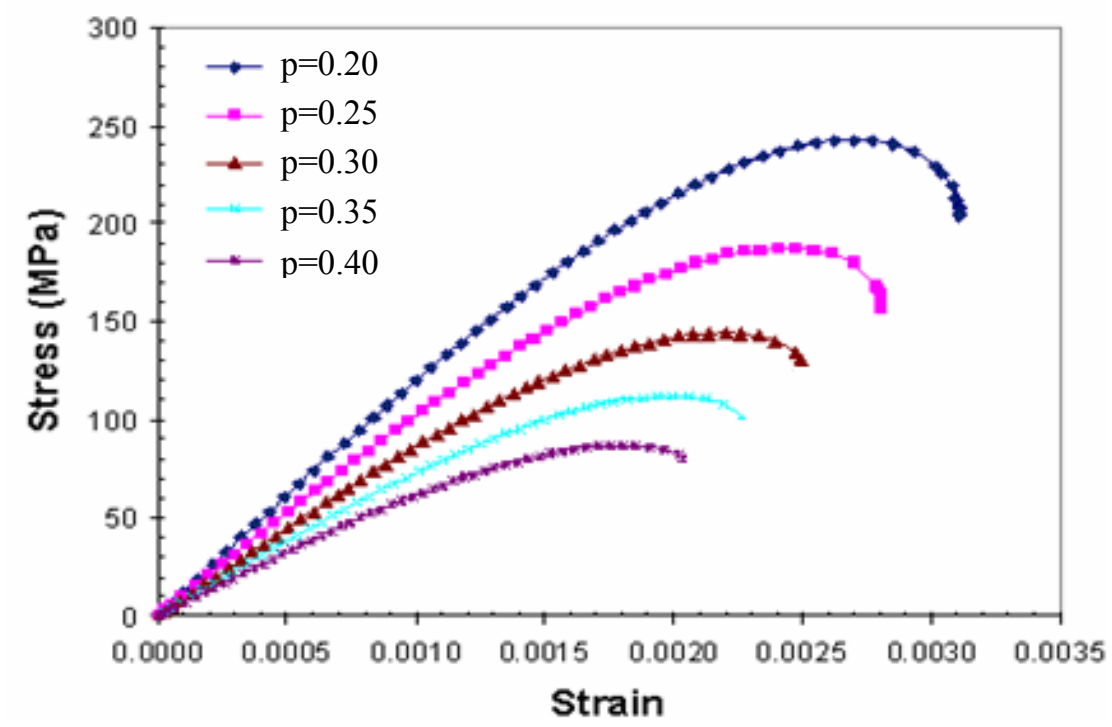

Figure 5-10 Predicted stress-strain curve of Ni-YSZ at $300^{\circ} \mathrm{K}$ for different porosities

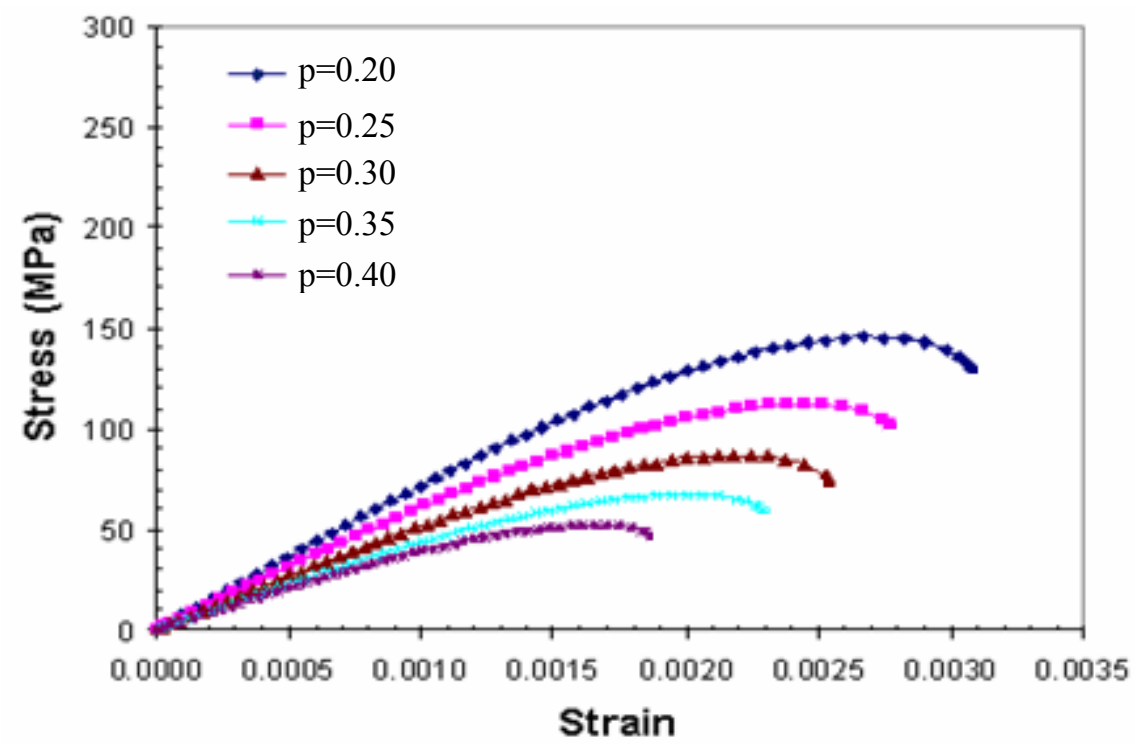

Figure 5-11 Predicted stress-strain curve of Ni-YSZ at $1073^{\circ} \mathrm{K}$ for different porosities 
Figure 5-10 and Figure 5-11 predict the stress-strain relations of Ni-YSZ at room temperature and $1073^{\circ} \mathrm{K}$ respectively, as a function of material porosity. It can be seen that the material degrades and fails at a lower level of strain at higher porosity if the temperature is kept constant. This phenomenon can be explained with the help of strain energy release rate i.e. Eq. (4. 22). As the material porosity increases, it requires a lower level of strain to initiate and coalescence microcracks in the material. Thus, lower load causes higher material degradation at higher material porosity.

Table 5-2 Predicted material parameters for Ni-YSZ at different temperatures and porosities

\begin{tabular}{|c|c|c|c|c|c|}
\hline Temperature & p (\%) & E (GPa) & S (MPa) & $\mathrm{K}_{\mathbf{0}}$ (MPa) & $\mathbf{h}$ \\
\hline \multirow{5}{*}{$\begin{array}{c}\text { Ambient } \\
\text { Temperature }\end{array}$} & 20 & 122.88 & 241.58 & 0.0070 & 0.128 \\
\hline & 25 & 104.93 & 187.00 & 0.0060 & 0.089 \\
\hline & 30 & 89.56 & 144.78 & 0.0050 & 0.061 \\
\hline & 35 & 76.50 & 112.08 & 0.0045 & 0.043 \\
\hline & 40 & 65.32 & 86.76 & 0.0035 & 0.030 \\
\hline \multirow{5}{*}{$1073^{\circ} \mathrm{K}$} & 20 & 73.46 & 144.95 & 0.0057 & 0.076 \\
\hline & 25 & 62.72 & 112.20 & 0.0043 & 0.053 \\
\hline & 30 & 53.56 & 86.54 & 0.0030 & 0.037 \\
\hline & 35 & 45.72 & 67.00 & 0.0023 & 0.026 \\
\hline & 40 & 39.05 & 51.87 & 0.0016 & 0.018 \\
\hline
\end{tabular}

The material parameters obtained from these relations are shown in Table 5-2. These parameters are used in the user-defined subroutine to predict the anode structural degradation under respective conditions. 


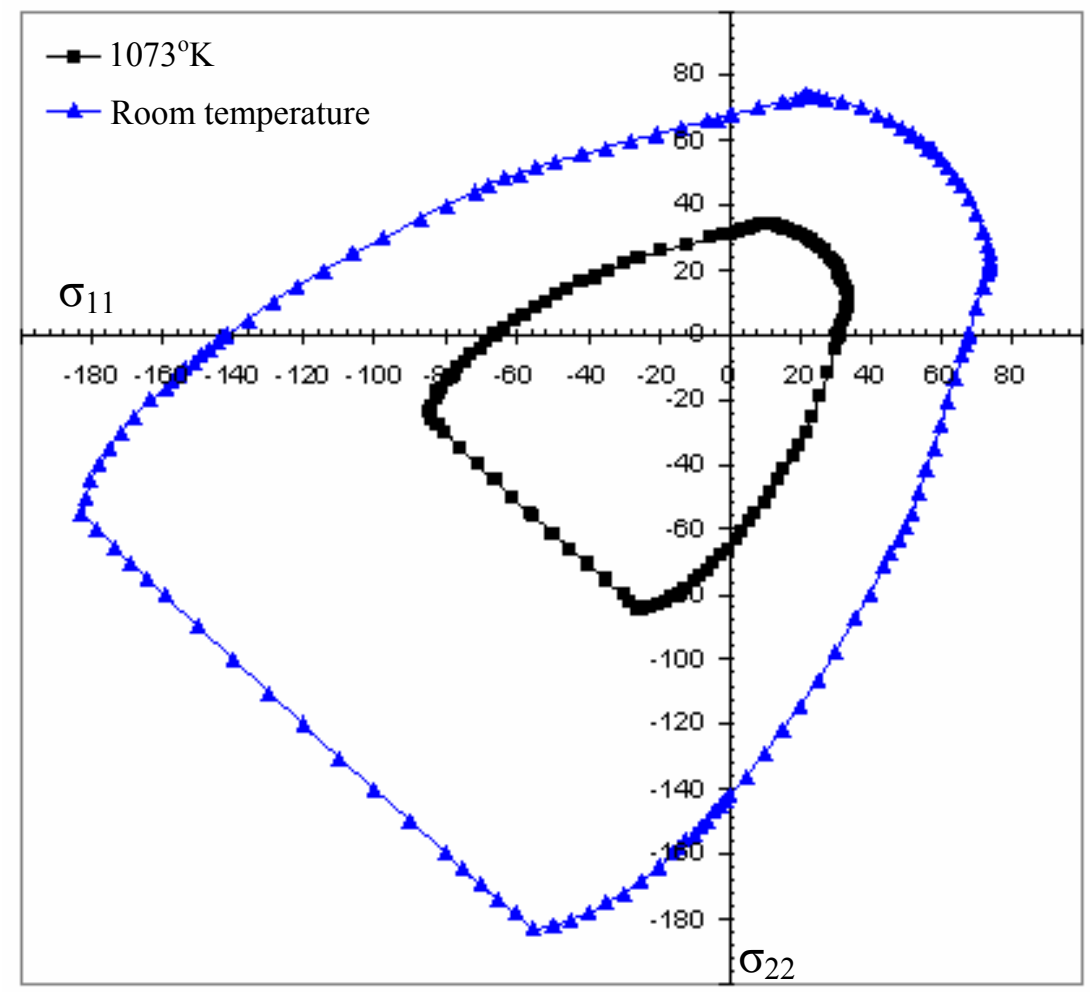

Figure 5-12 Ni-YSZ predicted initial damage surface biaxial stress space

Using these parameters, Ni-YSZ initial degradation surfaces are predicted as shown in Figure 5-12 at $1073{ }^{\circ} \mathrm{K}$ and room temperature in biaxial stress space $\left(\sigma_{33}\right)$. Similar surfaces can be obtained for $\sigma_{33} \neq 0$ in three dimensional stress spaces. The degradation surface defines the boundary of the current elastic region. If the state of the stress lies within the boundary, no damage evolution will take place. Conversely, if the state of the stress happens to be on the boundary of the surface and tends to move outward from the elastic region, the damage will further accumulate. It can be concluded from Figure 5-12 that the anode material starts to degrade well before the state of stress reached the material failure strength. 


\subsubsection{Verification of Contaminant Penetration Depth}

Phosphorus (P) is a major contaminant that interacts strongly with nickel contained in the SOFC anode and degrades its electrochemical performance and structural properties during long term operation [41, 60]. It forms secondary phases with the anode material which cause grain growth and microcrack formation within the anode support [60] as shown in Figure 2-22.

A recent study [60] at the Pacific Northwest National Laboratory (PNNL) on the interaction of phosphine $\left(\mathrm{PH}_{3}\right)$ with SOFC anode showed a correlation of the penetration depth with the contaminant concentration and the duration of exposure, as shown in Figure 4-8.

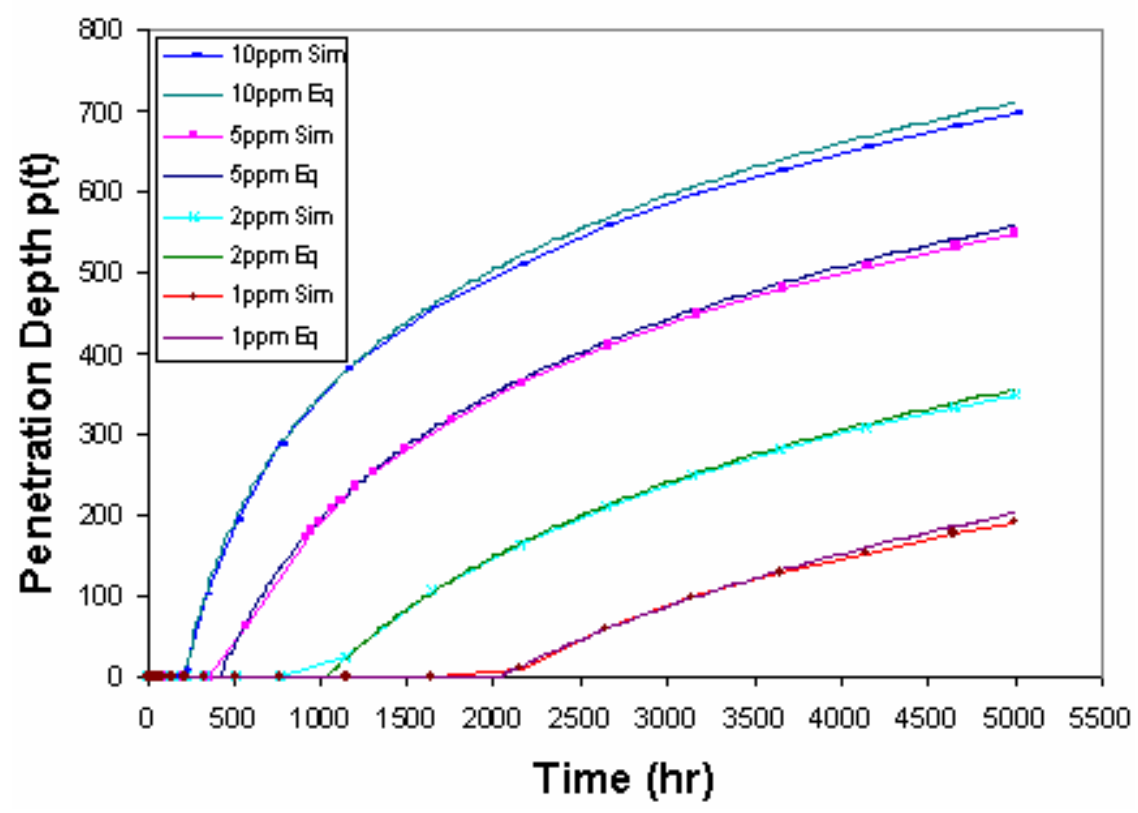

Figure 5-13 Comparison of penetration depth under different concentration of $\mathrm{PH}_{3}$

For the anode supported cell, the penetration curves shown in Figure 4-8 can be represented by the Eqs. (4. 52) and (4. 53) as explained earlier. These equations are incorporated in the model through a user-defined material subroutine in ABAQUS ${ }^{\mathrm{TM}}$ 
[96]. A comparison of the penetration depth deduced from Figure 4-8 and obtained from FEA simulation is shown in Figure 5-13. As can be seen from the figure, the model represents the penetration with good accuracy. The discrepancies at the start of penetration are due to the model discretization. 


\subsection{Button Cell Simulation Results}

The proposed durability model is implemented in the FEA software ABAQUS ${ }^{\mathrm{TM}}$ through a user-defined subroutine UMAT [96] to predict long-term anode structural behavior under fuel contaminants. The temperature field is one of the required inputs for the anode structure durability model that is obtained from DREAM-SOFC [101]. It is a three dimensional computational fluid dynamics solver developed by Dr. Celik's research group at West Virginia University. It is a time accurate model that can simulate transient operation of SOFCs and is apable of calculating distributions of electric potential, temperature, and species concentrations etc. Temperature dependent material properties for the PEN structure are primarily taken from the MENTAT-FC GUI $[87,88]$ and reference [89] material database that shown in Table 4-4, although the MENTAT-FC software is not utilized in these simulations. The temperature field from DREAM-SOFC is incorporated in ABAQUS ${ }^{\mathrm{TM}}$ to perform structural analyses as shown in Figure 5-14. The temperature variation through the cell thickness is negligible [81,101] and therefore it is not considered here. The cell diameter is $16 \mathrm{~mm}$, and anode, electrolyte and cathode thicknesses are $780 \mu \mathrm{m}, 20 \mu \mathrm{m}$, and $200 \mu \mathrm{m}$, respectively.

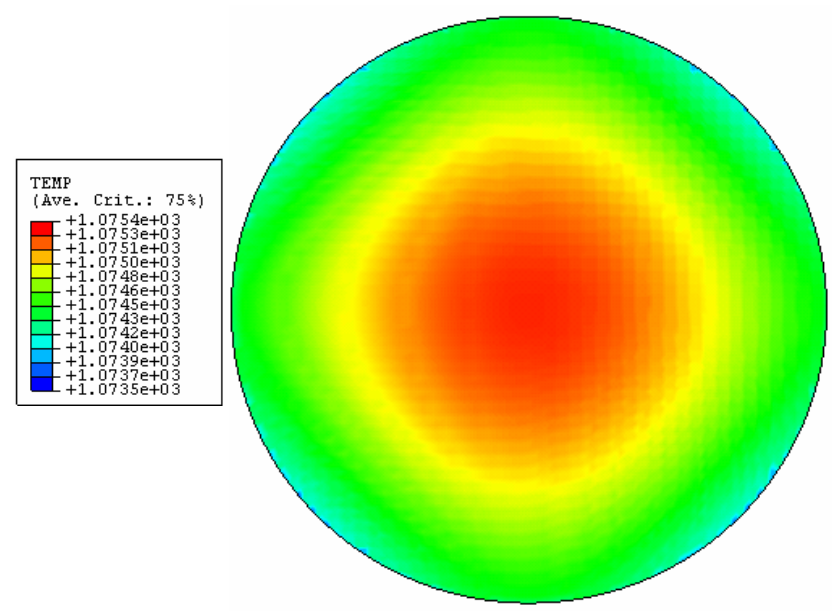

Figure 5-14 Temperature field $\left({ }^{\circ} \mathrm{K}\right)$ from DREAM-SOFC incorporated in ABAQUS ${ }^{T M}$ 


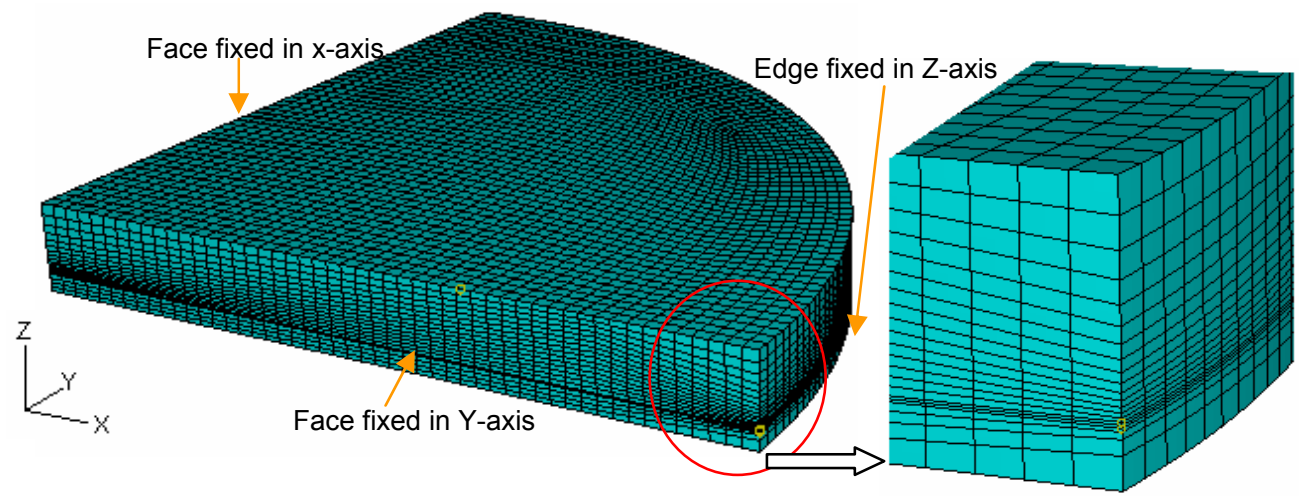

Figure 5-15 FE model of a button cell and physical boundary conditions

Figure 5-15 represents a finite element mesh of one quarter of the button cell. For better visualization, a coarse mesh is shown in the figure whereas a finer mesh is used in the FEA simulations. Due to symmetry, only one quarter of the button cell is analyzed in the FEA. The physical boundary conditions are applied in accordance with the discussion in sections 4.4.1 and 4.4.2. The stress free temperature is considered at which the PEN layers are deposited i.e. $1250^{\circ} \mathrm{C}$ [32]. The thermal stresses are determined by applying the temperature field obtained from DREAM-SOFC.

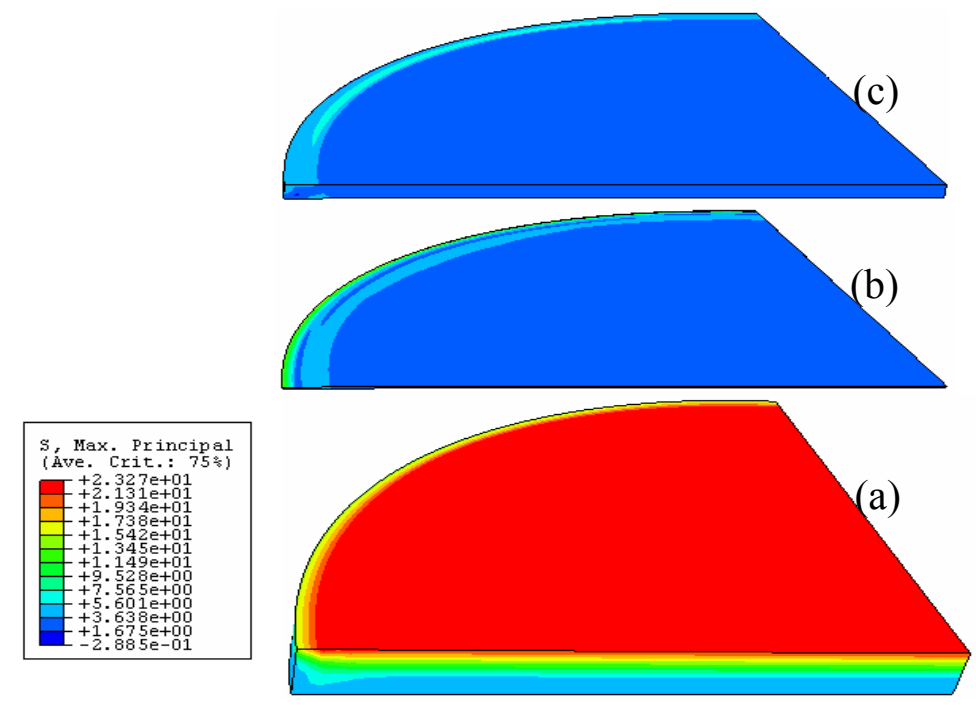

Figure 5-16 Principal stresses in PEN structure (a) anode (b) electrolyte (c) cathode 
Figure 5-16 shows the resulting maximum principal stresses through the PEN structure. The largest maximum principal stresses found in the anode are near the anode electrolyte interface. Fischer et al. [32] also reported a similar stress profile in the anode material. These stress values are lower than the average strength of the PEN structure [9, 81] under the specified conditions. The stress field generated by the external mechanical load is relatively insignificant compared to the thermal stresses [81] and therefore not included in the simulations.

\subsubsection{Anode Structural Degradation}

\subsubsection{Thermo-mechanical degradation}

The degradation growth in the anode material due to the thermo-mechanical effects is determined with the help of a user-subroutine. The degradation threshold variable $\left(\mathrm{K}_{\mathrm{o}}\right)$ and the degradation hardening/softening parameter (h) are taken from section 5.2.2. The results are shown without electrolyte and cathode layers for clarity. 


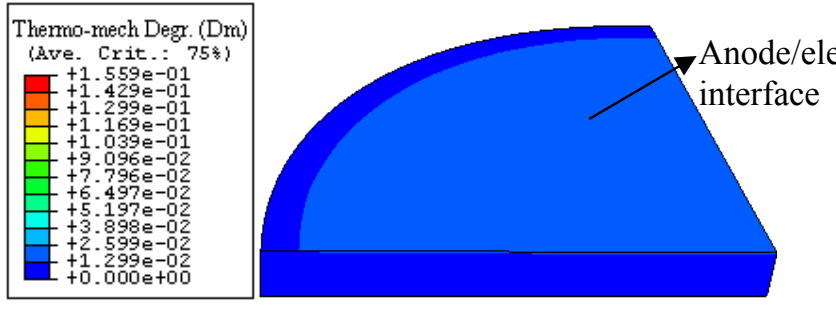

(a)

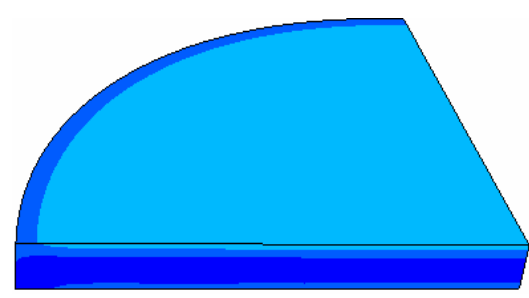

(c)

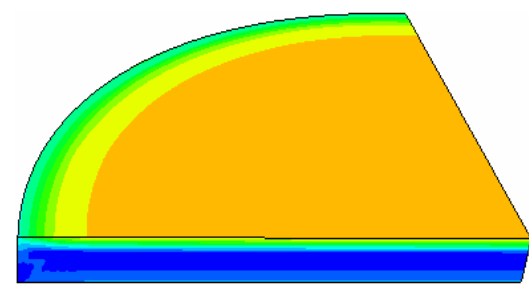

(e)

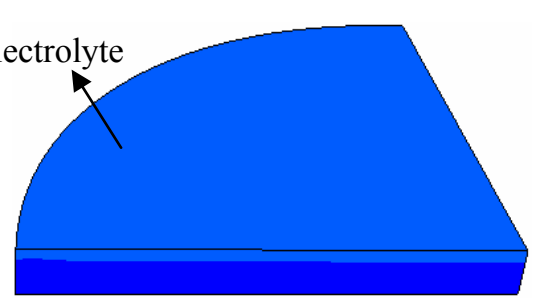

(b)

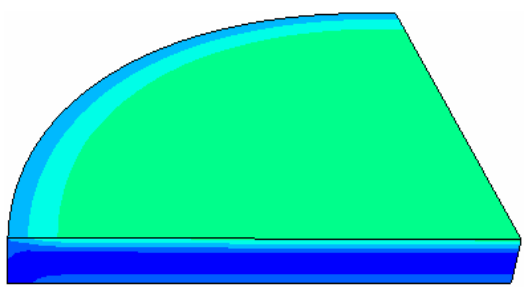

(d)

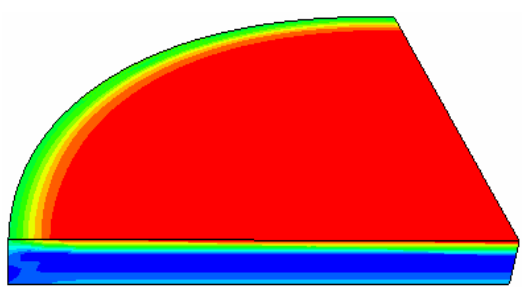

(f)

Figure 5-17 Evolution of thermo-mechanical degradation in anode material without incorporating fuel contaminant effects (a) $9500 \mathrm{~h}$ (b) $15000 \mathrm{~h}$ (c) $20000 \mathrm{~h}$ (d) $25000 \mathrm{~h}$ (e) $35000 h(f) 40000 h$

In the first step, pure thermo-mechanical degradation is determined without considering the fuel contaminant effects. In this case, the material degradation starts at the anode/electrolyte interface as shown in Figure 5-17 (a). With time, the material degradation accumulates in this region as shown in the subsequent figures. Although material degradation also appears at the anode exposed surface with time, it is relatively small as compared to the interface region as shown through the thickness in Figure 5-17 (f). When fuel contaminant effect is considered, the thermo-mechanical degradation profile will change as shown in Figure 5-18. 

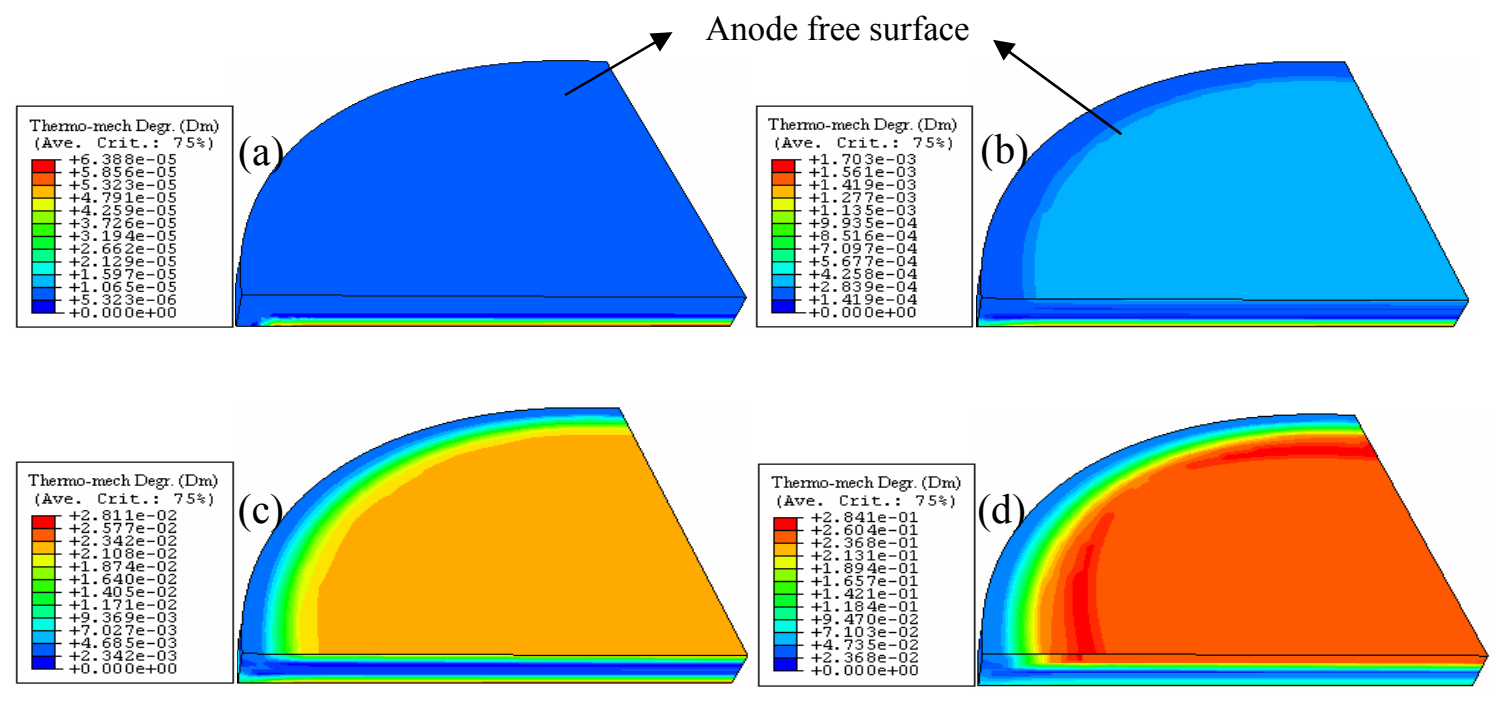

Figure 5-18 Thermo-mechanical degradation in anode material (a) 3900h (b) $7400 \mathrm{~h}$ (c) $15900 \mathrm{~h}(d) 21400 \mathrm{~h}$

At the outset, anode thermo-mechanical degradation is higher near the anode/electrolyte interface as compared to the exposed surface as shown in Figure 5-18 (a). This is due to the higher principal stresses in that region as shown in Figure 5-16. However, gradually the thermo-mechanical degradation becomes severe at the anode exposed surface as compared to the interface as shown in Figure 5-18 (c). It can be explained in terms of the microcracks initiation due the phosphine contamination interaction with the nickel contained in the anode material near its exposed surface. Because of the contaminant microcracks formation, the anode material becomes weaker in this region. As a consequence, the degradation threshold decreases and a lower level of stresses may generate a high density of microcracks. Finally, the degradation variable reaches its critical value first at the anode exposed surface as shown in Figure 5-18 (d). 


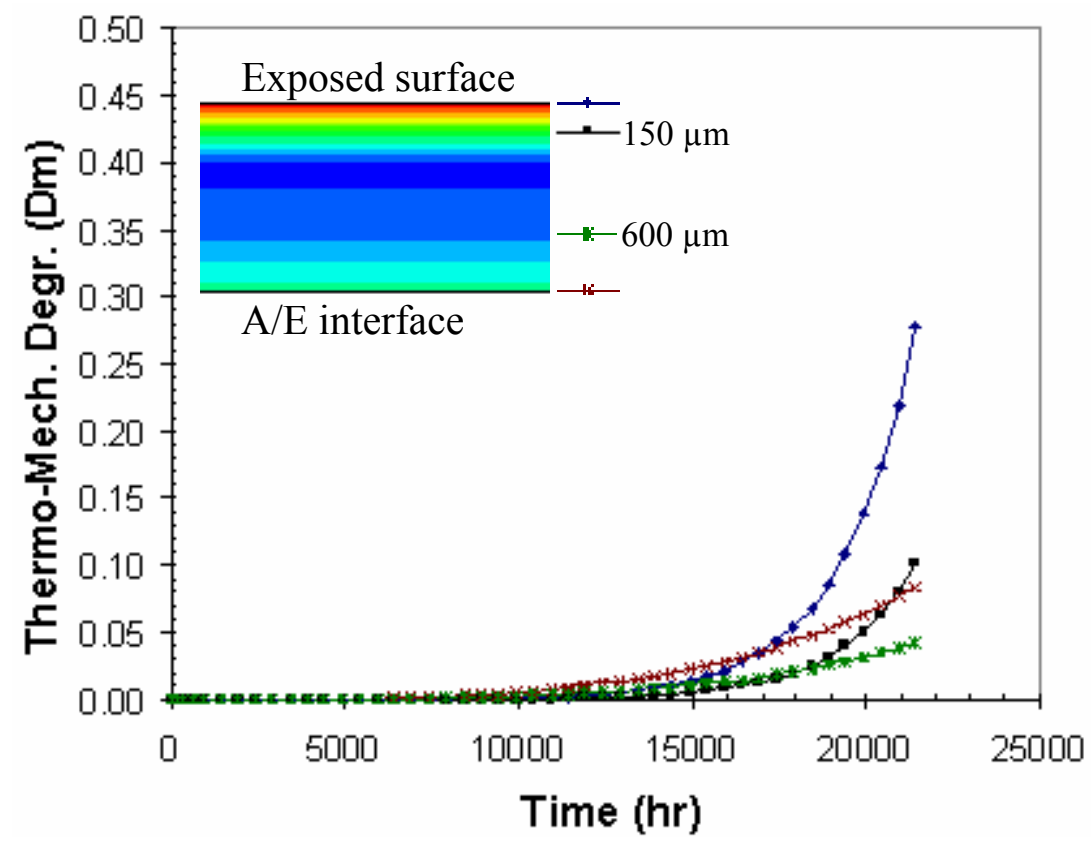

Figure 5-19 Evolution of thermo-mechanical degradation through anode thickness

Figure 5-19 shows the evolution of the thermo-mechanical degradation at the center of the anode through its thickness. As shown, the thermo-mechanical degradation is higher near the anode/electrolyte interface at the onset. With time, thermo-mechanical degradation increases at a higher rate at the surface than at the interface because of the microcracks initiation due to fuel contaminant interaction with the anode surface as explained before.

\subsubsection{Structural degradation due to contaminant interaction}

The effect of fuel contaminant on the anode microstructure is assumed to be independent of the themo-mechanical mechanisms. The effect of the contaminants is assumed such that $a_{1}=0.1$ for $\mathrm{PH}_{3}$ contamination. The cell is exposed to the coal syngas contaminant with $5 \mathrm{ppm}$ of $\mathrm{PH}_{3}$. In the case of a button cell, the contaminant concentration is assumed to be uniformly distributed on the anode surface. The syngas 
contaminants affect the anode exposed surface structural properties as shown in Figure 5-20.
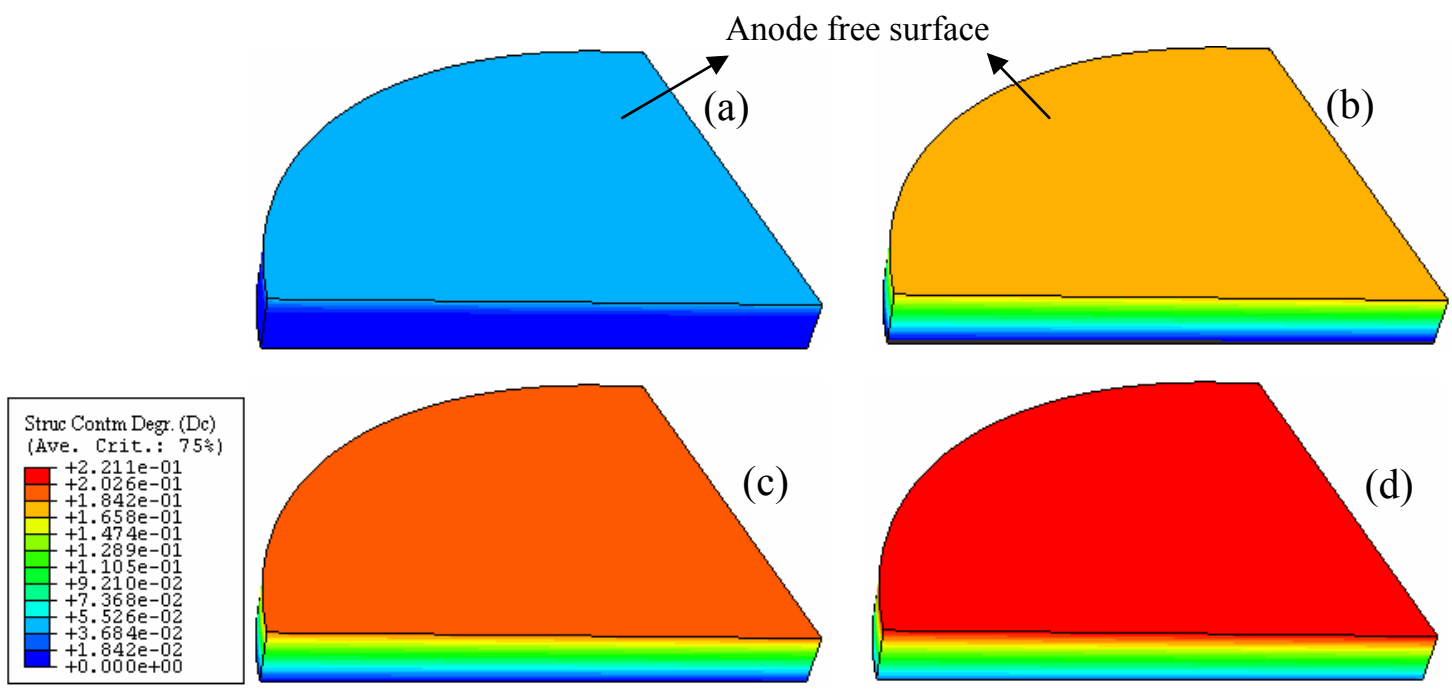

Figure 5-20 Structure contaminant degradation in anode under 5pm $\mathrm{PH}_{3}$ (a) 510h (b) $10400 h$ (c) $17900 h$ (d) $21400 \mathrm{~h}$

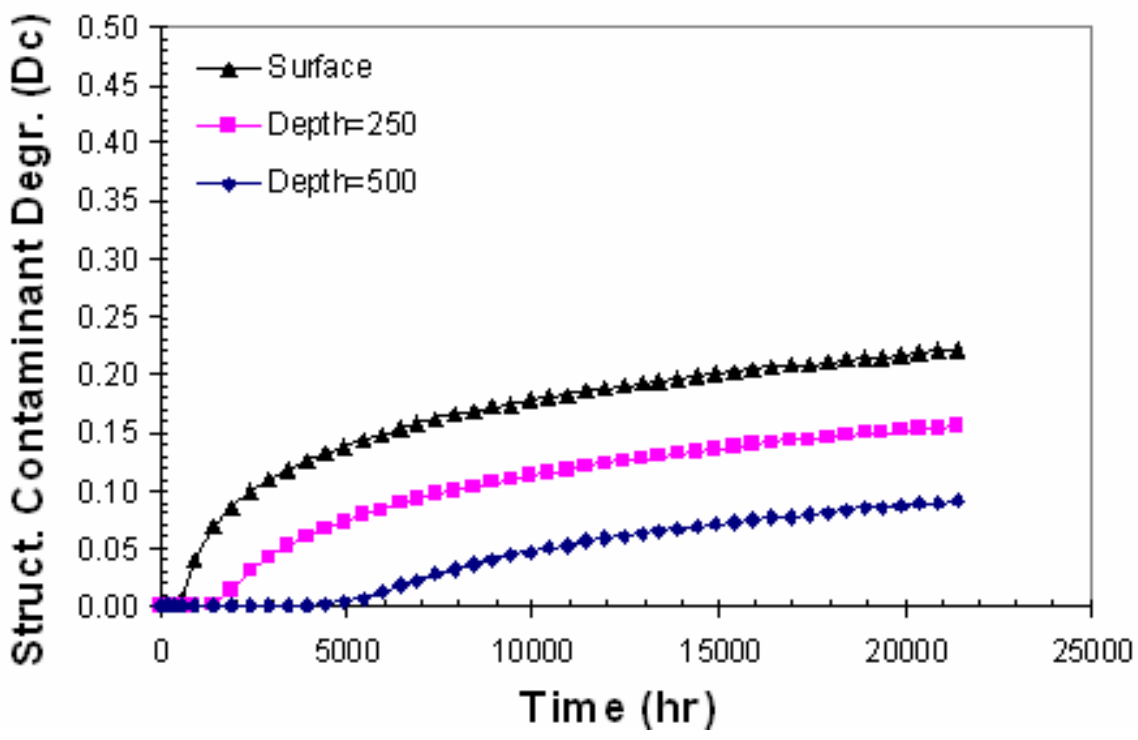

Figure 5-21 Evolution of structural contaminant degradation through the anode thickness under 5 ppm of $\mathrm{PH}_{3}$ 
Since the structural contaminant degradation is assumed to be independent of the other degradation mechanisms, the contaminant effects on the anode microstructure begin uniformly at the anode exposed surface and penetrate through the anode thickness with time as shown in Figure 5-20. Figure 5-21 shows the evolution of structural contaminant degradation effect at the center of the anode across the thickness exposed to 5ppm of $\mathrm{PH}_{3}$. Structural degradation rate due to the syngas contaminants is rapid initially but decreases with time. The degradation is proportional to the contamination concentration and time of exposure.

\subsubsection{Cumulative structural degradation}

The combined effect of the two degradation mechanisms can be determined from Eq. (4. 3) as described in section 4.1.2.
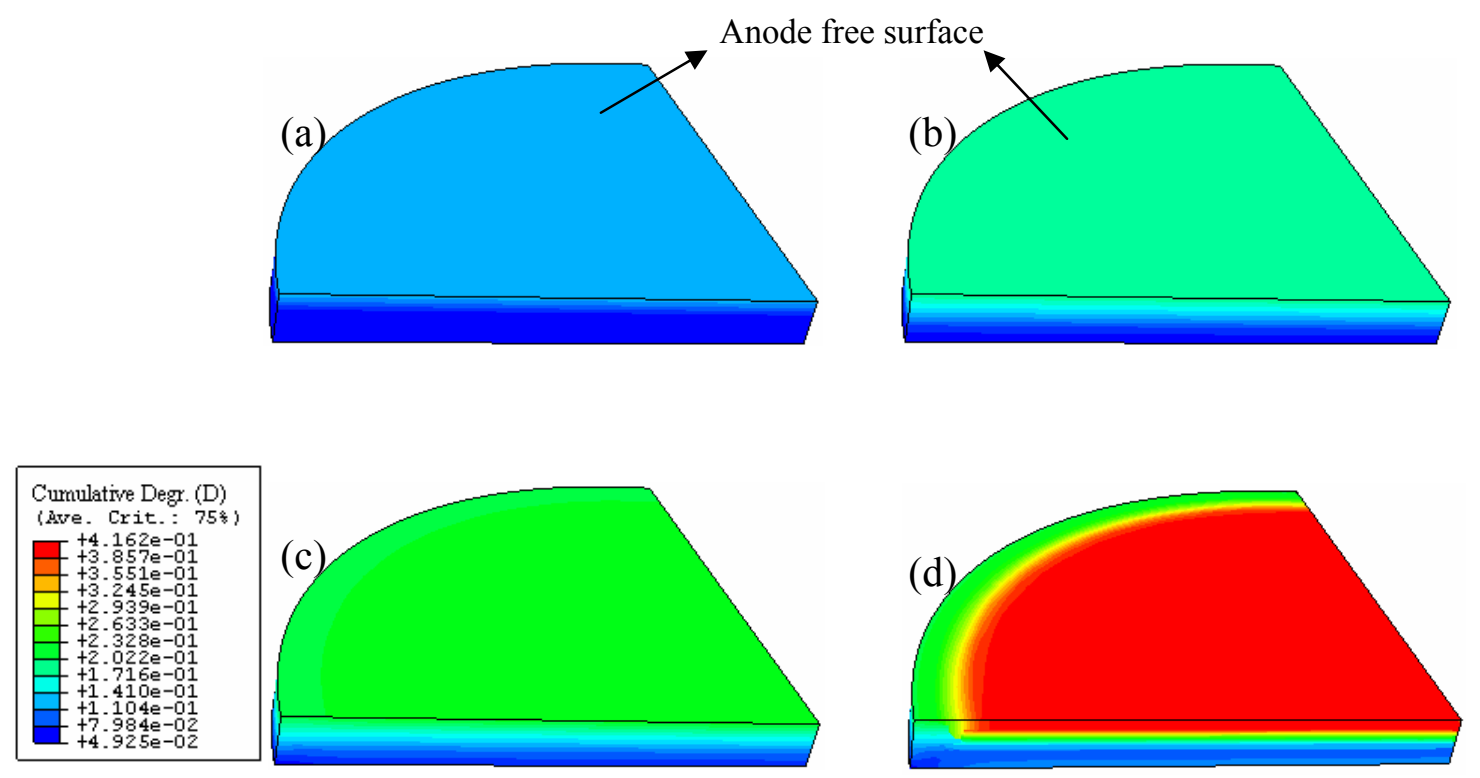

Figure 5-22 Cumulative degradation in anode material (a) 1900h (b) $7400 \mathrm{~h}$ (c) $15900 \mathrm{~h}$ (d) $21400 \mathrm{~h}$ 


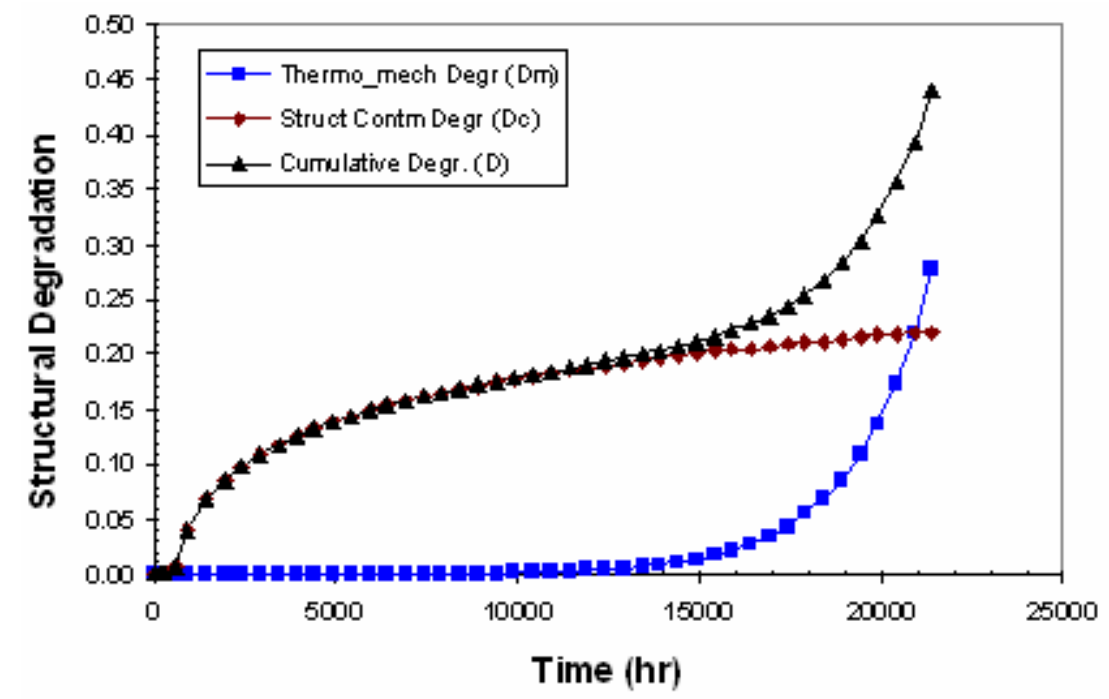

Figure 5-23 Evolution of anode structural degradation at the critical location

Initially, anode structural degradation is higher in two regions: at the anode/electrolyte interface (Figure 5-18 (a)) due to thermo-mechanical degradation and at the anode exposed surface (Figure 5-20) due to structure contaminant degradation. Gradually the structure degradation due the contaminant penetrates through the anode thickness and thermo-mechanical degradation evolves at the anode/electrolyte interface. Eventually the two degradation effects concentrate at the anode exposed surface and the cumulative degradation variable reaches its critical value as shown in Figure 5-22(d) and Figure 5-23.

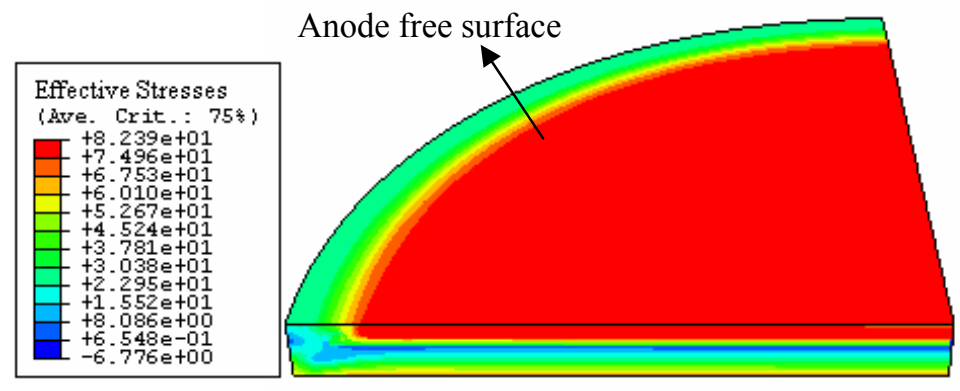

Figure 5-24 Effective stresses in the anode 


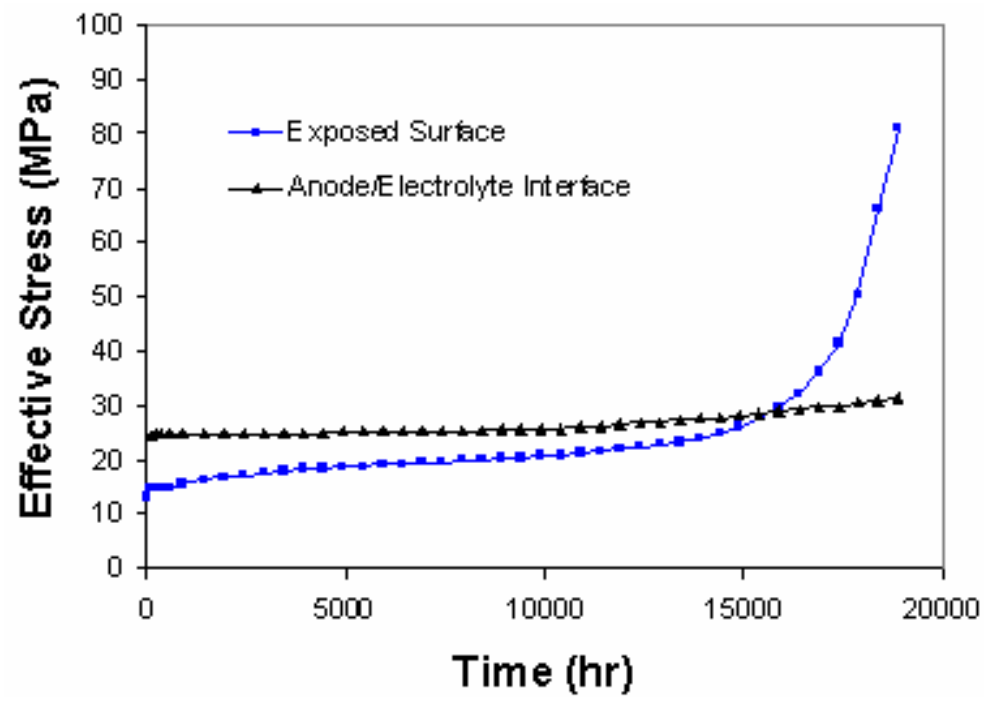

Figure 5-25 Evolution of effective stresses at the exposed surface and interface

The effective stress field through the anode thickness is shown in Figure 5-24 just before the impending structure failure. At this critical state, the effective stresses are higher at the anode free surface and are close to the failure stresses under the specified conditions [81]. The evolution of the effective stresses at the two locations is presented in Figure 5-25. Initially the maximum principal stresses are higher at the anode/electrolyte interface. With material degradation, the effective stresses evolved more rapidly at the anode free surface than at the anode/electrolyte interface due to the synergistic effects of microcracks formed by the thermo-mechanical and structure contaminant effects as explained in section 5.3.1.3. 

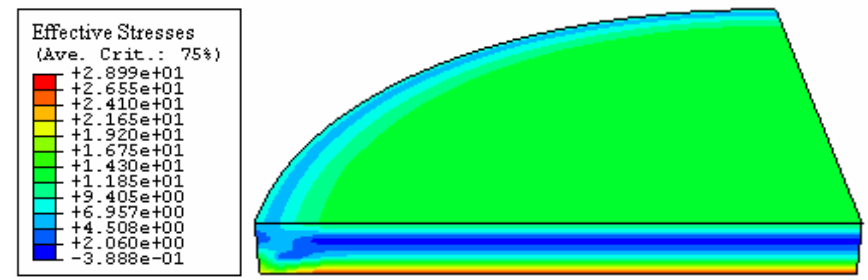

Figure 5-26 (a) Effective stresses through the anode thickness without contaminant

For comparison, the effective stresses in the anode are shown in Figure 5-26 under zero contaminant concentration after $40000 \mathrm{hr}$. As shown, the effective stresses are well below the critical values under zero contaminant concentration. In this case, the structural degradation and the corresponding effective stresses are higher at the anode/electrolyte interface.

\subsubsection{Parametric Analysis}

One of the main objectives of this research is to establish the acceptable limit of the $\mathrm{PH}_{3}$ contaminant in the syngas that would not catastrophically degrade anode structure for a specified period of time. In this section, parametric studies are performed in terms of contaminant concentration ( $\mathrm{ppm})$, contaminant factor $\left(\mathrm{a}_{1}\right)$, anode porosity $(\mathrm{p})$ and anode material properties such that the acceptable concentration of $\mathrm{PH}_{3}$ can be established under the assumed operating conditions.

\subsubsection{Contaminant factor $\left(a_{1}\right)$ and contaminant concentration (ppm)}

Contaminant factor $\left(a_{1}\right)$ is assumed to be $5 \%, 10 \%$ and $20 \%$; while the contaminant concentration is varied form $5 \mathrm{ppm}$ to the value which yields the critical structural degradation value $(D=0.4)$ for $40000 \mathrm{hr}$ of cell operation. 


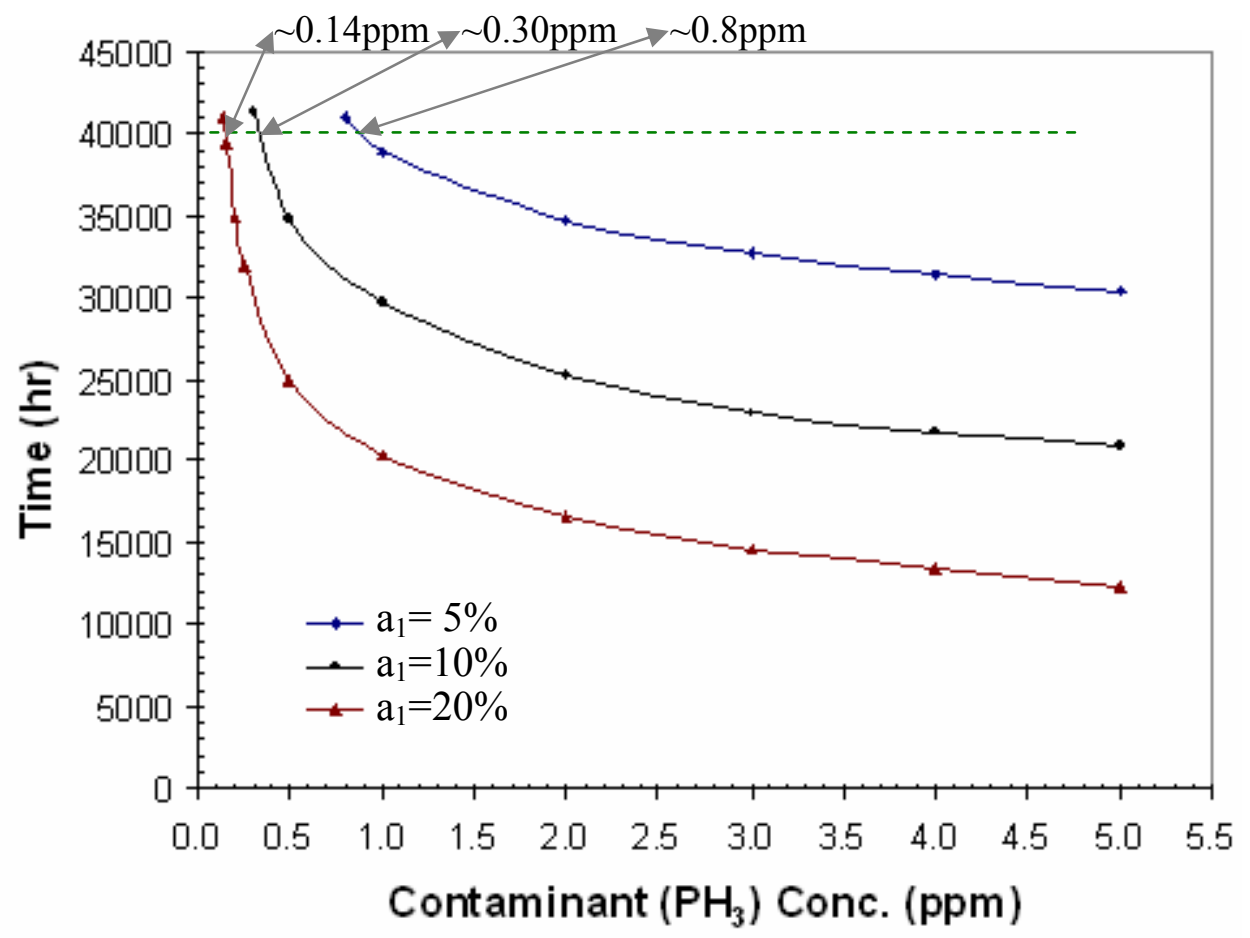

Figure 5-27 Predicted anode structural life in terms of contaminant concentration for different contaminant factor

Anode structural life increases exponentially as the contaminant concentration decreases as shown in Figure 5-27. At $\mathrm{a}_{1}=10 \%$, the contaminant concentration is found to be about $0.3 \mathrm{ppm}$ corresponding to the $40000 \mathrm{hr}$ of anode structural life. The three curves seem to be converged as the contaminant concentration approaches zero. In this case, the material may fail due to thermo-mechanical effects alone at higher lifetime.

\subsubsection{Anode porosity and contaminant concentration}

The effects of material porosity on the anode structural life are also examined. At constant contaminant factor $\left(a_{1}=10 \%\right)$, anode porosity is changed from $30 \%$ to $40 \%$. Anode material properties under these conditions are obtained from Table 4-4 and Table $5-2$. 


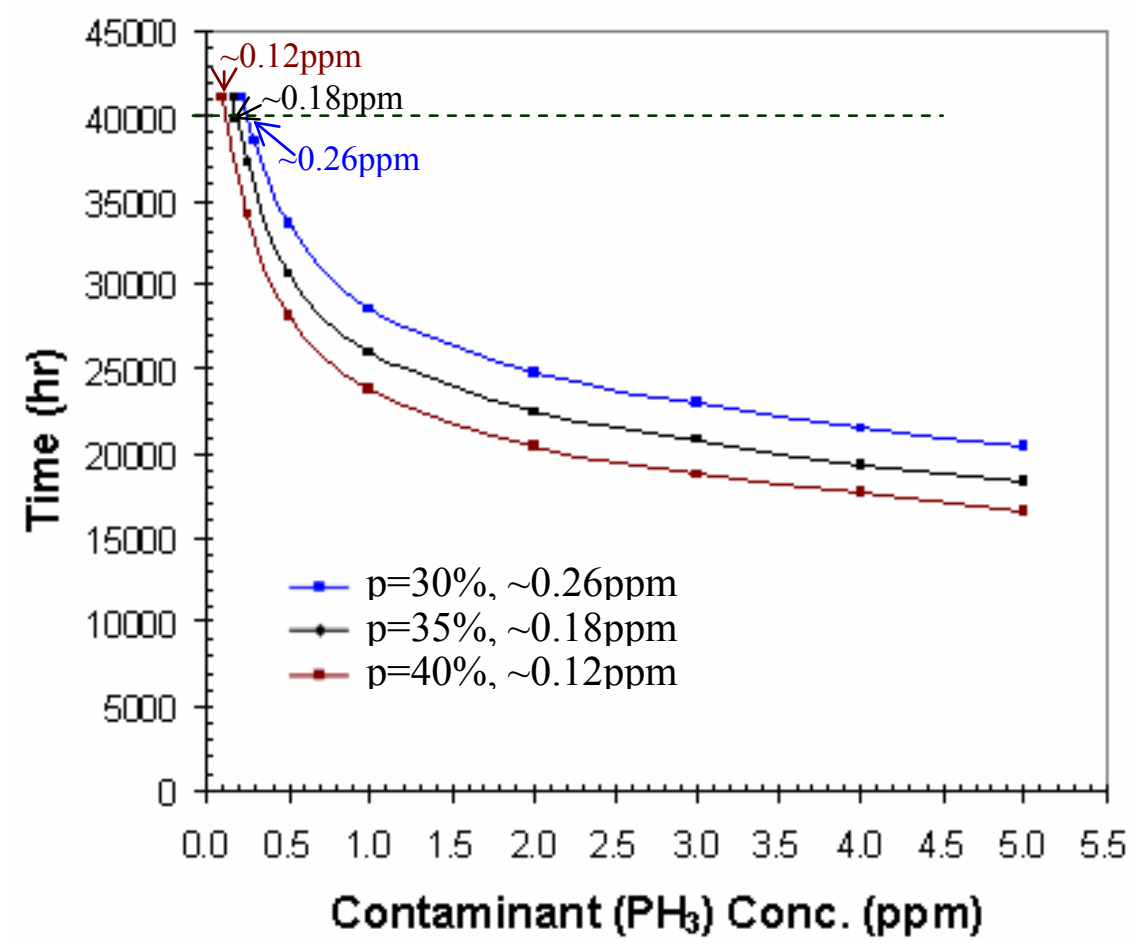

Figure 5-28 Predicted anode structural life in terms of contaminant concentration for different porosity

As shown in Figure 5-28, the acceptable contaminant limit decreases with the increase in porosity. At higher porosity, the material stiffness and strength reduce as discussed in section 4.4.5. Also, the damage threshold value is lower at higher porosity as discussed in section 5.2.2. At low concentrations $(<0.01 \mathrm{ppm})$, the structural degradation will be insignificant at the anode free surface because of the low MPS and fuel contaminant will take too much time to start penetrating into the surface (Figure 4-8). As it can be seen from Eq (4. 52)-(4. 53), and Figure 4-9, the time required to start penetration increases exponentially with the decrease in the contaminant concentration. Moreover at low concentrations, the critical location of anode material will shift from anode surface to the anode/electrolyte interface due to the higher principal stresses in that region as discussed in section 5.3.1. 


\subsubsection{Electrochemical vs. structural degradation}

Currently, most research efforts related to fuel cells are focused on their electrochemical performance. Anode structural degradation phenomena under synergistic effects of thermo-mechanical and fuel contaminant, in contrast, are not given much consideration. In addition to electrochemical performance, structural integrity of the SOFC anode is indispensable for successful long-term operation.

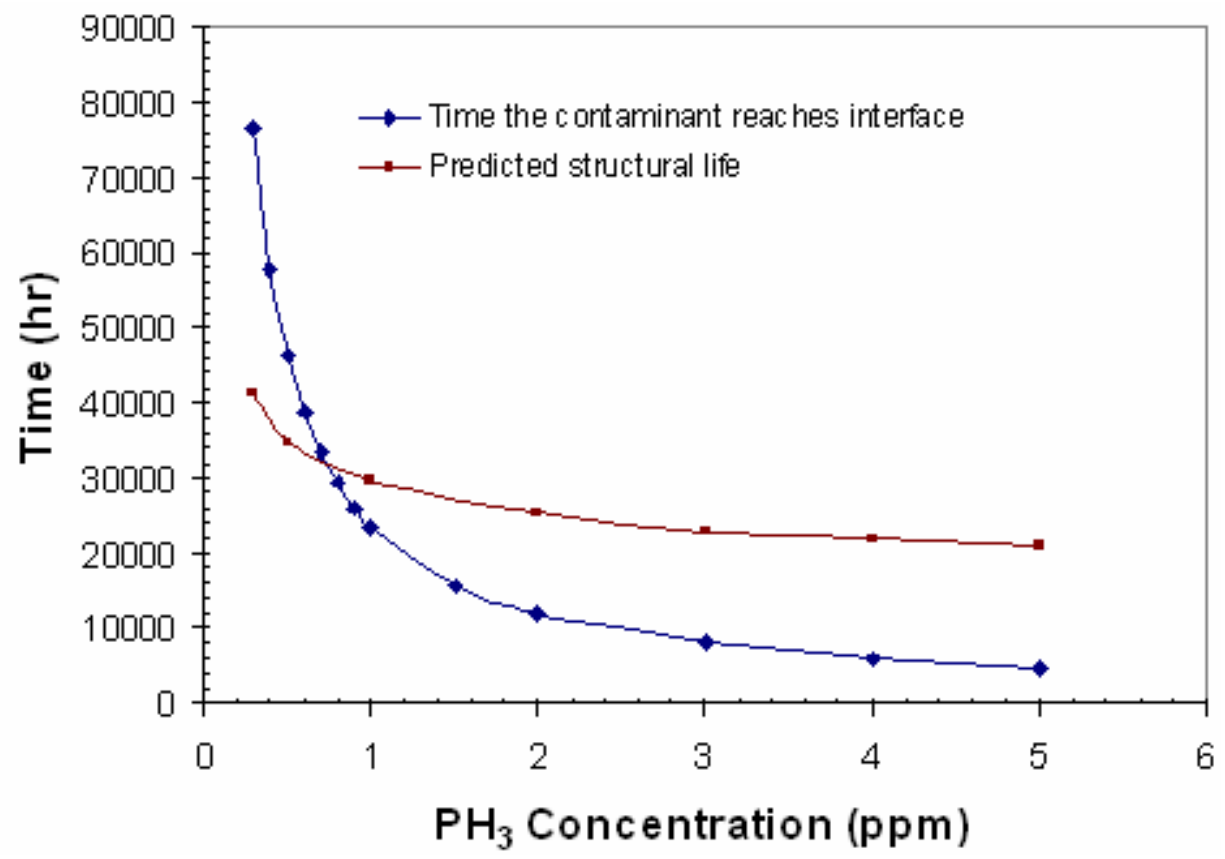

Figure 5-29 Comparison of predicted anode structural life and time required to reach to interface

The current general view is that the cell electrochemical degradation is the dominant factor that dictates SOFC working life when working under coal syngas. These conclusions are derived from accelerated exposure tests performed under much higher concentration of fuel contaminants. In the case of $\mathrm{PH}_{3}$, these exposures tests are usually performed with $5 \mathrm{ppm}$ or more [41, 50,65], whereas the concentration of $\mathrm{PH}_{3}$ in coalderived syngas has been estimated at $\sim 1.9 \mathrm{ppm}$ following warm gas cleanup [41, 102, 
103]. Consequentially, under high contaminant concentration, the cell electrochemical performance decreases to an unacceptable level in a short period of time before there is any measurable structural degradation. However, as indicated in Figure 5-29, under lower $\mathrm{PH}_{3}$ concentration the anode structure degradation may be significant as compared to its electrochemical degradation. 


\subsection{Planar-SOFC Simulation Results}

The anode structure durability model developed for the solid oxide fuel cell (SOFC) button cell is enhanced for the planar-SOFC anode exposed to syngas contaminants e.g. $\mathrm{PH}_{3}$. Due to its larger active area compared to button cell, planar-SOFC exhibits greater spatial and temporal temperature gradients which cause higher thermal stresses and thermo-mechanical degradation. Moreover, fuel contaminants are distributed on the anode surface which leads to non-uniform microstructure degradation of the anode along the fuel flow from cell inlet to outlet. Thus the durability model of planar-SOFC needs to be modified from button cell on the following bases.

- Planar-SOFCs have larger active area compared to button cell

- Greater temporal and spatial temperature gradient

- Higher thermal stresses and thermo-mechanical degradation

- Fuel contaminant effects on anode structure differ from fuel inlet to outlet

- Secondary phase propagates across the anode thickness and along the fuel flow

\subsubsection{Planar-SOFC Configurations}

In planar-SOFC configurations, fuel and oxidant flow over the anode and cathode respectively in a flow by manner as shown in Figure 2-2. It is the most common fuel cell stack configuration where individual unit cells are electrically connected by means of interconnects to generate desired power. The following three configurations are considered as shown in Figure 2-4.

(a) Co-flow: fuel and oxidant flow in the same direction

(b) Counter-flow: fuel and oxidant flow in opposite directions

(c) Cross-flow: fuel and oxidant flow perpendicular to each other 
In a co-flow configuration, fuel and oxidant flow in the same direction on the anode and cathode sides respectively. A schematic view of a co-flow planar-SOFC is shown in Figure 5-30 (a). The cell active area is $10 \mathrm{~cm} \times 10 \mathrm{~cm}$ and it contains 18 channels for fuel and air flow on each side. Further details about the cell geometry can be obtained from reference [101]. Figure 5-30 (b) shows the PEN assembly and its dimensions. In this model, a typical anode-supported PEN assembly is considered which is composed of 780 $\mu \mathrm{m}$ nickel-yttria stabilized zirconia (Ni-YSZ) anode, $20 \mu \mathrm{m}$ thick YSZ electrolyte, and $200 \mu \mathrm{m}$ thick Sr-doped $\mathrm{LaMnO}_{3}$ (LSM). Figure 5-30 (c) is the top view of the PEN assembly.
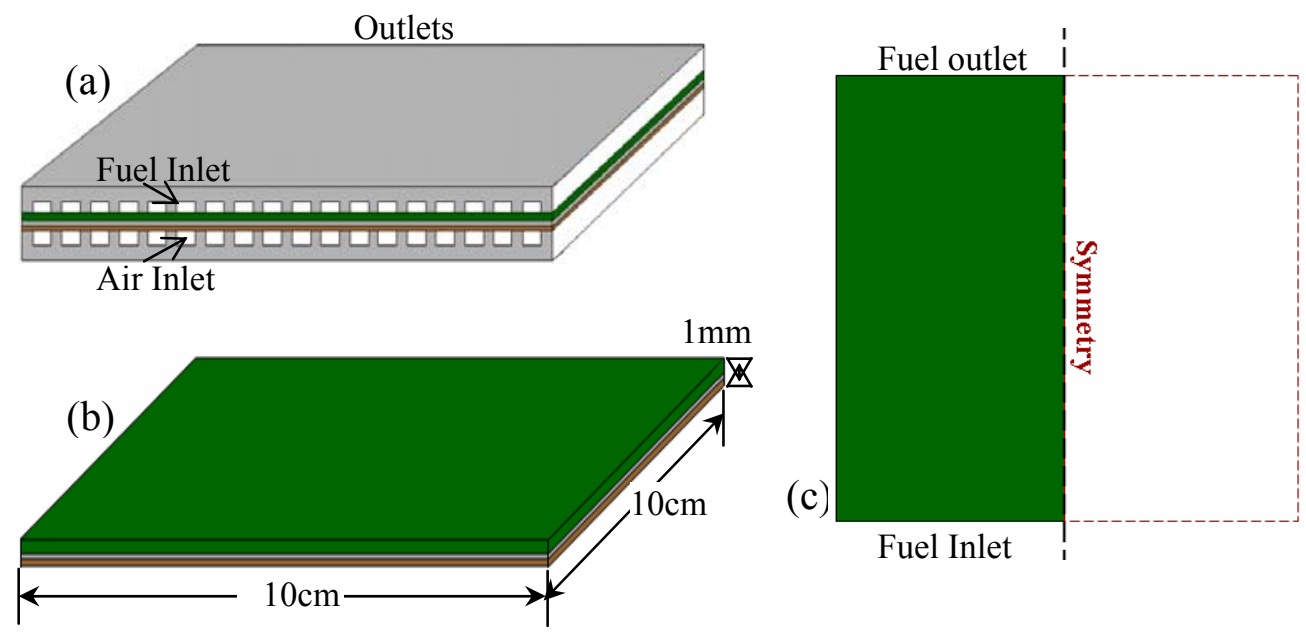

Figure 5-30 (a) Schematic view of a co-flow planar-SOFC (b) PEN structure (c) top view of the anode exposed surface

\subsubsection{Temperature and Contaminant Distribution}

The temperature field and contaminant concentration distribution inside the SOFC anode are the required inputs for the anode structure degradation model which are obtained from DREAM-SOFC [101]. It is a multi-physics code for SOFC modeling to 
assess its electrochemical and thermal performances. Due to symmetry in co-flow and counter-flow planar cells, only one-half of a $10 \mathrm{~cm}$ x $10 \mathrm{~cm}$ cell is analyzed in finite element analyses (FEA) as shown in Figure 5-30 (c). For cross-flow, full PEN structure is analyzed as there is no axis of symmetry in that case.
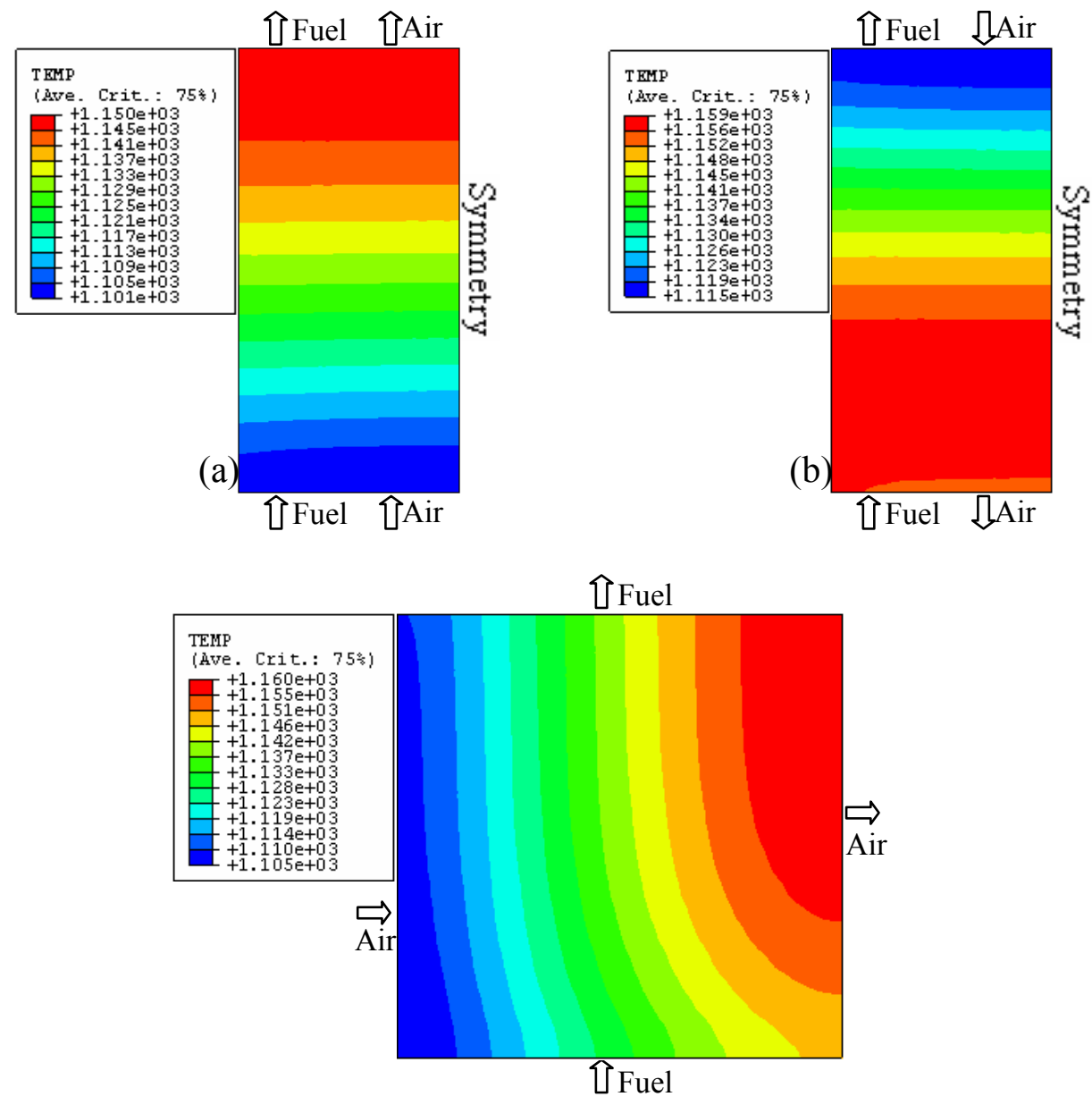

Figure 5-31 Temperature $\left({ }^{\circ} \mathrm{K}\right.$ ) profile on (a) co-flow planar (b) counter-flow and (c) cross-flow SOFC anode under same current density (20amp)

The temperature fields of planar-SOFCs are incorporated in FEA software ABAQUS $^{\mathrm{TM}}$ (ABAQUS Inc., Providence, RI) with the help of a user defined subroutine [96]. Figure 5-31 shows the temperature distributions for (a) co-flow, (b) counter-flow 
and (c) cross-flow configurations obtained from DREAM-SOFC operating under the same current (20 amp.). DREAM-SOFC utilizes the finite volume method to calculate the temperature distribution and species concentration inside the cell. Therefore the temperature data obtained from DREAM-SOFC must be interpolated from the finite volume center to the nodal point or to the integration points of the FEA mesh used in ABAQUS $^{\mathrm{TM}}$. The temperature distribution can be read in $\mathrm{ABAQUS}^{\mathrm{TM}}$ in a step at the nodal point with the help of the user-defined subroutine DISP or at the integration point with the help of user-defined subroutine, e.g. UMAT.

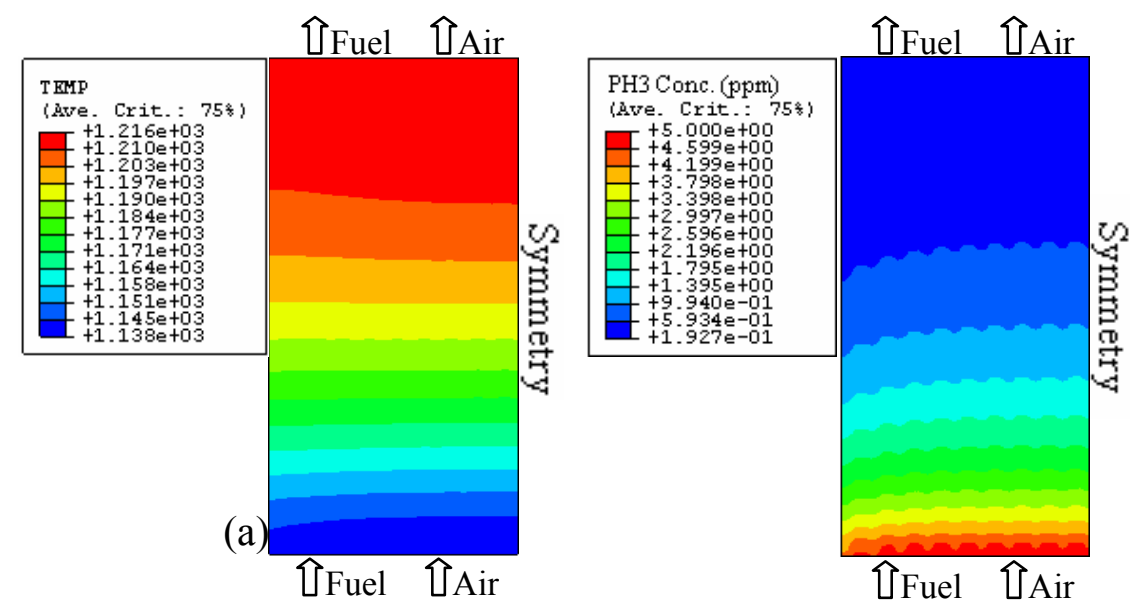

Figure 5-32 (a) Temperature field (b) $\mathrm{PH}_{3}$ contaminant profile on a co-flow planar SOFC anode at $20 \mathrm{amp}$

Figure 5-32 (a) shows the temperature distribution in the PEN structure for a co-flow cell operating under syngas at 30 amps and 50\% fuel utilization [104]. The thermodynamics equilibrium calculations [43] indicate that at the inlet edge, nearly $60 \%$ of the $\mathrm{Ni}$ was converted into $\mathrm{Ni}_{5} \mathrm{P}_{2}$ within $4000 \mathrm{~h}$ when exposed to $2 \mathrm{ppm}$ of $\mathrm{PH}_{3}$ at 800 ${ }^{\circ} \mathrm{C}$. Moreover, a large variation in the amount of the secondary phase formed at the inlet edge versus that of the outlet edge of the SOFC was observed. In fact, no significance amount of $\mathrm{Ni}_{5} \mathrm{P}_{2}$ was found at the outlet edge of the SOFC [43] within $4000 \mathrm{~h}$ of exposure. Based on the argument, the $\mathrm{PH}_{3}$ profile is deduced from DREAM-SOFC on the anode as shown in Figure 5-32 (b), whereby the inlet contaminant concentration was 
assumed to be $5 \mathrm{ppm}$. In flow by exposure tests, Marina et al. [50] detected extensive phosphorus capture within $\sim 4 \mathrm{~mm}$ of the fuel inlet when exposed to $0.5 \mathrm{ppm} \mathrm{of} \mathrm{PH}_{3}$ in syngas for $500 \mathrm{~h}$. Beyond $4 \mathrm{~mm}$ from the fuel inlet, no phosphorous was present. Under similar conditions, phosphorous completely captured within $5 \mathrm{~mm}$ from fuel inlet in 100 $\mathrm{h}$ test with a penetration depth of $50 \mu \mathrm{m}$. Experimental studies $[60,65]$ also found that when exposed to the fuel contaminant $\left(\mathrm{PH}_{3}\right)$, the surface nickel $(\mathrm{Ni})$ under the fuel inlet was converted into secondary phases whereas the surface $\mathrm{Ni}$ away from the fuel channel inlets was presented as the metal during short-term tests. These studies also suggested that the secondary phase will propagate with time along the fuel flow. These experimental results support the assumption made here to obtain the contaminant concentration on the anode.

\subsubsection{Physical Boundary Conditions}

Figure 5-33 represents a FEA model of one half of a co-flow planar cell. Quadratic brick elements with reduced integration are used to model the PEN structure as shown in Figure 5-33. For better visualization, a coarse mesh is shown in the figure whereas a finer mesh is used in the FEA simulations. The applied physical boundary conditions will only prevent rigid body motion

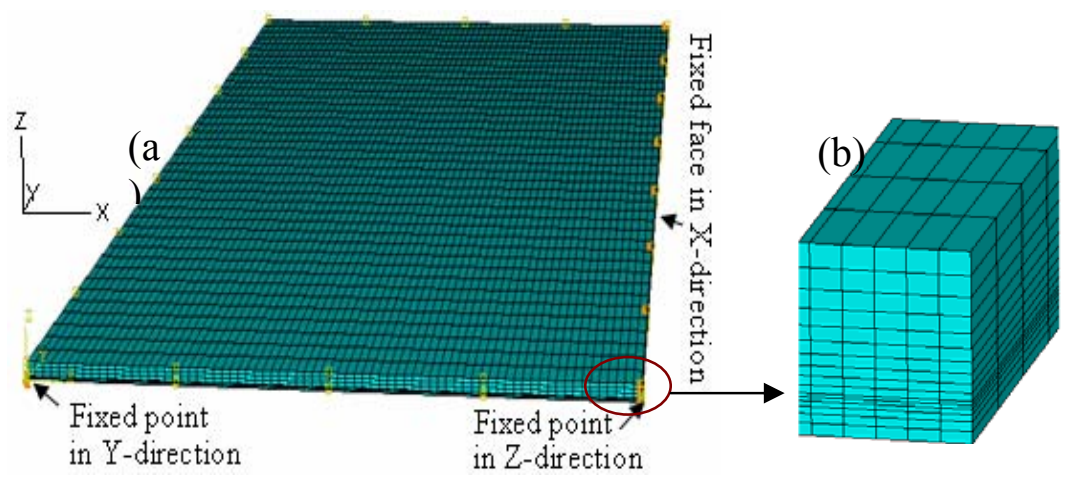

Figure 5-33 FEA model of the PEN structure and applied physical boundary conditions 


\subsubsection{Anode Structural Degradation}

The thermal stresses are determined by applying the temperature field (Figure 5-32 (a)) obtained from DREAM-SOFC [101], and boundary conditions discussed in section 5.4.3, into the FEA code ABAQUS ${ }^{\mathrm{TM}}$. Figure 5-34 shows the resulting maximum principal stresses (MPS) through the PEN structure in a co-flow configuration. The largest MPS found in the anode are at the anode electrolyte interface. These stress values are lower than the average strength of the PEN structure $[9,81]$ under the specified conditions.
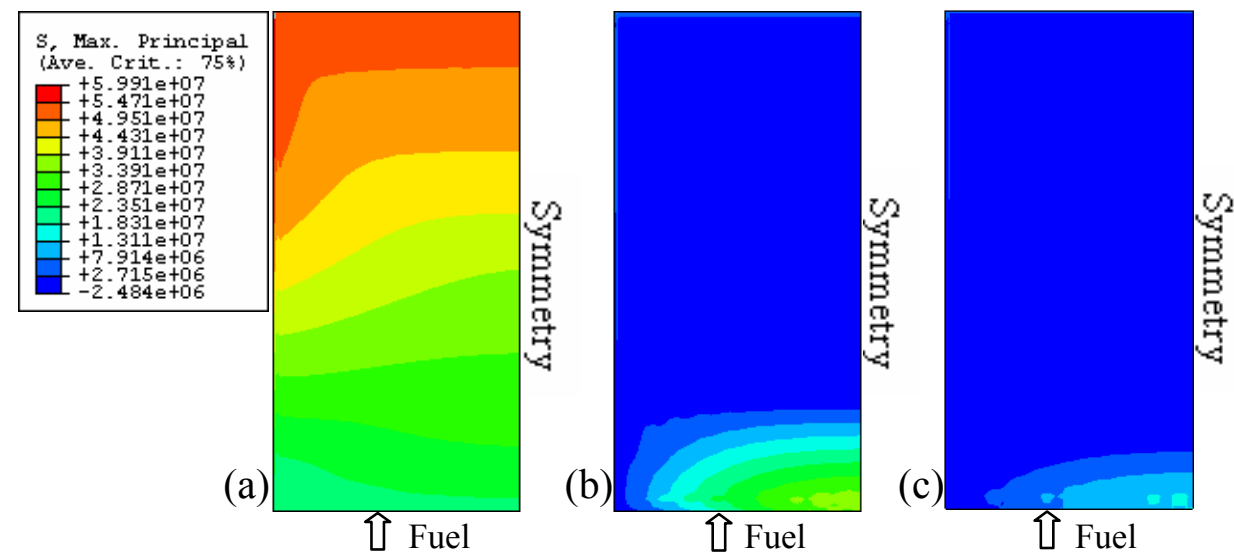

Figure 5-34 Principal stresses through the co-flow PEN structure (a) anode at the anodelelectrolyte interface (b) electrolyte (c) cathode

The highest MPS in the electrolyte and cathode layers occur near the fuel/air inlet as shown in Figure 5-34 (b)-(c). The stress profile in the electrolyte layer is similar to one reported by Yakabe et al. [16] for a co-flow case. The stress field generated by the external mechanical load is relatively insignificant compared to the thermal stresses [81] and therefore not included in the simulations. For a comparison the MPS distributions at anode/electrolyte interface for co-flow, counter-flow and cross-flow configurations, for a cell operating under similar current output (20 amps), are shown in Figure 5-35. 

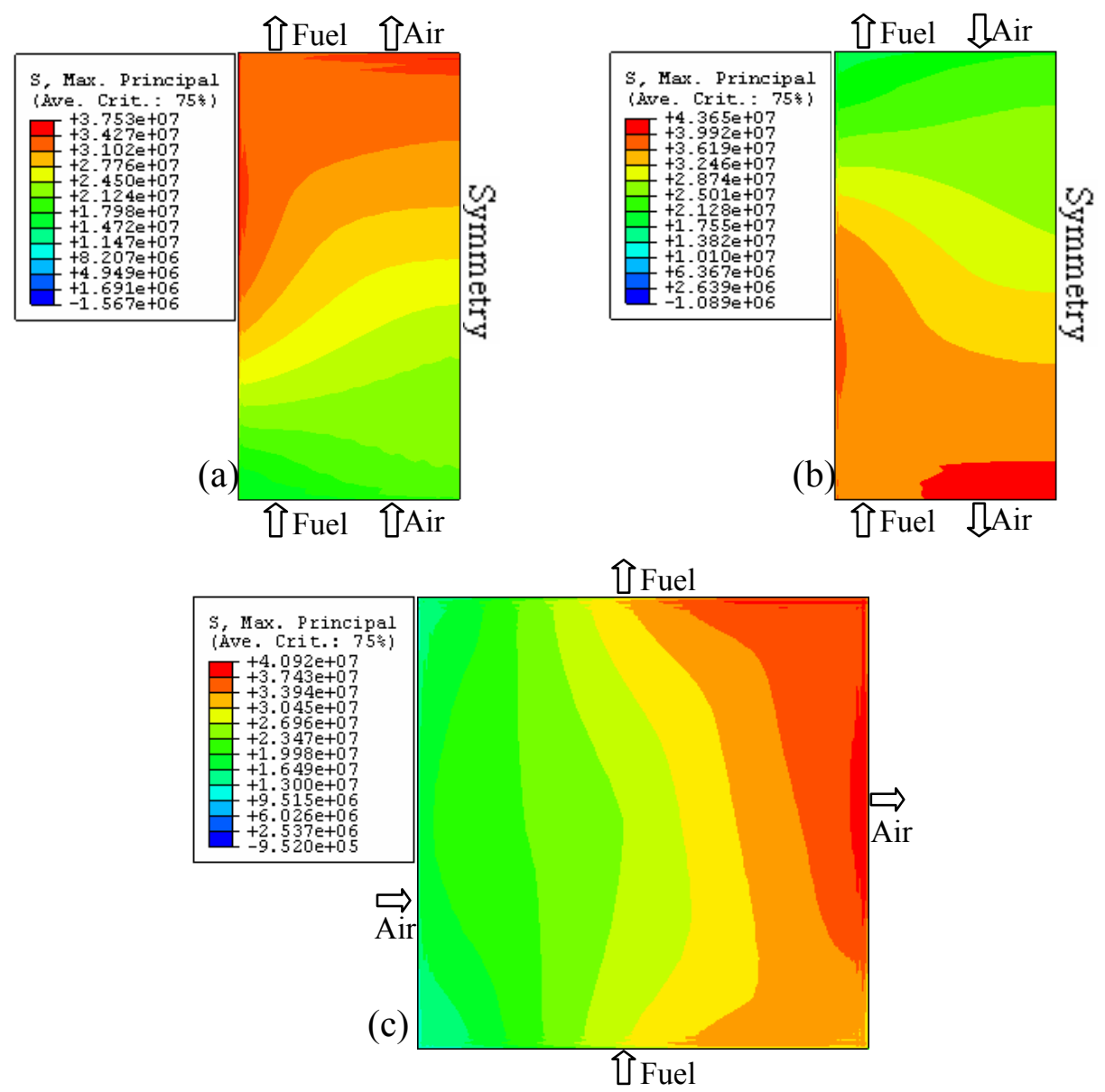

Figure 5-35 Principal stresses at the anodelelectrolyte interface (a) co-flow (b) counterflow (c) cross-flow

\subsubsection{Thermo-mechanical degradation}

Temperature dependent material properties for the PEN structure are primarily taken from the MENTAT-FC GUI [87, 88] and reference [89] database as shown in Table 4-4, although MENTAT-FC software is not utilized in these simulations. The degradation threshold variable $\left(\mathrm{K}_{\mathrm{o}}\right)$ and degradation hardening variable $(\mathrm{h})$ are taken as determined in section 5.2.2. The degradation growth in the anode material due to pure thermomechanical effects is determined with the help of a user-defined subroutine. The results are shown at the anode exposed surface (e) and at the anode electrolyte interface (i), and 
without electrolyte and cathode layers for clarity. The co-flow configuration is considered in the following simulation as a base case.

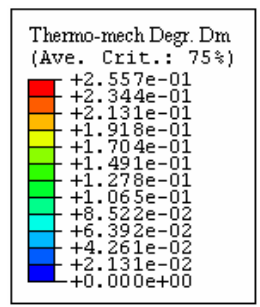

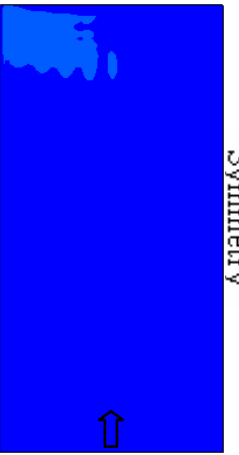

(a)

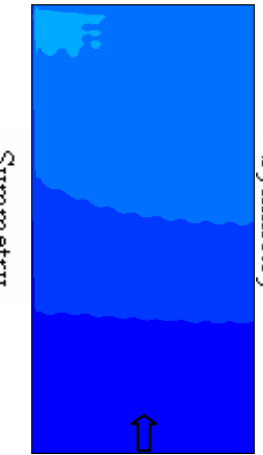

(b)

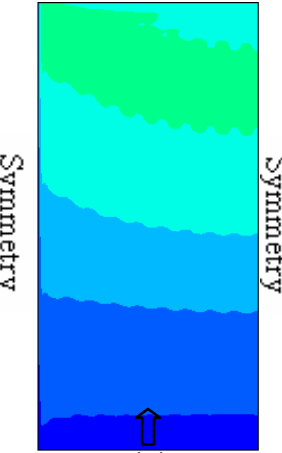

(c)

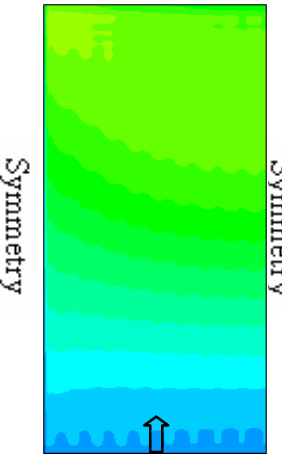

(d)

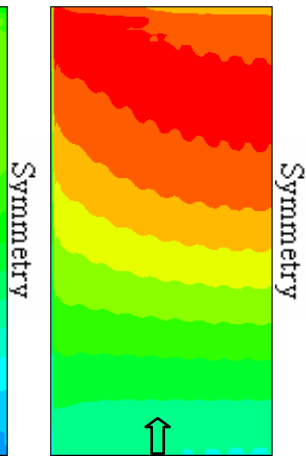

(e)

Figure 5-36 Evolution of thermo-mechanical degradation in anode at the anodelelectrolyte interface without incorporating fuel contaminant effects for co-flow(a) $5410 \mathrm{~h} \mathrm{(b)} 10410 \mathrm{~h} \mathrm{(c)} 20000 \mathrm{~h}$ (d) $30000 \mathrm{~h} \mathrm{(e)} 40000 \mathrm{~h}$

Figure 5-36 shows the evolution of thermo-mechanical degradation without incorporating the fuel contaminants effects on the anode structure for a co-flow case. In this case, the corner at the fuel outlet is the critical location for material failure which is a common observation in experiments. The critical location is consistent with the maximum principal stresses as shown in Figure 5-34 (a). 

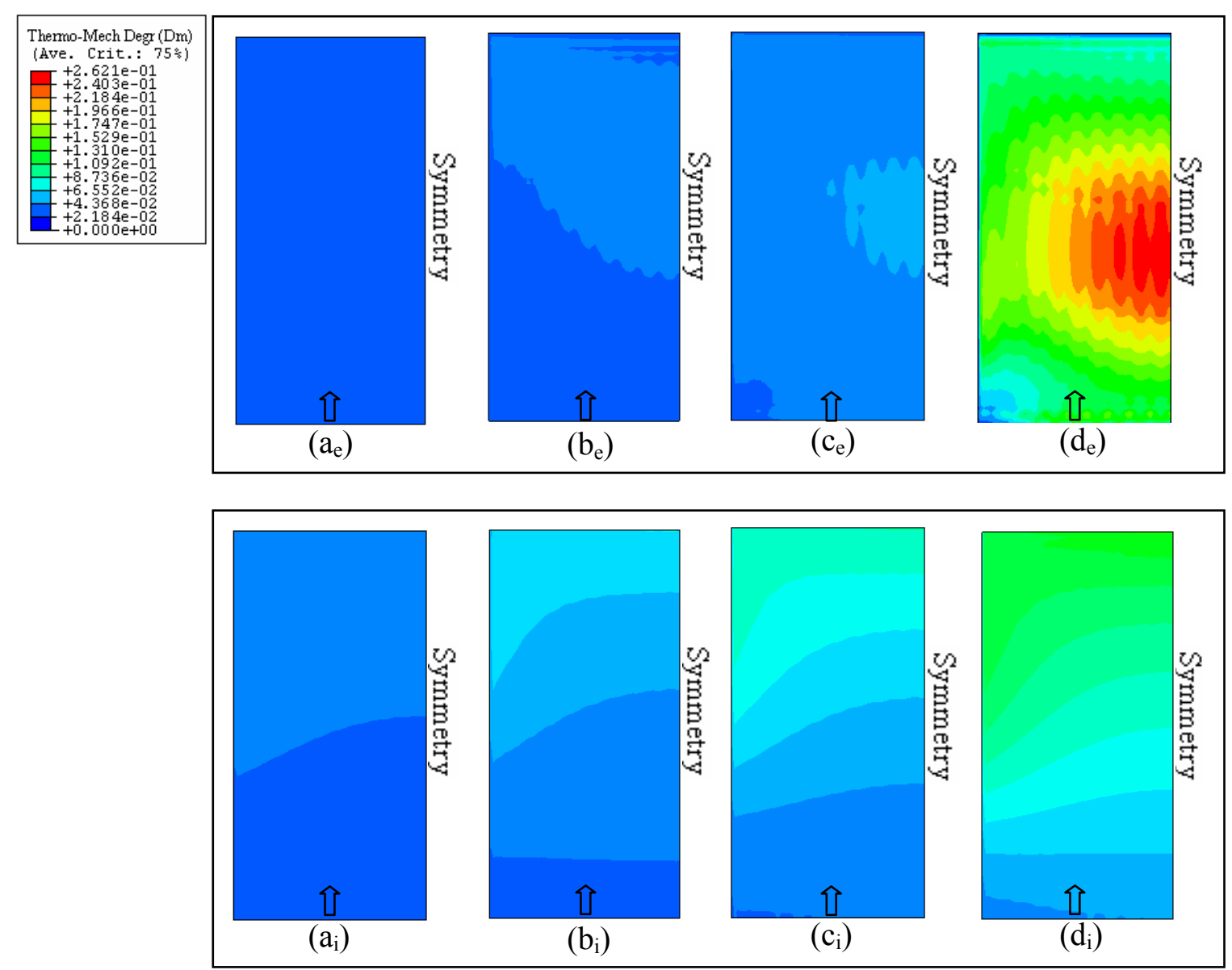

Figure 5-37 Thermo-mechanical degradation in anode at (i) interface and (e) exposed surface (a) $510 \mathrm{~h}$ (b) $7410 \mathrm{~h}$ (c) $12410 \mathrm{~h}$ (d) $18410 \mathrm{~h}$

In the next step, a thermo-mechanical degradation profile is determined as influenced by the fuel contaminant. In this case, thermo-mechanical degradation in the anode material initiates at the anode/electrolyte interface near the fuel outlet and propagates toward the fuel inlet as shown in Figure 5-37 (a-b). It is consistent with the higher MPS in that region as shown in Figure 5-34 (a). The model predicts that with time the contaminant structure effects increase at the exposed surface and reduces the degradation threshold at the surface as explained in section 5.4.4.2. With time the thermo-mechanical degradation becomes severe at the anode exposed surface as compared to the interface. It 
can be explained in terms of the microcracks initiation due the $\mathrm{PH}_{3}$ contamination interaction with the nickel contained in the anode material. Because of the contaminant microcracks initiation, the anode material becomes weaker in this region. As a consequence, the degradation threshold decreases and a lower level of stresses may generate a high density of microcracks. Finally, it reaches its critical value first near the middle of the anode exposed surface as shown Figure 5-37 (d).

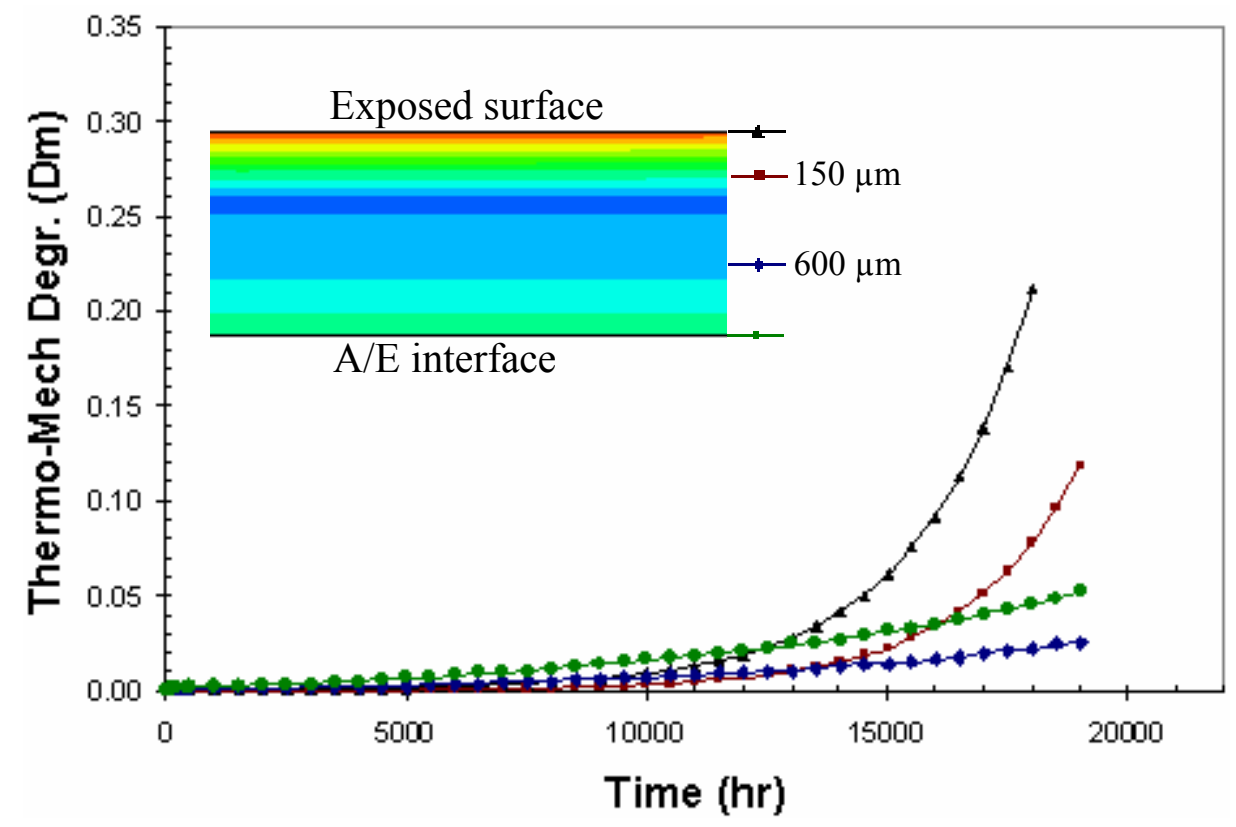

Figure 5-38 Evolution of the thermo-mechanical degradation at the critical location through the anode thickness

Figure 5-38 shows the evolution of the thermo-mechanical degradation at the critical location of the anode across its thickness. As shown, the thermo-mechanical degradation is higher near the anode/electrolyte interface at the onset because of higher stresses in that region. With time, thermo-mechanical degradation increases at higher rate at the surface than at the interface because of the microcracks initiation due to fuel contaminant interaction with the anode surface as explained before. 


\subsubsection{Structural degradation due to contaminant interaction}

The phosphine $\left(\mathrm{PH}_{3}\right)$ initial concentration on the anode surface is shown in Figure 5-32 (b). The effect of $\mathrm{PH}_{3}$ on the anode microstructure is assumed to be independent of the themo-mechanical mechanisms that mean the microcracks formation due to the thermo-mechanical degradation will not affect the former.

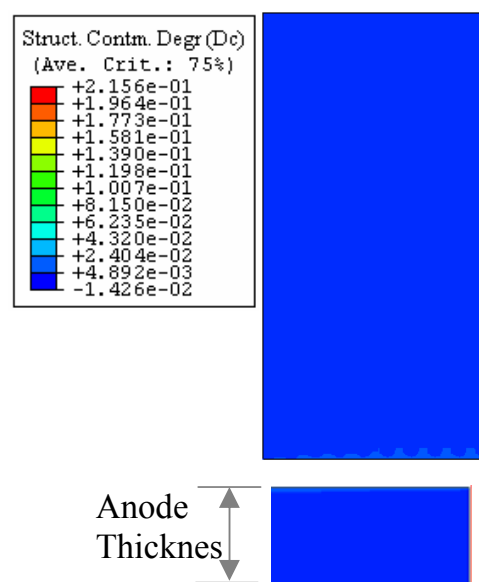

(a)

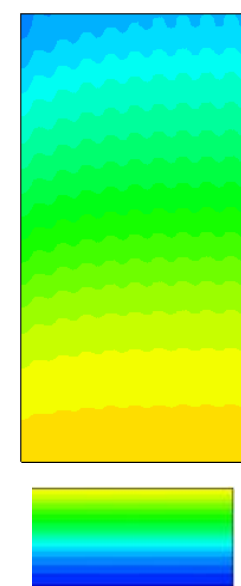

(b)

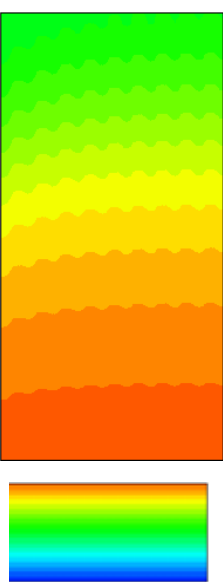

(c)

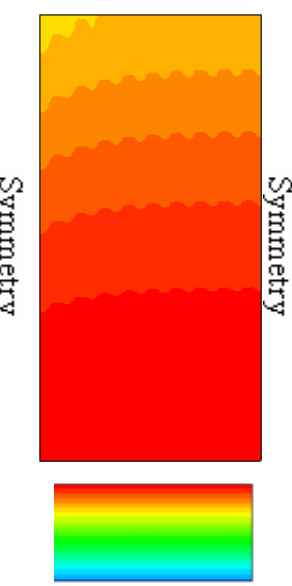

(d)

Figure 5-39 Anode structural degradation due to contaminant along the fuel flow and across anode thickness under 5ppm of $\mathrm{PH}_{3}$ exposure (a) $510 \mathrm{~h}$ (b) $7410 \mathrm{~h}$ (c) $12410 \mathrm{~h}$ (d) $18410 \mathrm{~h}$

The evolution of contaminant effects on the anode microstructure is shown in Figure 5-39. As would be expected, the anode structure degradation due to fuel contaminant starts at the fuel inlet and propagates along the fuel flow and across the anode thickness. In these simulations $a_{1}$ is assumed to be 0.1 . The degradation profile is regular because it is assumed to be independent of the thermo-mechanical degradation effects as mentioned earlier. 


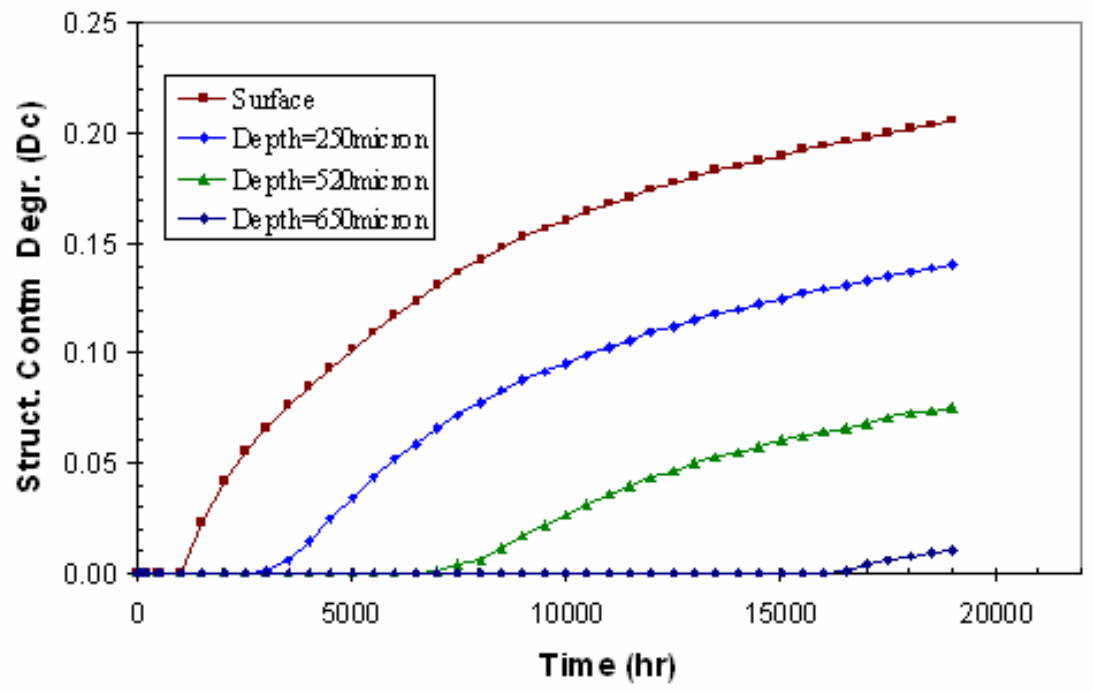

Figure 5-40 Evolution of the contaminant structural degradation at the critical location through the anode thickness

Figure 5-40 shows the evolution of structural degradation due to contaminant effect at the critical location of the anode across its thickness exposed to $5 \mathrm{ppm}$ of $\mathrm{PH}_{3}$. Structural degradation rate due to the contaminant is rapid initially, but decreases with time. The degradation is proportional to the contamination concentration and time of exposure.

\subsubsection{Cumulative structural degradation}

The cumulative effect on the anode structure due to the two degradation mechanisms is assumed to be multiplicative as described in section 4.1.2. Since anode material behaves as elastic brittle material from room to the operating temperature $[81,99]$, the critical degradation value is taken to be 0.4 [82]. The evolution of the cumulative degradation is shown in Figure 5-41 at the anode exposed surface (e) and anode/electrolyte interface (i). 


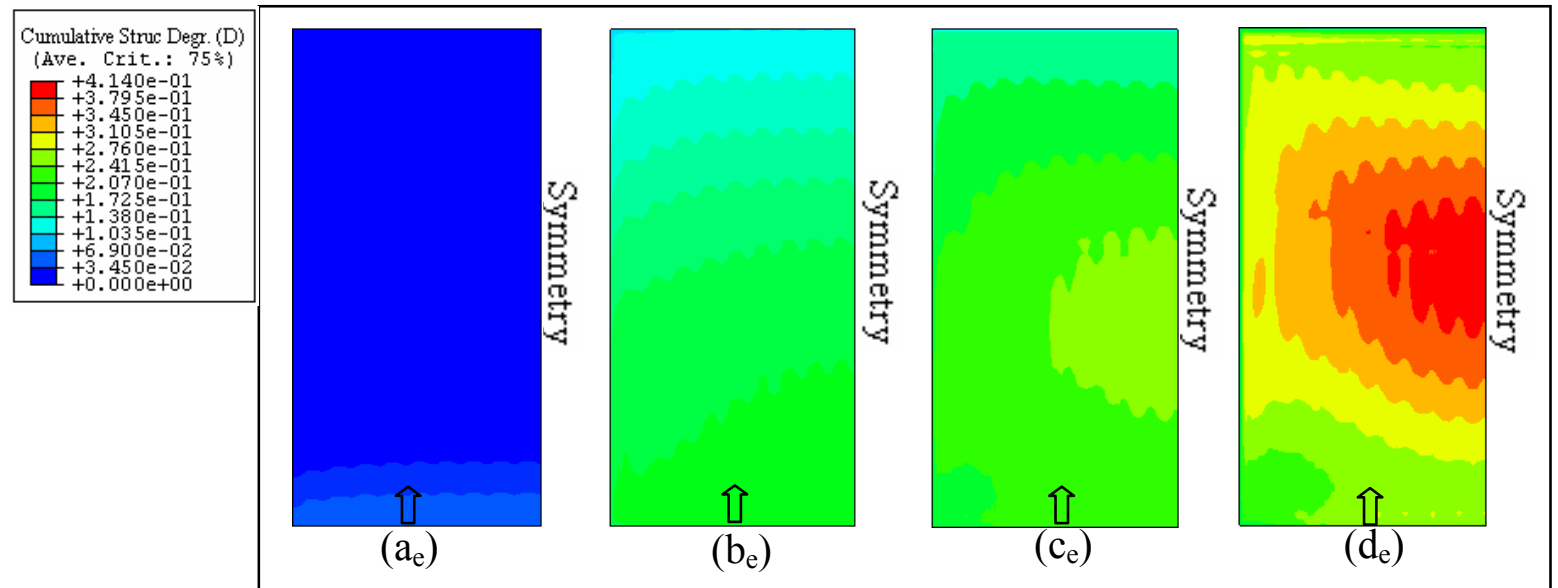

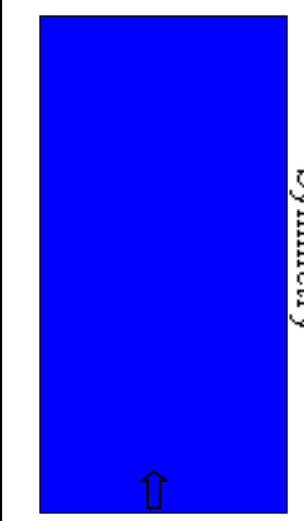

$\left(a_{i}\right)$

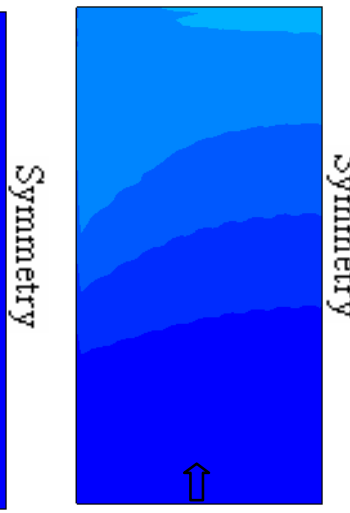

$\left(b_{i}\right)$

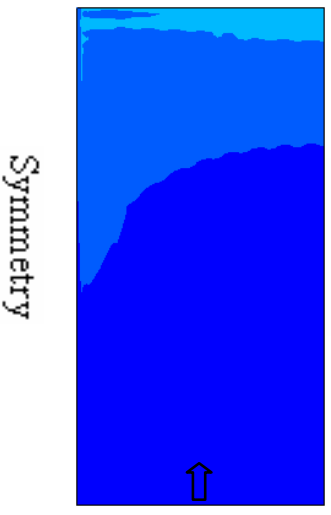

$\left(c_{i}\right)$

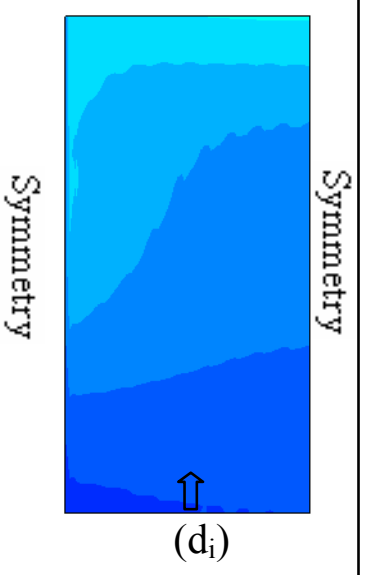

Figure 5-41 Cumulative structural degradation in anode at (i) interface and (e) exposed surface (a) $510 \mathrm{~h}$ (b) $12410 \mathrm{~h}$ (c) $16410 \mathrm{~h}$ (d) $18410 \mathrm{~h}$

Initially the cumulative degradation is dominant at the fuel inlet and propagates along the fuel flow largely due to the contaminant structural degradation. Gradually the thermo-mechanical degradation effect increases at the anode/electrolyte interface near the fuel outlet and propagates towards the fuel inlet. In the long run, the two degradation effects concentrate at the anode exposed surface and the cumulative degradation variable reaches its critical value near the mid-section of the anode depending on the operating temperature and contaminant concentration as shown in Figure 5-41 $\left(\mathrm{d}_{\mathrm{e}}\right)$. The variation of 
structural degradation on the anode surface along the fuel flow is shown in Figure 5-42. The critical location is about $4.2 \mathrm{~cm}$ from the fuel inlet under the specified conditions.

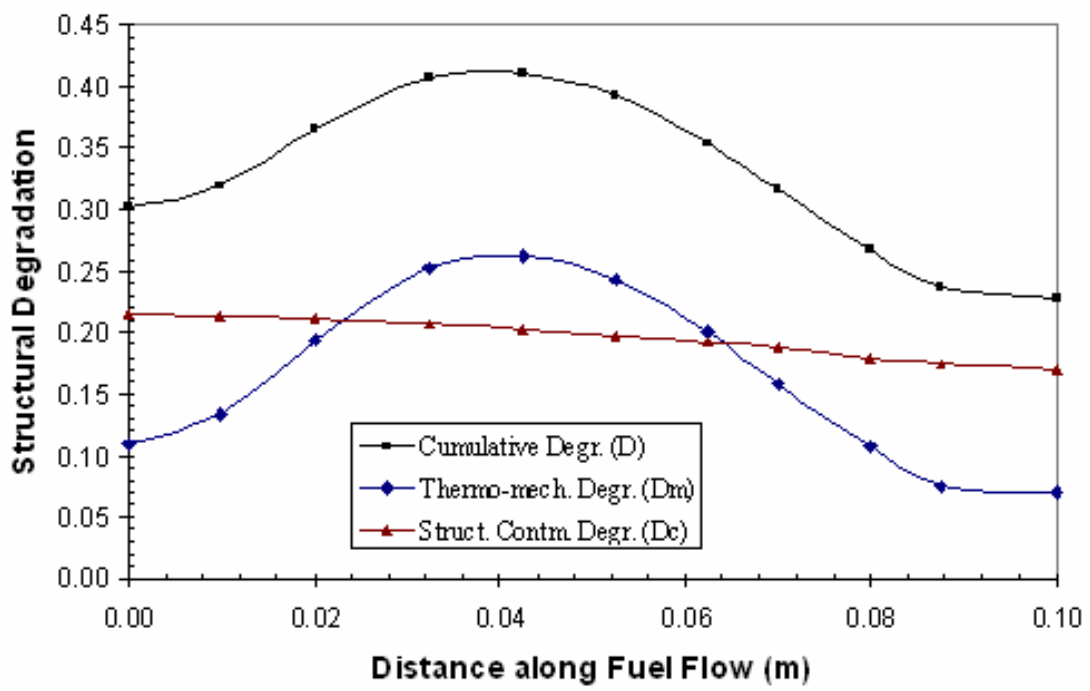

Figure 5-42 Variation of the structure degradation along the fuel flow on the surface

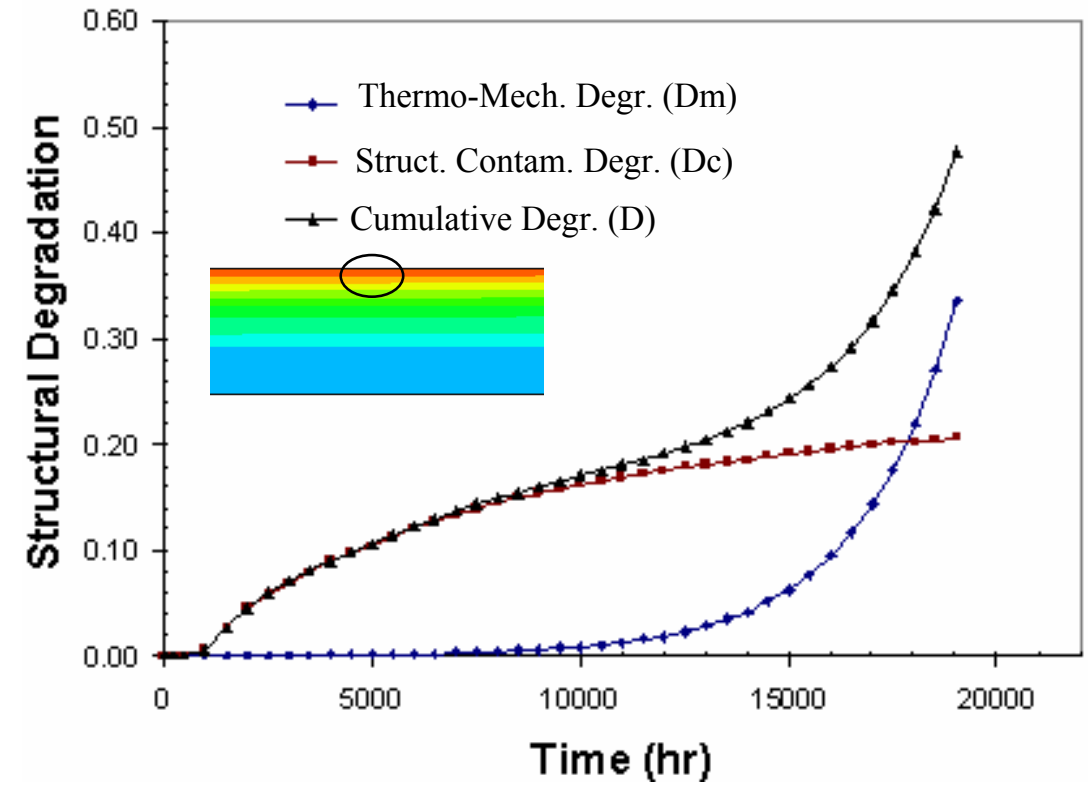

Figure 5-43 Evolution of the anode structural degradation at the critical location 
In the beginning, thermo-mechanical degradation increases slowly as compared to the structure contaminant degradation, but because of the microcrack formation due to the fuel contaminant, the thermo-mechanical effects become severe at that location as shown in Figure 5-43. Structural degradation rate due to fuel contaminant is rapid initially but decreases with time. At $5 \mathrm{ppm}$ of $\mathrm{PH}_{3}$, the contaminant penetration does not start until about $450 \mathrm{~h}$ of exposure as also can be seen in Figure 4-9. The knowledge obtained from this research will be useful to establish control parameters to achieve desired service life of SOFC stacks.

The ultimate goal of this research is to establish the maximum acceptable concentration of $\mathrm{PH}_{3}$ that would not catastrophically degrade anode structure to an unacceptable level for a specified period of time. In the model, the $\mathrm{PH}_{3}$ concentration can be reduced to a level that yields anode structural desired life time.

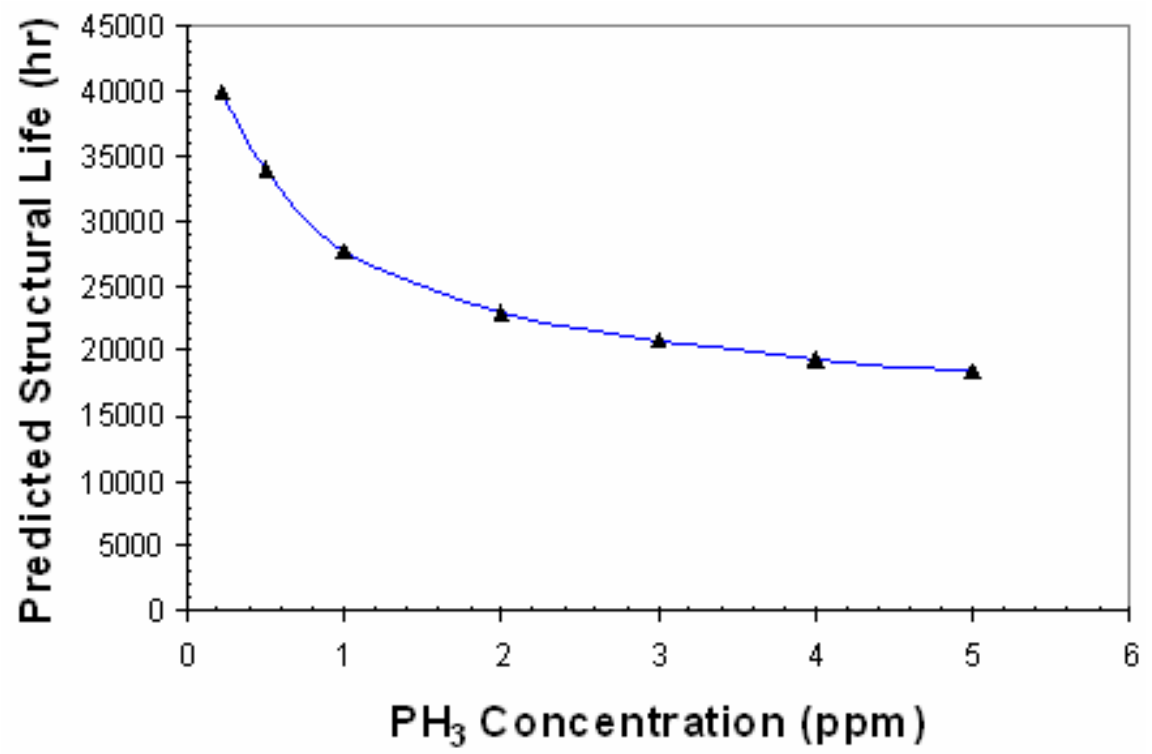

Figure 5-44 Predicted anode structural life in terms of contaminant concentration 
In this parametric study, the $\mathrm{PH}_{3}$ concentration is reduced from $5 \mathrm{ppm}$ until the $40000 \mathrm{hrs}$ of anode structural life is obtained as shown in Figure 5-44. With correct parameters, the proposed model is capable of predicting the anode structural life working under fuel contaminants and the maximum limit of concentration of the contaminants that would not degrade the anode structure to an unacceptable level for a specified period of time.

\subsubsection{Comparison of anode structural degradation for planar-SOFCs}

Co-flow, counter-flow and cross-flow configurations are distinguished according the relative flow directions of fuel and air on the anode and cathode respectively. In order to understand the anode structure degradation for the three configurations, a comparison analysis is made. Cells temperature fields and contaminant distributions are obtained for the three cases under similar operating conditions as shown in Figure 5-31. Anode structure degradation profiles are shown in Figure 5-45 under similar operating conditions i.e. same current density.
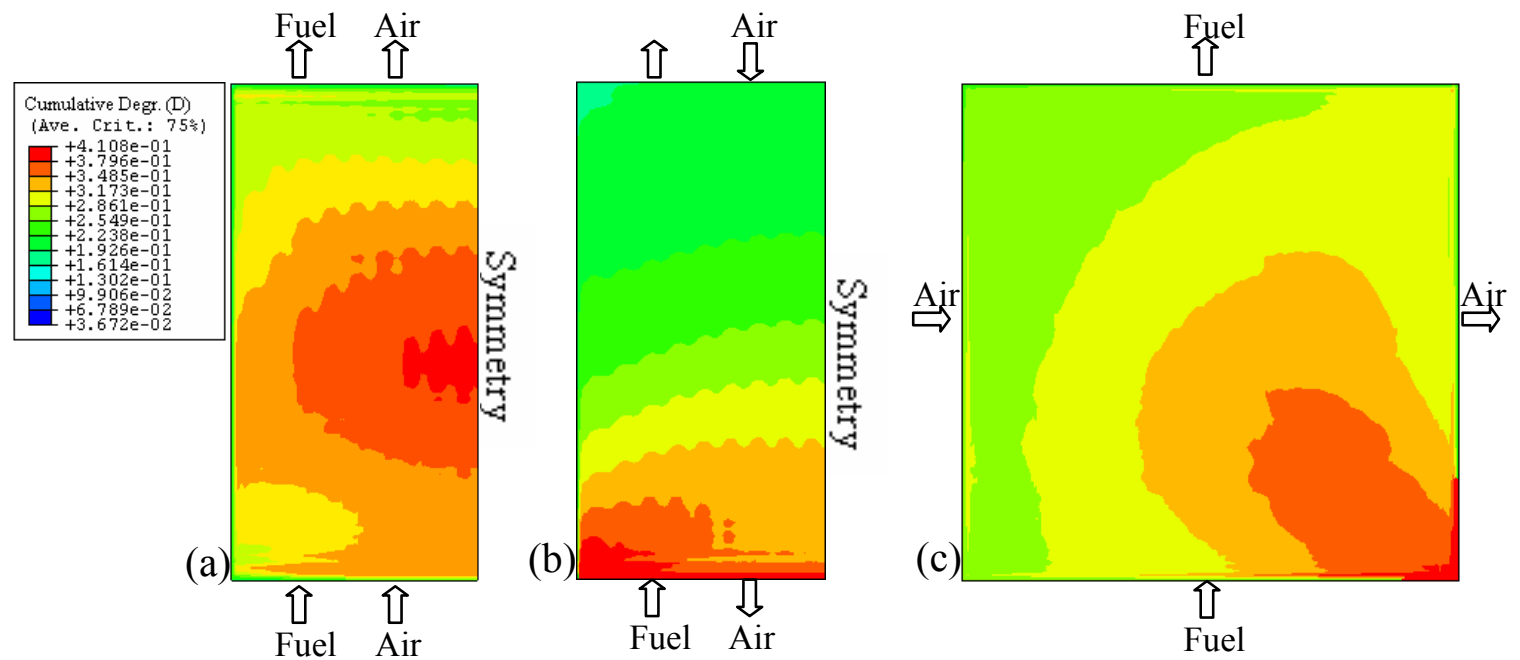

Figure 5-45 Anode structure failure locations comparison (a) co-flow:19920h (b) counter-flow: $16310 \mathrm{~h}$ (c) cross-flow: $18450 \mathrm{~h}$ 
The model predicts that the co-flow arrangement yields the longest anode structural life prediction as compared to the other two configurations under similar operating conditions. In co-flow configuration, thermo-mechanical degradation is severe at the fuel outlet and contaminant degradation starts near the fuel inlet, whereas in other configurations, thermo-mechanical and contaminant degradations start near the fuel inlet regions. 


\section{Chapter 6 CONCLUSION AND FUTURE WORK}

\subsection{Conclusions}

A phenomenological structural durability model is developed for the SOFC anode working under fuel gas contaminant (i.e. $\mathrm{PH}_{3}$ ). The model is capable of predicting thermo-mechanical degradation and contaminants effects on the anode structural properties. The model is implemented in finite element analysis (FEA) to predict the evolution of anode structural degradation during long-term operation.

To connect the experimental measurements and model, a two-layer analytical solution for surface deformation under uniform pressure is modified to obtain the surface deformation of a three-layer thin membrane under uniform pressure which can be considered as a button cell with anode, electrolyte and cathode layers. The analytical solution is validated using FEA.

The anode material (i.e. Ni-YSZ) behaves as an elastic brittle material from room temperature to SOFCs operating temperature. The proposed constitutive relations are validated by comparing the model results with the experimental and an independent model developed for elastic brittle material.

After the validation, the model formulation is used to predict the stress strain relations of Ni-YSZ at different temperatures and porosities. The material parameters are obtained from finite element analysis with the help of user-defined subroutines at these temperatures and porosities. It is found that the anode material degradation depends on the level of strain regardless of the temperature at the same porosity. On the other hand, 
the anode material degrades and fails at lower levels of strain at higher porosity at the same temperature.

Initially, the thermo-mechanical degradation is greater at the anode/electrolyte interface due to higher principal stresses in that region. In the long run, it becomes severe at the exposed surface due to the microcracks formed by contaminant interaction.

The structural degradation due to fuel contaminants interaction (i.e. $\mathrm{PH}_{3}$ ) begins from the anode exposed surface and penetrates into the anode thickness depending on the exposure time and contaminant concentration. It degrades the button cell anode uniformly as the contaminant is assumed to be uniformly distributed on the anode surface.

Anode structural life increases exponentially with decrease in the contaminant concentration. Under low concentration of contaminant, anode structure degradation may be significant as compared to the electrochemical degradation during long-term operation.

The proposed durability model is enhanced for the planar-SOFC anode exposed to phosphine $\left(\mathrm{PH}_{3}\right)$. Due to its larger active area compared to button cell, planar-SOFC exhibits greater spatial and temporal temperature gradients which cause higher thermal stresses and thermo-mechanical degradation.

The extended model predicts that the anode thermo-mechanical degradation is severe at the anode/electrolyte interface and it starts near the fuel gas outlet in the case of a coflow configuration, whereas the fuel gas contaminants effects on the anode microstructure begin at the fuel gas inlet and propagate through the anode thickness and along the fuel flow. 
In the co-flow configuration, thermo-mechanical degradation and structural degradation due to contaminant are at different locations. In counter-flow and cross-flow configurations, the two degradations are near the fuel inlet sections. Under similar operating conditions (current density), co-flow configuration yields a higher anode structural life than counter-flow or cross-flow configurations.

Under lower concentration of contaminants, the anode structural degradation may be significant as compared to the electrochemical degradation. With the correct parameters, the proposed model is capable of predicting the anode structural life working under fuel contaminants and thermo-mechanocal effects. Moreover, the model also establishes the maximum contaminant concentration that would not degrade the anode structure to an unacceptable level for a specified period of time.

\subsection{Future Work}

The model capability can be further enhanced by incorporating the following suggestions in the future model.

- Formulate the constitutive relations by considering the degradation induced anisotropy in the anode material.

- Correlate anode structural degradation with the cell electrochemical performance

- Verify or adjust the contaminant factor $\left(a_{1}\right)$ experimentally.

- Incorporate the thermo-mechanical degradation of the electrolyte and cathode with the anode thermo-mechanical and contaminant effects

- Include the interconnect channel effect on the PEN deformation

- Include redox cycle and thermal cycle effects on the anode microstructure 


\section{REFERENCES}

1. Fuel Cell Handbook, Seventh Edition, US Department of Energy, EG\&G Technical Services, Inc. 2004.

2. H. Koide, Y. Somaya, T. Yoshida, and T. Maruyama. "Properties of Ni/YSZ Cermet as Anode for SOFC", Solid State Ionics, 132, pp. 253-260 (2000).

3. S. M. Haile. "Fuel Cell Materials and Components", Acta Materialia, 51, pp. 5981-6000 (2003).

4. J. Larmine, and D. Andrews, "Fuel Cell Systems Explained," Chichester: John Wiley \& Sons Ltd. 2000.

5. L. Aguilar, S. Zha, Z. Cheng, J. Winnick, M. Liu. "A Solid Oxide Fuel Cell Operating on Hydrogen Sulfide $\left(\mathrm{H}_{2} \mathrm{~S}\right)$ and Sulfur-Containing Fuels," J. Power Sources, 135, pp. 17-24 (2004).

6. C. Yates and J. Winnick, "Anode Materials for a Hydrogen Sulfide Solid Oxide Fuel Cell,” J. Electrochem. Soc., 146 [8] pp. 2841-2844 (1999).

7. A. Gunji, C. Wen, J. Otomo, et al, "Carbon Deposition Behaviour on Ni-Scsz Anodes for Internal Reforming Solid Oxide Fuel Cells," J. Power Sources, 131, pp. 285-288 (2004).

8. O. Costa-Nunes, R. J. Gorte, and J.M. Vohs, "Comparison of the Performance of $\mathrm{Cu}-\mathrm{CeO}_{2}-\mathrm{YSZ}$ and $\mathrm{Ni}-\mathrm{YSZ}$ Composite SOFC Anodes with $\mathrm{H}_{2}, \mathrm{CO}$, and Syngas," J. Power Sources 141, pp. 241-249 (2005). 
9. M. Radovic, and E. Lara-Curzio, "Mechanical Properties of Tape Cast NickelBased Anode Materials for Solid Oxide Fuel Cells before and after Reduction in Hydrogen”, Acta Materialia, 52, pp. 5747-5756 (2004)

10. A. Selcuk, G. Merere, and A. Atkinson, "The Influence of Electrodes on the Strength of Planar Zirconia Solid Oxide Fuel Cells," J. Mater. Sci., 36, pp. 1173$1182(2001)$.

11. N. Q. Ming, T. Takahashi. Science and Technology of the Ceramic Fuel Cells. Amsterdam: Elsevier; 1995.

12. P. S. B. Sukhvinder, F. Karl, 1999, Don Jaffrey, John Newman, Electrical interconnect for a planar fuel cell, US Patent 6280868, http://people.bath.ac.uk/cf233/sofc.html

13. N. Besette, Status of the Acumentrics SOFC Program. SECA 2004 Annual Meeting and Core Program Review. 2004. Boston: US DOE NETL.

14. R. George, and A. Casanova. Developments in Siemens Westinghouse SOFC Program. 2003 Fuel Cell Seminar. 2003. Miami Beach, FL, USA: Department of Energy.

15. R. A. George. "Status of Tubular SOFC Field Unit Demonstrations", Journal of Power Sources, 86, pp. 134-139 (2000).

16. H. Yakabe, T. Ogiwara, M. Hishinuma, and I. Yasuda. "3-D Model Calculation for Planar SOFC", Journal of Power Sources, 102, pp. 144-154 (2001). 
17. C. Rayment, S. Sherwin. "Introduction to Fuel Cell Technology" Department of Aerospace and Mechanical Engineering, University of Notre Dame, 2003

18. D. Larrain , J. Van herle, and D. Favrat. "Simulation of SOFC Stack and Repeat Elements Including Interconnect Degradation and Anode Reoxidation Risk", Journal of Power Sources, 161, pp. 392-403 (2006).

19. H. Yokokawa, H. Tu, B. Iwanschitz, and Andreas Mai. "Fundamental Mechanisms Limiting Solid Oxide Fuel Cell Durability," Journal of Power Sources, 182, pp. 400-412 (2008).

20. W. Li, K. Hasinska, M. Seabaugh, S. Swartz, and J. Lannutti. "Curvature in Solid Oxide Fuel Cells", Journal of power sources, 138, pp. 145-155 (2004).

21. L. Liu, G-Y Kim, and A. Chandra. "Life Prediction of A Solid Oxide Fuel Cell Under Thermal Cycling Conditions", Proceedings of ASME 2009 Seventh International Fuel Cell Science, Engineering and Technology Conference, June 810, 2009 Newport Beach, California

22. A. Nakajo, C. Stiller, H. Gunnar, and O. Bolland, "Modeling of Thermal Stresses and Probability of Survival of Tubular SOFC", Journal of Power Sources, 158, pp. 287-294 (2006).

23. K. Tsukuma, Y. Kubota, and T. Tsukidate, "Thermal and Mechanical Properties of Y2O3-Stabilized Tetragonal Zirconia Polycrystals". Advances in Ceramics, Vol. 12, Science and Technology of Zirconia II. Edited by A. H. Heuer and L. W. Hobbs. American Ceramic Society, Columbus, OH, (1984). 
24. Y. Murakami, I. Nagano, H. Yamamoto, and H. Sakata. "Phase Equilibria and Phase Change during Ageing in the $\mathrm{ZrO}_{2}-\mathrm{Y}_{2} \mathrm{O}_{3}$ System", Journal of Materials Science, 16, pp. 1686-1688 (1997).

25. J. W. Zwanzigera and U. W. Zwanziger. "Residual Internal Stress in Partially Crystallized Photothermorefractive Glass: Evaluation by Nuclear Magnetic Resonance Spectroscopy and First Principles Calculations". Journal of Applied Physics, 99, pp. 083511.1-083511.6 (2006).

26. E. Lara-Curzio, M. Radovic, R. M. Trejo, K. An, C. R. Luttrell, and T. R. Watkins. "Reliability and Durability of Materials and Components for Solid Oxide Fuel Cells”. Fuel Cell Program Annual Report (2005).

27. F. Lofaj, G.V. Blessing and S.M. Wiederhorn. "Ultrasonic Velocity Technique for Nondestructive Quantification of Elastic Modules Degradation during Creep in Silicon Nitride". Journal of the American Ceramic Society, 86, pp. 817-822 (2003).

28. B. Nghiep Nguyen, Brian J Koeppel, Said Ahzi, Mohammad A Khaleel, and Prabhakar Singh. "Crack Growth in Solid Oxide Fuel Cell Materials: From Discrete to Continuum Damage Modeling" Journal of the American Ceramic Society, 89, pp. 1358-1368 (2006).

29. L. M. Kachanov. "Time of the Rupture Process under Creep Conditions," Izv. Akak. Nauk. S.S.R. Otd. Tech. Nauk. (1958).

30. W. Liu and J. Qu, "Creep Deformation of Ni/YSZ Cermet in SOFC," The $29^{\text {th }}$ Int. Conf. on Adv. Ceram. and Composites, Cocoa Beach, FL 2005 
31. H.Yokokawa, N. Sakai, W.Vielstich, A. Lamm, H.A. Gasteiger (Eds.), Handbook of Fuel Cells Fundamentals Technology and Application, vol. 1, John Wiley \& Sons, pp. 219-266 (2003).

32. W. Fischer, J. Malzbender, G. Blass, and R.W. Steinbrech. "Residual Stresses in Planar Solid Oxide Fuel Cells,” J. Power Sources, 150, pp. 73-77 (2005).

33. T. Zhang, Q. Zhu,W. L. Huang, Z. Xie, and X. Xin "Stress Field and Failure Probability Analysis for the Single Cell of Planar Solid Oxide Fuel Cells," J. Power Sources, 182, pp. 540-545 (2008)

34. G. Robert, A. Kaiser, and E. Batawi, in 6th European Solid Oxide Fuel Cell Forum Proceedings, M. Mogensen, Editor, pp. 193, European Fuel Cell Forum, Oberrohrdorf, Switzerland (2004).

35. D. Sarantaridis, and A. Atkinson. "Redox Cycling of Ni-Based Solid Oxide Fuel Cell Anodes: A Review", Fuel Cell, 07, pp. 246-258 (2007)

36. D. Fouquet, A.C. Muller, A. Weber, and E. Ivers-Tiffe, "Proceedings $5^{\text {th }}$ European SOFC Forum, (Ed. J. Huijsmans), Lucerne, Switzerland, pp. 467 (2002).

37. G. Stathis, D. Simwonis, F. Tietz, A. Moropoulou, and A. Naoumides, "Oxidation and Resulting Mechanical Properties of Ni/8YO - Stablized Zirconia anode Substrate for Solid-Oxide Fuel Cell”, J. Mater. Res. 17, pp. 951-958 (2002).

38. A. Faes, H. Lund-Frandsen, M. Pihlatie, A. Kaiser, and D. R. Goldstein. "Curvature and Strength of Ni-YSZ Solid Oxide Half-Cells after Redox 
Treatments" Proceedings of ASME 2009 Seventh International Fuel Cell Science, Engineering and Technology Conference, June 8-10, 2009 Newport Beach, California

39. M. Pihlatie, A. Kaiser and M. Mogensen. "Mechanical Properties of NiO/Ni-YSZ Composites Depending on Temperature, Porosity and Redox Cycling”, J. of the European Ceramics Society, 29, pp. 1657-1664 (2009).

40. M.A. Khaleel, Z. Lin, P. Singh, W. Surdoval, and D. Collin, "A Finite Element Analysis Modeling Tool for Solid Oxide Fuel Cell Development: Coupled Electrochemistry, Thermal and Flow Analysis in MARC ${ }^{\circledR}$, , J. of Power Sources, 130, pp. 136-148 (2004).

41. G.N. Krishnan, Palitha Jayaweera and Jordi Perez. "Effect of Coal Contaminants on Solid Oxide Fuel System Performance and Service Life" SRI Technical Progress Report (2006).

42. F.N. Cayan, M. Zhi, S.R. Pakalapati, I. Celik, N. Wu, and Randall Gemmen. "Effects of Coal Syngas Impurities on Anodes of Solid Oxide Fuel Cells," J. of Power Sources, 185, pp. 595-602 (2008)

43. J.P. Trembly, R.S. Gemmen, D.J. Bayless. "The Effect of IGFC Warm Gas Cleanup System Conditions on the Gas-Solid Partitioning and Form of Trace Species in Coal Syngas and their Interactions with SOFC Anodes" J. of Power Sources, 163, pp. 986-996 (2007)

44. J. Ratafia-Brown, L. Manfredo, J. Hoffmann, and M. Ramezzan, Major Environmental Aspects of Gasification-based Power Generation Technologies, Final Report, U.S. Department of Energy, 2002 
45. J. Cuzens, J. Mauzey, and R. Woods, "Fuel-Flexible Fuel Processor", Hydrogen Burner Technology, pp. 234 Fuel Cell Seminar Abstracts, Courtesy Associates, Inc., November 1998.

46. Theory and Application; Paper presented at the 1992 AIChE Annual Meeting: Miami Beach, FL, 1-6 November, 1992.

47. J. Trembly, A. Marquez, T. Ohrn, and D. Bayless. "Effects of Coal Syngas and $\mathrm{H}_{2} \mathrm{~S}$ on the Performance of Solid Oxide Fuel Cells: Single-Cell Tests", J. Power Sources, 163, pp. 263-273 (2006).

48. A. Verma, A.D. Rao, and G.S. Samuelsen. "Sensitivity Analysis of a Vision 21 Coal Based Zero Emission Power Plant”, Journal of Power Sources, 158, pp. 41742 (2006).

49. O. Marina, L. Pederson, G Coffey, and C. Coyle. "Coal-Based Fuel Cell Technology: Status, Needs, and Future Applications". Mini-Symposium, Morgantown WV (2007)

50. O.A. Marina, C.A. Coyle, E.C. Thomsen, D.J. Edwards, G.W. Coffey, L.R. Pederson. "Degradation Mechanisms of SOFC Anodes in Coal Gas Containing Phosphorus", Solid State Ionic 181 pp. 430-440 (2010)

51. K. V. Jensen, R. Wallenberg, Ib Chorkendorff, M. Mogensen. "Effect of Impurities on Structural and Electrochemical Properties of the Ni-YSZ Interface", Solid State Ionics 160, pp. 27-37 (2003) 
52. M. Radovic and E. Lara-Curzio. "Elastic Properties of Nickel-Based Anodes for Solid Oxide Fuel Cells as a Function of the Fraction of Reduced NiO”, J. Am. Ceram. Soc., 87 pp. 2242-2246 (2004)

53. S.C. Singhal, R.J. Ruka, J.E. Bauerle and C.J. Spengler. "Anode Development for Solid Oxide Fuel Cells", Final Technical Report, DOE/MC/22046-2371 (NIST Order No. DE87011136), U. S. Department of Energy, Washington, DC (1986)

54. Y. Matsuzaki, and I. Yasuda. "The Poisoning Effect of Sulfur-Containing Impurity Gas on a SOFC Anode: Part I. Dependence on Temperature, Time, and Impurity Concentration", Solid State Ionics, 132, pp. 261-269 (2000).

55. S. Zha, Z. Cheng, and Meilin Liu. "Sulfur Poisoning and Regeneration of NiBased Anodes in Solid Oxide Fuel Cells", J. Electrochem. Soc., Volume 154, Issue 2, pp. B201-B206 (2007).

56. Z. Cheng and Meilin Liu. "Characterization of Sulfur Poisoning of Ni-YSZ Anodes for Solid Oxide Fuel Cells using in Situ Raman Microspectroscopy" Solid State Ionics, 178, pp. 925-935 (2007).

57. M. Liu, Z. Cheng, Y. Choi, J. Wang, S. Zha. "Sulfur-Tolerant Anodes for SOFCs" Proceedings of the 7th Annual SECA Workshop, Philadelphia, PA, September 12-14, 2006

58. K. Sasaki, K. Susuki, A. Iyoshi, M. Uchimura, N. Imamura, H. Kusaba, Y. Teraoka, H. Fuchino, K. Tsujimoto, Y. Uchida, N. Jingo, Proceedings of the Ninth International Symposium on Solid Oxide Fuel Cells, The Electrochemical Society Proceedings Series, vol. 2005-07, The Electrochemical Society, Pennington, NJ, 2005, p. 1267. 
59. J.P. Trembly, R.S. Gemmen, and D.J. Bayless, "The Effect of Coal Syngas Containing $\mathrm{HCl}$ on the Performance of Solid Oxide Fuel Cells: Investigations into the Effect of Operational Temperature and $\mathrm{HCl}$ Concentration", Journal of Power Sources, 169, pp. 347-354 (2007).

60. O. Marina, L. Pederson, C. Coyle, E. Thomsen, D. Edwards, C. Nguyen, G. Coffey. "Interactions of Ni/YSZ Anodes Interactions of Ni/YSZ Anodes with Coal Gas Contaminants" 9th Annual SECA Workshop, Pittsburgh, PA. (2008).

61. B. Nielsen and J. Villaden, "Poisoning of Nickel Catalysts by Arsenic", Applied Catalysis, 11, pp. 123-128 (1984)

62. J.P. Trembly, R.S. Gemmen, D.J. Bayless. "The Effect of Coal Syngas Containing $\mathrm{AsH}_{3}$ on the Performance of SOFCs: Investigations into the Effect of Operational Temperature, Current Density and $\mathrm{AsH}_{3}$ Concentration" Journal of Power Sources, 171, pp. 818-825 (2007)

63. R. Quinn, T. Mebrahtu, T. A. Dahl, F. A. Lucrezi, and B. A. Toseland, "The Role of Arsine in the Deactivation of Methanol Synthesis Catalysts", Appl. Catal. 264, pp. 103-109 (2004).

64. V. Maurice, Y. A. Ryndin, G. Bergeret, L. Savary, J. P. Candy, and J. M. Basset. "Influence of the Dispersion of Metallic Particles on the Reaction of Triphenylarsine with Alumina-Supported Nickel" Journal of Catalysis, 204, pp. 192-199 (2001).

65. O. Marina, L. Pederson, C. Coyle, C. Cramer, G. Coffey, D. Edwards, and E. Thomsen. Ni/YSZ Anode Interactions with Arsenic, Chlorine, Phosphorus, 
Selenium, and Sulfur in Coal Gas. 2009 Fuel Cell Coal Syngas Contamination Studies Coordination Meeting, Pittsburgh March 19-20, 2009

66. K. Gerdes, J. Trembly, and R. Gemmen. "Effect of $\mathrm{H}_{2} \mathrm{Se}$ Exposure on Performance of Anode Supported SOFC, in: Proceedings of the Coal based Fuel Cell Technology: Status, Needs and Future Applications, Morgantown, WV, 2007.

67. N. Bonora. "A Nonlinear CDM Model for Ductile Failure", Engineering Fracture Mechanics, 58, pp. 11-28 (1997).

68. J. Lemaitre and R. Desmorat, "Engineering Damage Mechanics, Ductile, Creep, Fatigue and Brittle Failure". Springer Berlin (2005).

69. J. Robert Dorgan. "A Nonlocal Model for Coupled Damage-Plasticity Incorporating Gradients of Internal State Variables at Multiscales. PhD Dissertation” Louisiana State University (2006).

70. P.I. Kattan, and G.Z. Voyiadjis. Damage Mechanics with Finite Elements: Practical Applications with Composite Tools, Springer. (2001).

71. B. Gerard, G. P-Cabot, and C. Laborderie, "Coupled Diffusion-Damage Modeling and the Implications on Failure due to Strain Localization," Int. J. Solids Structures, 35, pp. 4107-4120 (1997).

72. D. Kuhl, F. Bangert, and G. Meschke. "Coupled Chemo-Mechanical Deterioration of Cementitious Materials Part II: Numerical Methods and Simulations", International Journal of Solids and Structures, 41, pp. 41-67 (2004). 
73. D. Gawin, F. Pesavento, and B.A. Schrefler. "Modelling of Hygro-Thermal Behaviour of Concrete at High Temperature with Thermo-Chemical and Mechanical Material Degradation”, Comput. Methods Appl. Mech. Engrg. 192 pp. 1731-1771 (2003).

74. Y. Xiao. "A Multi-Mechanism Damage Coupling Model” International Journal of Fatigue, 26, pp. 1241-1250 (2004).

75. J. Lemaitre. A Course on Damage Mechanics, Springer-Verlag Berlin.1992, ISBN 0387536094

76. J. Lemaitre. “A course on Damage Mechanics”. Springer Berlin (1996).

77. K. Kolari. "Damage Mechanics Model for Brittle Failure of Transversely Isotropic Solids, Finite Element Implementation". PhD Thesis (2007).

78. J.-P Cordebois, and F. Sidoroff. "Damage Induced Elastic Anisotropy", Proceedings of the Euromech Colloquium 115, Mechanical Behavior of AnisotropicSolids, Colloques Internationaux du Centre National de la Recherche Scientifique, 295, pp. 761-774 (1979).

79. Y. Y. Zhu, and S. Cescotto. "A Fully Coupled Elasto-Visco-Plastic Damage Theory for Anisotropic Materials", 32, pp. 1607-1641, (1995).

80. N. Taqieddin. "Elasto-Plastic and Damage Modeling of Reinforced Concrete" Dissertation, Louisiana State University, Baton Rouge, Louisiana, 2005

81. C.K. Lin, T.T. Chen, Y.P. Chyou, and L.K. Chiang. "Thermal Stress Analysis of a Planar SOFC Stack”, Journal of Power Sources, 164, pp. 238-251 (2007). 
82. S. Murakami and K. Kamiya. "Constitutive and Damage Evolution Equations of Elastic-Brittle Materials Based on Irreversible Thermodynamics". International Journal of Mech. Sci. 39, pp. 473-486 (1997).

83. C. L. Chow and J. Wang. "An Anisotropic Theory of Continuum Damage Mechanics for Ductile Fracture”. Int. J. Fract. Mech. 27, pp.547-558 (1987).

84. J.H Nicholas et al. "Mechanics of Composite Structures". MIT Press (1969).

85. S. Timoshenko and S. Woinowsky-Krieger, Theory of Plates and Shells, McGraw- Hill Book Company, Inc. (1959).

86. G. Sagnac, "L'ether lumineux demontre par l'effect du vent relatif dether dans un interferometre en rotation uniforme," Acadamie der Sciences, Paris Comptes Randus.(1913).

87. Johnson, K. I., Korolev, V. N., Koeppel, B. J., Recknagle, K. P., Khaleel, M. A., Malcolm, D., and Pursell, Z., 2005, "Finite Element Analysis of Solid Oxide Fuel Cells Using SOFC-MPTM and MSC. Marc/Mentat-FC'M," Pacific Northwest National Laboratory, Report No. PNNL-15154, Richland, WA.

88. K. Johnson. "Finite Element SOFC Analysis with SOFC-MP and MSC. Marc/Mentat-FC" SECA $6^{\text {th }}$ Annual Workshop, April 18-21, 2005.

89. K. Scott Weil, John E. Deibler, John S. Hardy, Dong Sang Kim, Guan-Guang Xia, L.A. Chick, and Chris A. Coyle. "Rupture Testing as a Tool for Developing Planar Solid Oxide Fuel Cell Seals" J. Mater. Eng. Perform, 13, pp. 316-326 (2004). 
90. M. Kupkove. "Porosity Dependence of Material Elastic Moduli" J. of Material Science, 28, pp. 5265-5268 (1993).

91. James C. Wang. "Young's Modulus of Porous Materials Part 1 Theoretical Derivation of Modulus-porosity Correlation” J. of Material Science, 19, pp. 801808 (1984).

92. R.W. Rice. "Evaluation and Extension of Physical Property-Porosity Models Based on Minimum Solid Area” J. Mater. Sci., 31, pp.102-118 (1996)

93. R.W. Rice, "Comparison of Physical Property-Porosity Behaviour with Minimum Solid Area Models,” J. Mater. Sci., 31, pp.1509-1528 (1996)

94. R. M. Spriggs. "Expression for Effect of Porosity on Elastic Modulus of Polycrystalline Refractory Materials, Particularly Aluminum Oxide," J. Am. Ceram. Soc., 44 pp. 628-629 (1961).

95. M. Radovic and E. Lara-Curzio "Changes of Elastic Properties of SOFC Anode during the Reduction of $\mathrm{NiO}$ to $\mathrm{Ni}$ in Hydrogen", J. Am. Ceram. Soc. 87, pp. $2242(2004)$

96. ABAQUS Online Documentation. ABAQUS Analysis User's Manual (Version $6.5-1)$

97. P. T. Wang. Complete Stress- Strain Curves of Concrete and its Effect on Ductility of Reinforced Concrete Members. Ph.D.Thesis, University of Illinois at Chicago Circle, IL (1977). 
98. J. Mazars and G. Pijaudier-Cabot. "Continuum Damage Theory-Application to Concrete" J. Engrg. Mech. 115, pp. 345-365 ( 1989)

99. F. Gutierrez-Mora, J.M. Ralph, J.L. Routbort. "High-Temperature Mechanical Properties of Anode-Supported Bilayers" Solid State Ionics 149 pp. 177- 184 (2002)

100. J.E.O. Ovri "A Parametric Study of the Biaxial Strength Test for Brittle Materials," Materials Chemistry and Physics 66 pp. 1-5 (2000)

101. Pakalapati SR. A New Reduced Order Model for Solid Oxide Fuel Cells. Dissertation, Mechanical and Aerospace Engineering Department, West Virginia University, Morgantown 2006.

102. S.A. Benson, T.A. Erickson, C.J. Zygarlicke, C.A. O'Keefe, K.A. Katrinak, S.E. Allen, D.J. Hassett, W.B. Hauserman, N.T. Holcombe, Proc. Advanced coal-fired power systems review meeting, Morgantown, WV USA, July 16-18 1996.

103. A.E. Pigeaud, J.J. Helbe, Proc. Coal-fired power systems 94 - Advances in IGCC, Morgantown, WV USA, June 21-23 1994

104. Francisco Elizalde-Blancas. Modeling Issues for Solid Oxide Fuel Cells Operating with Coal Syngas. Dissertation, Mechanical and Aerospace Engineering Department, West Virginia University, Morgantown 2009 